\title{
Modelling the footprint of the land on the atmosphere
}

\section{Wim Timmermans}




\section{MODELLING THE FOOTPRINT OF THE LAND ON THE ATMOSPHERE}


Graduation committee:

Prof. dr. J.D. Albertson

Prof. dr. L. Jia

Prof. dr. A.D. Nelson

dr. A. Olioso

Prof. dr. F.D. van der Meer

dr. J. Vila-Guerau de Arellano
Cornell University, United States of America Chinese Acadamy of Sciences, China University of Twente, The Netherlands INRA-Avignon, France

University of Twente, The Netherlands Wageningen University, The Netherlands

ITC dissertation number 290

ITC, P.O. Box 217, 7500 AE Enschede, The Netherlands

ISBN 978-90-365-4234-0

DOI $10.3990 / 1.9789036542340$

Cover designed by Wim Timmermans

Printed by ITC Printing Department

Copyright (c) 2016 by Wim Timmermans

\section{UNIVESITY OF TWENTE}

T1 FACULTy of gEO-INFORMATION SCIENCE AND EARTH OBSERVATION 


\title{
MODELLING THE FOOTPRINT OF THE LAND ON THE ATMOSPHERE
}

\author{
DISSERTATION
}

to obtain

the degree of doctor at the University of Twente, on the authority of the rector magnificus, prof.dr. H. Brinksma,

on account of the decision of the graduation committee, to be publicly defended

on Thursday the $3^{\text {rd }}$ of November 2016 at $14: 45$ hrs

by

Wilhelmus Johannes Timmermans

born on the $27^{\text {th }}$ of April 1968

in Losser, The Netherlands 
This thesis is approved by

Prof. dr. Z. Su, promoter

Prof. dr. ing. W. Verhoef, co-promoter 
voor pa en ma 



\section{Preface}

Hè hè, eindelijk! Eindelijk is het boekie af. Sommigen onder jullie zullen zeggen: "Dat werd tijd ook!", maar geloof me dat ondergetekende zelf dat nog het meest onderschrijft. Het is ongetwijfeld een enorm cliché, maar na 11 jaar met tussenpozen zwoegen op dit boekje viel er eind vorig jaar een enorme last van me af toen ik mijn ontwerp versie opstuurde. Wederom zullen sommigen zeggen: "Ho ho, 15 jaar zit dichter bij de waarheid!". Daar zit wat in, maar na diverse omzwervingen mag ik zelf graag Januari 2006 als start aanhouden, de datum dat ik mijn onderzoeksvoorstel bij Bob $\mathrm{Su}$, mijn promotor, inleverde.

Met Bob zijn we meteen aanbeland bij degene die ik ontzettend wil bedanken voor het jarenlang steunen en uit de wind houden wanneer mijn collega's ongetwijfeld weer eens vonden dat het nu toch wel lang genoeg geduurd had en ik maar eens echt aan het werk moest gaan. De eerlijkheid gebied echter te zeggen dat ik je ook wel eens vervloekte omdat er weer een extern gefinancierd project gecoördineerd moest worden. Bedankt ook voor de vele interessante contacten die dit door de jaren heen toch opleverde. Wat je me ook geleerd hebt, en dat kostte ook jaren want ik ben blijkbaar niet zo snel van begrip, is om vaker ja te zeggen wanneer er zich extern gefinancierde onderzoeks- of andere mogelijkheden voordeden. Ondanks dat ze me op het eerste gezicht niet interessant leken, of ik de kansen niet hoog inschatte, kortom, wanneer ik het weer eens negatief benaderde, liet jij me zien, of voelen, want de communicatie verliep niet altijd even soepel, dat je er gewoon voor moet gaan. Zo goed als altijd kwam er dan uiteindelijk iets goeds, leuks of interessants uit voort. Wout Verhoef kwam iets later mijn onderzoek binnen, maar wel op het juiste moment om me te laten blijven focussen en de nadruk er op te leggen de aandacht voor detail niet uit het oog te verliezen. Wout, bedankt hiervoor.

In a much earlier stage it was John Albertson who introduced me into the world of large eddy simulation after we got in contact through a presentation given as part of the Safari-2000 campaign. It took quite a few years before we managed to actually meet and then another few before the actual work started, but it laid the base for this little booklet. John, it has been a great pleasure getting to know you and I will never forget the wonderful and inspiring time I spent at Duke. When mentioning a nice period, definitely also Avignon comes to my mind, following an invitation by Albert Olioso, which I met for the first time in the fields of Barrax. Thank you Albert, for the nice atmosphere and for the nice discussions we had about aerodynamic 
roughness and old French and Dutch football players, during coffee breaks in that little coffee room in the lab. The good memories are only disturbed by the fact that during that stay the model showed persistent numerical instabilities for the first time. And they were persistent for years! It was just because of the help of Fernando Porté-Agel that finally I could remove these instabilities. After we met in Vienna, where we discussed the implementation of your submodels, you never stopped helping me by providing suggestions through numerous emails. This blonde would not have been able to implement them by only reading the literature; muchas gracias!

Iets dichter bij huis ben ik bijzondere dank verschuldigd aan Willem Vermin, die niet alleen mijn code heeft omgeschreven naar een parallelle versie zodat het op meerdere rekeneenheden tegelijk kon worden gedraaid, maar die me zelfs tot ver na zijn pensioen is blijven helpen. Zonder hem stond het model waarschijnlijk nu nog te rekenen. Nog dichter bij huis moet ik vooral waardering uitspreken voor al mijn collega's voor hun geduld en het aanhoren van mijn getier wanneer het model weer eens knalde. Twee springen er hierbij uit, namelijk Suhyb met wie ik menige out-of-the-box discussie voerde en Ben, bij wie ik stoom kon afblazen wanneer ik me weer eens over de ene of andere futiliteit aan het opwinden was.

En dan het dichtst bij huis, wil ik graag mijn vrienden bedanken ("To all my friends!") die ik hier niet allemaal bij naam wil noemen, onder andere vanwege het gevaar er een of twee te vergeten, maar voor wie ik in bepaalde periodes minder tijd had dan ik gewild zou hebben. Twee hier van dien ik toch even in het bijzonder te noemen, zij waren bereid mijn paranimfen te zijn; Janine en Karin: elke dank hier voor. Als laatste maar zeker niet als minste, en daar waar ik het eerder had over aan de basis staan is dat hier zeker van toepassing; dank aan mijn ouders, die me altijd hebben voorgehouden dat ik "goed moest leren".

Dat ga ik dan nu maar doen!

Wim Timmermans, November 2016 


\section{Table of Contents}

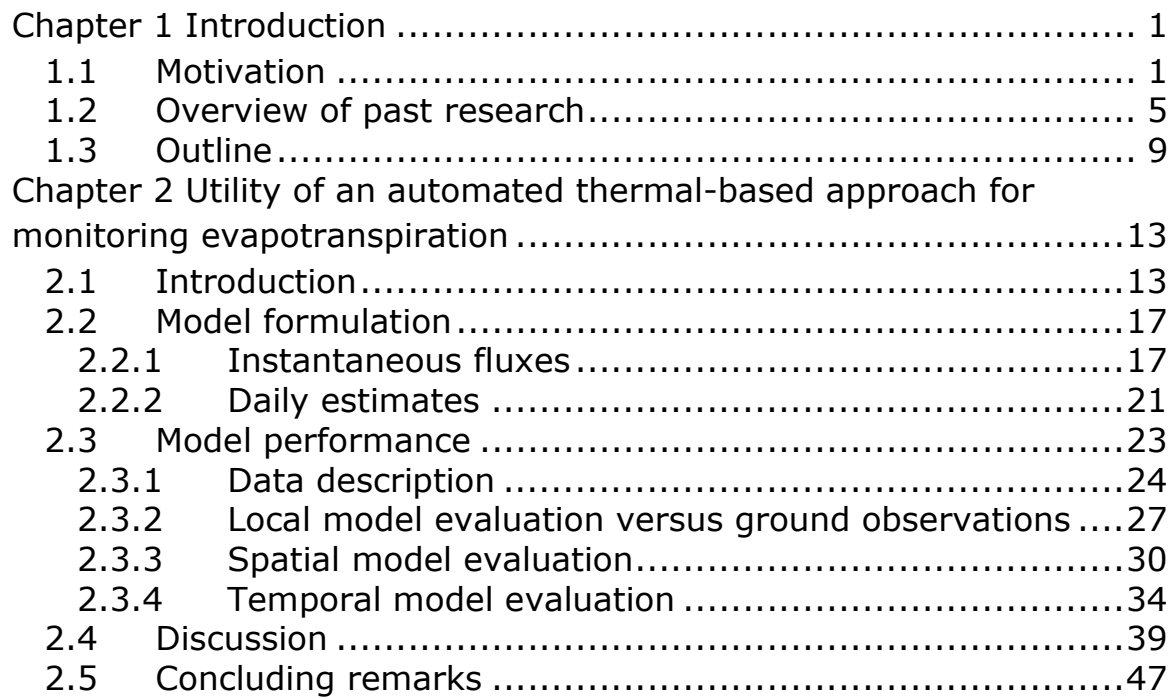

Chapter 3 Accounting for Atmospheric Boundary Layer variability on

flux estimation from RS observations................................. 51

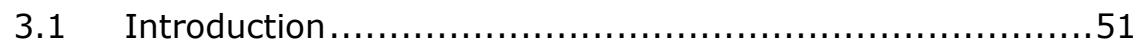

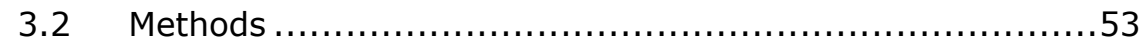

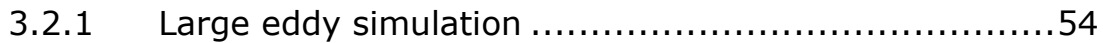

3.2.2 Dual source land surface model ..........................55

3.2.3 Assessment of surface impact on lower ABL.............58

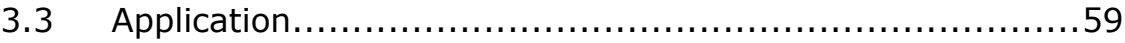

3.3.1 Data set .................................................. 59

3.3.2 Model simulations ......................................60

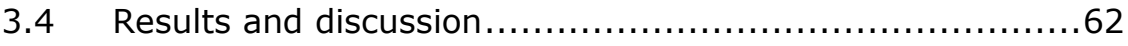

3.4.1 Model output.............................................62

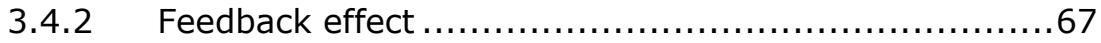

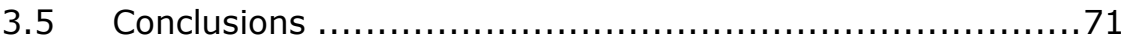

Chapter 4 Footprint issues in scintillometry over heterogeneous

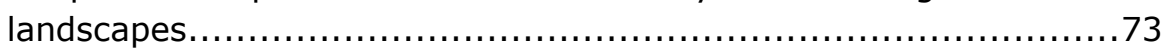

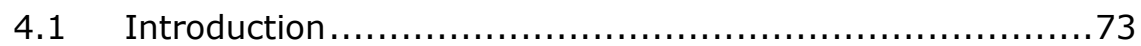

4.2 Scintillation technique .................................... 75

4.2.1 The homogeneous case ................................ 75

4.2.2 Application to a heterogeneous surface ..................77

4.2.3 Footprint implications ................................... 80

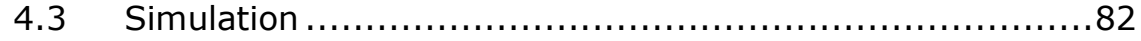

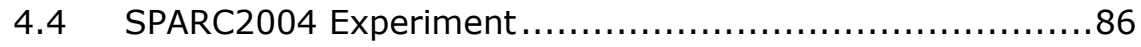

4.4.1 Experimental setup ..................................... 87

4.4.2 Input data ............................................ 90 


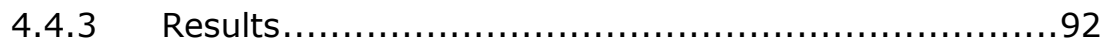

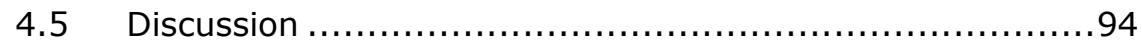

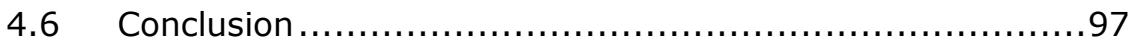

Chapter 5 An overview of the regional experiments for landatmosphere exchanges 2012 (REFLEX 2012) campaign ................99

5.1 Introduction................................................ 99

5.2 Main objectives and tasks of the campaign .................. 101

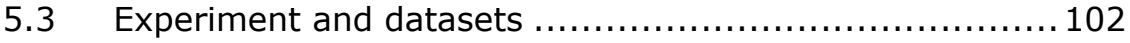

5.3.1 Experimental site and background climatology ......... 102

5.3.2 Remote sensing data acquisitions...................... 104

5.3.3 In situ measurements ................................. 108

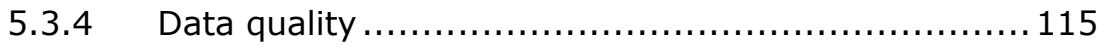

5.4 Preliminary results and recommendations ..................117 Chapter 6 Parameterization issues in modelling energy exchange

across the air-land interface .......................................... 119

6.1 Introduction ................................................ 120

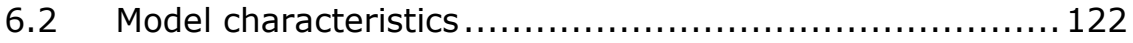

6.2.1 Governing equations ................................. 122

6.2.2 Sub-Grid Scale models ............................... 123

6.2.3 Bottom boundary conditions ............................ 125

6.2.4 Bottom spatial discretization .......................... 127

6.3 Model performance over synthetic homogeneous surfaces 128

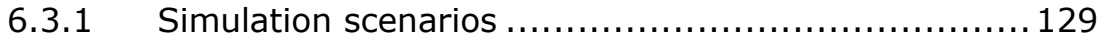

6.3 .2 Simulation results ..................................... 130

6.3.3 Discussion of scenarios................................ 133

6.4 Model performance over synthetic step-changes ............ 135

6.4.1 Simulation scenarios ................................... 135

6.4 .2 Simulation results ..................................... 136

6.4.3 Feedback effects....................................... 139

6.5 Model performance over a natural surface .................. 142

6.5.1 Data set and simulation description ...................... 142

6.5.2 Results versus observations ............................. 144

6.5.3 Feedback effects and discussion...................... 147

6.6 Summary and conclusion ................................. 154

Chapter 7 Summary and perspectives............................... 157

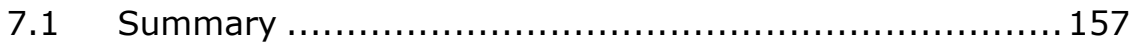

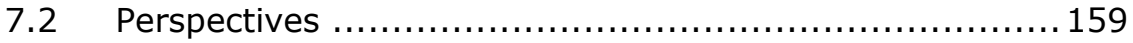

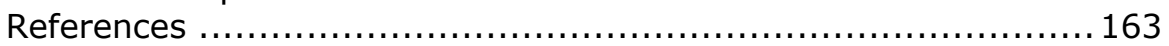

List of abbreviations .................................................. 183

List of symbols ........................................................ 187

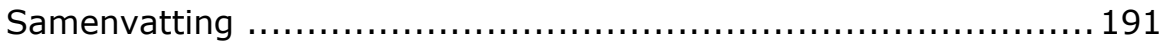

ITC Dissertation List.............................................. 194 


\section{Chapter 1 Introduction}

The central research objective formulated at the start of the work that is in front of you was:

"Find an estimate of the state of the air (or lower atmosphere) as a function of the state of the earth's surface and the average state of the lower atmosphere".

In other words, an attempt towards: "Modelling the footprint of the land on the atmosphere". In the following sections it is first explained why this is important, thereafter it is shown how it fits with preceding research, followed by a description of how this work got its final shape.

\subsection{Motivation}

This dissertation deals with the determination of the vertical transport of water vapour and heat at the earth's surface. More specifically, it deals with the determination of the distribution of these so-called turbulent fluxes by remote sensing techniques. Even more specifically, it deals with finding ways to make effective use of remote sensing techniques that are used to determine the distribution of surface fluxes of latent and sensible heat under conditions of surface and atmospheric heterogeneity. What does this mean and, above all, why is this important?

The spatial and temporal distribution of the surface fluxes of latent heat, $\lambda E$, and sensible heat, $H$, relates to the transport into the air of water (vapour) and heat respectively. It plays a role at many different scales and in many different disciplines. At a global scale, warming at the equator causes a broad low pressure region, and cooling at the poles causes high pressure regions. The pressure difference drives the main global general circulation pattern and as such determines the global climate system. The resulting flux patterns are not only the carriers for water vapour but also for other gasses such as nitrogen, oxygen, carbon dioxide and methane. Disturbances herein, either natural or anthropogenic, determine global climate 
change. At regional to local scales the transport and distribution of water vapour and temperature in the lower atmosphere determines how we experience the weather. For example an increased $\lambda E$ flux causes an increase in water vapour in the lower atmosphere. This produces an increase in absorbed thermal radiation by the atmosphere, leading in turn not only to an increase in temperature but to cloud formation as well. Potentially this leads to an increase in precipitation. These patterns influence surface water and runoff, groundwater and soil moisture. In short, they influence the water availability. Naturally, water availability is important for ecosystem sustainability and food production, and touches the fields of hydrology, biology, agronomy and irrigation management, meteorology and climatology, to name a few. Finally, at the very local scale the spatial distribution of latent and sensible heat fluxes may explain why drinking a cold beer is probably appreciated more on a paved terrace than in the swimming pool next to it.

From the preceding lines it is clear that the dynamics in the water and energy balances are directly linked and, especially over land, very heterogeneous in space and time at a wide range of scales. In the earth-atmosphere system the cycle of energy starts with the absorption of solar energy by the atmosphere and the earth's surface. The latter is by far the most relevant. At the earth's surface the solar radiation, which is basically the only source of energy for the earth-atmosphere system, is transformed into either enthalpy or latent heat. The enthalpy is related to the heating of the air or the surface, the latent heat is related to the change of phase of water. The latent heat is about a factor four larger than the enthalpy. Since condensation of water vapour is also heating the higher parts of the atmosphere, the heat exchange is the process by which the water and energy cycle are closely connected. Managing water availability therefore asks for a thorough understanding of this process. This can only be done by proper and continuous measurement of the enthalpy (sensible heat flux, $H$, or surface heat flux, $G$ ) and latent heat fluxes, $\lambda E$, at different scales, temporally and spatially. Due to the heterogeneous character of the sensible and latent heat fluxes, earth observation by remote sensing is the only means to monitor them in a consistent manner. 
However, current remote sensing techniques do not provide direct measurements of $H$ and $\lambda E$ but require a certain level of modelling, or post-processing. Though of a different nature, this holds true both for space- or air-borne techniques meant for spatial estimations, as well as for ground-based techniques providing local observations. The latter are typically used for validation.

Virtually all physically-based remote sensing techniques to determine $H$ and $\lambda E$ in a spatial manner utilize similar parameterizations. They all describe the turbulent flux exchange as a function of the difference between the state of the earth's surface and the overlying lower atmosphere and the ability of the earth's surface to exchange these fluxes. Having the capability of simultaneously sensing the different surface states in a heterogeneous area makes these remote sensing techniques a very suitable tool for mapping $H$ and $\lambda E$. Moreover, this may be done at a multitude of scales. Validation is generally done by eddy covariance and, nowadays more and more, by scintillometer observations. The latter utilize a signal which is integrated over, or related to, the path length, which is the distance between the transmitter and receiver of the scintillometer. This makes them potentially very suitable to be used over heterogeneous terrain as well.

However, despite the suitability of both the space- and airborne as well as the ground-based techniques for estimating turbulent fluxes over heterogeneous terrain, they theoretically require additional information that is in general not readily available. Both techniques usually rely on homogeneous input parameters which in reality are spatially and temporally variable. Algorithms that estimate $\lambda E$ and $H$ from air- or spaceborne remote sensing generally utilize homogeneous and static Atmospheric Boundary Layer ( $A B L)$ states as input. However, these are known to vary considerably, among others as a consequence of the fluxes themselves (i.e. the feedback effect). Ground-based sensing of $H$ by a scintillometer, over heterogeneous terrain generally involves assuming homogeneous, or area-averaged, land surface aerodynamic input parameters. Also these are typically variable over heterogeneous surfaces.

Spatial information needed in both approaches, i.e. spatially variable surface information for the scintillometer observations 
and spatially variable lower atmosphere information for the space- and air-borne approaches, may be obtained from remote sensing. However, for the ground-based flux estimates, the current state of algorithms for post-processing of the scintillometer observations is such that not much spatial detail in surface characteristics is used. Similarly, with respect to the space- and air-borne approaches, the current spatial and temporal resolution of sounders and lidar that measure the state of the $A B L$ is insufficient for application at the local to regional scale. The first problem (i.e. the need for spatial surface information) could be obtained from earth observation by remote sensing, but needs adjustment, or improvement, of post-processing algorithms. The second problem (i.e. the need for spatial $A B L$ information) may be approached in two fundamentally different ways, depending on requirements. One may try to obtain sufficient spatial variability in ABL states, or one may adapt models such that they become independent, or less dependent, on $A B L$ inputs.

At this point it may have become a bit clearer what is meant previously with "finding ways to make effective use of remote sensing techniques that are used to determine the distribution of surface fluxes of latent and sensible heat under conditions of surface and atmospheric heterogeneity" when stating what this dissertation is about. Naturally there are several ways to deal with the heterogeneity of the surface and the atmosphere. Intending to encompass all of them would not only be beyond the scope of this dissertation, but would be demonstrating an arrogance approaching megalomania. Therefore, in this dissertation, above all an attempt is made to "Find an estimate of the state of the air (or lower atmosphere) as a function of the state of the earth's surface and the average state of the lower atmosphere". This can then be used as an input in spaceand air-borne remote sensing-based approaches to determine turbulent fluxes at the earth's surface. Alongside this main objective, a manner is explored how to reduce sensitivity to lower ABL states in space- and air-borne models to estimate turbulent fluxes, as well as an approach to incorporate withinfootprint surface heterogeneity in ground-based scintillometer observations. Therefore, the objectives are categorized as "Incorporation of atmospheric influence", "Removal of 
Chapter 1

atmospheric influence" and "Incorporation of surface influence".

\subsection{Overview of past research}

Incorporation of atmospheric influence

Studying the $A B L$ asks for a statistical approach rather than a deterministic one, due to its turbulent character. However, averaging (also known as Reynolds averaging) the governing equations, i.e. the equation of state and the equations for conservation of momentum (Newton's second law, or NavierStokes equations), mass (continuity equation), moisture, heat (first law of thermodynamics), and of any scalar, results in a situation where there are more unknowns than equations. This is known as the closure problem. Since analytical or full numerical solution of the governing equations is not yet possible, the current approach to solve this problem is to relate the unknown turbulence quantities at a given point in space to known quantities of the flow at that same point.

Crucial work in this respect was carried out first by Fick (1855) who found this proportionality experimentally, analogue to the transport laws for heat by Fourier (1822) and for viscous shear by Newton (1686). It were Boussinesq (1877), who extended this law for viscous shear to turbulent flow, and Reynolds (1874), who supposed that the transport mechanisms for heat and momentum in turbulent flow might be similar. They paved the road for the development of present-day similarity theories for turbulent transport in the lower atmosphere, originally described by Monin and Obukhov (1954) and more recently summarized by Foken (2006). So-called first order closure schemes, also known as K-theory, utilize eddy transfer coefficients, or diffusivities, to relate the mean turbulent flux to the mean gradient of the quantity that is transported. As a consequence, turbulent flux exchange at the land-atmosphere boundary is generally described by some form of resistance scheme. The flux is then parameterized as a function of the differences of the state of the surface and the overlying air, divided by the resistance of the interface (the medium between the surface and the reference height to be precise) to exchange these fluxes. 
It was since the late seventies and early eighties of the $20^{\text {th }}$ century that the potential of thermal remote sensing for determining moisture and heat fluxes has been recognized (Idso et al., 1975; Jackson et al., 1983; Jackson et al., 1977; Price, 1982). The following advent of satellite remote sensing offered the possibility of collecting data of the earth's surface at a temporal and spatial scale potentially suitable for operational local and regional monitoring of turbulent flux exchanges. Almost twenty years later this resulted in the development of numerous remote sensing-driven soilvegetation-atmosphere-transfer (SVAT) schemes (Anderson et al., 1997; Bastiaanssen et al., 1998; Norman et al., 1995; Roerink et al., 2000; Su, 2002). Despite their varying complexity, in one way or another, they all utilize the provision of spatially variable data on surface state, generally Land Surface Temperature ( $L S T)$, to monitor the turbulent latent and sensible heat fluxes. An adequate review is provided in Kalma et al. (2008).

Several groups of approaches have since then evolved because these turbulent fluxes cannot be sensed directly; they depend on near-surface gradients in states of the ABL (Bateni et al., 2013). Recently, atmospheric sounders, such as the Atmospheric Infrared Sounder (AIRS) on board NASA's Aqua platform do provide $A B L$ profile data, see for example Raju et al. (2015). However, for operational local and regional monitoring of the turbulent fluxes the temporal resolution, as well as the horizontal and vertical spatial resolution, are by far insufficient. Therefore, in present-day remote sensing based land-atmosphere-interaction schemes, the state of the lower atmosphere is commonly assumed constant, although indications exist that the assumption of homogeneous atmospheric variables over a modelling domain may lead to erroneous flux estimations, as stated by Parlange et al. (1995) and Kustas and Albertson (2003).

Consequently, the flux estimates rely on spatially and temporally averaged meteorological parameters $\left(\theta_{\mathrm{a}}, q_{\mathrm{a}}, u\right)$ in the lower atmosphere and land surface parameters $\left(\theta_{0}, q_{0}, z_{0 \mathrm{M}}\right.$, $Z_{\mathrm{OH}}$ ) that can be considered point measurements in space and in time. However, the temporal and spatial scales of the atmospheric and land surface parameters being rather different, questions the validity of the currently utilized 
resistance schemes. Moreover, the temporal and spatial scales of either parameter do not necessarily match those of the processes governing the surface fluxes (Anderson et al., 2003). Therefore a better understanding of the impact of a heterogeneous land surface on the lower atmosphere and hence on the turbulent flux exchanges should potentially improve remote sensing-based flux estimates.

Hence, for over a decade now, research is carried out to examine whether and how incorporation of lower ABL variability in remote sensing-driven schemes can improve turbulent flux estimates (Albertson et al., 2001; Bertoldi et al., 2007; Bertoldi et al., 2008, 2013; Kustas \& Albertson, 2003). This is done by coupling a Large-Eddy Simulation (LES) model to a remote sensing-based Land Surface Model (LSM), whereby the coupling takes place in the lowest nodes of the LES model. Recently, turbulent flow models have been coupled to multilayered LSMs (Dupont et al., 2011; Dupont \& Brunet, 2008; Shao et al., 2013), but naturally the coupling takes place in the nodes near the surface, or wall in Computational Fluid Dynamics (CFD) vocabulary. It is well-known that the region near the surface is exactly where LES results need to be interpreted with care, even when applied over homogeneous surfaces (Abkar \& Porte-Agel, 2012; Bose \& Moin, 2014; Brasseur \& Wei, 2010; Podvin \& Fraigneau, 2014). Therefore, in this dissertation the aim is to properly couple a wellestablished LSM to an LES model to find a way of, and to demonstrate the effect of incorporating lower $A B L$ variability into a remote sensing-based LSM over a very heterogeneous area.

Removal of atmospheric influence

As extensively discussed in the previous section, satellite remote sensors potentially offer the possibility of collecting input land surface data at a suitable temporal and spatial scale for local to regional applications, but they cannot readily provide suitable spatially distributed atmospheric variables. However, remote sensing-based LSMs do require atmospheric input such as solar radiation, wind speed, air temperature, and vapour pressure over large heterogeneous areas (Jiang \& Islam, 2001). Consequently, several studies have either proposed the combined use of remotely sensed observations 
with LSMs that require minimal input data (Anderson et al., 1997; Norman et al., 1995; Roerink et al., 2000; Senay et al., 2013; Su, 2002), or they derive key meteorological data from the remotely sensed observations (Bastiaanssen et al., 1998; Bertoldi et al., 2008; Prihodko \& Goward, 1997; Prince et al., 1998 ), or they try to estimate the variability of the lower $A B L$ (Bertoldi et al., 2008; Schomburg et al., 2010).

As a result, numerous schemes have been developed in recent years with varying complexity. However, complex model parameterization to adequately represent regional or global scale turbulent flux exchanges is rarely possible at the appropriate spatial or temporal resolution (Anderson et al., 2003; Goetz et al., 1999). Moreover, operational models for flux estimation have shown varying degrees of success (Parlange et al., 1995). With reliable inputs, the more sophisticated models often provide more reliable estimates under a wider range of environmental conditions, but for operational use these models generally need a fair degree of model expertise by the operator as well. It is obvious that no model will outperform all others under all conditions. "A selection has to be based on the scale and purpose of the application as well as on the availability of the required data" Su et al. (2011).

When monitoring over regions having little ground information, or having only a few atmospheric observations, the inputs required by the more sophisticated models are not available or unreliable. This causes significant uncertainty in model output. Under such conditions, a simple modelling approach that requires minimal ancillary inputs may prove to be fairly robust. This holds true particularly for long-term monitoring where errors in short-term flux estimates are often modulated, for example when evaluated as cumulative water use over a growing season. This is the rationale for developing a very simple model for routine monitoring of surface turbulent fluxes, with emphasis on operationality, requiring minimum user expertise and minimum atmospheric input data.

\section{Incorporation of surface influence}

Validation of the aforementioned remote sensing-based algorithms, requires ground truth data that are directly comparable to the flux estimates obtained from such 
algorithms (Brunsell et al., 2011). The increasing popularity of using a Large Aperture Scintillometer (LAS) for doing so can be explained by both its ease of operation and relatively low cost, as well as by its potential capability of obtaining spatially aggregated flux estimates (Ezzahar \& Chehbouni, 2009). However, this validation exercise is not straightforward, due to two issues that are mainly related to the spatial heterogeneity of both the surface and the fluxes.

A first complication is due to the fact that, although over homogeneous terrain this methodology has proven to provide accurate estimates of sensible heat flux (de Bruin et al., 1995; McAneney et al., 1995; Meijninger \& de Bruin, 2000; Pauwels et al., 2008; Watts et al., 2000), it is also well-known that problems of a theoretical nature are faced when applying the scintillation technique over a heterogeneous surface (Bsaïbes et al., 2006; Chehbouni et al., 2000; Ezzahar et al., 2007; Lagouarde et al., 2002a). This is because it relies on MoninObukhov Similarity Theory (MOST), which is strictly only valid under homogeneous conditions.

A second problem relates to the direct comparison between the remote sensing-based and ground-based estimate of sensible heat flux. If the surface is heterogeneous, the signal measured by the LAS depends on "which part of the surface has the strongest influence on the sensor, and thus on the location and size of its so-called footprint" (Schmid, 2002). In almost all natural landscapes, the footprint will contain different land cover types and "a successful interpretation of the measured fluxes will depend on an appropriate footprint model" (Soegaard et al., 2003). Hence, a useful comparison between remote sensing-based and ground-based estimates of turbulent fluxes can only be done by accounting for heterogeneity within the footprint. In this dissertation therefore a footprint-weighted approach is developed to verify the suitability of the LAS for producing area-average estimates of turbulent fluxes over heterogeneous terrain by incorporating spatially variable surface characteristics.

\subsection{Outline}

Summarizing the previous sections, the parameterizations, or modelling, of the turbulent fluxes using remotely sensed land 
surface temperature as input, as well as ground observations that validate these parameterizations, are both used because of their applicability over heterogeneous surfaces whereas at the same time they are both limited just because of that heterogeneity. Similarly, the limitations for both the models as well as the ground observations have a theoretical character as well as a practical character. The theoretical limitation, which will not be dealt with in detail in this dissertation, is for both that the utilized theory (MOST) is strictly only valid under homogeneous conditions. The practical limitation for both is that required additional input parameters, being the $A B L$ state for the remote sensing-based models and the surface condition for the ground observations, are classically assumed spatially uniform, whereas obviously they are not.

It took me quite a while to even start understanding part of the consequences of the sentences above. The outline of this dissertation is a reflection of part of this learning process. I say "part of" because I am very much aware that this is an ongoing learning process, where I have no illusion of reaching full understanding of this fascinating topic at the crossing of the disciplines of physics, meteorology, hydrology and earth observation.

During this process of gaining a bit of experience with different parameterizations and sub-models and their specific requirements and performances, the awareness rose that the qualification "most suitable" not always depends solely on pure scientific criteria. The purpose of the application as well as the availability of necessary data might very well be dominant under certain given conditions. Understanding this led to the development of an automated tool for monitoring water use. This may easily be seen as a natural starting point toward a higher physical realism, and is therefore described in chapter 2 . This higher physical realism started with the coupling of an LES model with a remote sensing-based flux model, using data from the SPARC-2004 multi-disciplinary field experiment at the Las Tiesas agricultural experimental site near Barrax in Spain, in which I participated in 2004. The coupled model, which I have been updating and improving throughout this dissertation, gave me first insights on the feedback effects of surface heterogeneity on variability in the lower atmosphere. 
In addition, it provided me with a first impression of the impact of these feedback effects, mainly with respect to temperature, on the turbulent flux exchanges. This is described in chapter 3. The process of post-processing of the ground observations from the scintillometers we installed during that campaign, brought aware the need for an aggregation scheme capable of dealing with within-footprint surface heterogeneity. The development thereof is provided in chapter 4. Following application of the coupled model to other areas and additional analyses of both the feedback effects of temperature, water vapour and wind speed, as well as recent developments in computational fluid dynamics, raised some doubts about the model performance, especially in the near-surface region. This resulted in the implementation of new parameterizations and discretizations. Being involved in the organization of the REFLEX-2012 campaign, specifically designed to support advancement of the understanding of land-atmosphere interaction processes, provided me the opportunity to set up an observation scheme to test the new implementations. The campaign and its observations are described in chapter 5 whereas in chapter 6 the effects of the new implementations are presented. In chapter 7 an overview of the most relevant findings of this dissertation is provided followed by a perspective on potential future research lines. 


\title{
Chapter 2 Utility of an automated thermal-based approach for monitoring evapotranspiration*
}

\begin{abstract}
A very simple remote sensing-based model for water use monitoring is presented. The model acronym DATTUTDUT, (Deriving Atmosphere Turbulent Transport Useful To Dummies Using Temperature) is a word from a Dutch dialect which loosely translates as "It's unbelievable that it works". DATTUTDUT is fully automated and only requires a surface temperature map, making it simple to use and providing a rapid estimate of spatially-distributed fluxes. The algorithm is first tested over a range of environmental and landcover conditions using data from four short-term field experiments and then evaluated over a growing season in an agricultural region. Flux model output is in satisfactory agreement with observations and established remote sensing-based models, except under dry and partial canopy cover conditions. This suggests that DATTUTDUT has utility in identifying relative water use and as an operational tool providing initial estimates of ET anomalies in data-poor regions that would be confirmed using more robust modelling techniques.
\end{abstract}

\subsection{Introduction}

Knowledge of the surface energy balance is of prime interest to the fields of meteorology, hydrology and agronomy. Examples range from General Circulation Models (GCMs) for weather prediction and climate change to impacts of water use in threatened ecosystems, as well as the determination of crop water use, stress and yield in agro-ecosystems. Numerous soilvegetation-atmosphere transfer (SVAT) schemes have been developed in recent years with varying complexity. However,

\footnotetext{
* Based on Timmermans et al., Acta Geophys. 63, 6, pp. 1571-1608, 2015
} 
"complex model parameterization is rarely possible at appropriate spatial or temporal resolution to adequately represent regional or global scale turbulent heat exchange" (Goetz et al., 1999). Moreover, operational models for evapotranspiration (ET) estimation, using ground-based observations, have shown varying degrees of success (Parlange et al., 1995).

Satellite remote sensing potentially offers the possibility of collecting input data at a suitable temporal and spatial scale for regional applications. However, satellite observations cannot provide spatially distributed atmospheric variables often required by SVAT schemes. These inputs include solar radiation, wind speed, air temperature, and vapour pressure over large heterogeneous areas (Jiang \& Islam, 2001). Consequently, several studies have proposed the combined use of remotely sensed with SVAT approaches that require minimal ground data (Anderson et al., 1997; Bastiaanssen et al., 1998; Norman et al., 1995; Roerink et al., 2000; Senay et al., 2013; Su, 2002) or derive key meteorological data from the remotely sensed observations (Prihodko \& Goward, 1997; Prince et al., 1998). Generally, the surface energy balance equation is used to estimate actual evapotranspiration as a residual term (Jiang \& Islam, 2001). However, reliable estimation of surface energy balance components from remotely sensed observations typically requires land cover information about surface properties (i.e., land use/vegetation type, surface roughness, fractional vegetation cover) and a physically-based SVAT scheme having land surface parameterization of the turbulent energy exchange. For operational use of these models generally a fair degree of model expertise by the operator is needed as well.

Table 2-1 lists the input parameters and model user expertise on decisions that are necessary to apply the Two-Source Energy Balance (TSEB) model (Norman et al., 1995) and related Atmosphere Land Exchange Inverse (ALEXI) approach (Anderson et al., 1997; Anderson et al., 2005), the Surface Energy Balance System (SEBS) model (Su, 2002), the Surface Energy Balance Algorithm for Land (SEBAL) model (Bastiaanssen et al., 1998) and the Simplified Surface Energy 
Balance for operational applications (SSEBop) model (Senay et al., 2013) as compared to the current algorithm, DATTUTDUT. The table lists the main model inputs required by the different models, although sensitivity to these inputs significantly varies. For example only nominal estimates of the meteorological input (wind speed, air temperature and relative humidity) listed under the SEBAL algorithm are needed; the algorithms internal calibration process circumvents the need for accurate values. Similarly for the NDVI end-member selection for the TSEB and SEBS models is one of a number of possible methodologies used in determining fractional vegetation cover (Carlson \& Ripley, 1997; Choudhury et al., 1994).

Table 2-1 Main model input required by TSEB, ALEXI, SEBS, SEBAL, SSEBop and DATTUTDUT

\begin{tabular}{|c|c|c|c|c|c|c|}
\hline Necessary input & TSEB & ALEXI & SEBS & SEBAL & SSEBop & DATTUTDUT \\
\hline \multicolumn{7}{|l|}{ In-situ / Ancillary data: } \\
\hline Solar radiation, or: & $\sqrt{ }$ & $\sqrt{ }$ & $\sqrt{ }$ & $\sqrt{ }$ & & \\
\hline Atmospheric transmittance, or & $\sqrt{ }$ & $\sqrt{ }$ & $\sqrt{ }$ & $\sqrt{ }$ & & \\
\hline Elevation & & & & & $\sqrt{ }$ & \\
\hline Atmospheric pressure & $\sqrt{ }$ & & $\sqrt{ }$ & & & \\
\hline Wind speed & $\sqrt{ }$ & $\sqrt{ }$ & $\sqrt{ }$ & $\sqrt{ }$ & & \\
\hline Air temperature & $\sqrt{ }$ & & $\sqrt{ }$ & $\sqrt{ }$ & $\sqrt{ }$ & \\
\hline Relative humidity & $\sqrt{ }$ & & $\sqrt{ }$ & $\sqrt{ }$ & & \\
\hline Sensor viewing angle & $\sqrt{ }$ & $\sqrt{ }$ & & & & \\
\hline Radiosounding & & $\sqrt{ }$ & & & & \\
\hline Reference $E T$ & & & & & $\sqrt{ }$ & \\
\hline \multicolumn{7}{|l|}{ Remote sensing / Spatial data: } \\
\hline Reflectance & & & $\sqrt{ }$ & $\sqrt{ }$ & $\sqrt{ }$ & \\
\hline$N D V I / L A I$ & $\sqrt{ }$ & $\sqrt{ }$ & $\sqrt{ }$ & $\sqrt{ }$ & $\sqrt{ }$ & \\
\hline Surface temperature & $\sqrt{ }$ & $\sqrt{ }$ & $\sqrt{ }$ & $\sqrt{ }$ & $\sqrt{ }$ & $\sqrt{ }$ \\
\hline Landcover, or: & $\sqrt{ }$ & $\sqrt{ }$ & & & & \\
\hline Aerodynamic properties & $\sqrt{ }$ & $\sqrt{ }$ & $\sqrt{ }$ & & & \\
\hline \multicolumn{7}{|l|}{ User expertise: } \\
\hline Wet pixel selection & & & & $\sqrt{ }$ & & \\
\hline Dry pixel selection & & & & $\sqrt{ }$ & & \\
\hline NDVI end-member bare soil & $\sqrt{ }$ & & $\sqrt{ }$ & & & \\
\hline NDVI end-member full vegetation & $\sqrt{ }$ & & $\sqrt{ }$ & & & \\
\hline
\end{tabular}


In general, the more complex the model formulations of the land surface-atmosphere exchange, the more information/input variables are required. With reliable inputs, often the more sophisticated models provide more reliable estimates under a wider range of environmental conditions. However, when monitoring over regions having little ground information or ancillary observations of meteorological conditions, the inputs required by more sophisticated models are not available or unreliable, causing significant uncertainty in model output. Under such conditions, a simple modelling approach requiring minimal ancillary inputs could prove to be fairly robust, particularly for long-term water use monitoring where errors in short-term (daily) ET are often moderated, for example when evaluated as cumulative $E T$ over a growing season. This is the rationale for developing a very simple model for routine monitoring of the surface energy balance, with emphasis on an operational system requiring no user expertise the "Deriving Atmosphere Turbulent Transport Useful To Dummies Using Temperature (DATTUTDUT)" algorithm does not need any ancillary data and only requires a surface temperature image. Furthermore the algorithm in theory does not need any user inference and is fully automated, provided a cloud-free and atmospherically corrected radiometric surface temperature image is available.

The main objective of this chapter is to present an operational and automated remote sensing-based system requiring no calibration and suitable for monitoring spatially distributed water and heat fluxes and demonstrate advantages and limitations of using a very simple temperature-based approach. In section 2.2, the formulations and their physical basis are presented and justification for simplifications is discussed. Then, in section 2.3, the performance of the proposed model is analysed. Three different comparison protocols are followed to demonstrate different aspects of the models utility. First the ability of reproducing local energy fluxes in relation to results from well-established and more complex remote sensing-based modelling schemes over a range of environmental and climatologic conditions is presented. Secondly, a spatial model inter-comparison over a very heterogeneous area is carried out 
to evaluate extreme conditions and performance across a landscape. A third, temporal, evaluation then concerns the performance in estimating actual evapotranspiration over a growing season. In section 2.4 a discussion of the results of the different evaluations follows, after which the concluding remarks are provided in section 2.5. The validation data for the evaluations come from large scale interdisciplinary experiments conducted in a semi-arid rangeland region - Monsoon 1990 (Kustas et al., 1994a), a winter wheat/grazing-lands siteSouthern Great Plains 1997 (Jackson et al., 1999), a corn and soybean production region - SMEX/SMACEX 2002 (Kustas et al., 2005), an agricultural test site - REFLEX'12 (Timmermans et al., 2015a) and an irrigated agricultural site within an arid region - Gediz 1998 (Kite \& Droogers, 2000).

\subsection{Model formulation}

\subsubsection{Instantaneous fluxes}

Generally, remote sensing-based SVAT schemes use instantaneous observations of the land surface to provide estimates of instantaneous net radiation, $R_{N}$, soil, $G$, sensible, $H$, and latent, $\lambda E$, heat fluxes, all in $\mathrm{W} \cdot \mathrm{m}^{-2}$, by solving the energy balance equation:

$$
R_{N}=G+H+\lambda E
$$

where $\lambda$ represents the latent heat of vaporization $\left(\mathrm{J} \cdot \mathrm{kg}^{-1}\right)$ and $E$ is the evaporation rate of water per unit area $\left(\mathrm{kg} \cdot \mathrm{s}^{-1} \cdot \mathrm{m}^{-2}\right)$. The net radiation estimation is usually estimated by dividing it into its components:

$$
R_{N}=R_{S}^{\downarrow}+R_{S}^{\uparrow}+R_{L}^{\downarrow}+R_{L}^{\uparrow}=\left(1-\rho_{0}\right) \cdot R_{S}^{\downarrow}+\varepsilon_{0} \cdot \varepsilon_{a} \cdot \sigma \cdot T_{a}^{4}-\varepsilon_{0} \cdot \sigma \cdot T_{0}^{4}
$$

where $R$ stands for radiation, and the subscripts $\mathrm{N}, \mathrm{S}$, and $\mathrm{L}$ refer to net, shortwave and longwave, and the superscripted arrows indicate incoming (downward) and outgoing (upward) flux directions. Temperature (K) is represented by $T$, whereas the Greek symbols $\rho, \varepsilon$, and $\sigma$ represent albedo $(-)$, emissivity $(-)$ and the Stefan-Boltzmann constant $\left(5.6697 \cdot 10^{-8} \mathrm{Wm}^{-2} \mathrm{~K}^{-4}\right)$, respectively. Subscripts " 0 " and " $a$ " refer to surface and atmospheric level. Typically in these SVAT schemes the soil heat flux is estimated as a semi-empirical ratio to net radiation, using a constant ratio or a function of vegetation indices 
(Bateni et al., 2014). The available energy, $R_{N}-G$, is then distributed over the turbulent fluxes, $H$ and $\lambda E$, by either using the radiometric surface temperature to calculate $H$ and then obtain $\lambda E$ as a residual of the energy balance equation (Bastiaanssen et al., 1998; Norman et al., 1995; Su, 2002), or by incorporating the effect of vapour pressure deficit to estimate crop water use or a stress index (Jackson et al., 1981; Menenti \& Choudhury, 1993).

In the current approach we attempt to solve Eq. (2.1) and (2.2) in an automated manner by parameterizing all variables using only $T_{0}$ and its end-members, $T_{\min }$ and $T_{\max }$ as an input. These temperature extremes are derived from the image itself, which should be cloud free and have constant atmospheric conditions.

The surface albedo has been reported to vary with surface temperature depending on moisture conditions by several authors (Bastiaanssen et al., 1998; Jacob et al., 2002). Other approaches assume nominal values for soil and vegetation reflective properties (French et al., 2003; Kustas \& Norman, 1999). Here, the surface albedo is thought to vary linearly with radiometric surface temperature between 0.05 and 0.25 , following:

$$
\rho_{0}=0.05+\left(\frac{T_{0}-T_{\min }}{T_{\max }-T_{\min }}\right) \cdot 0.2
$$

These somewhat arbitrary values are taken from Brutsaert (1982) and Garratt (1992); the basic assumption is that dark densely vegetated objects appear cooler and bright bare objects such as soils and rock outcrops generally appear hot.

The shortwave incoming radiation follows from:

$$
R_{S}^{\downarrow}=\tau_{S W} \cdot S_{\text {exo }}
$$

where $\tau_{\mathrm{SW}}$ represents the shortwave atmospheric transmissivity $(-)$ and $S_{\text {exo }}\left(\mathrm{W} \cdot \mathrm{m}^{-2}\right)$ is the exo-atmospheric shortwave radiation which depends only on the sun-earth geometry (Campbell \& Norman, 1998; Monteith \& Unsworth, 1990).

To facilitate a fully automatic and fast operational scheme, nominal values are taken for transmissivity and emissivity values. For clear sky conditions Burridge and Gadd (1974) presented a very simple parameterization for instantaneous shortwave atmospheric transmissivity $(-)$, following;

$$
\tau_{S W}=0.6+0.2 \cdot \sin (\alpha)
$$


where $\alpha$ represents the solar elevation angle (rad), useful when dealing with large image scenes where solar angles are not constant. However, for simplicity here a constant value of 0.7 is taken for the atmospheric transmissivity. Numerous empirical relations are reported for apparent atmospheric emissivity (Brutsaert, 1982). If the following approximation (Bastiaanssen et al., 1998) is adopted;

$$
\varepsilon_{a}=1.08 \cdot\left(-\ln \tau_{S W}\right)^{0.265}
$$

in combination with an atmospheric transmissivity of 0.7 an apparent atmospheric emissivity of about 0.8 is obtained. Since most natural objects emit radiation at least at an efficiency of $96 \%$ (Garratt, 1992) the surface emissivity (-) is taken equal to unity. Taking the air temperature equal to $T_{\min }$ in combination with these nominal values for emissivity, all radiation components can now be determined following Eq. (2.2).

The ratio between soil heat flux and net radiation, $\Gamma[-]$, is reported to vary from 0.05 for fully vegetated areas (Choudhury, 1987; Monteith \& Unsworth, 1990) to 0.45 for bare soil (Brutsaert, 1982; Choudhury, 1987). In a similar fashion as for the surface albedo a linear relation with radiometric surface temperature is assumed:

$$
\Gamma=\frac{G}{R_{N}}=0.05+\left(\frac{T_{0}-T_{\min }}{T_{\max }-T_{\min }}\right) \cdot 0.4
$$

The underlying assumption is again that dark densely vegetated areas appear cooler (Bastiaanssen et al., 1998; Menenti \& Choudhury, 1993; Roerink et al., 2000) and over densely vegetated areas a smaller part of the net radiation is reaching the surface. Bare soil generally appears hotter and over these areas a larger part of the net radiation will be available to heat the soil surface.

A common feature of thermal-based methods is that radiometric surface temperature is the key remotely-sensed parameter partitioning the available energy between sensible and latent heat. This is also reflected in several sensitivity studies (Anderson et al., 1997; Bastiaanssen, 1995; Kustas \& Norman, 1999) and especially in model inter-comparisons (Zhan et al., 1996) where surface temperature clearly is the input variable that has the largest impact on model output. It 
is also important to note that surface layer air temperature is also a critical variable for many of the models that require a surface-air temperature gradient unless there is a built-in procedure that removes or minimizes this requirement (Anderson et al., 2007; Timmermans et al., 2007). A modelling framework that minimizes the effect of errors in surface and surface layer air temperatures on the calculation of the turbulent fluxes was proposed by Bastiaanssen et al. (1998). Their methodology, SEBAL, basically assumes linearity between surface-air temperature differences and surface temperature, where the slope is defined by dry and wet areas (hydrologic extremes or end-members) within the scene having maximum and minimum surface temperatures and heat fluxes, $H$ and $\lambda E$, determined from the energy balance equation (Eq. 2.1). When evaluating such a technique, along with other traditional remote sensing-based SVAT models, French et al. (2005b) and Timmermans et al. (2007) found that the linearity assumption in the SEBAL scheme is not universally valid, a phenomenon also recognized by Bastiaanssen et al. (1998) in their original paper. However, this relation has utility in providing an internal calibration for effectively partitioning the available energy between $H$ and $\lambda E$ over the scene as long as there are no significant land cover differences (i.e., agricultural versus forested areas) within the scene which would have a major impact on aerodynamic properties (Norman et al., 2006). In SEBAL the assumption is made that at a certain maximum radiometric surface temperature the latent heat flux is zero, whereas sensible heat flux is at its minimum rate at a certain minimum radiometric surface temperature. However, instead of using flux inversion at the extremes which requires iterative processes to determine the resistance-heat flux relation, here a simple linear relation between evaporative fraction $(\Lambda)$ and surface temperature extremes is assumed:

$$
\Lambda=\frac{\lambda E}{\lambda E+H}=\frac{\lambda E}{R_{N}-G}=\frac{T_{\max }-T_{0}}{T_{\max }-T_{\min }}
$$

There needs to be hydrological contrast in the image, meaning that both the wet and dry conditions are present in the image scene, a necessary condition for methods that are trying to derive the turbulent fluxes from hydrological contrast (Bastiaanssen et al., 1998; Menenti \& Choudhury, 1993; Pelgrum \& Bastiaanssen, 1996; Roerink et al., 2000). The 
maximum temperature, $T_{\max }$ is taken as the hottest pixel in the image. The minimum temperature, $T_{\min }(\mathrm{K})$, is taken as the $0.5 \%$ lowest temperature in the image, meaning that $0.5 \%$ of the entire image is colder than $T_{\min }$. The reason for not taking the lowest temperature in the image is to avoid extreme conditions (open water) and to take that part of the image that is transpiring at a potential rate. Following Tasumi et al. (2000), the hottest location in the image is used to determine $T_{\max }$ in Eq. (2.8). Similar approaches based on the same physical principle, have been proposed since the early days of operational thermal infrared remote sensing (Jackson et al., 1981; Jiang \& Islam, 2001; Roerink et al., 2000). However, the main differences with the current approach are that DATTUTDUT is tuning-free, fully automated and only requires an $L S T$ image as input.

\subsubsection{Daily estimates}

Extending essentially instantaneous fluxes from a satellite "snapshot" observation to daily values either involves multitemporal observations such as from geostationary satellite observations (Anderson et al., 1997; Mecikalski et al., 1999; Norman et al., 2000) or assuming a constant energy partitioning over the daytime period. By assuming selfpreservation (conservative relative partition of the energy flux among its components) in the diurnal evolution of the energy balance, $\Lambda$ can be taken as constant throughout the day. It has been demonstrated that this assumption holds for environmental conditions where soil moisture does not change significantly (Crago, 1996; Kustas et al., 1994b; Nichols \& Cuenca, 1993; Shuttleworth et al., 1989). This assumption is also used in other models, such as SEBAL (Bastiaanssen et al., 1998) and S-SEBI (Roerink et al., 2000).

Since geostationary satellites only provide useful data for midlatitudes at a rather low spatial resolution $(\sim 5-10 \mathrm{~km})$ and also because of a need for a simplified approach, hence minimum computational requirements, here the assumption of constant evaporative fraction over the daytime period is adopted. However recent work has shown that this assumption might be violated under certain conditions (Chehbouni et al., 2008; 
Delogu et al., 2012; Gentine et al., 2007) and a recent study suggests using at-surface solar radiation is the most robust for up-scaling instantaneous ET over a range of environmental conditions (Cammalleri et al., 2014). Nevertheless, this approach provides reasonable estimation of daily amounts of evapotranspiration from the instantaneous estimates during the daytime (Brutsaert \& Chen, 1996).

Since the evaporative fraction is estimated from Eq. (2.8) and the soil heat flux is assumed to cancel on a daily basis, one only needs an estimate of the daily amount of net radiation to obtain the daily amount of latent heat, $\lambda E_{24}$, both in $\mathrm{MJ} \mathrm{m}^{-2}$;

$$
\Lambda_{i}=\Lambda_{24}=\frac{\lambda E_{i}}{\lambda E_{i}+H_{i}}=\frac{\lambda E_{24}}{\lambda E_{24}+H_{24}}=\frac{\lambda E_{24}}{R_{N, 24}-G_{24}}=\frac{\lambda E_{24}}{R_{N, 24}}
$$

The daily amount of net radiation $R_{\mathrm{N}, 24}\left(\mathrm{MJ} \mathrm{m}^{-2}\right)$ is calculated following;

$$
R_{N, 24}=R_{S, N, 24}+R_{L, N, 24}
$$

where subscripts $S$ and $L$ represent shortwave and longwave radiation and subscripts $\mathrm{N}$ and 24 stand for net and 24 hours respectively. Several methods exist for estimating both components. Here the daily shortwave net radiation (MJ) is estimated following:

$$
R_{S, N, 24}=\left(1-\rho_{0,24}\right) \cdot \tau_{S W, 24} \cdot S_{\text {exo,24 }}
$$

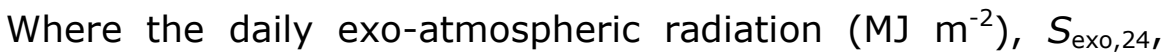
depends only on trigonometric astronomic relations, readily available from handbooks (Campbell \& Norman, 1998; Duffie \& Beckman, 1991; Monteith \& Unsworth, 1990) or by integrating the exo-atmospheric radiation from sunrise to sunset. Daily average surface albedo, $\rho_{0,24}$, is obtained from multiplying the instantaneous value with a constant $c_{1}(-)$. According to Menenti et al. (1989) $c_{1}$ may be taken equal to 1.1 when compared to typical daytime surface albedo values. Daily average transmissivity values $(-), \tau_{\mathrm{SW}, 24}$, may be obtained from several sources. Here we adopted the instantaneous value under the assumption of a cloud free day.

For the longwave components a semi-empirical relation developed by de Bruin (1987) for daily average net longwave radiation, $R_{\mathrm{L}, \mathrm{N}, 24-\text { avg }}\left(\mathrm{W} \mathrm{m}^{-2}\right)$, is used: 


$$
R_{L, N, 24-\text { avg }}=-110 \cdot \tau_{24}
$$

To convert this quantity to daily net longwave radiation, in $\mathrm{MJ}$ $\mathrm{m}^{-2}$, it needs to be multiplied with the daylength (s). The daily net longwave radiation is assumed constant over the scene.

In order to obtain daily amounts of water evaporated and transpired, $E_{24}\left(\mathrm{~kg} \mathrm{~m}^{-2}\right)$, the daily total of latent heat, $\lambda E_{24}$, needs be corrected for the latent heat of vaporization, $\lambda\left[\mathrm{MJ} \mathrm{kg}^{-}\right.$ ${ }^{1}$ ]. This latent heat of vaporization depends to some extent on air temperature, for which $T_{\min }$ is taken:

$\lambda=2.501-0.002361 \cdot\left(T_{\min }-273.15\right)$

Although we developed the scheme to be fully automated and also such that no ancillary data is needed, it is obvious that if additional data are available these may be applied accordingly. Since the algorithm is physically based, use of these ancillary data should potentially further improve the algorithm performance.

\subsection{Model performance}

To demonstrate different aspects of the model's utility, three different comparison protocols are followed. First the ability of estimating local energy fluxes is presented. In order to ensure both a range of environmental and climatic conditions as well as sufficient ground truth data, four study areas having extensive field observations were selected for evaluating DATTUTDUT output and to compare results with published results using more established and more complex remote sensing-based energy balance models (French et al., 2005b; Timmermans et al., 2015a; Timmermans et al., 2007). The other remote sensing energy balance modelling approaches applied to these data sets are SEBAL as originally formulated in Bastiaanssen et al. (1998) and two versions of the TSEB (Norman et al., 1995). One version uses local meteorological observations (French et al., 2003; Kustas \& Norman, 1997) and was applied to the Monsoon'90, SGP'97 and REFLEX'12 experiments. The other version, ALEXI, is a time-integrated approach with TSEB coupled to an atmospheric boundary layer growth model and requiring thermal-IR observations at two instances in the early and mid-morning period (Anderson et al., 
1997; French et al., 2005b) and was applied to the SMACEX'02 experimental site.

Secondly, a spatial model inter-comparison between DATTUTDUT and the SEBAL and TSEB algorithms over a very heterogeneous area is carried out to evaluate extreme conditions and model performance across a landscape. Data from the REFLEX'12 experiment (Timmermans et al., 2015a) over an agricultural test-site near Barrax, Spain, is used here since the area is characterized by the co-existence of dry and hot bare soil and a variety of well-watered crops.

Thirdly, with a fully automated algorithm using midday surface temperature that does not require ancillary data on land use, fractional vegetation cover, or meteorological inputs, just hydrological extremes (wet and dry pixel) within the scene for estimating the surface energy balance, the challenge remains to demonstrate its utility for operational monitoring of longerterm water use. This is done by applying the scheme to data collected at two sites during the joint IWMI (International Water Management Institute)/GDRS (General Directorate of Rural Services, Government of Turkey) study of the Gediz River Basin as described in Kite and Droogers (2000). The DATTUTDUT algorithm is evaluated against published results from other methodologies. However, in this case the purpose is to evaluate its utility for operational water use monitoring purposes.

\subsubsection{Data description}

Monsoon'90

The Monsoon '90 field experiment is described in Kustas et al. (1994a), and covers a semiarid rangeland in the Walnut Gulch Experimental Watershed near Tucson, Arizona. The remote sensing data used in this analysis were acquired with the NS001 sensor mounted in a NASA C-130 aircraft. The NS001 instrument has eight bands, of which seven correspond to the Landsat Thematic Mapper instrument. This provided aircraftbased VIS, NIR and TIR measurements from three days during early August 1990 are used, representing dry (DOY 213), intermediate (DOY 221) and wet (DOY216) conditions. Land 
cover data, necessary for the TSEB algorithm, was taken from classifying Landsat TM data of September 1990. A detailed description of the dataset used is provided in Humes et al. (1994), with the note that here data from DOY 213 is used instead of the data from DOY 209 used in that particular study. There were eight flux tower sites distributed over the watershed covering the main land cover types. Details of the tower measurements are given in Kustas et al. (1994a).

SGP'97

The Southern Great Plains '97 (SGP-97) experiment is summarized by Jackson et al. (1999). The data set included VIS, NIR and TIR remote measurements over the EL Reno, Oklahoma site and comprised fallow and tilled winter wheat and grassland/pasture fields. Data collected were from the Thermal Infrared Multi-spectral Scanner (TIMS) and the Thematic Mapper Simulator (TMS) airborne instruments. Data from two days during the summer of 1997, representing wet (DOY180) and dry (DOY 183) conditions, are used at a spatial resolution of 15 meters, covering agricultural fields (both bare and vegetated) and natural riparian areas. The land use data originates from 30 meter resolution imagery, based on the combination of known ground conditions and Landsat TM imagery from DOY 205 that same year. Details of the processing of the remote sensing imagery can be found in French et al. (2003). There were four flux towers covering the main land cover types. Details of the tower measurements are given in Twine et al. (2000).

\section{SMACEX'02}

The Soil Moisture Atmosphere Coupling Experiment 2002 (SMACEX02) data set described by Kustas et al. (2005) was collected over an experimental watershed in central Iowa, USA, an upper Midwest corn and soybean production region. The experiment took place during the 2002 growing season. An ASTER image collected on DOY 182 (July 1, 2002) was used. The landcover map was derived from a supervised classification of Landsat imagery and ground truth observations carried out in June and July. Flux tower measurements were available from 10 locations distributed over the study area to obtain representative areal sampling (Prueger et al., 2005). 


\section{REFLEX'12}

The REFLEX'12 campaign was an airborne campaign to support the understanding of land-atmosphere interaction processes (Timmermans et al., 2015a). The experiment was carried out over the Las Tiesas Experimental Farm test site near Barrax in the La-Mancha region in Spain, maintained by the Provincial Technical Agronomical Institute (ITAP). The campaign took place during 10 days in the end of July 2012, when the nonirrigated parts of the area are characterized by extremely dry conditions. Airborne imagery from the Airborne Hyperspectral Sensor (AHS) obtained during DOY 207 (de Miguel et al., 2015) was used in this analysis. Flux tower observations and a Large Aperture Scintillometer (LAS) covering four sites with distinctly different landcover provided groundtruth (Van der Tol et al., 2015).

\section{GEDIZ'98}

The intercomparison study over an irrigated area in the Gediz River Basin in Western Turkey is described in detail in Kite and Droogers (2000). For the analysis carried out here a total of 73 level-1B NOAA-AVHRR images were downloaded from the internet and pre-processed into surface reflectance and surface temperature images. The procedures followed are described in detail in Gieske and Meijninger (2005). Flux observations were available from two locations within the study region. A Large Aperture Scintillometer (LAS) was deployed over a valley in the Gediz River Basin in Western Turkey. The path length of the scintillometer was $2.7 \mathrm{~km}$ and provided surface fluxes at a scale comparable to the AVHRR imagery. The land use in the valley was heterogeneous consisting of $60 \%$ of raison grape, $15 \%$ cotton, $15 \%$ of fruit trees, $5 \%$ pasture and $5 \%$ of mixed tree species. The second location consisted of an irrigated cotton field, located west of Menemen, in a cotton production region, homogeneous at the AVHRR pixel scale. Fluxes at this location were obtained from a fast-response temperature sensor using the temperature variance method (de Bruin, 1994). In addition net radiation, soil heat flux and additional meteorological measurements were obtained at this location (Meijninger \& de Bruin, 2000). 


\subsubsection{Local model evaluation versus ground observations}

The main assumption in the current algorithm concerns the linearity between "instantaneous" scaled temperature and halfhourly evaporative fraction via Eq. (2.8). The datasets described above provided the opportunity to validate that assumption. In Fig. 2-1 the observed evaporative fraction $(\Lambda)$, is plotted versus the scaled temperature as defined in Eq. (2.8) for all four experiments. The RMSD-value (see Table 2-2 for definition) between the observations and model estimates for the four experiments is approximately 0.13 . A linear regression with a coefficient of determination, $\rho^{2}$, equal to 0.65 (0.81 and 0.62 for TSEB and SEBAL respectively) was found with a slope of 0.71 ( 0.98 and 0.79 for TSEB and SEBAL respectively) and an intercept of $0.22(0.02$ and 0.10 for TSEB and SEBAL respectively). A slope close to unity with a small intercept provides support for the use of Eq. (2.8) for these landscapes. Note that there was no model tuning in applying the DATTUTDUT algorithm.

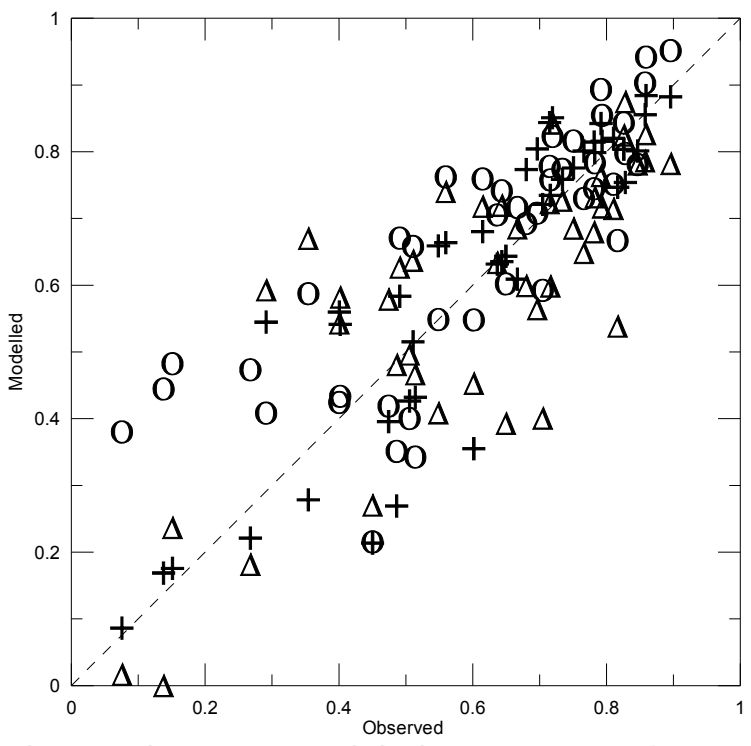

Figure 2-1 Observed versus modeled evaporative fraction for all four experiments, using DATTUTDUT $(0)$, SEBAL $(\Delta)$ and TSEB $(+)$

The scatter between DATTUTDUT-derived $\Lambda$ and observations increases significantly with increasing dry or stressed 
conditions (i.e., lower $\Lambda$ values). On the other hand, the trend for SEBAL is a relatively large dispersion around intermediate values of $\Lambda$, whereas this is less so with the TSEB approach. The extremely stressed cases $(\Lambda<0.3)$ originate from sites in the REFLEX'12 dataset which were sparsely vegetated. Removing these observations from the analysis for the DATTUTDUT model resulted in a minor increase in $\rho^{2}$ from 0.65 to 0.68. However, more important, the slope and intercept changed from 0.71 and 0.22 to 0.94 and 0.06 respectively. While the REFLEX'12 conditions may be considered rather extreme in terms of vegetation stress and heterogeneity in canopy cover, reliable estimates under such conditions are necessary for accurately monitoring the spatial and temporal variations in fluxes across many landscapes.

The results for the four energy balance components for the three models are illustrated in Fig. 2-2 and performance of the models is evaluated using difference statistics by Willmot (1984).
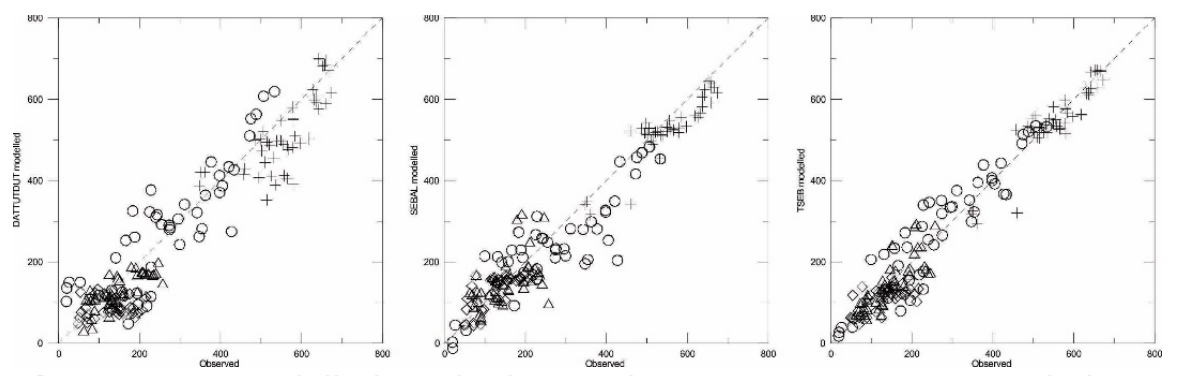

Figure 2-2 Modelled and observed instantaneous energy balance components of $R_{\mathrm{N}}(+), G(\diamond), H(\Delta)$ and $\lambda E(\mathbf{0})$ in $\mathrm{W} \mathrm{m}^{-2}$ for the Monsoon'90 (DOY 213, 216 and 221), SGP'97 (DOY 180 and 183), SMACEX (DOY 182) and REFLEX'12 (DOY 207) sites, for the three models

Table 2-2 lists the definitions and the quantities of the various difference statistics for the surface energy balance components as well as for the evaporative fraction. These include the RMSD, the mean absolute difference (MAD), and the mean absolute percent difference (MAPD). There is no distinction made between the four experimental datasets, and the figure indicates that the scatter with the measurements is generally greater with DATTUTDUT and SEBAL than with TSEB. In particular the net radiation estimates of the DATTUTDUT 
algorithm tend to have greater discrepancies with the observations, which are more prominent at the lower values.

Table 2-2 Description of statistics and quantitative measures of model performance for SEBAL(S), TSEB(T) and DATTUTDUT(D)

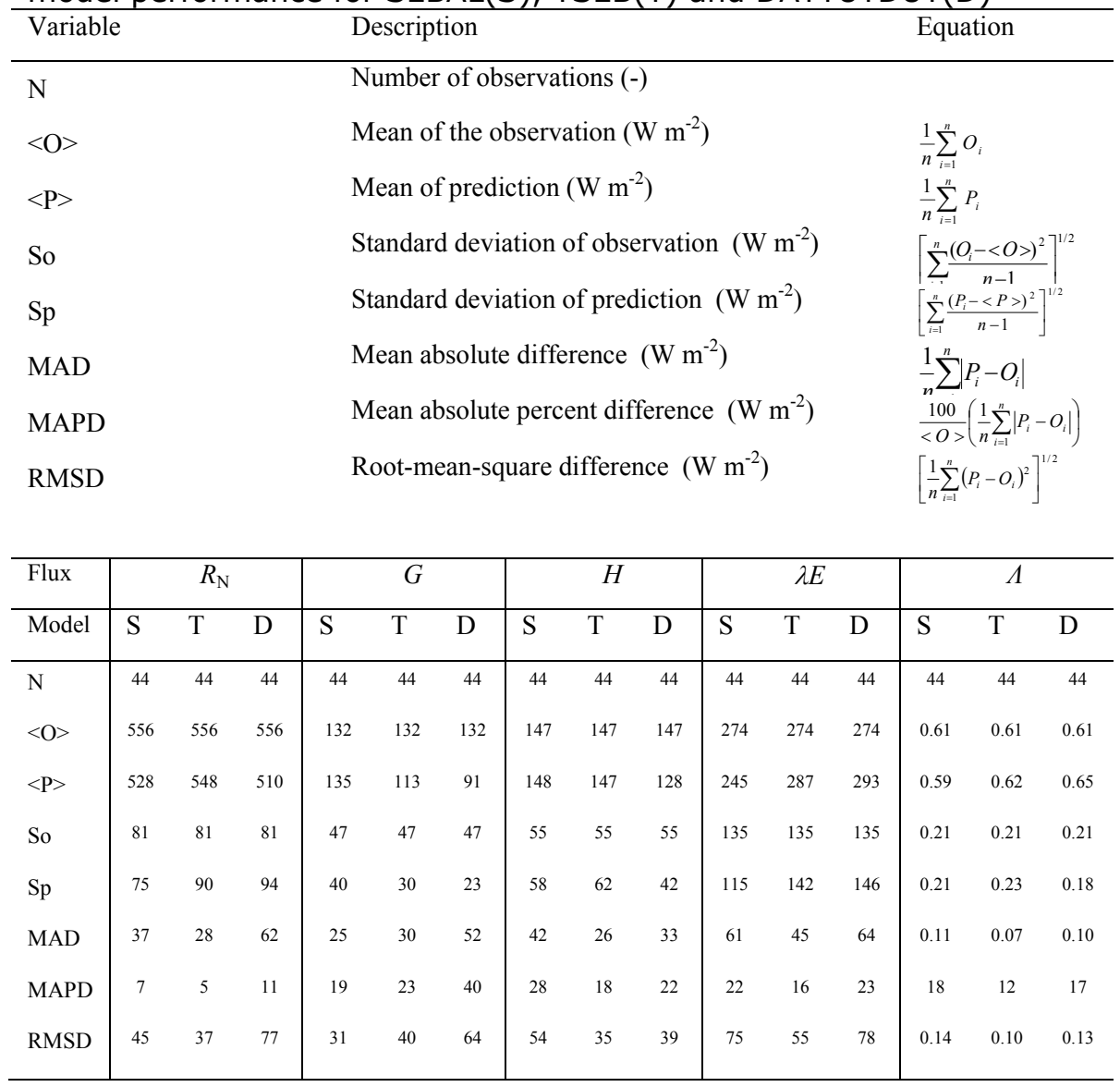

The mean difference between observation and prediction for $R_{\mathrm{N}}$ were about 10 and $30\left[\mathrm{~W} \cdot \mathrm{m}^{-2}\right]$ for TSEB and SEBAL respectively and around $45\left[\mathrm{~W} \cdot \mathrm{m}^{-2}\right]$ for DATTUTDUT. With respect to the predicted soil heat fluxes, also the largest discrepancies with observations are noted for the DATTUTDUT scheme, an under-estimation of around $40\left[\mathrm{~W} \cdot \mathrm{m}^{-2}\right]$, partly because of its direct linkage with $R_{\mathrm{N}}$. However, the main objective here is to demonstrate the utility of the current scheme for determining spatially distributed water and heat 
fluxes, which are governed by the amount of available energy, $R_{\mathrm{N}}-G$. Since over- and under-estimations of $R_{\mathrm{N}}$ and $G$ are generally paired, there is reasonable agreement in modelled and observed available energy.

Mean biases between observation and prediction for sensible heat flux were negligible for TSEB and SEBAL and nearly $20 \mathrm{~W}$ $\mathrm{m}^{-2}$ for the DATTUTDUT scheme. Biases in latent heat flux were lowest for TSEB $\left(\sim 15 \mathrm{~W} \mathrm{~m}^{-2}\right), 20 \mathrm{~W} \mathrm{~m}^{-2}$ for DATTUTDUT and highest for SEBAL at $\sim 30 \mathrm{~W} \mathrm{~m} \mathrm{~m}^{-2}$. The RMSD-values for the three models range from 35 to $55 \mathrm{~W} \mathrm{~m}^{-2}$ for $\mathrm{H}$ and from 55 to $80 \mathrm{~W} \mathrm{~m}^{-2}$ for $\lambda E$. A point worth mentioning here is that significant energy balance closure gaps $\left(\sim 100 \mathrm{~W} \mathrm{~m}^{-2}\right)$ were sometimes evident in the flux tower data (Prueger et al., 2005; Twine et al., 2000; Van der Tol et al., 2015). Although the measurements were corrected for lack of energy balance closure (French et al., 2005a, b), the model-measurement differences do include scatter attributed to uncertainty/energy balance closure errors in the flux observations.

The described predictions of $H$ and $\lambda E$ translate directly into $\Lambda$, and because of its relevance for the current approach the performance statistics for $\Lambda$ are shown in Table 2-2 as well. All three models show an almost perfect match between the mean observed and mean predicted value, where the discrepancy of DATTUTDUT is largest but still minimal at $4 \%$. This is mainly caused by the aforementioned deviations between observations and predictions of the turbulent fluxes at dry and sparsely vegetated locations. RMSD-values for TSEB are 0.10 whereas SEBAL and DATTUTDUT show values of 0.14 and 0.13 respectively.

\subsubsection{Spatial model evaluation}

The Barrax area is characterized by rather extreme conditions covering the full range in fractional vegetation cover as well as in moisture conditions, rendering sensible heat fluxes ranging from stable conditions to values as high as $400 \mathrm{~W} \cdot \mathrm{m}^{-2}$ (Timmermans et al., 2008). Therefore, the REFLEX campaign offered an excellent opportunity to analyse spatial differences in model output. 
Maps of model output for evaporative fraction are shown in the upper panels of Fig. 2-3 for TSEB, SEBAL and DATTUTDUT. The patterns in evaporative fraction are similar for all three models. Spatial correlation between DATTUTDUT and TSEB is 0.92, between DATTUTDUT and SEBAL it is 0.40, and between TSEB and SEBAL this equals 0.38 . The relatively low correlation between SEBAL and TSEB is mainly caused by the difference in estimation of surface roughness length for momentum, as noted by Timmermans et al. (2007), and will not be discussed further here. The relatively high correlation between TSEB and DATTUTDUT is encouraging, given the simplicity of the latter. However, despite the rather good spatial agreement of evaporative fraction between the three models, especially between TSEB and DATTUTDUT, there are absolute differences of up to 0.50 [-] for some areas (see Table 2-3). How these translate into absolute values of latent heat flux is shown in the lower panels of Fig. 2-3; over certain areas differences of up to $150 \mathrm{~W} \cdot \mathrm{m}^{-2}$ are noted. These are significant differences, similar to those reported by Timmermans et al. (2007) between SEBAL and TSEB model output of sensible heat flux.
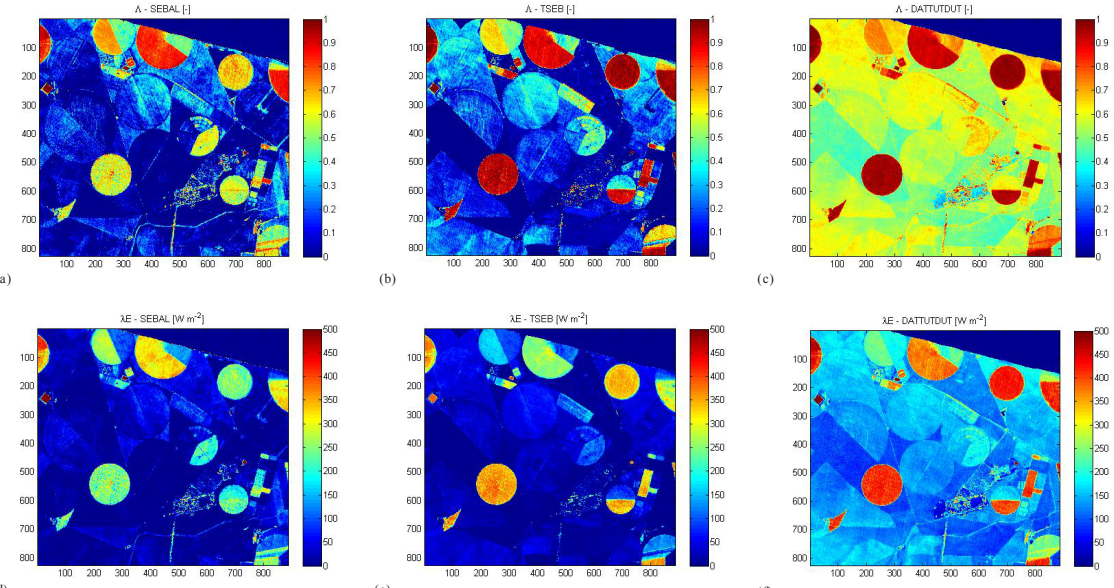

Figure 2-3 Distribution of model output $\Lambda$ and $\lambda E$ for all three models

For the relatively wet, thus irrigated, areas the three schemes show a rather similar response, which is also reflected in Table 2-3. For the drier, non-irrigated, parts of the area the DATTUTDUT scheme shows considerably higher values for $\Lambda$ as 
compared to SEBAL and TSEB. This is also reflected in Fig. 2-1, where the 4 driest observations originate from the REFLEX'12 campaign, over a vineyard, a wheat stubble field, a forest nursery and a camelina field (Andreu et al., 2015). SEBAL and TSEB show reasonable to good performance for these sites versus observations, whereas the simple scheme has clear problems producing the proper output under these circumstances. Apart from the earlier-mentioned issue of not parameterizing the aerodynamic roughness effects by DATTUTDUT, which is especially noticed in dry and aerodynamically rough areas, another issue here is the high spatial resolution of the REFLEX'12 imagery in combination with the automated end-member selection, $T_{\min }$ and $T_{\max }$. The latter issue causes an increase in the sensitivity of DATTUTDUT to variability in the heat fluxes under dry conditions.

Table 2-3 LST and Evaporative Fraction averaged for the main landcover units

\begin{tabular}{llccccc}
\hline Landcover & $L S T[\mathrm{~K}]$ & & \multicolumn{3}{c}{ Evaporative Fraction [-] } \\
\hline & Avg & St.Dev & SEBAL & TSEB & $\begin{array}{c}\text { DATTUTDUT } \\
\text { Original }\end{array}$ & Adjusted \\
\hline Bare pasture & 315.9 & 2.7 & 0.09 & 0.01 & 0.49 & 0.00 \\
Barley stubble & 312.3 & 1.7 & 0.14 & 0.29 & 0.59 & 0.19 \\
Building & 312.4 & 6.3 & 0.08 & 0.08 & 0.59 & 0.19 \\
Camelina & 315.9 & 1.6 & -0.09 & 0.04 & 0.49 & -0.00 \\
Corn & 299.5 & 1.9 & 0.60 & 0.91 & 0.95 & 0.87 \\
Crops & 310.3 & 4.1 & 0.23 & 0.41 & 0.65 & 0.30 \\
Fallow land & 315.7 & 2.7 & 0.13 & 0.01 & 0.50 & 0.01 \\
Forest nursery & 314.7 & 1.7 & 0.21 & 0.04 & 0.53 & 0.06 \\
Grass & 301.8 & 2.7 & 0.57 & 0.89 & 0.88 & 0.74 \\
Harvested cropland & 312.3 & 1.9 & -0.08 & 0.20 & 0.59 & 0.19 \\
Open water & 296.9 & 5.0 & 0.95 & 1.07 & 1.02 & 1.00 \\
Orchard & 314.5 & 5.0 & 0.07 & 0.10 & 0.53 & 0.08 \\
Poppy & 309.2 & 2.1 & 0.63 & 0.51 & 0.68 & 0.35 \\
Sunflower & 301.4 & 3.6 & 0.78 & 0.84 & 0.89 & 0.76 \\
Vineyard & 312.8 & 1.8 & 0.13 & 0.06 & 0.58 & 0.16 \\
Wheat stubble & 313.1 & 1.3 & -0.07 & 0.20 & 0.57 & 0.15 \\
\hline
\end{tabular}

The spatial resolution equals 4.0 meter and therefore a high within-field variation of land surface temperature is observed (Table 2-3). In addition, there is a large number of fields of different landcover that were dry and hot at the time of image acquisition. Consequently the histogram distribution of $L S T$, middle panel of Fig. 2-4, has an exceptionally long tail on the high end. Selecting the hottest pixel in the image to represent $T_{\max }$ in Eq. (2.8), under these conditions, results in a significant 
portion of the image yielding too high evaporative fraction estimates from DATTUTDUT .
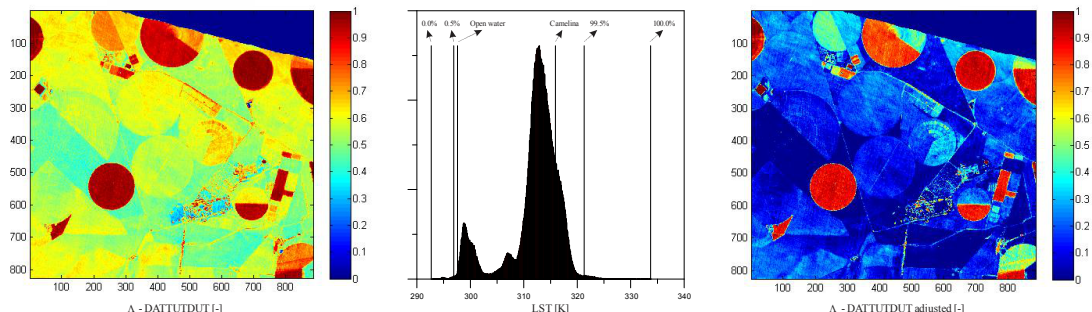

Figure 2-4 Influence of end-member selection on model output

It is beyond the scope of the current contribution to perform a detailed sensitivity analysis on the selection of the endmembers in the line of Timmermans et al. (2007). However, in the $L S T$ histogram in Fig. 2-4 the absolute minimum $(0.0 \%)$ and maximum $(100.0 \%)$ are indicated as well as the $0.5 \%$ and $99.5 \%$ minimum and maximum values of $L S T$. The DATTUTDUT model uses the $0.5 \%$ and $100.0 \%$ values for $T_{\min }$ and $T_{\max }$, which are $297.6 \mathrm{~K}$ and $333.7 \mathrm{~K}$ respectively.

To demonstrate the effect of end-member selection on spatial model results, $T_{\min }$ and $T_{\max }$ are selected based on the minimum and maximum $L S T$ averaged per landcover unit (Table 2-3). In the left and right panel of Fig. 2-4 the model output for $\Lambda$ is shown for the original model run and for the adjusted end-members respectively. The average results grouped per landcover type are shown in the right-most column of Table 2-3. A considerable improvement in spatial agreement is seen after this adjustment. With the exception of built-up areas (Buildings) and poppy landcover units the DATTUTDUT model results are comparable to the more physically-based approaches (see Table 2-3). This indicates that over problematic, i.e. dry and sparsely vegetated, areas model results may improve considerably after adjusting the end-member values based on landcover. A procedure could be developed based on landcover information to ensure proper linking between $T_{\min }$ and $T_{\max }$ and the hydrological extremes (wet and dry conditions), a technique also used in other indextype of models (Kalma et al., 2008). However, in this paper the objective is to demonstrate the utility of a completely 
automated approach without user adjustments for monitoring evapotranspiration.

\subsubsection{Temporal model evaluation}

The daily average net radiation from the SEBAL and DATTUTDUT schemes is compared with the ground observations in Fig. 2-5. Although the procedure used in Gieske and Meijninger (2005) to derive daily average net radiation is not exclusively related to the SEBAL algorithm, for simplicity the results are referred to as SEBAL estimates. For both schemes the $R_{N}$ estimates shown are taken from the pixel at the cotton site, where the weather station is situated. Both models seem to follow the temporal trend and magnitudes of the observations rather well, although SEBAL shows slightly higher estimates at the beginning of the season, whereas DATTUDUT shows slightly higher values towards the end of the season. The overall general agreement is supported by the relatively low RMSD value between modelled and measured daily $R_{\mathrm{N}}$ which is $\sim 20\left[\mathrm{~W} \cdot \mathrm{m}^{-2}\right]$ (MAPD $\sim 10 \%$ ), for both the SEBAL and DATTUTDUT algorithms.

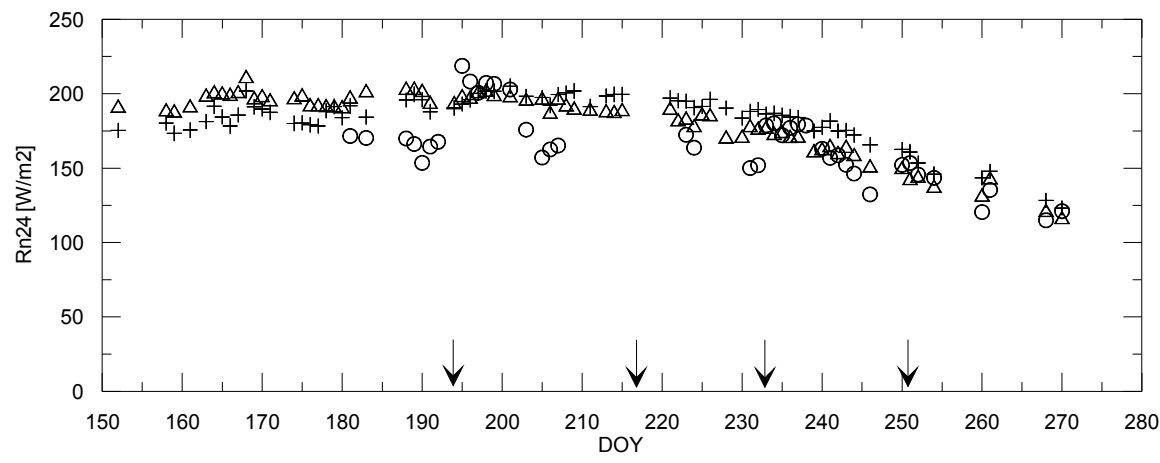

Figure 2-5 Daily values of net radiation for the cotton site plotted against day number. AVHRR-DATTUTDUT values (+) and SEBAL estimates $(\Delta)$ are compared with those determined with the weather station $(0)$ on the cotton field

Following irrigation, indicated by arrows in Fig. 2-5, the ground observations show an increase in net radiation, due to a decrease in both albedo and surface temperature. However, this effect is not clearly seen in the satellite approaches where 
only a minor increase is computed which is slightly more pronounced for the DATTUTDUT estimates.

The turbulent flux observations are areal averages which depend on wind speed, wind direction and aerodynamic properties of the upwind landscape and can be determined using so-called footprint calculations (Schmid, 1994; Timmermans et al., 2009). Due to the absence of detailed wind direction and wind speed information in the current study the average of a four-pixel window is taken over the cotton site. A similar four-pixel window is taken in the centre of the heterogeneous valley in the middle of the scintillometer transect since this is the area contributing the most to the observed signal. In Fig. 2-6, the estimated evaporative fractions from both remote sensing techniques are compared for the homogeneous cotton site and the heterogeneous valley site, Fig. 2-6a and 2-6b respectively. In addition an intercomparison of model output of the time evolution of evaporative fraction over the growing season is shown in Fig. 2-6c and 2-6d. It is clearly seen that correlation in model output for the cotton site is much higher than for the valley site (coefficient of determination, $\rho^{2}$, is 0.915 and 0.054 respectively). For the valley site there is actually a negative correlation - although it is statistically not significantly different from zero. Over this site evaporative fraction estimates from SEBAL increase slightly over the season, whereas DATTUTDUT output has a decreasing trend over the season. 

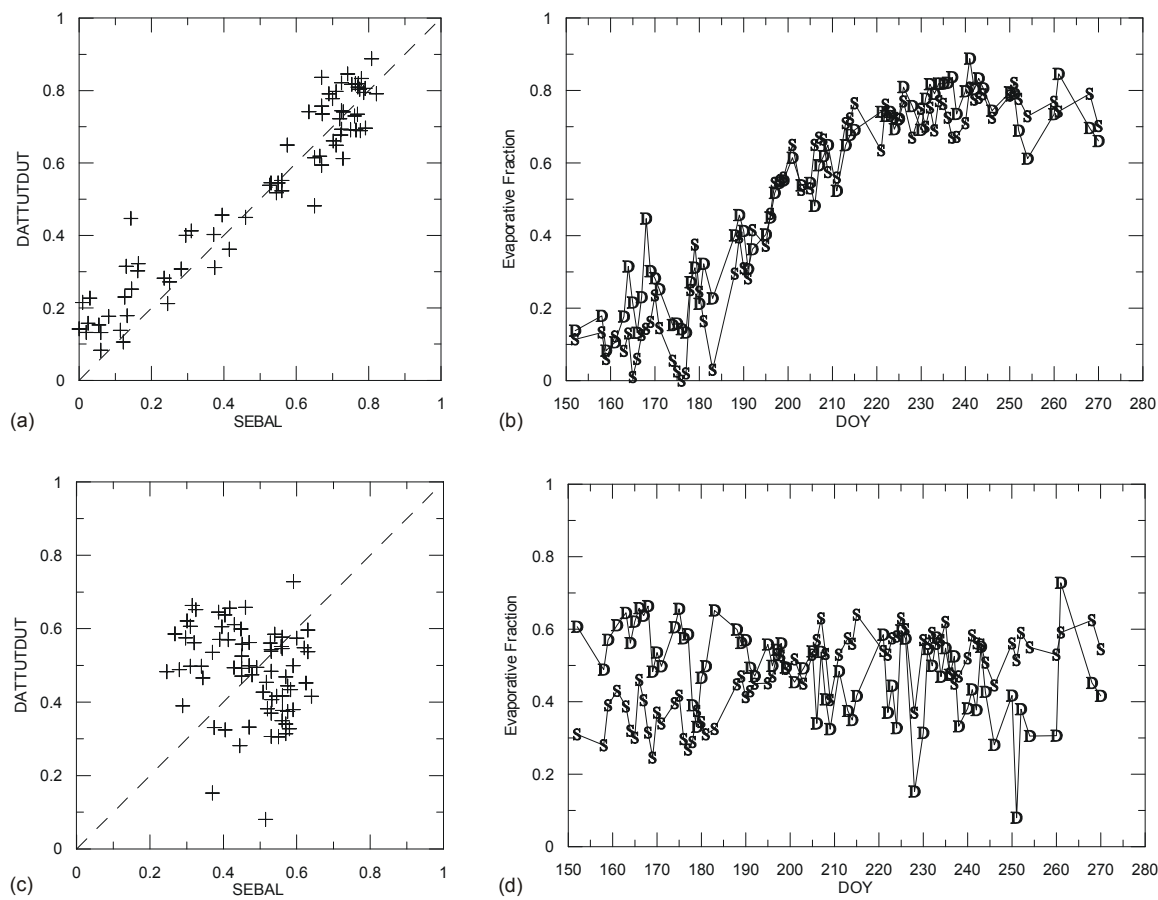

Figure 2-6 DATTUTDUT (D-symbol) and SEBAL (S-symbol) evaporative fraction estimates for the cotton (upper panels) and the valley site (lower panels), versus each other and over time.

A comparison of model output with observations of daily $E T$, for both methods estimated using Eq. (2.9), is illustrated for both sites in Fig. 2-7. In Fig. 2-7a, 2-7b and 2-7c results are displayed for the cotton site and in 2-7d, 2-7e, and 2-7f, results are shown for the valley location. Following Gieske and Meijninger (2005) the LAS data is combined with the AVHRRderived daily $R_{N}$ estimates to derive daily amounts of $E T$ from Eq. (2.9).

In the model-measurement comparisons of daily $E T$ displayed in Fig. 2-7, both models tend to underestimate the ground observations for both sites, with SEBAL output showing significantly greater bias. This effect is particularly evident in the beginning of the season, as seen in Fig. 2-7c and 2-7f and even clearer in Fig. 2-6b and 2-6d where DATTUTDUT estimates of evaporative fraction are higher than those of SEBAL. The better performance of the DATTUTDAT scheme 
over the growing season is supported by the difference statistics for the cotton site, which yielded RMSD values of 1.7 and $1.3 \mathrm{~mm}$ day $^{-1}$ (MAPD values of 35 and 28\%) for SEBAL and DATTUTDUT, respectively.
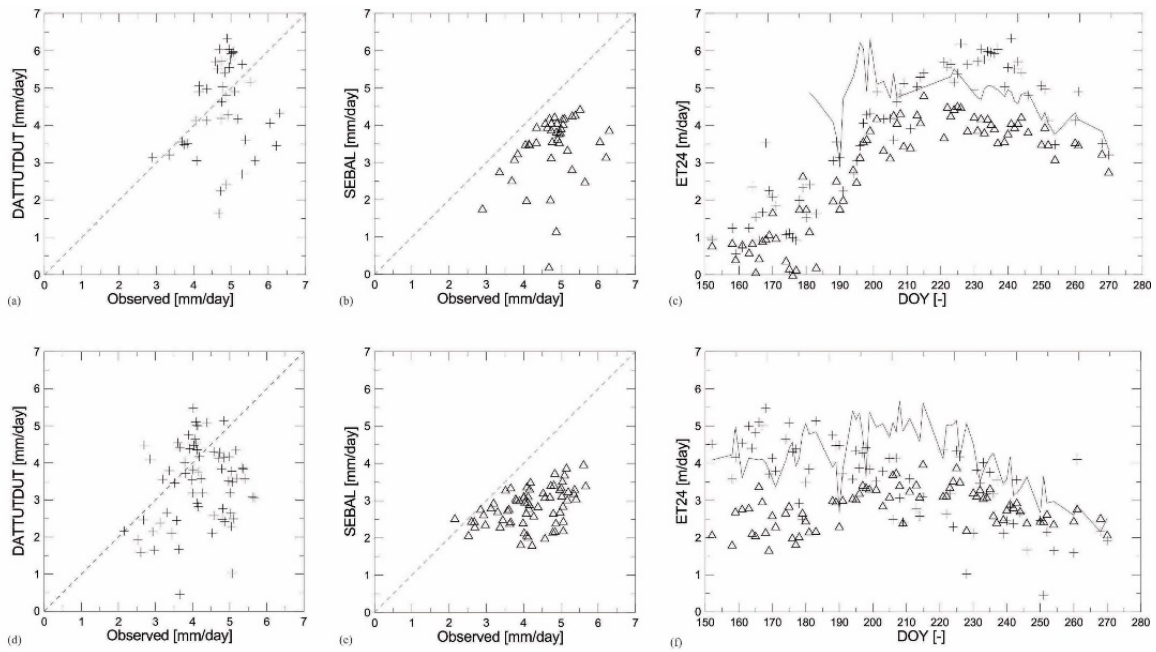

Figure 2-7 Daily amounts of evapotranspiration, $E T$ ( $\mathrm{mm} /$ day), over the cotton ( $a, b$ and $c)$ and valley site (d, e, and f). For panels $a, b, d$ and $f$, model results versus observations are illustrated. For panels $c$ and $f$, the observations $(-)$ as well as the SEBAL $(\Delta)$ and DATTUTDUT $(+)$ results are plotted temporally over the course of the growing season

Over the valley site the RMSD values for SEBAL and DATTUTDUT are rather similar, namely $\sim 1.5 \mathrm{~mm}^{\text {day }^{-1} \text { with }}$ MAPD value of $\sim 35 \%$. In Fig. 2-7f, the DATTUTDUT and the ground observations follow a similar temporal trend, but DATTUTDUT slightly underestimates the daily amounts in the second half of the growing season with respect to ground observations. On the other hand, SEBAL estimates show little temporal variation over the season. Since the net radiation estimation from both models is rather similar over the growing season for this site (coefficient of determination, $\rho^{2}$, is equal to 0.8 ), the difference in $E T$ estimates has to originate from the different estimates of the evaporative fraction. Generally in the second half of the growing season the two methods are in better agreement with the observations, although there is a slight underestimation by both remote sensing-based 
approaches with respect to the measurements over the valley site.

Cumulative $E T$ values are shown in Fig. 2-8 for the cotton site as presented by Gieske and Meijninger (2005) using the ground observations and SEBAL output for the monitoring period spanning a rain free period from DOY 150 to 270 (May 30 until September 28 1998). Using a simple water budget, by differencing the total irrigation and percolation, provides an independent indication of the cumulative $E T$ in this period. Droogers and Bastiaanssen (2002) reported a total of $545 \mathrm{~mm}$ supplied for irrigation in this period and a yearly percolation of $284 \mathrm{~mm}$, continuously downward throughout the year. Assuming equally distributed percolation over the year, yields a total water use for the monitoring period of $452 \mathrm{~mm}$. However, since figures for grape landcover indicated less percolation, and at times even capillary rise during the growing season, this figure might be slightly higher. The components of the simple water budget are also shown in Fig. 2-8, where "In" represents the total amount of irrigation and "Out" stands for the total outgoing bottom flux or percolation for the monitoring period.

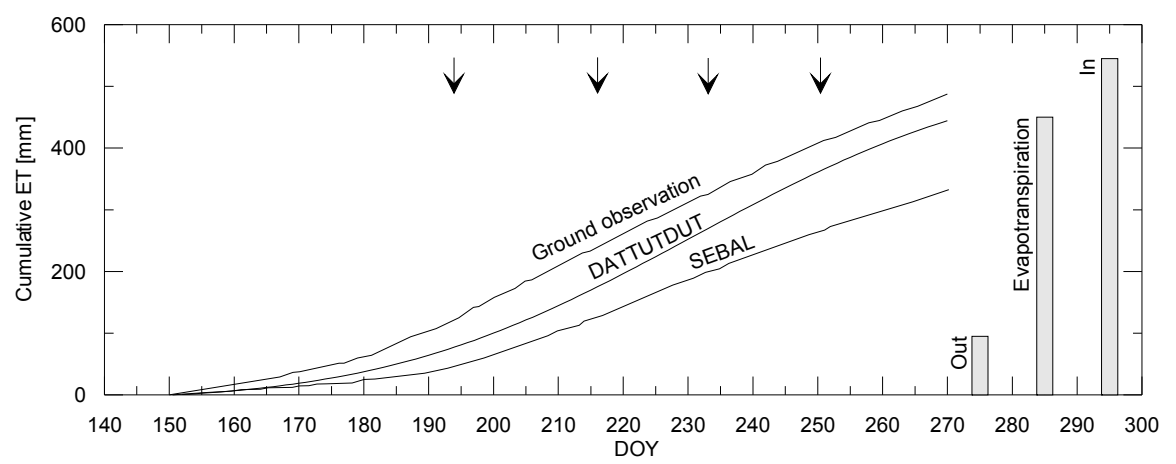

Figure 2-8 Cumulative $E T$ values derived from the temperature variance observations and from DATTUTDUT and SEBAL over the irrigated cotton site. The figure also displays the totals resulting from a simple water budget calculation where "In" represents the total amount of irrigation and "Out" is the total outgoing bottom flux or percolation for the monitoring period and the "Evapotranspiration" = In-Out

Plotting cumulative $E T$ moderates some of the scatter and errors in daily $E T$, and makes clearer the systematic bias between the models and observations (Gieske \& Meijninger, 
2005). Comparing the two remote sensing models, and the simple water balance method with the ground measurements, yields underestimates of 44,155 and $38 \mathrm{~mm}$ with DATTUTDUT, SEBAL and simple water balance methods, respectively. Relative to cumulative $E T$ for the monitoring period this yields MAPD values between ET observations and DATTUTDUT, SEBAL and simple water balance estimates of 9,32 and $8 \%$, respectively.

The underestimation of $E T$ during the growing season by the remote sensing methods is a concern and needs to be investigated in greater detail. With regard to the trends, it appears that both remote sensing based methods respond fairly well to the start of the growing season (irrigation days are indicated by arrows). However, the DATTUTDUT method yields the greatest rise (slope) during the main irrigation period (roughly from DOY 210 to 250), possibly indicating a better performance under these conditions.

\subsection{Discussion}

In a remote sensing model intercomparison study Timmermans et al. (2007) documented the poor performance in estimating heat fluxes when applying a version of SEBAL over dry and sparsely vegetated conditions. Similarly an intercomparison study by Choi et al. (2009) over the SMEX/SMACEX 2002 study region found significant discrepancies in modelled turbulent heat flux patterns between TSEB and the Mapping EvapoTranspiration at high Resolution using Internalized Calibration (METRIC) approach, a derivative of SEBAL, that were largely correlated with vegetation density. Generally, the largest discrepancies, primarily a bias in $H$, between these two models occurred in areas with partial vegetation cover. A similar result is noted in the current study.

The reported disagreement in $R_{N}$ for DATTUTDUT has several reasons which are counter-acting in both the shortwave and the longwave radiation components. Unfortunately only a limited amount of radiation component observations are available for the datasets used. Mainly net radiometers and pyranometers were used to measure $R_{\mathrm{N}}$ and $R_{\mathrm{S}} \downarrow$, whereas only 
at a few sites albedo measurements were carried out. Concerning the incoming radiation components, the SEBAL and TSEB algorithms use observations of $R_{\mathrm{S}} \downarrow$ whereas DATTUTDUT assumes a constant transmissivity of $0.7[-]$ in combination with the exo-atmospheric radiation. The average observed transmissivity for the dataset used was $0.79[-]$, yielding an average under-estimation around $70\left[\mathrm{~W} \cdot \mathrm{m}^{-2}\right]$ at the average observed $R_{\mathrm{S}}{ }^{\prime}$ (i.e. $800\left[\mathrm{~W} \cdot \mathrm{m}^{-2}\right]$ ). On the other hand, using the set transmissivity to derive an atmospheric emissivity using Eq. (2.6) yields an over-estimation of some $40\left[\mathrm{~W} \cdot \mathrm{m}^{-2}\right]$ at an average air temperature of around 300 [K] for $R_{\mathrm{L}} \downarrow$. With respect to the outgoing radiation components the DATTUTDUT assumptions also generally result in compensating errors. At the few sites where albedo was measured, 6 in total, the TSEB and SEBAL algorithms showed a near-perfect fit with the observations, whereas the DATTUTDUT scheme showed an under-estimation of around $50 \%$. With average values of $R_{\mathrm{S}} \downarrow$ and albedo (i.e. $0.2[-]$ ) this yields an over-estimation of $R_{\mathrm{N}}$ around $80\left[\mathrm{~W} \cdot \mathrm{m}^{-2}\right]$. Using a surface emissivity equal to unity with an average high-end surface temperature of around 315 [K], an over-estimation of $R_{\mathrm{L}}{ }^{\top}$ of about $30\left[\mathrm{~W} \cdot \mathrm{m}^{-2}\right]$ is noted as compared to using typical bare soil emissivities of $0.95[-]$. Although the average net effect is rather limited, around 20 $\left[\mathrm{W} \cdot \mathrm{m}^{-2}\right]$, largest deviations are noted over hot and dry, sparsely vegetated areas. The incoming radiation components are spatially rather homogeneous but at these dry and sparsely vegetated locations the outgoing radiation components are largest. Therefore, under these circumstances, the DATTUTDUT assumptions of unity surface emissivity and linearity between albedo and temperature produce the largest discrepancies, i.e. an under-estimation, with both the SEBAL and TSEB output as well as with the observations of $R_{\mathrm{N}}$.

As mentioned before, a large part of the discrepancy between the modelled and observed values for $G$ is caused by the direct linkage of $G$ with $R_{N}$. A second reason might be an oversimplification of the relation between $G$ and $R_{N}$ used here, see Eq. (2.7). Assuming the surface temperature is the only indicator that determines how much radiation is penetrating through the vegetation and reaching the soil is not only an oversimplified metric for determining vegetation density but 
also gives erroneous results under wet surface soil moisture conditions. Consequently the standard deviation of the predicted $G$ values is considerably lower than that of the observations, although to a lesser extent this is also noted for TSEB and SEBAL. A relatively flat response and underestimation for soil heat fluxes is a phenomenon seen more often in remote sensing-based SVAT models (Jacob et al., 2002; Timmermans et al., 2007). This, despite attempts to incorporate the dynamic behaviour of the $G$ ratio by either introducing a time-dependence (Kustas et al., 1998; Santanello \& Freidl, 2003), or by incorporating the surface temperature in a semi-empirical manner (Bastiaanssen et al., 1998).

Concerning the turbulent fluxes, in past studies, for midday convective conditions, typically an RMSD-value between modelled and measured turbulent heat fluxes of approximately $50 \mathrm{~W} \mathrm{~m}^{-2}$ or less and/or MAPD-value of less than $20 \%$ is considered an acceptable agreement (Hanna \& Chang, 1991; Kalma et al., 2008; Kustas \& Norman, 2000; Twine et al., 2000). This level of agreement considers the fact that energy closure problems (Oncley et al., 2002) and uncertainties in footprint analysis (Foken \& Leclerc, 2004; Hoedjes et al., 2007; Timmermans et al., 2009) cause uncertainties in $H$ and $\lambda E$ tower measurements that are often similar in magnitude to model-measurement differences of $\sim 50 \mathrm{~W} \mathrm{~m}^{-2}$. In Table 2-2, the difference statistics for the TSEB scheme meet these error criteria, while, the errors using DATTUTDUT and SEBAL do not. Nevertheless, the simpler schemes requiring less input data and expertise to run (particularly DATTUTDUT) still give useful $H$ and $\lambda E$ estimates except under dry and sparsely vegetated conditions.

The DATTUTDUT approach uses the evaporative fraction concept in combination with daily $R_{\mathrm{N}}$ estimates to produce daily $E T$ values. Therefore the absolute discrepancies in $H$ and $\lambda E$ become less critical, which was also noted in the temporal evaluation of the model. The general trend of observed daily $E T$ values over a growing season for two sites in Turkey is reproduced reasonably well, with DATTUTDUT outperforming the SEBAL scheme. 
Root Mean Squared Differences between both satellite-based model estimates and observed daily $R_{\mathrm{N}}$ over the growing season were mainly caused by the difference in scale of the observations. The net radiation, measured at 2.5 meter, was representative at the local or patch scale which are on the order of $150 \mathrm{~m}^{2}$. Although the observation site, which was located in a $300 \times 500 \mathrm{~m}^{2}$ cotton field surrounded by other cotton fields, was homogeneous at the AVHRR resolution with respect to land use, the irrigation pattern varied for each farm (Kite \& Droogers, 2000). This may explain the more smooth response of the satellite-based approaches for net radiation as compared to the ground observations, which were more strongly influenced by irrigation activity.

Despite the simplification of using a constant atmospheric transmissivity over the growing season the RMSD values for daily $R_{\mathrm{N}}$ were only around 20 [Wm-2]. Substituting a variable transmissivity over the season, using Eq. (2.5), did not significantly improve the DATTUTDUT results. An average increase over the season of 3 [\%] in $R_{N}$ was noted, which was mainly caused by deviations toward the end of the season, which were up to a maximum of 8.5 [\%]. Over the cotton site this caused a deterioration in RMSD for daily ET from 1.31 to $1.38\left[\mathrm{~mm} \cdot \mathrm{day}^{-1}\right]$ and for the valley site a slight improvement from 1.45 to $1.41\left[\mathrm{~mm} \cdot \mathrm{day}^{-1}\right]$.

A potentially larger source of error in both SEBAL and DATTUTDUT is the selection of the extreme pixels, as also noted in the spatial intercomparison. According to Meijninger (2003), the selection of the dry pixels in the initial, nonirrigated period, may be tenuous due to the difficulty in finding representative dry pixels under regionally humid and wet surface conditions that typically exist in the early period of the growing season here. Under such circumstances, selecting dry pixels that in reality do not represent the true dry extreme, and hence the "dry pixel" $E T>0$, causes a bias (underestimation of $E T$ ) for other pixels in the scene as these techniques force more of the available energy to be partitioned into $H$ instead of $\lambda E$. There is slightly less of a bias issue or underestimation for the DATTUTDUT scheme because the 
selection of the dry pixel is automated and always is the highest temperature value in the image.

An example of the issue in assigning wet and dry pixel temperatures is provided in Fig. 2-9, where scatterplots of surface temperature versus albedo are shown for a day early in the season (DOY 167) and one later in the growing season (DOY 196) accompanied by the frequency distribution of the surface temperature. The solid lines indicate the wet and dry pixel temperature automatically selected by the DATTUTDUT algorithm, where the shaded area in the frequency distribution represents the $0.5 \%$ of the total area determining the wet pixel selection. The dotted lines indicate the area where the dry pixel is most likely to be selected following the standard SEBAL procedure. Note that selecting a proper dry pixel for the SEBAL procedure from the scatterplot in Fig. 2-9 (b) is more straightforward than in the case of Fig. 2-9 (a). 

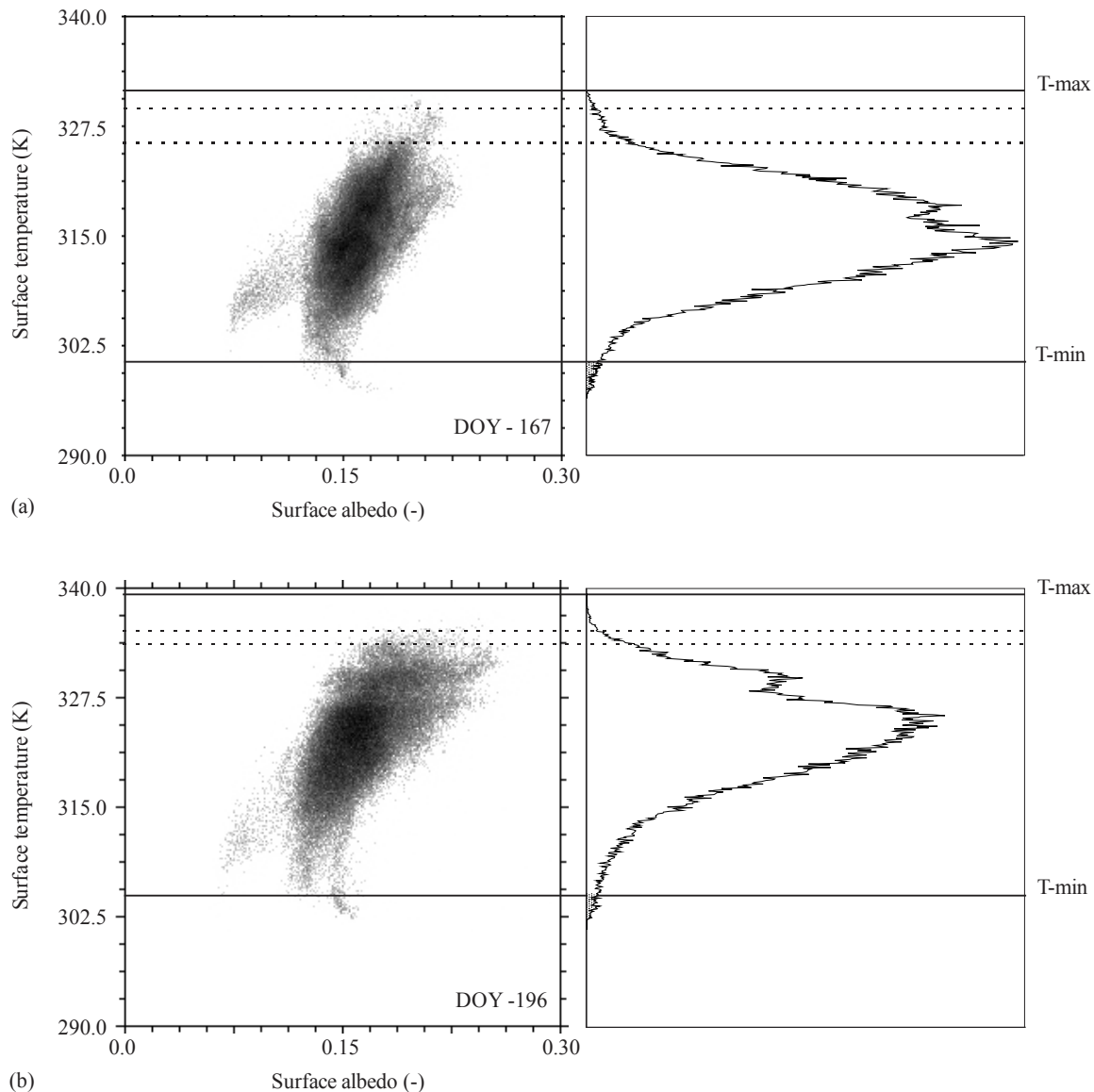

(b)

Figure 2-9 Scatterplots of surface temperature versus surface albedo for an early season day (DOY 167) and a mid-season day (DOY196) image. The solid lines indicate the wet $\left(T_{\min }\right)$ and dry $\left(T_{\max }\right)$ pixel temperature automatically selected by the DATTUTDUT algorithm, where the shaded area in the frequency distribution represents the $0.5 \%$ of the total area determining the wet pixel selection. The dotted lines indicate the likely $T_{\max }$ values for the dry pixel following the standard SEBAL procedure

Although this procedure is automated in the case of DATTUTDUT, this does point out a limitation of these types of schemes, namely that a wet and a dry pixel are required within the scene. The existence of totally wet and dry pixels may not be present, and also it will be pixel-resolution dependent, as also illustrated in section 2.3.3. 
With respect to daily $E T$, for the cotton site both satellite methods and the observations showed a similar behaviour over the study period, see Fig. 2-7c. During the first half of the season, observations yield the highest ET values, SEBAL the lowest and with the DATTUTDUT estimates somewhere in between. Apart from the temperature selection procedure this may be caused by a fairly large negative soil heat flux observed during the first days after irrigation. Since the satellite based methods assume a negligible daily soil heat flux, both turbulent fluxes will be under-estimated, since daily available energy $\left(R_{N, 24}-G_{24}\right)$ is under-estimated. From roughly DOY 225 to 245 DATTUTDUT is overestimating and SEBAL is underestimating the observed $E T$ by similar magnitudes. There is no obvious explanation for this result. From DOY 245 until 270 , which is the end of the growing season, DATTUTDUT is in close agreement with the observation, whereas SEBAL slightly underestimates the daily $E T$.

The reported RMSD values for daily $E T$ seem rather large, but Kite and Droogers (2000) showed similar discrepancies for two selected days (DOY 177 and 241) using 9 different methods of estimating daily $E T$. Average $E T$ values over the cotton site for the two days were 3.5 and $4.6 \mathrm{~mm}^{\text {day }}{ }^{-1}$ respectively, whereas standard deviations among the different methods were as high as 1.6 and $1.1 \mathrm{~mm}$ day $^{-1}$. The $E T$ values from SEBAL and DATTUTDUT for the two days were 0.1 and 0.8 for DOY 177 and 6.3 and 4.1 for DOY 241, respectively. For DOY 241, the two model estimates fall within the variation of other methods, but for the start of the season (DOY 177) both models showed an under-estimation, which is attributed to the assumption of negligible soil heat flux described above. The average $E T$ value computed by Kite \& Droogers (2000) for the valley site was $\sim 4.0 \mathrm{~mm}$ day $^{-1}$ with a standard deviation of $1.0 \mathrm{~mm}$ day $^{-1}$ for both DOY 177 and 241. Daily ET from SEBAL and DATTUTDUT for these days are 1.8 and $4.4 \mathrm{~mm}$ for DOY 177 and 3.0 and $2.8 \mathrm{~mm}$ for DOY 241. Again for DOY 241 both models fall within the variation of other methods while there is a slight under-estimation for DOY 177.

Model validation is usually performed using a handful of towerbased flux observations which are usually situated in 
homogeneous sites and as such typically are not representative of extreme or unique conditions. As such, assessing model performance with measurements at several selected sites does not guarantee that a model will provide reliable flux estimates over the whole scene, particularly in heterogeneous landscapes (Timmermans et al., 2007). Therefore, a spatial model evaluation was carried out over the Barrax site. Sensitivity to the selection of proper temperature end-members was demonstrated and results suggested a procedure might be developed to ensure proper linking between $T_{\min }$ and $T_{\max }$ and the hydrologic extremes. However, forested areas can have high sensible heat fluxes and low surface-air temperature difference due to a very low aerodynamic resistance. This situation will not be properly accommodated by a model that does not parameterize aerodynamic roughness effects on the flux-gradient relationship. To investigate model performance and assumptions under such conditions requires a study as described in Norman et al. (2006), that involves an intercomparison and analysis of fluxes generated by different remote sensing-based modelling approaches in comparison to detailed simulations for a full range in hydrologic and aerodynamic conditions using a complex multi-source soilplant-environment model. Simulations from a detailed SVAT from a study evaluating the effects of sub-pixel variability by Kustas and Norman (2000) could serve as a test case. However, this is beyond the scope of the current contribution, which is focused on demonstrating the model utility covering a wide range in fractional vegetation cover, soil moisture and meteorological conditions.

In summary, the simple schemes requiring less input data and expertise to run (particularly DATTUTDUT) still give useful $H$ and $\lambda E$ estimates except under very dry and sparsely vegetated conditions. The difference in model performance between TSEB, SEBAL and DATTUTDUT over such locations may have different reasons, such as the explicit use of meteorological data in TSEB and SEBAL and not in DATTUTDUT, or the way aerodynamic properties are prescribed, one-source for SEBAL, two-source for TSEB and not for DATTUTDUT, effects which have been examined by many others (Choi et al., 2009; French et al., 2005b; Timmermans et 
al., 2007). However, since the discrepancies with local flux observations for DATTUTDUT mainly occur over dry and sparsely vegetated areas, we firmly believe that the underestimation of $R_{N}$, combined with the selection of $T_{\max }$ using high resolution imagery, at these locations are the main reasons. At these locations the latent heat flux is set to zero. Would the estimate of available energy have been higher at these locations, the majority of the available energy would have been attributed to the sensible heat flux, which would reduce the evaporative fraction.

\subsection{Concluding remarks}

In this study a remote sensing-based framework (DATTUTDUT) is developed for the automated estimation of surface energy balance components from remotely sensed radiometric surface temperature only. The method can be used to derive a spatially distributed map of actual evapotranspiration over large heterogeneous areas, provided that hydrologic extremes or wet and dry conditions are present.

Maps of surface energy balance components using the current approach were compared to ground observations and to two other more complex remote sensing-based land surface models that have been validated numerous times in the literature. The inter-comparisons were made using large scale field experimental data collected over heterogeneous landscapes under a wide range of environmental conditions. This simple and fully automated scheme was shown to provide estimates of the available energy (net radiation less soil heat flux) and turbulent (sensible and latent heat) fluxes comparable to these established and more complex remote sensing-based schemes, but only under less extreme and heterogeneous environmental conditions. Discrepancies with observations were significant using either SEBAL, version of Bastiaanssen et al. (1998), or DATTUTDUT approaches under dry sparsely vegetated areas.

The DATTUTDUT scheme was also applied to an irrigated site for the purposes of evaluating its utility for seasonal monitoring of crop water use. The scheme provided estimates of daily $E T$ that generally underestimate the observations with significant 
scatter. Clearly there are environmental conditions (both hydrometeorological and land cover/land use) that limit the utility of both the DATTUTDUT and SEBAL schemes. For example, early in the growing season wet and dry pixels are difficult to identify and when the region is under water stressed conditions, this procedure is also less reliable unless land use is considered in defining $T_{\max }$ (see Table 2-3). Moreover, the DATTUTDUT scheme cannot account for the effect of significant variation of aerodynamic properties of the landscape, which can have a dramatic impact on the flux-gradient relationship (Norman et al., 2006). However, given the simplicity of the algorithm and its ease of use, the proposed model has utility in identifying areas of high and low water use even if the $E T$ magnitudes are error-prone (see Fig. 2-3) and therefore could be an operational tool for rapid monitoring of relative water use or plant stress conditions in regions having little ground information. Once such areas of relatively low and high ET are identified, more physically-based models such as ALEXI/DisALEXI (Anderson et al., 2011) could be run to more reliably quantify the $E T /$ stress conditions.

To gain a greater sense of the level of uncertainty in $E T$ mapping and monitoring using the current approach, model inter-comparison studies of the type conducted by Timmermans et al. (2007) between the DATTUTDUT scheme and more established remote-sensing based approaches, such as ALEXI/DisALEXI and SEBAL, but also for other simple index methods such as S-SEBI and SSEBop, are planned for a variety of landscapes containing a wide range in land use/vegetation cover and environmental conditions.

In the paper on which this chapter was based the authors acknowledge funding from the NASA Interdisciplinary Research Program in Earth Sciences, EOS/Land Surface Hydrology Program and the Terrestrial Hydrology Program as well as USDA-ARS funding which made possible the experimental data sets from Monsoon '90, SGP '97 and SMACEX02, respectively. Funding from the European Community's 7th Framework Programme (FP7/2008-2013) under EUFAR contract $n^{\circ}$ 227159, Cost Action ES0903-EUROSPEC and ESA Grant $\mathrm{D} / \mathrm{EOP} / \mathrm{rp} / 2012 / 48$ made possible the experimental dataset 
from the REFLEX'12 Campaign. The authors thank Dr. Wouter Meijninger and Dr. Ambro Gieske for providing the Gediz data, which made it possible to conduct this study. They also thank Dr. Henk de Bruin and Dr. Martha Anderson for their critical and helpful comments and suggestions. USDA is an equal opportunity provider and employer. 


\title{
Chapter 3 Accounting for Atmospheric Boundary Layer variability on flux estimation from RS observations*
}

\begin{abstract}
A Large Eddy Simulation (LES) model is coupled to a RS based SVAT that accounts for soil and vegetation in order to study the feedback effects between surface state and spatial variability in fluxes, through the induction of spatial variability in the lower atmosphere. As such, this study focuses on sensible heat flux exchange. The simulations indicated that changes are introduced to the flux distributions mainly at higher surface temperatures. A scale-dependent method is presented to account for feedback effects. This showed most significant correlation between surface and air temperature at scales from 500 - $1000 \mathrm{~m}$ and modulated the spatial variance of sensible heat flux. This suggests that feedback effects act to limit the spatial variability in fluxes and ignoring them will cause the largest errors at the extremes.
\end{abstract}

\subsection{Introduction}

The study of land-atmosphere interactions and thus of the atmospheric boundary layer requires a statistical approach rather than a deterministic one, due to its turbulent character. However, averaging the governing equations, i.e. the equation of state and the equations for conservation of momentum (Newton's second law, or Navier-Stokes equations), mass (continuity equation), moisture, heat (first law of thermodynamics), and of any scalar results in a situation where there are more unknowns than equations (closure problem). Since analytical or full numerical solution of the governing equations is generally not possible, the traditional approach to solve for this closure problem is to relate the unknown turbulence quantities at a given point in space to known

\footnotetext{
* Based on Timmermans et.al., Int. J. Remote Sens. 29, 17-18, pp. 5275-5290, 2008
} 
quantities of the flow at that same point. So-called first order closure schemes, typically used in remote sensing based land surface modelling, for example utilize eddy transfer coefficients, or diffusivities, to relate the mean turbulent flux to the mean gradient of the quantity that is transported.

Consequently, turbulent flux exchange at the land-atmosphere interface is generally described as a function of the differences of the state of the surface and the overlying air, and of the ability of the interface (the earth's surface) to exchange these fluxes. However, this ability, or conductance of the earth's surface, as well as the states of both the surface and air in turn are a function of the fluxes themselves ("feedback mechanism"). Moreover, these feedback mechanisms are very strongly scale dependant (Albertson \& Parlange, 1999b; Anderson et al., 2003).

In present-day remote sensing based land-atmosphereinteraction schemes, which generally follow some form of resistance network, the state of the lower atmosphere is commonly assumed constant, although indications exist that the assumption of homogeneous atmospheric variables over a modelling domain may lead to erroneous flux estimation (Kustas \& Albertson, 2003; Parlange et al., 1995). As such, the flux estimates rely on spatially and temporally averaged meteorological parameters, such as potential air temperature, $\theta_{\mathrm{a}}$, specific humidity, $q_{\mathrm{a}}$, and windspeed, $u$, in the lower atmosphere and land surface parameters, potential surface temperature, $\theta_{0}$, humidity, $q_{0}$, and surface roughness lengths for momentum, $z_{\mathrm{OM}}$, and for heat, $z_{\mathrm{OH}}$, that can be considered point measurements in space and in time. These, rather different, temporal and spatial scales of the atmospheric and land surface parameters, question the validity of the resistance scheme. Therefore, in order to improve remote sensing based estimates of turbulent exchanges the variability of the lower atmospheric boundary layer needs to be taken into account.

Despite its rather demanding numerical calculations, the large eddy simulation (LES) technique has become an increasingly popular tool for a physical understanding of the impact of heterogeneous land surfaces on the lower Atmospheric Boundary Layer (ABL), (Avissar \& Schmidt, 1998; Bou-Zeid et al., 2004). The recent development of a framework for coupling remotely sensed land surface data into an LES model by 
Albertson et al. (2001) provides the possibility for dynamic flux prediction in space and time, based on local differences between surface states and near surface air properties. Here, an adapted version is developed and implemented for the SPARC 2004 dataset (Su et al., 2005) to study the effects of the surface state on the lower ABL. A better understanding of the impact of such a heterogeneous land surface on the lower atmosphere and hence on the turbulent exchanges would potentially improve remote sensing based flux estimates.

The first part of this chapter demonstrates the potential improvements for remote sensing based flux estimations using spatially non-uniform atmospheric parameters. Differences between turbulent flux output from the dynamically coupled model and from classical, decoupled, approaches, using spatially uniform atmospheric parameters and spatially variable atmospheric parameters, are explored. The second part focuses on first attempts to assess the surface impact on the lower $\mathrm{ABL}$ at multiple scales.

\subsection{Methods}

It is beyond the scope of this study to describe the dynamic modelling aspects of the atmospheric boundary layer ( $A B L)$, and details of the original inclusion of a dual source land surface flux model into an LES scheme is provided in Albertson et al. (2001). However, a patch-version of the dual source model as described in Norman et al. (1995) is modified here to match the dynamic character of the LES code in a similar way as in Albertson et al. (2001). In this section a brief description of how the LES scheme models the boundary layer dynamics, the adapted dual source model and the wavelet technique to analyse the feedback effects from the surface into the lower $A B L$, is provided. Details of the LES and the dual source codes are given in Albertson (1996), Albertson and Parlange (1999a), Albertson and Parlange (1999b) and Kustas and Norman (1999), Norman et al. (1995) respectively, whereas a complete overview of the wavelet technique is provided in Addison (2002). 


\subsubsection{Large eddy simulation}

Modelling the turbulent flow with velocity $u$ in an atmospheric boundary layer in general comes down to solving the continuity equation:

$\frac{\partial \mathrm{u}_{j}}{\partial \mathrm{x}_{j}}=0$

and the Navier-Stokes equations (both using Einstein's summation notation) for an incompressible fluid with constant viscosity, $v$ :

$\frac{\partial \mathrm{u}_{i}}{\partial t}+\mathrm{u}_{j} \frac{\partial \mathrm{u}_{i}}{\partial \mathrm{x}_{j}}=-g \delta_{i 3}-\frac{1}{\rho_{a}} \frac{\partial \mathrm{p}}{\partial \mathrm{x}_{i}}+v \frac{\partial^{2} \mathrm{u}_{i}}{\partial \mathrm{x}_{j}^{2}}$

where time is represented by $t$, the acceleration due to gravity is given by $g, \delta_{13}$ represents the Kronecker delta and $\rho_{\mathrm{a}}$ is the density of air, whereas $p$ represents pressure. The transport of any scalar is represented by:

$\frac{\partial c}{\partial t}+u_{j} \frac{\partial c}{\partial x_{j}}=v_{c} \frac{\partial^{2} c}{\partial x_{j}^{2}}$

where $c$ represents the scalar concentration of interest (for example specific humidity or potential temperature) and $v_{\mathrm{C}}$ is the molecular diffusivity of the scalar in air (Brutsaert, 1982; Stull, 1988).

Since a numerical solution in time and space of the governing equations on the full range of scales is currently not possible, a reduction in the degrees of freedom being simulated is needed. Traditionally this is done by so-called Reynolds Averaging Navier-Stokes (RANS) simulation, where the equations are averaged such that the mean field is derived subject to a closure model that approximates the complete set of turbulence effects (Katul \& Albertson, 1998; Katul \& Albertson, 1999). In an LES model the governing equations are not averaged but instead the turbulent fields, e.g. a velocity component or water vapour concentration, are spatially filtered to the scale of a numerical grid, rather than fully averaged. The turbulent field is then separated into a resolved and an unresolved, or sub-filter, component, see Albertson and Parlange (1999b). As apparent from the name LES, the filtered Navier-Stokes equations simulate the effects of the land surface conditions on the larger sized eddies. Although only the larger eddies are resolved and the larger scale turbulence is 
responsible for the major part of the transport of water and energy, a sub-grid model does approximate the transport by the unresolved eddies. As a consequence, the LES technique is well suited for studying the interaction between heterogeneous land surfaces and the $A B L$.

The solution of the filtered equations is subject to the specification of appropriate boundary conditions. The horizontal directions have periodic boundary conditions, which is a necessary approach in turbulence simulation "because it is critical to have fully developed turbulence on both the inflow and exit faces of the domain" (Albertson et al., 2001). The top boundary of the computational domain is positioned well above the top of the boundary layer. The top condition is one of vanishing vertical gradients of all primitive variables and no vertical flow across the boundary. Critical to the turbulence structure of the atmospheric boundary layer is the bottom boundary condition, here defined by a dual source land surface model. Through this linking, the water and heat exchanges exert a feedback on the properties of the lower $A B L$, and as such dynamically influence the exchange rates.

\subsubsection{Dual source land surface model}

The main characteristic of the land surface model used here is that it discriminates between a soil and a vegetation component, aiming at a more physical description of heterogeneous surfaces when dealing with radiative and aerodynamic properties. The model, which is a patch version of the parallel resistance network described by (Norman et al., 1995), is originally designed to use input data primarily from remote sensing platforms. As such, several simplifying assumptions about energy partitioning between soil and vegetation reduced both computation time as well as required input data.

Required remote sensing input consists of spatial information on surface temperature, horizontal and vertical vegetation density, as well as albedo. Observed radiometric surface temperature, $T_{r}$, is used to estimate canopy and soil temperatures ( $T_{\mathrm{c}}$ and $T_{\mathrm{s}}$, respectively) as a function of the fractional canopy cover, $f_{\mathrm{c}}$, with a simple non-linear mixing model: 
$T_{R}^{4}=f_{C} T_{c}^{4}+\left(1-f_{C}\right) T_{s}^{4}$.

As a first estimate, the part of the latent heat flux, $\lambda E$, where $\lambda$ represents the latent heat of vaporization and $E$ is the rate of evaporation, that originates from the canopy, $\lambda E_{C}$, is computed by the well-known Priestley and Taylor approach (Priestly \& Taylor, 1972), see Eq. (3.5), which works reasonably well under unstressed vegetation conditions. The canopy sensible heat flux, $H_{\mathrm{C}}$ is then determined as a residual. Once $T_{\mathrm{S}}$ is determined from equation (3.4), it is possible to estimate the soil sensible heat flux, $H_{\mathrm{S}}$, through the Monin-Obukhov relationship (Brutsaert, 1982) between sensible heat flux and the profile shape of temperature in an unstable boundary layer, see also equations (3.6 - 3.8). Energy budget considerations for the soil fraction yield the latent heat flux for the soil, $\lambda E_{S}$, as a residual, assuming the soil heat flux, $G$, as a constant fraction of the soil net radiation $R_{\mathrm{NS}}$. If $\lambda E_{\mathrm{S}}$ is negative, then the soil is likely to be dry and $\lambda E_{S}$ is set to zero. Under these circumstances, the soil sensible heat flux is calculated as a residual, which yields an adjusted soil temperature. Equation (3.4) then provides a new estimate for the canopy temperature which, by using again the Monin-Obukhov relation, is used to calculate a new estimate for the canopy sensible heat flux. As such all the fluxes are recalculated, leading to a lower value of the constant $\alpha_{\text {PT }}$ in Eq. (3.5), which means that the vegetation is under stress (Kustas \& Norman, 1999).

Finally all fluxes are calculated as weighted averages of the canopy and soil components, where the total $H$ and $\lambda E$ fluxes are the lower boundary condition of the LES code in the coupled model. Summarizing the above, this implies the following for the parameterization of the canopy and soil components of the latent heat fluxes:

$\lambda E=f_{c} \lambda E_{C}+\left(1-f_{c}\right) \lambda E_{S}=f_{c} R_{N C} \alpha_{P T} \frac{s}{(s+\gamma)}+\left(1-f_{c}\right)\left(R_{N S}-H_{S}-G\right)$

where the net canopy radiation $R_{N C}$ is a function of $T_{C}, s$ is the slope of the saturation vapour pressure, and $\gamma$ is the psychrometric constant, with values of the Priestley and Taylor constant, $\alpha_{\mathrm{PT}}$, taken equal to 1.26 for potential evaporation, and

$H=f_{c} H_{C}+\left(1-f_{c}\right) H_{S}=\rho_{a} C_{p}\left[f_{c} \frac{\left(\theta_{C}-\theta_{a}\right)}{r_{a H}}+\left(1-f_{c}\right) \frac{\left(\theta_{S}-\theta_{a}\right)}{r_{a H}+r_{s}}\right]$ 
for the sensible heat fluxes, where $\rho_{a}$ is the air density, $c_{P}$ the specific heat of air at constant pressure, $\theta$ represents potential temperature for the soil (s) and canopy (c) components, whereas $\theta_{a}$ is the potential temperature of the overlying air at reference height $z$, parameter $r_{\mathrm{s}}$ is the soil resistance to heat transport and $r_{\mathrm{aH}}$ the aerodynamic resistance, given by:

$$
r_{a H}=\frac{\left[\ln \left(\frac{z-d_{0}}{z_{0 M}}\right)-\psi_{M}(z, L)\right]\left[\ln \left(\frac{z-d_{0}}{z_{0 H}}\right)-\psi_{H}(z, L)\right]}{k^{2} u}
$$

in which $d_{0}$ represents zero-plane displacement height, $z_{\mathrm{OM}}$ is the surface roughness for momentum transport, $Z_{\mathrm{OH}}$ is the scalar roughness height for heat transfer, $k$ the Von Karman constant, $u$ the wind speed at height $z, \Psi_{\mathrm{M}}$ and $\Psi_{\mathrm{H}}$ the stability correction functions for momentum and sensible heat transfer respectively. $L$ is the Monin-Obhukov length defined as:

$L=-\frac{\rho_{a} C_{p} u_{*}^{3} \theta_{v}}{k g H}$

where $g$ is the acceleration due to gravity, $u_{*}$ the friction velocity and $\theta_{v}$ the potential virtual temperature near the surface.

Required aerodynamic properties, such as canopy height, displacement height, aerodynamic roughness and leaf width, may be taken from a land-cover map, since the model is not very sensitive to these parameters. Furthermore, micrometeorological measurements of incoming shortwave radiation, air-temperature, -humidity and -pressure and wind speed are required as input parameters. They can be assigned a-priori in the decoupled model and are taken from the LES output in the lowest grid points in the coupled model. To obtain a comparison between the decoupled model runs and the coupled model runs as fair as possible, the meteorological input parameters necessary for the decoupled model are taken from time-averaged (30 minutes) and horizontally averaged LES output in the lowest grid points; see also the section on model simulations. 


\subsubsection{Assessment of surface impact on lower ABL}

Developing an operational tool to account for atmospheric heterogeneity in RS-based flux estimation ("surfaceatmosphere interaction"), involves the mapping of remotely sensed observations of surface fields into air fields near the ground. This concerns exploring the propagation of surface heterogeneity effects into the lower ABL. Since these interaction mechanisms are known to be largely scaledependant, the correlation between surface fields with lower ABL fields needs to be analysed at multiple scales.

Using the Discrete Wavelet Transform (DWT), it is possible to perform a multi-resolution decomposition of a discrete signal $x(t)$ of finite length $N=2 M$ through the range of scales $0<m$ $<M$ in the form:

$$
x_{m}(t)=x_{m-1}(t)-d_{m}(t)
$$

where $x_{m}(t)$ is the signal approximation at scale $m$ and $d_{\mathrm{m}}(t)$ its detail:

$$
d_{m}(t)=\sum_{n=0}^{2^{m-m}-1} T_{m, n} \psi_{m, n}(t)
$$

where $T_{\mathrm{m}, \mathrm{n}}$ is the wavelet coefficient, and $\Psi_{\mathrm{m}, \mathrm{n}}(t)$ is the wavelet function. The mean signal approximation at the largest scale $M$ is equal to the input signal mean. The signal detail at the scale $m$ has a zero mean and contains only the information content of the signal at this scale. The original signal $x_{0}$ can be reconstructed iteratively with successive approximations in the form:

$$
x_{0}(t)=x_{M}(t)+\sum_{m=1}^{M} d_{m}(t)
$$

In two dimensions, where $t$ is a vector $t=\left(t_{1}, t_{2}\right)$, the approach is the same, except that now there are 3 components of the wavelet and its coefficients in the horizontal, vertical and diagonal direction. For a complete review on wavelet decomposition techniques one is referred to Addison (2002). 


\subsection{Application}

In this section first the data set and experimental conditions as well as the model simulations, settings and initializations, along with the model scenarios, are described. Thereafter a description of the model output, both spatially distributed as well as versus observations, is presented.

\subsubsection{Data set}

The data set used by the model was collected during the ESA SPARC (SPectra bARrax Campaign) 2004 field experiment conducted at the Las Tiesas Experimental Farm test site at Barrax in the La-Mancha region in Spain, maintained by the Provincial Technical Agronomical Institute (ITAP). The campaign took place during two weeks in mid-summer when natural surfaces are under water-stress. This agricultural area, which is partly irrigated, comprises land covers ranging from completely bare soil to fully vegetated parcels with canopy heights from several centimeters up to two meter. The area is rather flat and is situated at an average 700 meters above mean sea level.
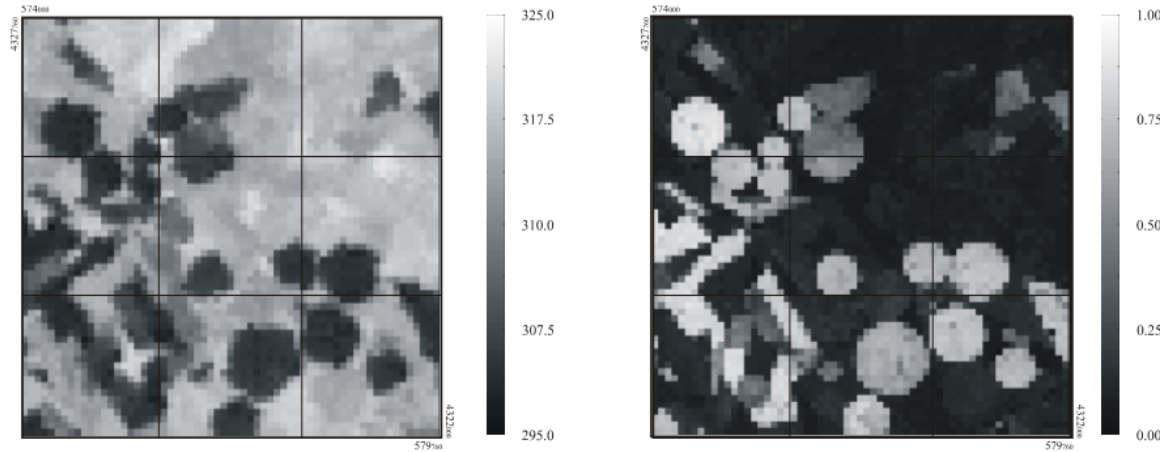

Figure 3-1 a) Spatial distribution of the surface radiometric temperature $T_{\mathrm{r}}(\mathrm{K})$; b) Same for the fractional vegetation cover $f_{\mathrm{c}}(-)$.

Required remotely sensed input is taken from the visible, nearinfrared and thermal infrared channels of an ASTER overpass 
on July the 18th at 11.08 GMT. After atmospheric correction, broadband surface albedo is derived from 6 shortwave channels following Liang (2000), vegetation density is retrieved from NDVI using 2 VNIR bands and a method described by Choudhury et al. (1994), whereas surface temperature is retrieved from a temperature-emissivity separation (TES) algorithm (Gillespie et al., 1998) using all five TIR bands at 90 meter resolution. A land-cover map, derived from a combination of the SPARC2004 land use database and a supervised classification of the 15 meter resolution ASTER imagery (afterwards resampled to the 90 meter grid size), was used to provide the aerodynamic surface properties by assessing canopy height, $h_{\mathrm{c}}$, surface roughness length for momentum transport, $z_{0 \mathrm{M}}$, zero-plane displacement height, $d_{0}$, and leaf-width, $w$.

Flux tower observations at six sites provided meteorological data, energy fluxes, incoming and outgoing shortwave and longwave radiation as well as soil and sensible heat fluxes. The measurements, which are described in detail by Su et al. (2005), were performed over typical land-cover units, comprising of a forest nursery (FN), a wheat stubble field (WS), a vineyard (V) where a scintillometer (Vs) and an eddycorrelation system (Ve) were installed, a sunflower field (SF) and at the edge of a corn field (C). This last site was situated adjacent to the vineyard, covering either site depending on wind direction. To compare the model output with these observations, a simple footprint model (Hsieh et al., 2000) is used to calculate the relative contribution of pixels in the source-area of the observations. Atmospheric soundings were taken twice daily, to compute temperature and humidity as a function of height.

\subsubsection{Model simulations}

Large eddy simulations are run on a three-dimensional grid, typically with a horizontal resolution of about $100 \mathrm{~m}$ and a vertical extent exceeding the scale height of the $A B L$, about 2 kilometer, (Anderson et al., 2003).

In the current study, the horizontal resolution is chosen equal to the resolution of the ASTER thermal channels $(90 \mathrm{~m})$, 
covering a region of both $5760 \mathrm{~m}$ in the longitudinal direction ( $x$-direction, defined along the main wind direction) and lateral direction $(y)$ and $1950 \mathrm{~m}$ in the vertical direction ( $z$ ). Vertical resolution was chosen at $15 \mathrm{~m}$, resulting in a domain of $64 \times 64 \times 130$ spatial nodes.

Averages of mixed-layer wind speed and potential temperature and free atmospheric lapse rate derived from the two soundings were employed in initializing the general vertical structure of the LES model simulations. The capping inversion was set at $1150 \mathrm{~m}$ above the surface and the temperature lapse rate in the capping inversion was initialized as $9.5 \mathrm{~K} \cdot \mathrm{km}^{-1}$ to correspond with the experimental conditions. An incoming solar radiation of $890 \mathrm{~W} \cdot \mathrm{m}^{-2}$ was assumed constant in time. Average potential air temperature at $7.5 \mathrm{~m}$ elevation was approximately $32.0^{\circ} \mathrm{C}$, air humidity $8.5 \mathrm{~g} \cdot \mathrm{kg}^{-1}$, and wind speed $5.5 \mathrm{~m} \cdot \mathrm{s}^{-1}$.

The code is run for a spin-up period, defined to continue until the turbulent kinetic energy of the simulated $A B L$ becomes quasi-steady (Albertson \& Parlange, 1999a, b). During this period the turbulence of the simulated $A B L$ becomes fully developed and the flow field reaches equilibrium with the underlying boundary conditions. The spin-up period is followed by an averaging period over 30 minutes, where the surface fluxes and flow field variables are time-averaged. Measured mixed layer values compared well with time and horizontally averaged profiles produced by the LES, Figure 3-2. The timeaveraged fields given by the coupled model simulation are used here for analysis along with the remotely sensed boundary conditions.
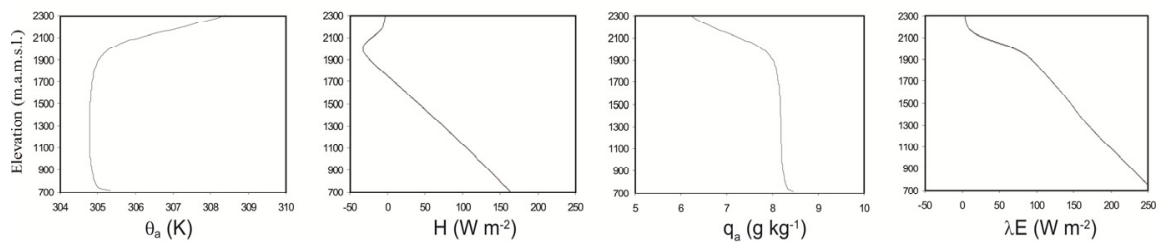

Figure 3-2 Time-averaged and horizontally averaged vertical profiles of potential air temperature $\left(\theta_{\mathrm{a}}\right)$, sensible heat flux $(H)$, specific humidity $(q)$ and latent heat flux $(\lambda E)$ from LES model runs over the SPARC2004 site. The surface fluxes can be noted as the intercepts in the $H$ and $\lambda E$ plots. 
To demonstrate the impact of using uniform atmospheric parameters, or applying de-coupled models, for estimating heat transfer between the earth's surface and the lower ABL different model scenarios are run. In scenario 1 , the model is run fully dynamically coupled. In scenario 2, the spatial averages of the near surface time-averaged air temperature and wind speed output of scenario 1 , have been used to force a decoupled simulation, i.e. employing uniform atmospheric parameters, using only the dual source model. Only for demonstration purposes, the time-averaged spatially variable near surface fields of scenario 1 have been used to force another decoupled simulation; scenario 3.

\subsection{Results and discussion}

The impact of using uniform atmospheric parameters for estimating heat transfer between the earth's surface and the lower $A B L$ is first evaluated by comparing the output from the different scenarios versus field observations. Spatial patterns of remotely sensed observations, flux estimations and $A B L$ state are described after which an analysis of the feedback effects is made.

\subsubsection{Model output}

Validation of sensible heat flux output versus ground observations for the six sites is provided in Figure 3-3a and summarized in Table 3-1. With the notable exception of the corn site (mixed pixel effects at this resolution), where all three scenarios under-estimated the observed sensible heat flux with

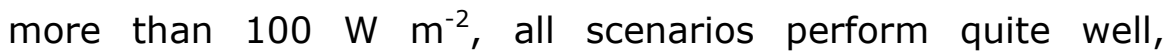
indicating the robust performance of the land surface model used, noting that no parameter tuning was performed. 


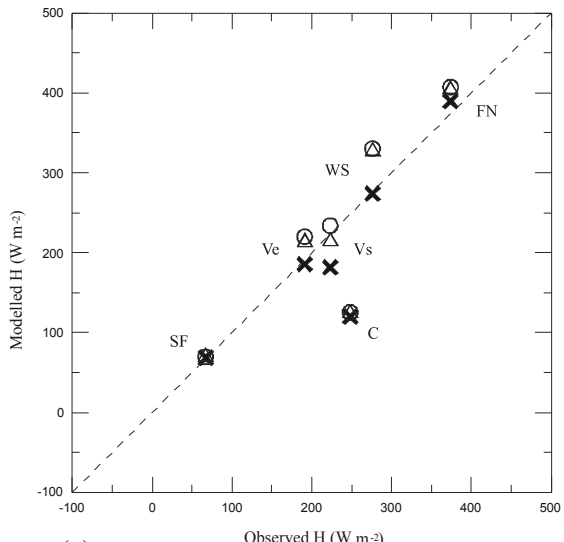

(a)

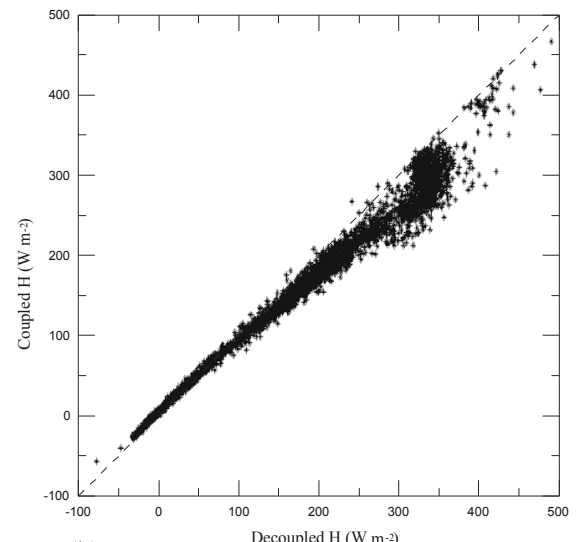

(b)

Figure 3-3 Model output for sensible heat flux: a) Different scenarios versus observations, where an " $x$ " represents output from scenario 1. The decoupled scenarios are represented by the "open" symbols; a circle for scenario 2 and a triangle for scenario 3. Observations are made over a forest nursery (FN), a wheat stubble field (WS), a vineyard (V) containing a scintillometer (Vs) and an eddy-correlation system (Ve), a sunflower field (SF) and at a corn field (C); b) Coupled model versus decoupled model using uniform atmospheric parameters.

Table 3-1 Root Mean Squared Differences (RMSD) illustrating model performance for the different scenarios

\begin{tabular}{lccc}
\hline Scenario & 1 & 2 & 3 \\
\hline All observations & 55.4 & 57.8 & 56.8 \\
Corn site excluded & 19.9 & 31.6 & 30.6 \\
\hline
\end{tabular}

The Root Mean Squared Difference (RMSD) between predicted and observed values of sensible heat fluxes for all three scenarios were lower than $60 \mathrm{~W} \cdot \mathrm{m}^{-2}$. Due to practical considerations the instrumentation at the corn site had to be situated rather close to the edge of the field, which invoked rather unrealistic sensible heat flux estimates at the current resolution. When excluding this measurement from the statistical analysis the results improve dramatically down to 30 $\mathrm{W} \cdot \mathrm{m}^{-2}$.

Note the improvement in the prediction of the coupled against the decoupled models, especially when the "problematic" corn site is excluded from the analysis. Although small, there also is a very minor improvement of using variable atmospheric 
parameters over uniform atmospheric parameters in the decoupled model runs. This improvement being rather small is currently assumed to originate from directional influences that are simulated in the coupled model but are not possible to simulate in the decoupled model. Research on this aspect will be undertaken.

Due to feedback effects of the surface temperature on the lower ABL air temperature (Figures 3-5b and 3-6), lower fluxes are noted in the coupled model as compared to the decoupled versions, at higher surface temperatures, as shown in Figure 3$3 \mathrm{~b}$. In addition, differences occur as a consequence of differences in stability effects due to temperature feedback effects as well as variable wind-speed effects, which are not studied in detail in the present study.

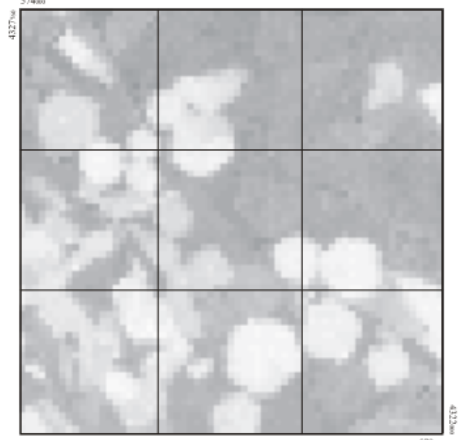

(a)

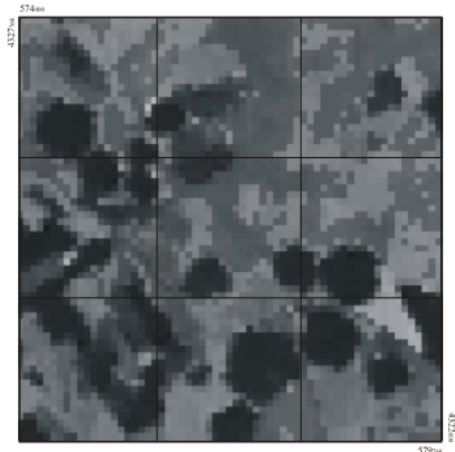

(c)

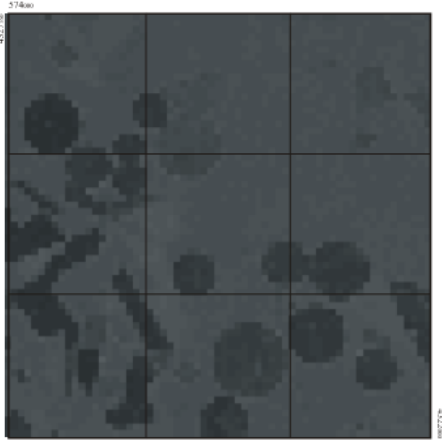

(b)

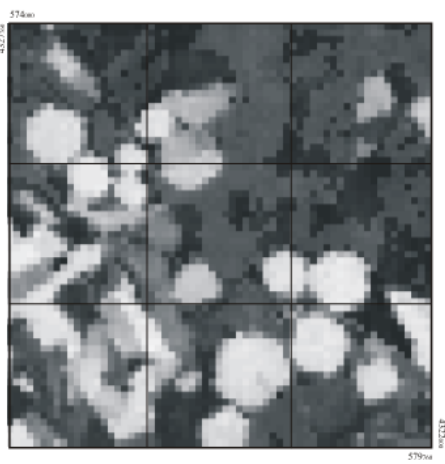

(d)

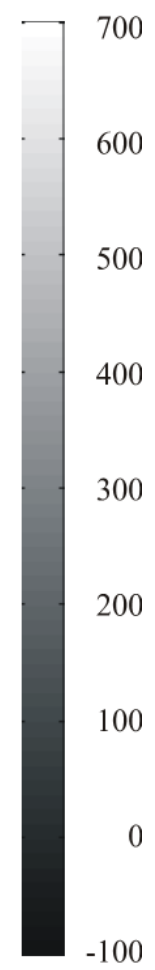

Figure 3-4 Spatial distribution of the surface energy fluxes ( $\mathrm{W} \mathrm{m}^{-2}$ ) for the coupled simulation: a) Net radiation flux $R_{N} ;$ b) Soil heat flux $G$; c) Sensible heat flux $H$; d) Latent heat flux $\lambda E$. 
The time-averaged flux fields are presented in Figure 3-4 and the spatial distribution is strongly determined by the land cover and the water status. The regions of high $R_{N}$ are highly influenced by the lower albedo for the vegetated areas. The sensible heat flux is also most strongly influenced by the irrigated vegetated areas, with higher surface roughness and vegetation cover, and lower surface temperature (Figure 3-2) as compared to the surrounding dry areas (bare soil and wheat stubble). This induces negative $H$ (Figure 3-4c) and a rate for $\lambda E$ (Figure 3-4d) higher than the available energy $R_{\mathrm{N}}-G$ (Figure 3-4a and 3-4b) in the vegetated areas; the "oasis" effect (Stull, 1988). In these areas the feedback effects result in higher, i.e. less negative, sensible heat fluxes in the coupled model runs as compared to the decoupled model run, see Figure 3-3b. High values for $H$ are seen in the dry areas, with a distinct contrast in the local surface stability conditions, which seem related to local roughness characteristics.

Table 3-2 Correlation coefficients, $\rho$, between time-averaged surface sensible $(H)$ and latent $(\lambda E)$ heat fluxes and surface states, fractional vegetation cover $\left(f_{\mathrm{c}}\right)$ and surface roughness for momentum $\left(z_{\mathrm{OM}}\right)$

\begin{tabular}{lccc}
\hline & $T_{\mathrm{r}}$ & $f_{\mathrm{c}}$ & $Z_{\mathrm{OM}}$ \\
\hline$H$ & 0.88 & -0.76 & -0.42 \\
$\lambda E$ & -0.96 & 0.90 & 0.59 \\
\hline
\end{tabular}

The values of the correlation coefficients, with a $95 \%$ confidence interval, that were observed between the surface states and the time-averaged surface flux fields are reported in Table 3-2. As expected, there is a strong relation between surface temperature and sensible heat flux, with the departure from a perfect fit due to the effects of the fractional vegetation cover variability, the wind field variability (and as such related to the surface roughness for momentum, $z_{0 \mathrm{M}}$ ), and the interaction between air and surface temperature. The nature of the study area yields a very high correlation between fractional vegetation cover and latent heat flux. Such a high correlation would not exist when vegetation would be under stress, which is hardly the case in this irrigated agricultural area. 
Table 3-3 Spatial averages and variability of surface turbulent fluxes

\begin{tabular}{lcccc}
\hline & $\begin{array}{c}H- \\
\text { average }\end{array}$ & $\begin{array}{c}H \text {-standard } \\
\text { deviation }\end{array}$ & $\begin{array}{c}\lambda E- \\
\text { average }\end{array}$ & $\begin{array}{c}\lambda E \text {-standard } \\
\text { deviation }\end{array}$ \\
\hline Coupled & 161.1 & 10.1 & 251.2 & 17.8 \\
Decoupled & 183.7 & 11.9 & 225.1 & 20.2 \\
\hline
\end{tabular}

If the spatially averaged values of the surface heat fluxes of the coupled simulation are compared to those of the decoupled simulation, Table 3-3, some differences are seen. Average sensible heat flux is about $20 \mathrm{~W} \cdot \mathrm{m}^{-2}$, more than $12 \%$, lower (mainly due to a reduction of higher sensible heat fluxes) in the coupled simulation, accompanied by a slight reduction in standard deviation, as compared to the de coupled simulation. This results supports the conclusion by Kustas and Albertson (2003), who, in a case study for a semi-arid environment, found that feedbacks act to limit the spatial variability in the flux.

Table 3-4 Correlation coefficients, $\rho$, between surface heat flux, $H$, and temperature, $T_{r}$, and $A B L$ state (air temperature, $T_{a}$, and wind speed, $u$ ). For completeness also surface states that directly influence resistances, fractional vegetation cover $\left(f_{\mathrm{c}}\right)$ and surface roughness for momentum $\left(z_{0 M}\right)$, are added

\begin{tabular}{ccccc}
\hline & $T_{\mathrm{a}}$ & $u$ & $f_{\mathrm{c}}$ & $Z_{0 \mathrm{M}}$ \\
\hline$H$ & 0.68 & 0.27 & -0.76 & -0.42 \\
$T_{r}$ & 0.69 & 0.31 & -0.89 & -0.64 \\
\hline
\end{tabular}

To examine the feedback effects, the correlation, with $95 \%$ confidence interval, between surface sensible heat flux and surface temperature on one side and lower atmospheric boundary layer state on the other side are shown in Table 3-4. There is a clear positive relation between surface and air temperature and a somewhat weaker relation with the lower $A B L$ wind field. This means that both mechanisms are important, but the interaction of the wind field is non-linear, also due to indirect influences through the aerodynamic resistances, see Equations (3.6-3.8). To gain further insight in these mechanisms a start is made with the most significant one; the surface- air-temperature feedback. 


\subsubsection{Feedback effect}

Clear evidence of interaction between surface states and mean $A B L$ properties is shown in Figure $3-5 b$, showing the positive correlation between surface temperature and the timeaveraged air temperature in the lower part (taken at $7.5 \mathrm{~m}$ ) of the ABL, see also Table 3-4.
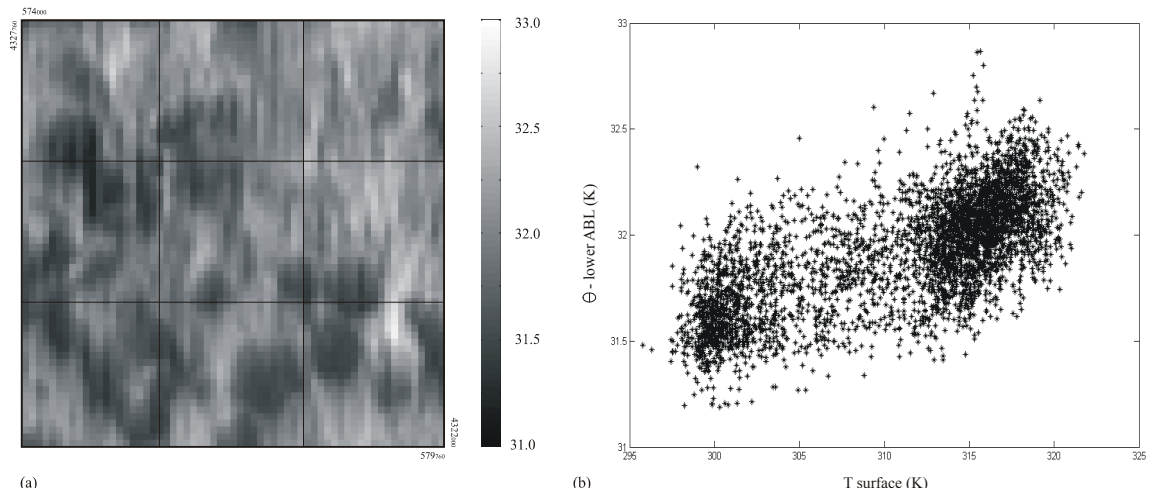

Figure 3-5 a) Spatial distribution of time-averaged lower ABL $(7.5 \mathrm{~m}$ above the ground) potential temperature simulated by the coupled model; b) Scatterplot of radiometric surface temperature and the time-averaged lower $\mathrm{ABL}$ potential temperature.

An additional conclusion that can be drawn from this scatterplot is that the variability in surface temperature maps into a reduced horizontal variability in time-averaged air temperature. Although there are two distinguished areas seen, from the notable distinction between irrigated crops and dry bare areas, they both show a similar positive correlation. The relationship between the time-averaged $\mathrm{ABL}$ state and the surface temperature is not very strong, which might indicate other effects such as fractional cover and roughness characteristics. As is know from previous studies (Humes et al., 1997; Mahrt et al., 1994), the spatial length scale of the surface variability has an influence on the degree of influence of the surface temperature on the air temperature. Therefore an analysis after the correlations between $T_{r}$ and $T_{a}$ is made at multiple scales. 
The spatial fields of $T_{\mathrm{r}}$ and $T_{\mathrm{a}}$ have been decomposed with a 2dimensional discrete wavelet transform, using a simple Haar base wavelet (Addison, 2002). Then the original field is reconstructed at each spatial scale using only the detail of that particular scale. This means that the fields at each scale of Figure 3-6 contain only the information content at their scale. This makes it possible to study the scale-dependent correlation of the spatial fields under consideration. At the top of Figure 36 the original signals are shown, each image beneath corresponds to the detail at a certain scale, where the units are Kelvin. The numbers correspond to the scale " $m$ " as mentioned in Equations (3.9-3.11), going from 1 (coarse resolution, here representing $2880 \mathrm{~m}$ ) to 6 (finest resolution, here $90 \mathrm{~m}$ ). 


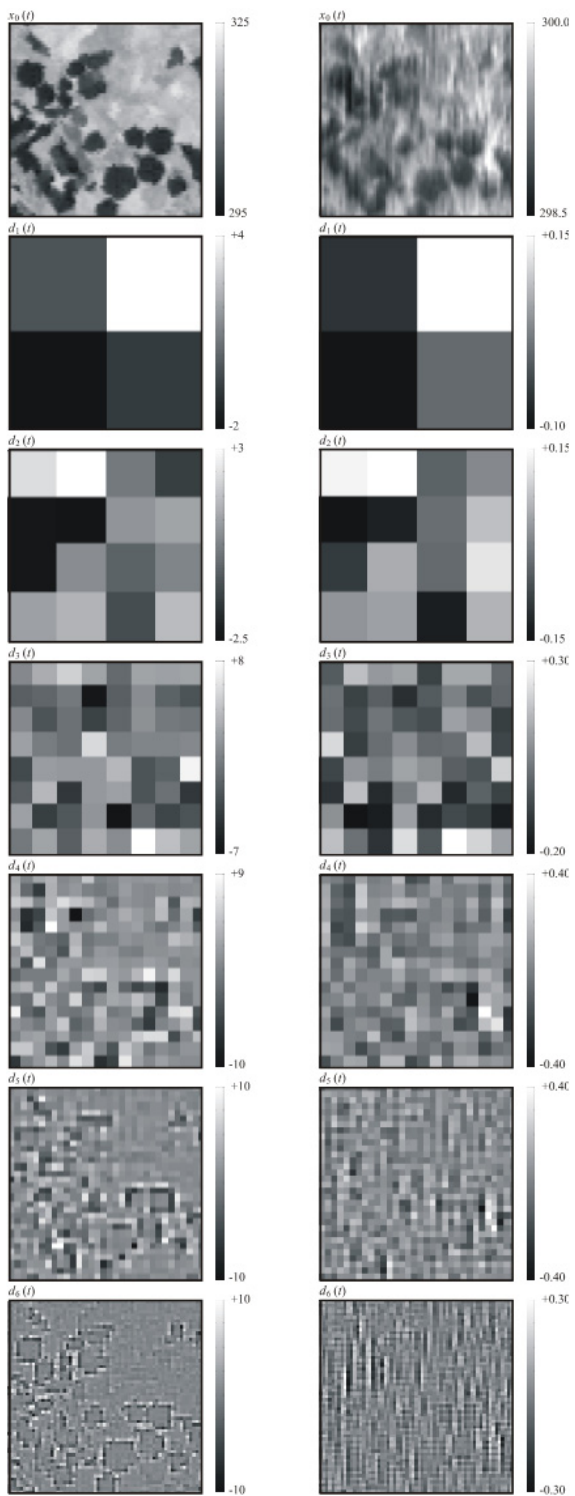

Figure 3-6 Multiscale wavelet decomposition of the radiometric surface temperature (on the left) and the lower $A B L$ (on the right) temperature field. At the top the original signals are shown, each image corresponds to the detail at a certain scale, where the units are Kelvin. The index numbers in $d_{m}(t)$ correspond to the scale " $m$ " as mentioned in equations (3.9-3.11), going from 1 (coarse resolution, here representing $2880 \mathrm{~m}$ ) to 6 (finest resolution, here 90 $\mathrm{m})$. 
The correlation coefficients between surface and air temperatures at each scale of the wavelet decomposition are shown in Figure 3-7 a. It appears that the small-scale surface features that translate significantly less into variations in air temperature, exist primarily below a length scale of about 750 $\mathrm{m}$. The large-scale features show a much higher correlation. To further explore the propagation of surface heterogeneity effects into the surface atmospheric field, the standard deviations of $T_{\mathrm{r}}$ and $T_{\mathrm{a}}$, i.e. a measure of the energy of the signal at each scale (Kustas \& Albertson, 2003), are compared in Figure 3-7 b). Despite the signal of $T_{a}$ being much weaker, in both fields two dominant scales are observed. One is noticed around $300-$ $500 \mathrm{~m}$ corresponding to the detail with scale $\mathrm{m}$ equal to 4 of Figure 3-6, and another one at or over $3000 \mathrm{~m}$, corresponding to the detail with scale 1 in Figure 3-6. Those two scales are in fact the two dominant scales of the surface heterogeneity (see Figure 3-2); one for the irrigated crop fields and one for the combination of agricultural land under active use and barren dry land in the upper right quarter of the domain. Finally Figure 3-7 c) shows the rate between the standard deviation of $T_{\mathrm{r}}$ and $T_{\mathrm{a}}$, indicating that the maximum rate of the propagation of surface heterogeneity into the surface atmospheric field is for scales around $1500 \mathrm{~m}$ here. Although these results seem to confirm what was found by Albertson et al. (2001), namely that "the spatial variability of the air temperature was induced preferentially from variations in surface temperature occurring at scales of more than 500-1000 m", complementary research over different surface types is needed. In addition, the small values for the standard deviation of air temperature as compared to those of the surface temperature, Figures 3-5 to 3-7, suggest that a finer vertical mesh close to the surface might be more appropriate in the LES calculations. 

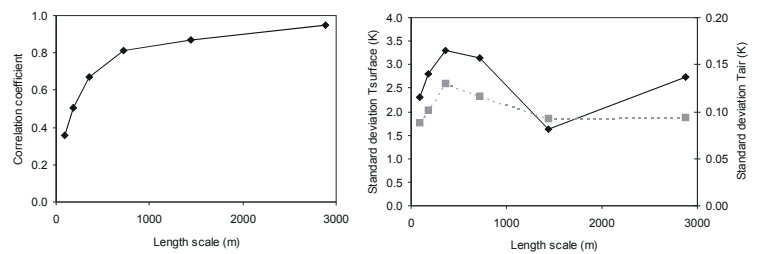

(b)

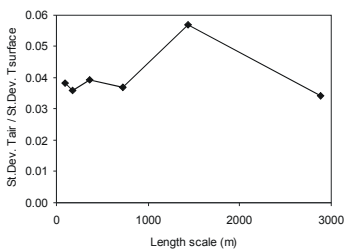

Figure 3-7 Relations between surface radiometric temperature $\left(T_{\mathrm{r}}\right)$ and the lower $A B L$ temperature field $\left(T_{a}\right)$ as a function of scale: a) Correlation between $T_{\mathrm{r}}$ and $T_{\mathrm{a}} ; \mathrm{b}$ ) Standard deviation of $T_{\mathrm{r}}$ (black diamonds) and $T_{\mathrm{a}}$ (gray squares); c) Ratio between standard deviation of $T_{\mathrm{r}}$ and $T_{\mathrm{a}}$.

\subsection{Conclusions}

The approach of Albertson et al. (2001) was used to link an LES model with remotely sensed land surface states using a dual-source land surface scheme to assess land-atmosphere coupling over a very heterogeneous landscape. Simulations with the coupled model have been performed during clear-sky summertime daily conditions at the Barrax test site in the LaMancha region, using data collected during the ESA SPARC 2004 field experiment. The coupled model was applied in a decoupled way, with static uniform atmospheric variables and once with spatially variable atmospheric variables and in a dynamically coupled way, with spatially variable dynamic atmospheric variables, using ASTER multi-spectral imagery.

The surface fluxes predicted by all model runs compare well with observations, and the spatial distribution is strongly determined by the distribution of the irrigated areas. Significant difference was observed in the spatial averages of the fluxes simulated by the coupled simulation compared with the decoupled versions. In addition, the coupled simulation shows a slight decrease in the spatial variance, suggesting a negative feedback between surface temperature and air temperature. While the feedback mechanism between surface temperature and air temperature acts to limit the spatial variability in the surface fluxes, as was found by Kustas and Albertson (2003), a non-linear interaction between surface properties and the surface wind field is observed here. Further investigation in this direction is required to better understand 
the effect of the surface spatial variability on the wind field. A multi-scale analysis is made of the inter-action between surface and air temperature fields. The results confirmed what was found by Albertson et al. (2001), namely that "the spatial variability of the air temperature was induced preferentially from variations in surface temperature occurring at scales of more than 500-1000 m", although other surfaces types should be investigated.

Subsequent analyses of results as in the underlying study will enable us to develop a simplified mapping, wherein surface fields could be decomposed into various scale-components of relevant parameters and a multi-scale mapping performed into lower ABL fields of these parameters. As such, they may be used in improving de-coupled remote sensing based flux modelling schemes. Including feedback effects resulted in reduced spatial flux variability, indicating that ignoring the atmospheric feedback from land surface turbulent exchanges will cause the largest errors at the extremes. Hence, omitting the full coupling of land surfaces with the lower atmospheric boundary layer may lead to erroneous flux prediction in areas that are under extreme conditions, which are of particular interest.

In the paper on which this chapter was based the authors acknowledge funding by NASA Grant NAG13-99008. 


\title{
Chapter 4 Footprint issues in scintillometry over heterogeneous landscapes*
}

\begin{abstract}
Scintillometry is widely recognized as a potential tool for obtaining spatially aggregated sensible heat fluxes at regional scales. Although many investigations have been made over contrasting component surfaces, few aggregation schemes consider footprint contributions. In this paper an approach is presented to infer average sensible heat flux over a very heterogeneous landscape by using a large aperture scintillometer. The methodology is demonstrated on simulated data and tested on a time series of measurements obtained during the SPARC2004 experiment in Barrax, Spain. Results show that the two-dimensional footprint approach yields more accurate results of aggregated sensible heat flux than traditional methods.
\end{abstract}

\subsection{Introduction}

"Spatial variation in land surface sensible heat fluxes is a critical factor in producing and modifying regional atmospheric circulations" (Avissar \& Pielke, 1989) and has been a major subject of research during the past two decades (Chehbouni et al., 2000). Nowadays remote sensing algorithms are widely used for estimating these spatially distributed surface fluxes. To validate these algorithms, ground truth data are required that are directly comparable to the flux estimates obtained from such algorithms. The increasing popularity of using a large aperture scintillometer (LAS) for doing so can be explained by both its ease of operation and relatively low cost as well as by its potential capability of obtaining spatially aggregated flux estimates. However, this validation exercise is not as straightforward as one may hope for, due to mainly two

\footnotetext{
* Based on Timmermans et.al., Hydrol. Earth Syst. Sci. 13, pp. 21792190, 2009
} 
issues that are related to the spatial heterogeneity of both the surface and the fluxes.

A first complication is due to the fact that although over homogeneous terrain this methodology has proven to provide accurate estimates of sensible heat flux (de Bruin et al., 1995; McAneney et al., 1995; Meijninger \& de Bruin, 2000; Pauwels et al., 2008; Watts et al., 2000), it is also well-known that some problems of theoretical nature are faced when applying the scintillation technique over a heterogeneous surface (Bsaïbes et al., 2006; Chehbouni et al., 2000; Ezzahar et al., 2007; Lagouarde et al., 2002a).

Apart from these problems that are related to applying the scintillation technique over heterogeneous areas as such, a second problem relates to the direct comparison between the remote sensing-based and ground-based estimate of sensible heat flux. If the surface is heterogeneous, the signal measured by the sensor, the LAS in this case, depends on which part of the surface has the strongest influence on the sensor, and thus on the location and size of its so-called footprint (Schmid, 2002). In most natural landscapes, the footprint will contain different landcover types and "a successful interpretation of the measured fluxes will depend on an appropriate footprint model" (Soegaard et al., 2003). Therefore the only useful comparison between remote sensing-based and ground-based estimates of sensible heat flux can be done by accounting for heterogeneity within the footprint.

Shuttleworth (1988) argued that the most effective way to synthesize grid-area, weighted average values of surface characteristics, is to use remote sensing techniques to diagnose areas which can be treated as a particular surface type and then to compute the average value of the surface characteristics assigned to each component cover weighted by its remotely sensed area-average frequency of occurrence. He stated that "the effective area-average value of land surface parameters is estimated as a weighted average over the component cover types in each grid through that function involving the parameter which most succinctly expresses its relationship with the associated surface flux", which is exactly what we will attempt here.

The objective of this chapter is to verify the suitability of the LAS for producing area-average estimates of sensible heat flux 
over heterogeneous terrain and its applicability for validating spatially distributed flux estimates from remote sensing observations. A footprint-weighted approach is proposed in section 2 to aggregate surface characteristics, taking into account within footprint heterogeneity by using information obtained through remote sensing. The approach is tested on simulated data in section 3 and applied over a very heterogeneous test site in Barrax (Spain) in section 4. A discussion on the results follows in section 5 and this chapter is concluded with some remarks in section 6 .

\subsection{Scintillation technique}

In this section first a summary of the physical background of the LAS measurement is provided, described also in detail in Chehbouni et al. (2000), Lagouarde et al. (2002b) and Wang et al. (1978), which is valid for observations over a homogeneous surface. Then a review is provided on typical problems over heterogeneous surfaces, followed by a section dealing with implications for estimating fluxes from LAS observations over a heterogeneous landscape.

\subsubsection{The homogeneous case}

Large Aperture Scintillometers (LAS) provide a measurement of the structure parameter for the refractive index $C_{N}{ }^{2}\left[\mathrm{~m}^{-2 / 3}\right]$ derived from the intensity fluctuations of an optical beam between a transmitter and a receiver. The variance of the natural logarithm of the irradiance $I$ incident at the receiver is given by:

$\sigma_{\ln (I)}^{2}=\overline{[\ln (I)-\overline{\ln (I)}]^{2}}=\int_{0}^{1} C_{N}^{2}(u) W(u) d u$

where the overbar is a spatial averaging, and $W(u)$ is a nonuniform, bell-shaped weighting function:

$W(u)=16 \pi^{2} k_{i}^{2} \cdot P \cdot \int_{0}^{\infty} K \Phi_{N}(K) \sin ^{2} \cdot\left(\frac{K^{2} P u(1-u)}{2 k_{i}}\right) \cdot\left(\frac{2 J_{1}(X)}{X}\right)^{4} d K$

where $u[-]$ is the normalized path distance, $x[\mathrm{~m}]$, from the transmitter, equal to $x / P$, with $P$ being the path length [m]. The optical wave number, $k_{i}=2 \pi / \lambda_{i}$ and $X=1 / 2 K D u$, where $D$ is the diameter of the receiver/transmitter aperture and $K$ the three- 
dimensional spatial wave number. $J_{1}$ is a Bessel function of the first kind of order one, and $\Phi_{\mathrm{N}}$, the three-dimensional Kolmogorov spectrum of the refractive index fluctuations, which describes the turbulent medium in terms of its Fourier components $K$, is given by:

$\Phi_{N}(K)=0.033 \cdot C_{N}^{2} K^{-11 / 3}$

Integration of Eq. (4.2) combined with Eqs. (4.1) and (4.3), yields the spatial average value of the structure parameter as obtained from a LAS, following Wang et al. (1978):

$\left\langle C_{N}{ }^{2}\right\rangle=1.12 \cdot \sigma_{\ln (I)}^{2} \cdot D^{7 / 3} \cdot P^{-3}$

where the brackets on the left hand side of the equation indicate a spatial average of the measured refractive index.

Several authors (de Bruin et al., 1993; Green et al., 2001; McAneney et al., 1995) have described the theory in detail for deriving turbulent exchange from scintillation measurements over uniform surfaces, which is summarized here. In the optical domain, when humidity fluctuations in the atmosphere have a much smaller influence on the signal than temperature fluctuations, the structure parameter for temperature, $C_{\mathrm{T}}^{2}$ $\left[\mathrm{K}^{2} \cdot \mathrm{m}^{-2 / 3}\right]$ can be derived from $C_{\mathrm{N}}{ }^{2}$ as measured by a scintillometer following Wesely (1976):

$C_{T}^{2}=C_{N}^{2}\left(\frac{T_{a}^{2}}{\gamma_{a} \cdot p}\right)^{2} \cdot\left(1+\frac{0.03}{\beta}\right)^{-2}$

Here, $T_{a}$ represents air temperature $[\mathrm{K}], \gamma_{a}$ is the refractive index for air $\left[7.9 \cdot 10^{-7} \mathrm{~K} \cdot \mathrm{Pa}^{-1}\right], p[\mathrm{~Pa}]$ is atmospheric pressure and $B[-]$ is the well-known Bowen ratio, here used as a correction term for humidity related scintillations. Similarity relationships (Wyngaard et al., 1971) based on Monin-Obukhov Similarity Theory, provide the possibility to derive sensible heat flux, $H\left[\mathrm{~W} \cdot \mathrm{m}^{-2}\right]$, through the use of the temperature scale, $T_{*}$ $[\mathrm{K}]$, following:

$C_{T}^{2}=T_{*}^{2}\left(z-d_{0}\right)^{-2 / 3} \cdot \varphi_{H}\left(\frac{z-d_{0}}{L}\right)$

where $z[\mathrm{~m}]$ is the effective height (Hartogensis et al., 2003) of the LAS measurement, $d_{0}[\mathrm{~m}]$ the displacement height, $\phi_{\mathrm{H}}[-]$ the universal stability function for heat transfer. The temperature scale is defined as:

$T_{*}=\frac{-H}{\rho \cdot c_{p} \cdot u_{*}}$

Here $\rho\left[\mathrm{kg} \cdot \mathrm{m}^{-3}\right]$ is the density of air, $c_{\mathrm{p}}\left[\mathrm{J} \cdot \mathrm{kg}^{-1} \cdot \mathrm{K}^{-1}\right]$ is the specific heat of air at constant pressure and $u_{*}\left[\mathrm{~m} \cdot \mathrm{s}^{-1}\right]$ is the 
well-known friction velocity. The form of the stability functions adopted here are taken from Green et al. (2001):

$\varphi_{H}\left(\frac{z-d_{0}}{L}\right)=c_{T 1} \cdot\left(1+c_{T 2} \cdot\left|\frac{z-d_{0}}{L}\right|\right)^{-2 / 3}$ for $\left(\mathrm{z}-\mathrm{d}_{0}\right) / \mathrm{L}<0$ (unstable)

$\varphi_{H}\left(\frac{z-d_{0}}{L}\right)=c_{T 1} \cdot\left(1+c_{T 3} \cdot\left(\frac{z-d_{0}}{L}\right)^{2 / 3}\right)$ for $\left(z-d_{0}\right) / L>0$ (stable)

where $L[\mathrm{~m}]$ is the Monin-Obhukov length, defined as:

$L=\frac{u_{*}^{2} \cdot T_{a}}{g \cdot k \cdot T_{*}}$

in which $g\left[\mathrm{~m} \cdot \mathrm{s}^{-2}\right]$ is the gravitational constant and $k[-]$ the von Karman constant. The constants $c_{\mathrm{T} 1}, c_{\mathrm{T} 2}$ and $c_{\mathrm{T} 3}[-]$ are taken equal to 4.9, 6.1 and 2.4 respectively (Wyngaard et al., 1971). There is no general consensus on the stability function for stable conditions (Eq. 4.8b), however, in this work we use the coefficients proposed by Wyngaard et al. (1971) as mentioned above.

Obtaining the sensible heat flux from a scintillometer measurement over homogeneous terrain thus invokes solving $H$ from Eqs. (4.5 to 4.9). This requires measurements of a number of additional parameters; air temperature, air pressure, Bowen ratio, displacement height and friction velocity. Since measurements of friction velocity are not generally available, independent windspeed measurements, $u$, at reference height $z_{\mathrm{u}}$ may be combined with an estimate of surface roughness length, $z_{0}$, following:

$u_{*}=k \cdot u \cdot\left[\ln \left(\frac{z_{u}-d}{z_{0}}\right)-\psi_{M}\left(\frac{z_{u}-d}{L}\right)\right]^{-1}$

where $\psi_{\mathrm{M}}[-]$ is the integrated stability function (Panofsky \& Dutton, 1984), to obtain estimates of friction velocity.

Generally an estimation of the aerodynamic properties of the terrain, surface roughness length and displacement height, estimated as a fraction of canopy height, following Brutsaert (1982), ensures an accurate estimate of sensible heat flux over homogeneous terrain.

\subsubsection{Application to a heterogeneous surface}

When the theory described above is applied over a heterogeneous surface, comprising of two or more patches or agricultural fields, additional assumptions need to be made. Besides doubts on the validity of Monin-Obhukov similarity 
theory below the blending height over a heterogeneous surface, problems exist as on how to parameterize an equivalent or areally averaged temperature scale, and friction velocity (Ezzahar et al., 2007; Lagouarde et al., 2002b), as well as how to deal with the non-linear sensitivity of the scintillometer to $C_{N}{ }^{2}$ along its beam. Lagouarde et al. (2002a) presented an approach for a two-surface composite case where aggregated estimates for displacement height were obtained using:

$\left\langle d_{0}\right\rangle=r \cdot d_{01}+(1-r) \cdot d_{02}$

where the brackets indicate a spatial average and $r$ indicates the proportion of surface 1 under the beam of the scintillometer, whereas subscripts 1 and 2 refer to the two surface components, or patches, under the beam of the scintillometer. An estimate for the areal averaged roughness length is obtained from one of the two following schemes:

$$
\begin{aligned}
& \ln \left\langle z_{0}\right\rangle=r \cdot \ln \left(z_{01}\right)+(1-r) \cdot \ln \left(z_{02}\right) \\
& \left(\ln \left(\frac{z-<>}{\left.<z_{0}\right\rangle}\right)\right)^{-2}=r \cdot\left(\ln \left(\frac{z-d_{1}}{z_{01}}\right)\right)^{-2}+(1-r) \cdot\left(\ln \left(\frac{z-d_{2}}{z_{02}}\right)\right)^{-2}
\end{aligned}
$$

A mean wind speed then is obtained according to an aggregation scheme based on a linear transit time for an air parcel along the path length, resulting in:

$\langle u\rangle=\frac{u_{1} \cdot u_{2}}{r \cdot u_{2}+(1-r) \cdot u_{1}}$

Integration of the weighting function of the scintillometer from 0 to $r$ and from (1-r) to 1 provides weighting factors, $W_{i}$, with $i$ the component number. They are used to obtain an average value of $C_{\mathrm{N}}{ }^{2}$ assumed to originate from the two components following:

$\left\langle C_{N}^{2}\right\rangle=W_{1} \cdot C_{N_{1}}^{2}+W_{2} \cdot C_{N_{2}}^{2}$

which is then used to derive an aggregated sensible heat flux in a similar fashion as described above. Lagouarde et al. (2002) compared these versus reference values for sensible heat, obtained from sonic measurements at the two surface components weighted following the same approach as in Eq. (4.11). As such the reference flux was defined as the average of the component fluxes weighted by the ratio of their contribution to the path length of the scintillometer. This yielded small but systematic overestimation by the scintillometer-based estimates. A sensitivity analysis on a simple model simulating the integration methodology showed 
that the composition of the path length, the contrast in fluxes and, to a lesser extent, the aerodynamic properties of the two surface components, induced the deviations between the scintillometer-based estimates and the reference values of sensible heat flux. An underestimation (overestimation) by the LAS depended on whether the largest field in the path length was the wettest (driest) part.

A slightly different approach is described by Ezzahar et al. (2007), who estimated $C_{N}{ }^{2}$ at grid scale from component LAS measurements, where the components consisted of an olive orchard with two contrasting fields. Demonstrating that MoninObhukov similarity theory applies below the blending height, they obtained a grid-scale sensible heat flux, $\langle H\rangle$, following:

$\langle H\rangle=r \cdot H_{L A S-1}+(1-r) \cdot H_{L A S-2}$

Subscripts 1 and 2 here indicate variables associated with the two surface components, or patches, and $r$ indicates the proportion of surface 1 to the total grid. Simplifying Eq. (4.15) to:

$\left\langle u_{*} T_{*}\right\rangle=r \cdot u_{*_{1}} T_{* 1}+(1-r) \cdot u_{*_{2}} T_{*_{2}}$

and combining Eq. (4.5) and Eq. (4.8a) with Eq. (4.15) an expression for $C_{\mathrm{N}}{ }^{2}$ aggregated at grid was obtained:

$\left\langle C_{N}{ }^{2}\right\rangle=\langle y\rangle^{-1} \cdot\left(y_{1} C_{N 1}{ }^{2}+y_{2} C_{N 2}{ }^{2}\right)$

with:

$y_{i}=\left(r_{i}\right) \frac{u_{*_{i}}\left(1+0.03 \frac{0.03}{\beta_{i}}\right)^{-2} \cdot\left(z_{0 i}-d_{i}\right)^{2 / 3}}{T_{*_{i}} \cdot\left(1+c_{T 2} \frac{\left(z_{0 i}-d_{i}\right)}{L}\right)^{-2 / 3}}$

where $i$ is either component 1 or 2 , indicating the grid-scale average (angular brackets), and $r_{\mathrm{i}}=1$ for $\langle y\rangle, r_{\mathrm{i}}=r$ for $y_{1}$ and $r_{\mathrm{i}}=(1-r)$ for $y_{2}$.

Grid-scale averages of displacement height and roughness length are then obtained in a similar way as proposed by Lagouarde et al. (2002a) through Eq. (4.11) and Eq. (4.12b) respectively.

In the approach described by Ezzahar et al. (2007) the aggregated, or grid-scale, sensible heat flux reflects an average sensible heat flux over those parts of the grid that are observed.

In their experiment the source areas of the two LAS systems appeared to be approximately equal, rendering $r_{1}$ equal to $r_{2}$ equal to 0.5 in Eqs. (4.15-4.18). They note however that a third LAS, covering the two patches, would not provide a 
measurement that can be used to validate their aggregation method, since this scintillometer would have a varying contribution of the two patches, depending on wind direction. Moreover, these contributions would be influenced by the weighting function of such a LAS.

\subsubsection{Footprint implications}

So far, we were mainly treating the heterogeneous surface as a one-dimensional two-component area. However, when measurements are made below the blending height a portion of the upstream surface, the source area, influences the sensor. Numerous so-called footprint models are described in the literature that relate the measured flux at a certain height to the weighted spatial distribution of the surface fluxes that contribute to the measurement. Meijninger et al. (2002) described that for applying this concept to the LAS "one has to combine the footprint function with the spatial weighting function of the LAS" in order to estimate the relative contribution of the surface fluxes to the measured flux.

We used a simple three-dimensional footprint model that calculates the source strength, $F_{X^{\prime}, y^{\prime},}$ for a single observation point, following:

$F_{x^{\prime}, y^{\prime}}=\frac{F_{x^{\prime}}}{\sqrt{2 \pi \sigma_{y^{\prime}}}} \cdot e^{-\left(y^{\prime 2} / 2 \sigma_{y^{\prime}}^{2}\right)}$

where $\sigma_{y^{\prime}}$ is the cross wind spread in the direction $y^{\prime}$ perpendicular to the wind direction $\left(x^{\prime}\right)$ and $F_{x^{\prime}}$ is the relative contribution per running meter along the wind direction, as:

$$
F_{x^{\prime}}=\frac{u}{u_{*}} \cdot \frac{z_{m}}{k x^{\prime 2}} \cdot e^{-\left(u / u_{*}\right) \cdot\left(z_{m} / k x^{\prime}\right)}
$$

where $k$ is von Karman constant and $z_{\mathrm{m}}$ the measuring height. The footprint model, described in detail in Soegaard et al. (2003), is then combined with the weighting function of the LAS to obtain the relative contribution of each of the contributing component surface covers, $r f p_{i}$, where the subscript $i$ refers to a particular surface component. The LAS path is thought to consist of a series of single observation points each for which a single source strength is calculated using Eqs. (4.19-4.20). Each of these source strengths is then multiplied with the LAS weighting function, $W(u)$. Summation of the individual points, normalized by the total sum of the 
source areas, then yields the LAS weighted footprint. It should be noted that the footprint model used here is chosen for its relatively simple implementation. In principle any other footprint model (Horst \& Weil, 1992; Schmid, 2002; Schuepp et al., 1990) may be used.

Spatially distributed information on surface aerodynamic properties was input to this model to account for within footprint heterogeneity. This relative footprint-weighted contribution is then used to obtain aggregated displacement height, surface roughness and structure parameter of air following Eqs. (4.11), (4.12a), (4.17) and (4.18), where $r_{i}$ should be replaced by $r f p_{i}$. The objective here is to obtain an aggregated structure parameter as would be obtained from a single LAS measurement over different components, as opposed to Ezzahar et al. (2007) who aimed at a grid-scale aggregated flux. To achieve this, $r_{\mathrm{i}}$ needs to be replaced by $r f p_{\mathrm{i}}$ in Eqs. (4.11), (4.12a), (4.17) and (4.18).

The approach described above is tested on simulated data in a one-dimensional manner in Sect. 4.3. A one-dimensional treatment assumes the components are only contributing along the path of the scintillometer. This implies that only the LAS weighting function is influencing the component contribution. The LAS derived sensible heat flux, $H_{\text {sim, }}$ is obtained from prescribed component sensible heat fluxes, $H_{1}$ and $H_{2}$. The procedure is such that the component structure parameters, $C_{N, i}{ }^{2}$, where $i$ is either 1 or 2 , are calculated from inverting the procedure outlined by Eqs. (4.5 to 4.9). These are then weighted according to Eqs. (4.17) and (4.18), using $r f p_{i}$ instead of $r_{\mathrm{i}}$, to simulate a $\left\langle C_{\mathrm{N}}{ }^{2}\right\rangle$ that a LAS would have measured, which is then used to obtain $H_{\text {sim }}$. Following, $H_{\text {sim }}$ is compared versus a reference sensible heat flux, $H_{\text {ref. }}$ The reference flux is directly derived from the component fluxes, $H_{1}$ and $H_{2}$, weighted by their relative contribution, following:

$H_{r e f}=r f p_{1} \cdot H_{1}+r f p_{2} \cdot H_{2}$

In section 4.4 the aggregation approach is then applied in a two dimensional manner, incorporating the spatial distribution of the contributing components. Data used was collected during the SPARC2004 field campaign in Barrax (Spain) and is described in detail in Su et al. (2008). 


\subsection{Simulation}

The (1-dimensional) case of a composite surface comprising of two plots is simulated. We chose two components with very contrasting sensible heat flux and assumed similar parameter values as used in Lagouarde et al. (2002a). This meant that for plot 1 we randomly generated sensible heat fluxes between 0 and $50 \mathrm{Wm}^{-2}$ and for plot 2 between 350 and $400 \mathrm{Wm}^{-2}$. Roughness length and displacement height were taken as $1 / 8$ and 2/3 times the canopy height, following Brutsaert (1982), where the canopy heights for the plots were given random heights uniformly distributed between 0.015 and $1.5 \mathrm{~m}$. Windspeed, $u_{\text {ref, }}$ chosen at a reference height, $z_{\text {ref }}$ equal to 50 $\mathrm{m}$ to ensure reasonably uniform windspeed, was given random values between 0.5 and $6.0 \mathrm{~ms}^{-1}$, and the contributing areas, $r_{1,2}$, were given random numbers between 0 and 1 , such that their sum was equal to unity. Other parameters were kept constant, available energy (necessary to calculate a Bowen ratio) equal to $450 \mathrm{Wm}^{-2}$ and air temperature, $T_{\mathrm{a}}$, equal to 301 $\mathrm{K}$.

These data were input to a simulation (5000 runs) using different aggregation methods. The first simulation followed the approach described in detail in Lagouarde et al (2002a). Since the reference flux here is derived from the component fluxes weighted by the contributing areas, $r_{1,2}$, in the remainder of this text it is referred to as L-r. A second simulation concerned the same approach, but now with the reference flux defined as in Eq. (4.21). We will refer to this simulation as L-rfp. The third simulation followed the approach described in Ezzahar et al. (2007), also using the reference flux defined following Eq. (4.21). Therefore we will refer to it as E-rfp. The fourth simulation concerned the new approach described in the current contribution, N-rfp.

Results are presented in Fig. 4-1, where in the left panels the simulated fluxes are plotted versus the reference fluxes. The right panels show the difference, $H_{\text {sim }}-H_{\text {ref, }}$ versus the contributing area, either $r$ (the first simulation) or $r f p$ (the other simulations). A low value for $r$ means a low contribution from surface component 1 . The chosen contrast in sensible heat flux resulted in differences $H_{1}-H_{2}$ ranging from -400 to $300 \mathrm{Wm}^{-2}$, similar to the range in Lagouarde et al. (2002a).

They presented their results composing $H_{\text {ref }}$ from its 
components by not taking into account the weighting function of the LAS. We have plotted the results in Fig. 4-1.a and 4-1.e, which resembles the "diamond" class in Fig. 10 of Lagouarde et al. (2002a). The results from the second simulation (L-rfp), where $H_{\text {ref }}$ was composed by taking the weighting function of the LAS into account, are shown in Fig 4-1.b and 4-1.f. Simulation results from the E-rfp simulation are given in Fig. 41.C and 4-1.g, whereas results obtained from the N-rfp approach are given in Fig 4-1.d and 4-1.h. 

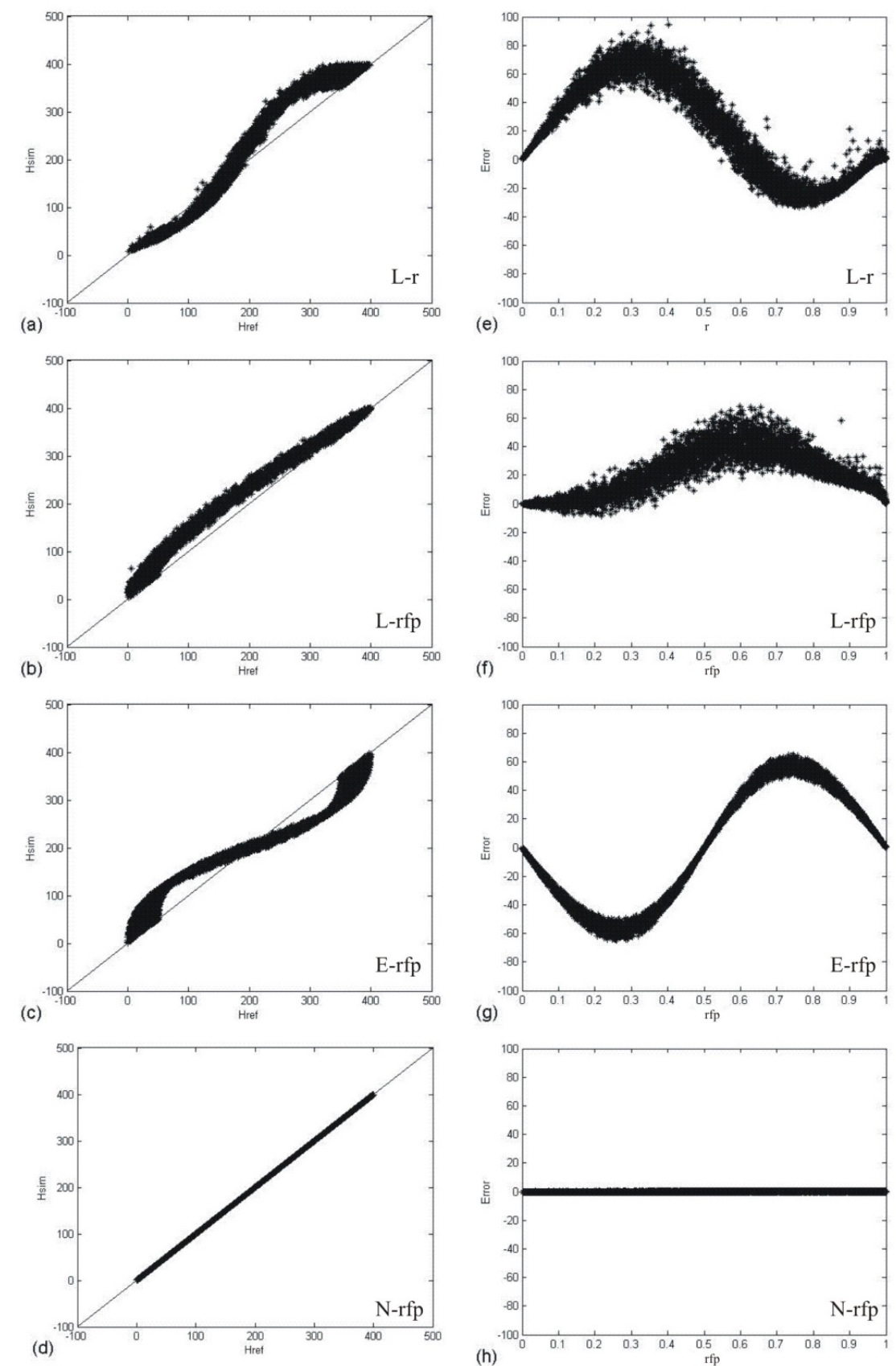

Figure 4-1 Simulation results for a two-component surface using aggregation approaches L-r, L-rfp, E-rfp and N-rfp (see main text for 
additional explanation). Left panels show simulated versus reference fluxes, right panels show the "error", $H_{\text {sim }}-H_{\text {ref, }}$ versus the contributing area, $r$ or $r f p$.

An important difference between the existing approaches is that the first one, Lagouarde et al. (2002a), constructs an aggregated LAS signal, $\left\langle C_{\mathrm{N}}^{2}\right\rangle$, from component $C_{\mathrm{N}}^{2}$ according to the LAS weighting function. This aggregated signal then represents an LAS measurement of $\langle H\rangle$ over the two areas. The second approach, Ezzahar et al. (2007), constructs an aggregated $\left\langle C_{N}{ }^{2}\right\rangle$, directly from LAS measured component $C_{N}{ }^{2}$ avoiding the weighting function. As such this $\left\langle C_{N}{ }^{2}\right\rangle$ will yield an $\langle H\rangle$ that represents a spatially weighted average, or gridscale average, sensible heat flux.

When $H_{1}<H_{2}$ and $r<(1-r)$, the approach originally suggested by Lagouarde et al. (2002a) yielded an over-estimation of $H_{\text {sim }}$ with respect to $H_{\text {ref. }}$. This is because the method does take the LAS weighting function, $W(u)$, into consideration for obtaining an aggregated $C_{N}{ }^{2}$, whereas for the calculation of the reference sensible heat flux, $H_{\text {ref, }}$ a linear weighting based on the contributing area is assumed. This systematic effect is removed when taking the weighting function into account. However, still deviations, originating from difference in component aerodynamic characteristics, are noted which can be attributed to the assumption of Eq. (4.14).

This problem was solved analytically by Ezzahar et al. (2007) resulting in Eqs. (4.17) and (4.18). However, when applying their approach on a LAS signal measured over a twocomponent contrasting surface, the reference sensible heat flux, $H_{\text {ref, }}$ should also be estimated from the component sensible heat fluxes weighted by the weighting function of the LAS. In the case of $H_{1}<H_{2}$ and $r<(1-r)$, the $H_{\text {ref }}$ will be higher than the $H_{\text {sim }}$ since the method does not incorporate the weighting function of the LAS, resulting in an underestimation of $H_{\text {sim }}$. This phenomenon is illustrated in Fig. 4-1c. and 4-1g. When taking the weighting function into account for determining the relative component contribution to the aggregated $C_{N}{ }^{2}$, as well as to the aggregated aerodynamic properties, the errors reduce to zero (see Fig 4-1.d. and 41.h.), meaning that the nature of the scintillometer measurements is properly simulated. It should be noted though that when applying the methodology of Ezzahar et al. (2007) 
and assuming $H_{\text {ref }}$ to originate from a simple linear weighting of the component fluxes, the results are similar to those presented here. However, when utilizing LAS observations for validating spatially distributed flux estimates, the relative contribution of component areas needs to be known. Therefore, in such cases, the footprint calculations as well as the weighting function should be taken into account.

\subsection{SPARC2004 Experiment}

Observations of water and heat fluxes (Su et al., 2008) were made during the ESA SPARC (SPectra bARrax Campaign) 2004 field experiment conducted at the Las Tiesas Experimental Farm test site at Barrax in the La-Mancha region in Spain, maintained by the Provincial Technical Agronomical Institute (ITAP).

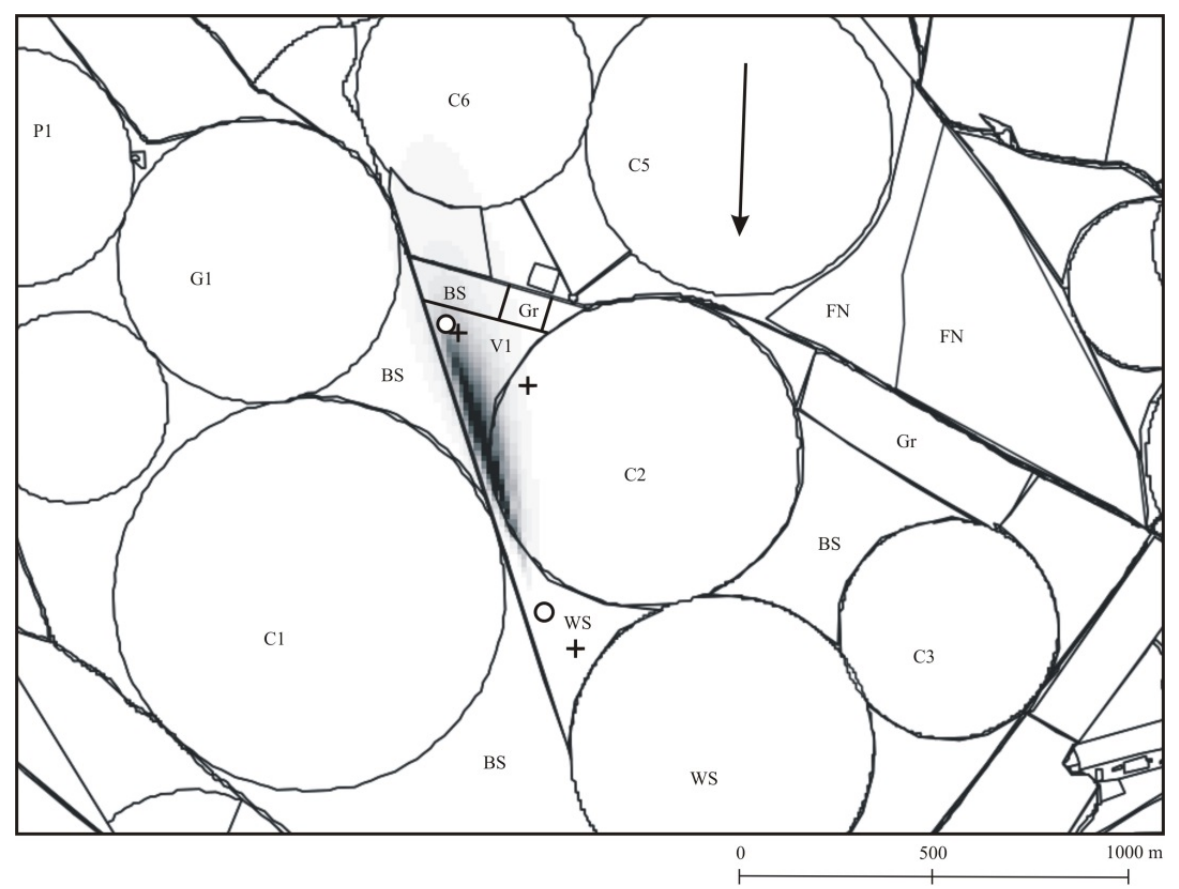

Figure 4-2 Map (North oriented) of the experimental set-up at the Las Tiesas experimental farm, showing landcover units and scintillometer weighted observation source area. The LAS is represented by two white circles, and the sonic anemometers by 
(three) crosses, whereas an arrow indicates the wind direction. Letters represent landcovers vineyard ("V"), grass ("Gr"), corn ("C"), bare soil ("BS"), wheat stubble ("WS"), garlic ("G"), potato ("P") and forest nursery ("FN"), whereas the numbers refer to the respective field numbers.

This agricultural area, which is partly irrigated, comprises land covers ranging from completely bare soil to fully vegetated parcels with canopy heights from several centimeters up to two meters. The area is rather flat and is situated at an average $700 \mathrm{~m}$ above mean sea level. The campaign took place from the $12^{\text {th }}$ to the $21^{\text {st }}$ of July when natural surfaces are under water-stress since rainfall is mainly absent during this period. Daily minimum and maximum temperatures measured over the vineyard during the period were 14.3 and $31.6^{\circ}$ Celsius. Prevailing wind directions are ranging from typically southeastern direction during morning hours, changing towards a northern direction during late afternoon. This meant that around noon, which coincided with nominal airborne and spaceborne image acquisitions, eastern winds were prevailing.

\subsubsection{Experimental setup}

A Kipp and Zonen Large Aperture Scintillometer (LAS), formerly Micromet Scientific LAS-150, was installed in the centre of the test site. The receiver of the LAS was installed at a height of $5.06 \mathrm{~m}$ at the north-western side of a triangular shaped vineyard ("V1" in Fig 4-2.) with sides measuring about $200 \mathrm{~m}$ each, and quite variable canopy heights, depending on age of the crops, ranging from 1.0 up to $2.0 \mathrm{~m}$. The transmitter was positioned at a distance of $784 \mathrm{~m}$ in a harvested wheat field containing at parts dry wheat stubbles of about 0.15 to $0.20 \mathrm{~m}$ height. Installation height here was $4.64 \mathrm{~m}$, yielding an effective measurement height of $4.85 \mathrm{~m}$ of the LAS, since the area is extremely flat. The data were sampled and stored at a $1 \mathrm{~Hz}$ frequency. The demodulated carrier signal was also stored, which was used for determining potential malfunctioning of the LAS. During the post-processing the data was averaged over 10 minute intervals, a period imposed to provide easy comparison with reference eddy correlation measurements. After the post-processing a visual check was performed, possible due to the relatively short duration of the 
campaign, and spikes in the observations were removed. The agricultural fields directly surrounding the LAS setup consisted of pivot-irrigated, dense cropped corn fields, bare soil (though alternated by dried hordeum), garlic and grassland, whereas at slightly larger distances a potato field and a forest nursery as well as some other cornfields and a small orchard in the northern part of the area were located. Although most of the bare soil and stubble were very dry, most crops in the area were irrigated. Particularly the relatively large corn fields were heavily irrigated, which at times resulted in stable conditions over the corn during daytime. Due to the prevailing wind directions we assumed the main fields influencing the LAS would be "V1", "C2" and "WS", see Fig. 4-2.

A Gill 3D sonic anemometer was installed over the vineyard (field "V1") in the vicinity of the LAS receiver, about $50 \mathrm{~m}$ from the northern edge of the vineyard, with local crop heights about $1.1 \mathrm{~m}$. Raw data here was sampled at a $20 \mathrm{~Hz}$ frequency and stored at a portable computer using Campbell's PC208W v.3.3 software. Flux calculations were made using the Alteddy software developed at ALTERRA, Wageningen, The Netherlands and averaged over 10, 30 and 60 minute intervals. Possible low frequency losses resulting from short integration times (Von Randow et al., 2008) could be ruled out as the longer integration times did not bring about any significant increase in flux estimation, see also Su et al. (2008). A Young 81000 3D sonic anemometer was installed at a height of $4.4 \mathrm{~m}$ at the western side of field "C2", measuring the fluxes from the corn during prevailing wind directions and at times from the vineyard during western winds. Raw $10 \mathrm{~Hz}$ data of the 3D ultrasonic anemometer were stored on a portable computer using the program Tourbillon v. 1.0., which has been developed at the Institut National de la Recherche Agronomique (INRA), Bioclimatology Section, Bordeaux, France. Flux calculations have been checked at several time integration lengths (using the classical EDIRE software), without noticing large differences indicating that integration losses were not critical. Due to the rotating pivot irrigation system the sensor had to be mounted at the edge of the corn field with average crop heights about 1.8 to $2.2 \mathrm{~m}$. A Campbell CA27T, 1D sonic anemometer was set up at a height of $1.1 \mathrm{~m}$ over the dry wheat stubble field (field "WS"), some $150 \mathrm{~m}$ 
south-east of the LAS transmitter. The nominal calculation procedure given in the CA27 manual was followed relying on a 10 minute covariance calculation with a $10 \mathrm{~Hz}$ scanning time. For the sake of proper comparison the 10 minute averaging interval data is used on all the data.

As such the landcover components potentially influencing the LAS observations were monitored during 6 days, from DOY 197 to 202 , in 2004. The observations were made just outside the protected area of the Las Tiesas experimental farm, which gave reason to remove part of the instrumentation during night-time hours. Due to periodic malfunctioning of some of the sonic anemometers also no continuous dataset could be obtained. However, after averaging to 10 minute intervals a data set of 69 observations was produced, containing LAS as well as all three sonic measurements, see Table 4-1.

Table 4-1 Summary of sensible heat flux measurements and instrumentation used.

\begin{tabular}{lllll}
\hline Instrument & $\begin{array}{l}\text { Height } \\
{[\mathrm{m}]}\end{array}$ & Field & $\begin{array}{l}\text { Sampling } \\
\text { rate [Hz] }\end{array}$ & $\begin{array}{l}\text { Averaging time } \\
{[\mathrm{min}]}\end{array}$ \\
\hline LAS150-Receiver & 5.06 & V1 & 1 & 10 \\
LAS150-Transmitter & 4.64 & WS & 1 & 10 \\
Young 81000 3D sonic & 4.4 & C2 & 10 & 10 \\
Campbell CA27T 1D sonic & 1.1 & WS & 10 & 10 \\
Gill 3D sonic & 3.4 & V1 & 20 & $10,30,60$ \\
\hline
\end{tabular}

The temporal evolution of the latter is shown in Figure 4-3. This final dataset, containing flux observations on DOY 198, 199, 200 and 202 recorded between 08:00 and 16:00 UTC, was then used for further analysis. 


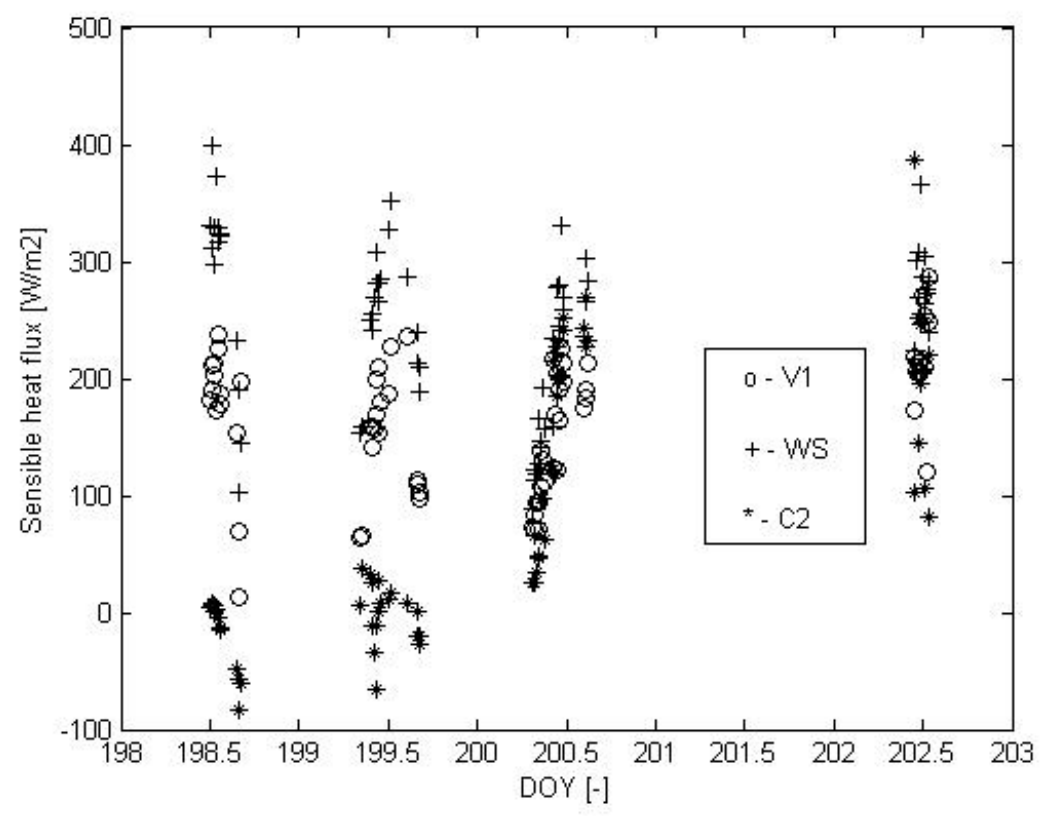

Figure 4-3 Quality checked sensible heat fluxes measured by the sonic anemometers over the vineyard, wheat stubble and corn field for the duration of the experiment.

\subsubsection{Input data}

Parameters needed for estimating $\left\langle C_{\mathrm{N}}{ }^{2}\right\rangle$ comprise spatially aggregated available energy, $\left\langle R_{\mathrm{N}}-G\right\rangle$, air temperature $\left\langle T_{\mathrm{a}}\right\rangle$ and friction velocity $\left\langle u_{*}\right\rangle$.

Here the available energy is used for calculating the Bowen ration, which is a correction term in Eq. (4.5). Since the net radiation and soil heat flux only appear in this corrective factor in an in-direct way, their accuracy is not critical (Lagouarde et al., 2002a). Because the net radiation and soil heat flux could not be measured in all sites we concentrated on the vineyard measurements. The bulk of the 69 observations were made between 10:00 and 15:00 UTC, during which the available energy varied between $400 \mathrm{Wm}^{-2}$ and $500 \mathrm{Wm}^{-2}$. Therefore we have adopted a spatially constant average of $450 \mathrm{Wm}^{-2}$.

For $\left\langle T_{a}\right\rangle$ we have used a measurement obtained at about $5 \mathrm{~m}$ above the ground over the vineyard, which is in the centre of the experimental area. In addition, simulations have indicated 
that spatial variation in air temperature over the area typically are in the order of $1.5 \mathrm{~K}$ (Timmermans et al., 2008), which we feel justifies using a single measurement of air temperature here. Moreover, the observation is time-averaged implying that local variations may have been reduced.

Although the development of internal boundary layers above each surface component may slightly alter the blending height concept (Wieringa, 1986), the blending height concept is used here. Wind speed measurements taken at $4.88[\mathrm{~m}]$ above the ground over the vineyard are transferred to the blending height, which is then taken as a representative aggregate windspeed, $\langle u\rangle$, for the area. Aggregated displacement height and surface roughness length were obtained from Eqs. (4.11) and (4.12a), where $r$ is replaced by $r f p$. In addition, Eqs. (4.11) and $(4.12 \mathrm{a})$ were expanded to three components, representing the vineyard, the wheat stubble and the corn field. Spatially distributed information on component characteristics was obtained from a landcover classification based on an ASTER image in its original resolution $(15 \mathrm{~m})$ in combination with a look-up table containing associated canopy height (Van der Kwast et al., 2009). For the wheat the surface roughness length was estimated as the canopy height divided by 8 (Brutsaert, 1982), yielding a value of 0.03 [m].

Since the corn crops were very dense, their surface was considerably smoother than could be expected based solely on the height of the canopy (Shaw \& Pereira, 1982). Analysing measurements from the sonic anemometer over the corn during near neutral atmospheric stability conditions yielded roughness length values between 0.03 and $0.09 \mathrm{~m}$, with an average of $0.068 \mathrm{~m}$. The same procedure was followed for the vineyard. Here the roughness estimates were clustered around two values, depending on wind direction. Parallel to the roworientation of the crops we found roughness values around $0.14 \mathrm{~m}$, whereas perpendicular to the rows values around 0.18 $\mathrm{m}$ were found. Depending on wind direction either one of them was assigned to the vineyard.

Displacement height for the three landcover components was obtained by taking it equal to two-third of the canopy height for the corn and vineyard. For the harvested wheat, a displacement height of $0[\mathrm{~m}]$ was taken, since it consisted of 
rather irregularly spaced wheat stubble, rendering the displacement height principle not applicable.

\subsubsection{Results}

We have applied the footprint approach using the method presented by Soegaard et al. (2003) combined with the weighting function of the LAS, $W(u)$, following Meijninger et al. (2002). Sensible heat fluxes, $H_{\text {LAS }}$, were calculated from the scintillation measurements (hence, $H_{\text {LAS }}$ instead of $H_{\text {sim }}$ ) using the aggregated parameters as described in the previous section. Values of the average sensible heat flux obtained with the scintillometer are plotted versus the reference measurements from the sonic anemometers obtained from Eq. (4.21) in Fig. 4-4.
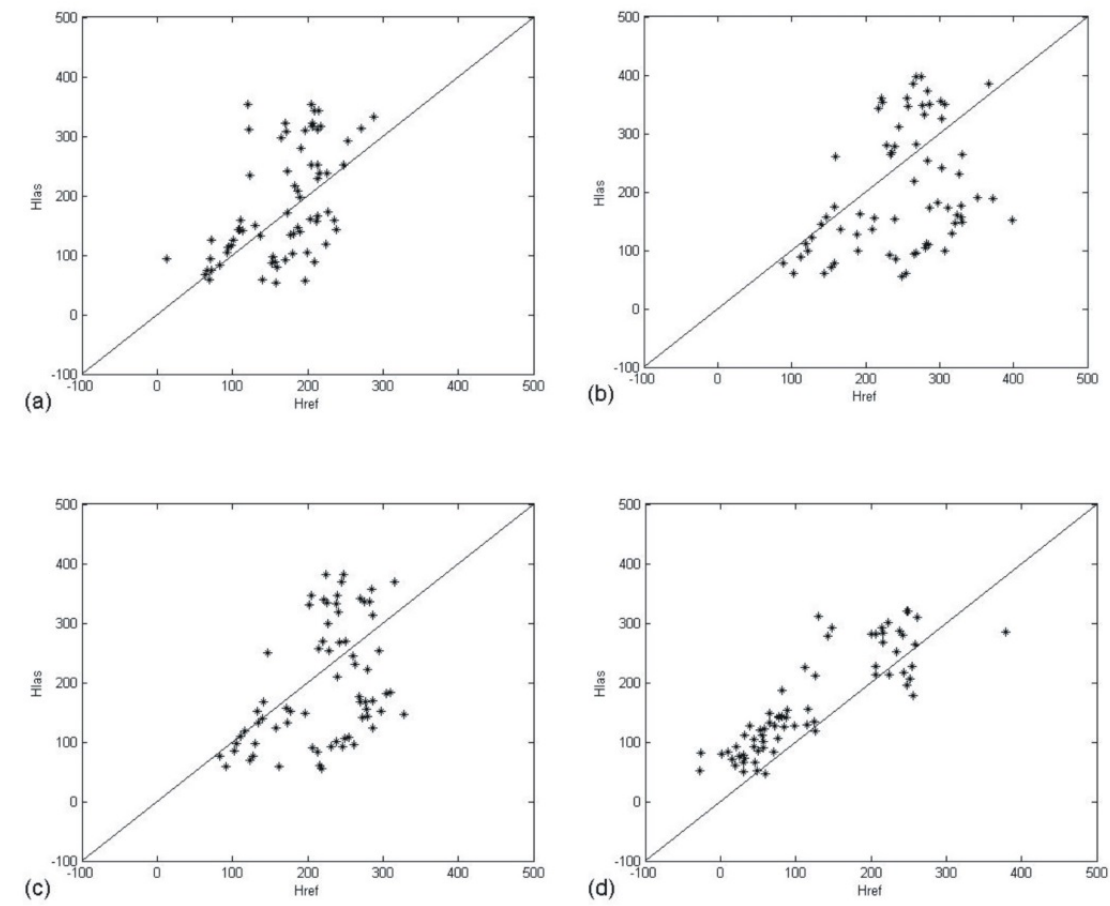

Figure 4-4 Comparison between spatially-aggregated sensible heat fluxes derived from sonic anemometers $\left(H_{\text {ref }}\right)$ and scintillometry $\left(H_{\mathrm{LAS}}\right)$. Upper panels show results from the 0-D approach, assuming a homogeneous landuse of either vineyard (a) or wheat stubble (b). 
The lower panels show results from the 1-D (c) and 2-D (d) approaches, assuming the surface to be composed of vineyard and wheat stubble and vineyard, wheat stubble and corn respectively.

To demonstrate the impact of the two-dimensional footprint in the current case, additional calculations were performed, assuming either a homogeneous land cover consisting of a vineyard or a wheat field, so-called zero-dimensional approaches, as well as a one-dimensional analysis, assuming a two-component surface consisting of vineyard and wheat stubble. Reference values of sensible heat flux in the homogeneous, or zero-dimensional, cases were taken from the sonic measurements in the respective fields, whereas in the 1$D$ and 2-D cases they were calculated following Eq. (4.21). Naturally, adding the corn component, only possible when treating the LAS measurement in a two-dimensional way, both $H_{\text {ref }}$ and $H_{\text {LAS }}$ decreased as a result of low sensible heat flux for the corn. The upper panels in Fig. 4-4 show the results when assuming the LAS is measuring over a homogeneous surface, entirely consisting of vineyard (left panel) or wheat stubble (right panel). The lower panels show the results for the onedimensional (left panel) and two-dimensional (right panel) cases. A summary of the results is provided in Table 4-2.

Table 4-2 Coefficient of determination, $\rho^{2}$, and Root Mean Squared Differences (RMSD) between aggregated LAS observations and reference values for sensible heat flux using different approaches.

\begin{tabular}{lcc}
\hline Approach & $\rho^{2}$ & RMSD [W· $\left.\mathrm{m}^{-2}\right]$ \\
\hline 0-D (V1) & 0.28 & 81.6 \\
0-D (WS) & 0.12 & 113.7 \\
1-D (V1-WS) & 0.18 & 96.5 \\
2-D (V1-WS-C2) & 0.74 & 67.7 \\
\hline
\end{tabular}

It goes without saying that ignoring the influence of the corn field in the aggregation process, obvious for the zero- and onedimensional cases, for the current case is not realistic. Large discrepancies between $H_{\text {LAS }}$ and $H_{\text {ref }}$ are noticed in these cases and coefficients of determination were never exceeding 0.28. Dramatic improvement in both correlation coefficient, $\rho$, and RMSD is seen when applying the two-dimensional approach, although still relatively high deviations are noticed. 
An attempt is made to further improve these estimates using prior knowledge on flux contrasts between the surface components. This is discussed in the following section.

\subsection{Discussion}

When aggregating the aerodynamic properties of the surface components, reasonable estimates can be obtained from the canopy heights. This yields the possibility to estimate component friction velocities, assuming a wind speed measurement at sufficient height is available. If furthermore estimates of the contrast between the fluxes of the different components are available this would potentially improve the estimation of the aggregated flux, since these are then the only remaining parameters determining the relative contributions of $C_{\mathrm{Ni}}^{2}$ in Eqs. (4.17-4.18) to $\left\langle C_{\mathrm{N}}^{2}\right\rangle$.

We have run aggregations using several different ratios of sensible heat flux which could reasonably be expected for the three land cover components. However, no reasonable results were obtained which is attributed to the high variation of the ratio between the sensible heat fluxes measured over the different fields with time, see also Fig 4-3. The fluxes over the vineyard and wheat stubble were rather stable for the days of observation, but rather large fluctuations for the corn were noted, most probably due to irrigation. However, to test whether improvements could be established, we have used the measured ratios between the component fluxes and implemented these in the aggregation scheme. The results for this simulation are displayed in Fig. 4-5a. 

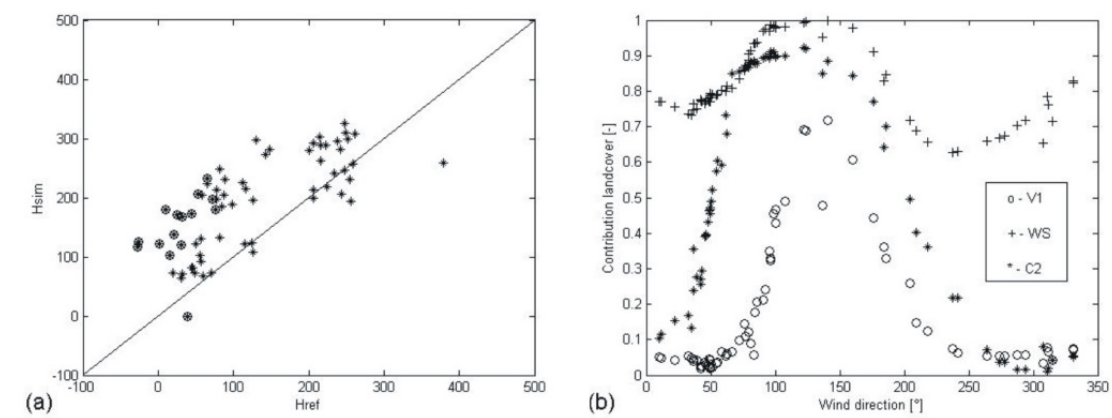

Figure 4-5 Simulated versus reference fluxes, assuming known ratio of component fluxes. Influence of atmospheric stability contrast, stable by circles (a), homogeneity of sonic footprints related to wind direction (b).

Surprisingly, the results deteriorated with respect to the aggregation not using prior knowledge on flux ratios.

One of the obvious reasons is the simultaneous occurrence of unstable and stable conditions within the footprint of the LAS. Under certain conditions the irrigated cornfields created an oasis effect in the elsewhere dry and hot surroundings, causing at times stable conditions over the corn. In such cases, which are represented by a low or even negative reference flux, Eqs. (4.17-4.18) do not hold since the LAS cannot discriminate between upward or downward fluxes. In Fig. 4-5.a these cases are marked by circles. It is clearly noticed that for those cases the deviation is considerably larger than for the cases where only unstable conditions occurred. However, after excluding these cases from the simulation still deviations remained.

Despite careful analysis of the local circumstances and prevailing wind directions when setting up the experiment, it could not be avoided that at certain moments during the campaign the footprint of the LAS included land covers where no reference observations of sensible heat flux were made. Since the aggregation procedure for the aerodynamic properties demands that the sum of the relative contributions of the components is equal to unity, the values for $r f p_{i}$ were normalized by dividing them by the sum of the three components where the actual reference measurements were taken. However, during $73 \%$ of the time the three components contributed for more than $75 \%$ to the total footprint of the LAS, which we believe is acceptable. Under these 
circumstances one could think of using thermal remote sensing information to produce estimates of fluxes for components that were not covered by sonic anemometers (Hoedjes et al., 2007). However, this information was not available for the duration of the experiment.

Another reason for a mismatch between $H_{\text {LAS }}$ and $H_{\text {ref }}$ is attributed to incorrect component fluxes. Obviously the sonic measurements are also characterized by their respective footprints, which, like the LAS footprint, is variable in time, depending mainly on wind direction. The instrumentation was installed such that during prevailing wind directions they would produce the most "pure", or highest quality observations. These occurred during the first few days of the experiment as may also be noted from Fig. 4.3. Unfortunately wind directions changed during the experiment, resulting in lesser quality EC observations mainly for the vineyard and corn. However, with the change of wind direction to the west, also the corn was almost entirely excluded from the scintillometer footprint, rendering this observation less crucial.

Figure 4.5b. shows the contribution of the field where the sonic anemometers were located relative to the total contributing source area as a function of wind direction. The vineyard is represented by open circles, the wheat stubble by crosses and the corn is represented by closed diamonds. It is clearly noticed that when wind directions are between 100 and $180^{\circ}$, resembling eastern to southern directions, the footprints were most "pure", or homogeneous.

A plot of the results of the aggregation scheme for estimating $H$ only for wind directions between 100 and $180^{\circ}$ are presented in Fig. 4-6a. Although for some points a near perfect fit is obtained, there are still a few observations that generate large discrepancies between $H_{\text {LAS }}$ and $H_{\text {ref }}$. Since in the simulations no discrepancies between $H_{\text {LAS }}$ and $H_{\text {ref }}$ occurred, the reason here, apart from contrasting stability, must lie in the component fluxes being incorrect, not pure, or incomplete, meaning the footprint of the LAS contained more covers than only vineyard, wheat stubble or corn.

The discrepancies between $H_{\text {LAS }}$ and $H_{\text {ref }}$ seem related to the contrast between the component fluxes, as shown in Fig. 4-6b. For illustration purposes the maximum ratio, between the corn and the wheat stubble fluxes, is set to 5 in the figure. Because 
of this, one outlier is not shown, which showed $H$ componentratios around 200 and a difference between $H_{\text {LAS }}$ and $H_{\text {ref }}$ equal to $88.5 \mathrm{Wm}^{-2}$. It appears that generally a larger contrast between the component fluxes invokes larger discrepancy between $H_{\text {LAS }}$ and $H_{\text {ref. }}$. There seems to be one exception to this, which is the point with the highest error. However, inspection revealed that this point had about $20 \%$ of its footprint not covered by any of the three surface components measured by a sonic anemometer. Moreover, the sonic anemometer of the vineyard for this particular observation only had a $48 \%$ contribution from the vineyard itself, despite a favourable wind direction.
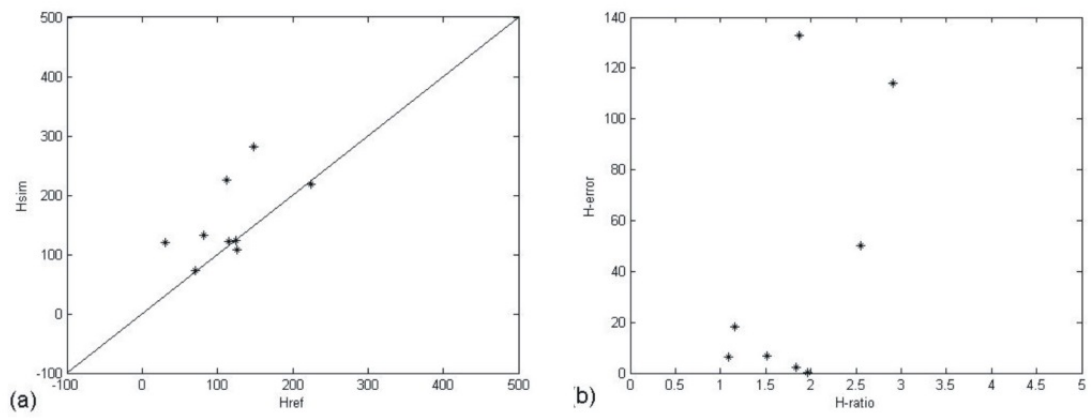

Figure 4-6 Simulation results from the N-rfp approach, during southeastern wind directions (a) and discrepancy between $H_{\text {LAS }}$ and $H_{\text {ref }}$ in relation to component flux contrast (b), between the corn and the wheat stubble.

A threshold value seems to be present at a contrast ratio about 2. Below this value differences between $H_{\text {LAS }}$ and $H_{\text {ref }}$ are within $20 \mathrm{Wm}^{-2}$, above this value discrepancies rapidly increase. This indicates that when the contrast of surface fluxes for different landcover components were too large (i.e. the ratio is larger than 2), the LAS measurement experienced problems.

\subsection{Conclusion}

A methodology is proposed to produce LAS-derived areaaverages of sensible heat fluxes suitable for validating spatially distributed models that estimate surface fluxes by remote sensing observations. The soundness of the method is 
demonstrated by reproducing reference fluxes from component fluxes. Although model results were considerably better than using traditional approaches when applied over the very heterogeneous Barrax test site, some complications are noticed.

These were partly due to the nature of the available data. First of all there is the well-known problem of energy balance closure (Foken, 2008) associated with eddy covariance measurements. Although no major low-frequency losses were noticed when analysing the vineyard data, there may have been such effects over the wheat stubble or corn.

In addition, during a limited number of observations both stable and unstable conditions occurred within the footprint of the LAS. Due to the nature of the measurement technique the LAS is not able to distinguish between these conditions, consequently the method does not work and the LAS estimates deviated from the reference values under these circumstances. Though limited in number, during some moments wind directions were such that the footprint of the LAS encompassed land cover units where no reference observations of sensible heat flux were available. The same phenomenon, changing wind-direction, at times caused the footprint of the reference observations not being homogeneous. Obviously this can hardly be avoided when dealing with agricultural patches under natural conditions. However, when the contrast between land cover components is not too large, deviations between LAS based estimates and reference values were within $20 \mathrm{Wm}^{-2}$.

In the paper on which this chapter was based the authors acknowledge funding though ESA $18307 / 04 / \mathrm{NL} / \mathrm{FF}$. The authors thank Ambro Gieske from ITC for his help in the installation and maintenance of the scintillometer ground station and Li Jia and Jan Elbers from ALTERRA for their help in the installation and maintenance of the sonic anemometer ground stations and the processing of the eddy correlation data. 


\title{
Chapter 5 An overview of the regional experiments for land-atmosphere exchanges 2012 (REFLEX 2012) campaign *
}

\begin{abstract}
The REFLEX12 campaign was initiated as part of a training course on the organization of an airborne campaign to support advancement of the understanding of land-atmosphere interaction processes. This chapter describes the campaign, its objectives and observations, remote as well as insitu. The observations took place at the experimental Las Tiesas farm in an agricultural area in the South of Spain. During a period of ten days measurements were made to capture the main processes controlling the local and regional landatmosphere exchanges. Apart from multi-temporal, multi-directional and multi-spatial space-borne and airborne observations, measurements of the local meteorology, energy fluxes, soil temperature profiles, soil moisture profiles, surface temperature, canopy structure as well as leaf-level measurements were carried out. Additional thermo-dynamical monitoring took place at selected sites. After presenting the different types of measurements, some examples are given to illustrate the potential of the observations made.
\end{abstract}

\subsection{Introduction}

Quantification of bio-geophysical variables of different surfaces is essential for understanding the earth system and for the development of earth system models for prediction of climate and environmental change (Kornelsen \& Coulibalya, 2013; Mishra \& Singh, 2011; Rast et al., 2014; Seneviratne et al., 2010; Wang \& Dickinson, 2012). Remote sensing monitoring is essential for the development and validation of these observational and process models as well as retrieval

\footnotetext{
* Based on Timmermans et al., Acta Geophys. 63, 6, pp. 1465-1484, 2015
} 
algorithms (Gamon et al., 2010; Rodell et al., 2004; Salama et al., 2012; Van Dijk \& Renzullo, 2011; Yebra et al., 2013).

Understanding the retrieval of bio-geophysical variables from optical-thermal and microwave data and the modelling of the underlying processes over inhomogeneous terrain remains problematic due to a lack of observational data at appropriate scales (McCabe \& Wood, 2006; Timmermans et al., 2013; Timmermans et al., 2008; Wu \& Li, 2009). Thereto a campaign was designed to use airborne sensors for multi-angular hyperspectral optical-thermal data acquisition and to collect field measurements over several land-cover units. In addition optical-thermal satellite data for the same period were acquired. The obtained data-set was then used for model validation and inversion algorithms that are used to extract quantitative surface variables and for land-atmosphere interaction studies.

To advance the understanding of land-atmosphere exchanges of water and heat at spatial and temporal scales, measurements of these exchanges and of thermo-dynamic states of the atmosphere and surface were carried out over several land-cover units. Since turbulent fluxes occur from molecular to regional scales and are influenced by internal biophysical characteristics and external forcing (e.g. solar radiation and wind), the measurements of these fluxes are very challenging over heterogeneous terrain (Novick et al., 2014; Prueger et al., 2012). Because the terrain heterogeneity (in terms of surface roughness and soil and vegetation properties) in combination with the turbulent fluxes causes thermodynamic changes of the surface state, a number of ground based instruments is employed. These were distributed over several different land-cover units to ensure a complete observation and understanding of these fluxes at spatial and temporal scales.

The campaign was carried out under the umbrella of the REFLEX12 training course supported by the FP7-funded EUFAR (European Facility For Airborne Research) and Cost Actionfunded ES0903 EUROSPEC projects and took place in Albacete and Barrax, Spain, during 18 to 28 July 2012. The theme of the course was the organizing and conducting of a hyper-spectral 
multi-angular airborne campaign in the framework of multiscale ("leaf-to-ecosystem") land-atmosphere exchange research.

\subsection{Main objectives and tasks of the campaign}

The general objectives of the campaign were:

- Advancement of the process understanding that describes radiative and turbulent transfer in landatmosphere interactions.

- Acquisition of simultaneous multi-temporal, multiangular and multi-sensor hyper-spectral data over a heterogeneous area.

- Validation of bio-geophysical variables extraction from satellite data using airborne and in-situ data.

- Improvement of soil moisture retrieval by using both multi-angular and hyper-spectral optical-thermal observations.

To reach these objectives a specific tailor-made flight plan was designed concurrent to field measurements supporting the airborne data processing and analysis. To ensure the availability of multi-angular and multi-scale optical-thermal observations, satellite data, comprising Compact High Resolution Imaging Spectrometer - Project for On-Board Autonomy (CHRIS-PROBA) and Meteosat Second Generation (MSG) were collected during the campaign as well. The CASA 212-INTA airplane was used for mounting the Airborne Hyperspectral Scanner (AHS) and Compact Airborne Spectrographic Imager (CASI) sensors in order to collect multisensor hyper-spectral data and a flight plan was developed such as to ensure multi-angular and multi-temporal observations at high spatial resolution.

Information of the atmospheric state, which mainly concerns the Aerosol Optical Thickness (AOT), the ozone and water vapour content, is needed to carry out atmospheric corrections of spaceborne and airborne measurements. Several types of atmospheric and field-based observations supporting this were obtained simultaneously, comprising of atmospheric soundings as well as in-situ measurements using sun photometers. 
Different groups were simultaneously operating ASD (Analytical Spectral Devices) FieldSpec Pro FR, CIMEL and Everest radiometers for measuring reflectance and emittance from calibration targets in the solar and thermal range of the electromagnetic spectrum.

Knowledge of the heat transfer, needed for understanding the exchanges of water vapour and energy between a canopy and the surrounding atmosphere, was obtained in several ways, depending on the scale. Locally this involved the monitoring of individual leaf and soil sunlit and shadowed temperatures, whereas more towards a regional scale, micro-meteorological and turbulent flux measurements were carried out from masts at specific selected sites. These comprised eddy-covariance (EC) and Large Aperture Scintillometer (LAS) measurements, covering multiple land-cover units, in combination with profile observations of specific humidity, air temperature and windspeed and profiles of soil temperature, soil heat flux and soil moisture.

Finally, a limited amount of field-based biophysical (soil, vegetation and water) measurements were carried out over different land-cover units. They among others comprised estimates of Fractional Vegetation Cover (FVC), Leaf Area Index (LAI), Photosynthetically Active Radiation $(P A R)$, leaf reflectance, leaf transmittance, surface emissivity and soil moisture.

\subsection{Experiment and datasets}

\subsubsection{Experimental site and background climatology}

The campaign area was the well-known Barrax test site, situated at a plateau $700 \mathrm{~m}$ above sea level within the La Mancha region, in the South-East of Spain, Fig. 5-1. The agricultural area is located in the west of the Albacete province, $20 \mathrm{~km}$ from the capital town Albacete. 


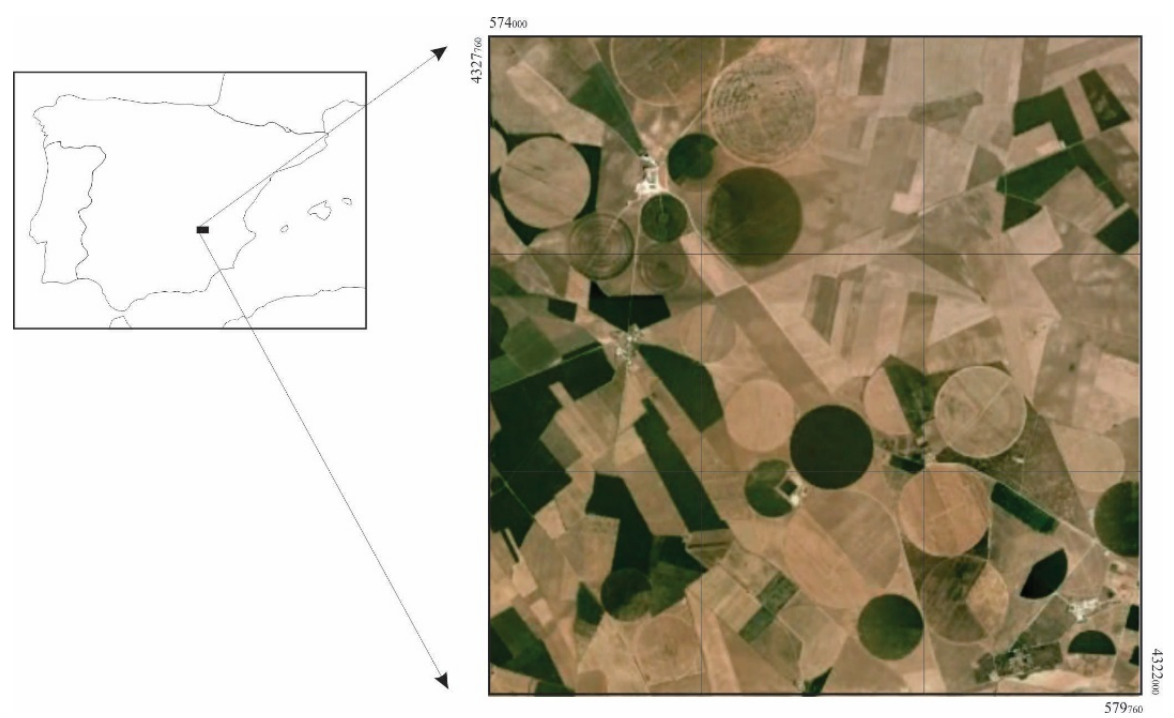

Figure 5-1 Site location (zoom from Google Earth)

The area is characterized by a flat morphology and large, uniform land use units and consists of approximately $65 \%$ dry land and $35 \%$ irrigated land with different agricultural crops and orchards. Field sizes range from a few tens of meters up to almost $1 \mathrm{~km}$ in diameter, where the larger fields are circular shaped and irrigated by a rotating pivot system.

The majority of the campaign activities were concentrated in the fields of the Las Tiesas experimental farm, operated by the Instituto Tecnico Agronomico Provincial (ITAP) of Albacete, Spain, which has been used extensively in previous campaigns for calibration and validation of remote sensing observations (Sobrino et al., 2009; Su et al., 2008). A landcover map for the Las Tiesas fields is digitally available. The main land use types during the current campaign included bare soil, vineyard, maize, forest nursery, barley (stubble), wheat (stubble), poppy, (young) sunflower, walnut and pistachio orchards and camelina (from the mustard family). At the time of the campaign, most of the crops were already harvested. The only canopies with a significant green vegetation fraction during the campaign were maize, vineyard and sunflower (early growth stage) as well as orchards and forest nursery. 
The La Mancha region has a mid-latitude semi-arid climate with most of the rainfall concentrated during the spring and autumn seasons, and lower levels during the summer. With an annual rainfall which averages around $350 \mathrm{~mm}$, La Mancha is one of the driest regions of Europe and potential evaporation rates reach up to $900 \mathrm{~mm}$ per year. Due to these dry conditions combined with intensive irrigation practices the regional water table is about $20-30 \mathrm{~m}$ below the land surface.

The area is characterized by cold winters and hot dry summers. Monthly averages of minimum temperature range from $2{ }^{\circ} \mathrm{C}$ in January to $19{ }^{\circ} \mathrm{C}$ during July, whereas monthly maximum temperatures range from $11^{\circ} \mathrm{C}$ to $34^{\circ} \mathrm{C}$ in these months. During the summer months temperatures above $40^{\circ} \mathrm{C}$ are not uncommon and rainfall is rare.

\subsubsection{Remote sensing data acquisitions}

\section{Satellite data acquisitions}

To comply with the multi-directional, multi-temporal and multispatial character of the land-atmosphere exchange experiment undertaken, space-borne observations from two specific platforms were acquired during the campaign. The multitemporal aspect was covered by the acquisition of MSG observations every 15 minutes during the entire campaign at a low spatial resolution of $3 \mathrm{~km}$, whereas the multi-directional aspect was covered by acquiring Compact High Resolution Imaging Spectrometer (CHRIS) data at a relatively high spatial resolution of 36 meter.

CHRIS is a small and relatively light (weight less than $15 \mathrm{~kg}$ ) spectrometer and it operates in push-broom mode. Its main application areas are in forestry, environmental monitoring and precision farming. Its orbit is at $600 \mathrm{~km}$, which results in a 14 $\mathrm{km}$ swath with a spatial resolution of $18 \mathrm{~m}$. This is slightly variable because the altitude varies along the orbit. CHRIS is mounted on the PROBA (PRoject for On-Board Autonomy) platform, which has steering capabilities in the along- and across-track directions. This enables observation of selectable targets far outside the nominal field of view of $1.3^{\circ}$. Images are generally acquired in sets of 5 , taken at along track angles of \pm 55 degrees, \pm 36 degrees, and at nadir, see Fig. 5-2. 


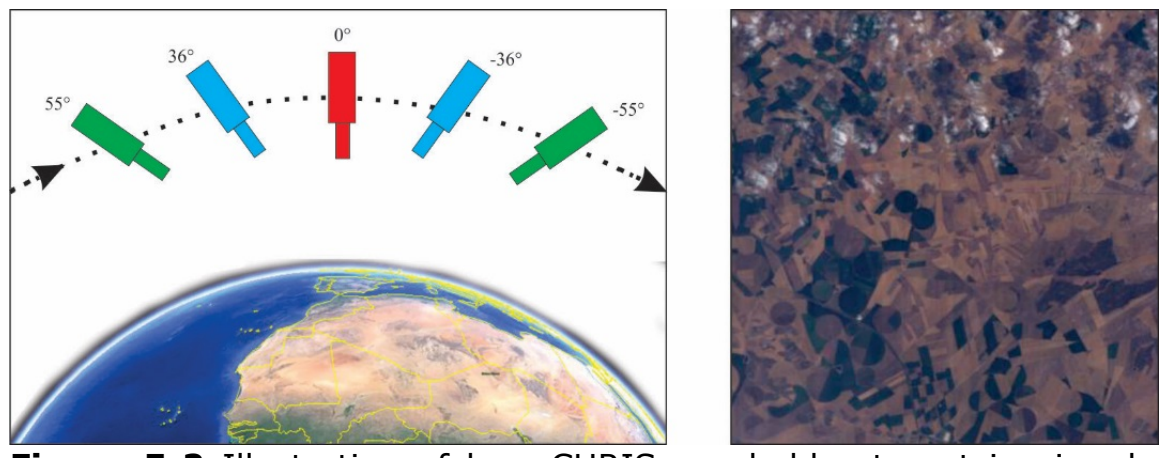

Figure 5-2 Illustration of how CHRIS can hold a target in view by using PROBA's pitch control (left panel) and nadir view of CHRISPROBA acquisition over the Barrax site on 22 July 2012, 07:56 UTC (right panel), channels 23-9-5 for RGB

CHRIS operates in the visible to near infrared wavelength region (400 nm to $1050 \mathrm{~nm}$ ) and can either operate in 63 spectral bands at a reduced spatial resolution of $36 \mathrm{~m}$, or with 18 bands at full spatial resolution. Its spectral resolution is variable from 2-3 nm at the blue end of the spectrum, to some $12 \mathrm{~nm}$ at the $1050 \mathrm{~nm}$ edge. The instrument is very flexible and different sets of bands and configurations can be used for different applications.

The Meteosat Second Generation 1 (MSG1) satellite, renamed Meteosat-8, carries the Spinning Enhanced Visible and Infrared Imager (SEVIRI) which is its main payload. This optical imaging radiometer consists of three visible and near infrared channels, eight infrared channels and one visible broadband channel called the High Resolution Visible channel (HRV). The spatial resolution of SEVIRI channels is $3 \mathrm{~km}$ at sub-satellite point, except for the HRV channel which has a $1 \mathrm{~km}$ resolution. The temporal resolution is 15 minutes. The data acquisition for the period of the campaign was standard and the imagery is freely available. For downloading the data the following link from the Unified Meteorological Archive and Retrieval Facility (UMARF) is recommended:

http://www.eumetsat.int/Home/Main/DataAccess/EUMETSATD ataCentre/index.htm?|=en

where one should select: "High Rate SEVIRI Level 1.5 Image data" and select "HRIT data sets in tar file" to receive HRIT files. Background information and the freeware to process the 
data is available at: http://52north.org/communities/earthobservation/about-geonetcast.

An overview of the sensor characteristics of the satellite and airborne observations is provided in Table 5-1.

\section{Airborne data acquisitions}

Two airborne sensors have been operated during the REFLEX12 campaign to acquire important data for bio-geo-physical variable estimation over the Barrax site. The Airborne Hyperspectral Scanner (AHS) and Compact Airborne Imaging Spectrometer (CASI) sensors were mounted on the CASA 212200 N/S 270 "Paternina" airplane of INTA. Because the campaign was primarily aiming at land-atmosphere interactions, the thermal observation capacities of the AHS sensor were prioritized. Therefore the flight configuration was designed such that if conflicting criteria between AHS and CASI occurred, preference was given to AHS.

With respect to the timing of the airborne data acquisitions, there were no constraints with respect to linking the acquisitions to simultaneous satellite overpasses; the CHRISPROBA overpass fell outside the possible window for airborne acquisitions due to the unavailability of the airplane, whereas the MSG acquisitions have a frequency much higher than an airborne acquisition window (typically one hour or more).

From a scientific viewpoint it was desirable to obtain at least one night-time acquisition in order to determine thermal inertia. Thermal inertia is highly correlated with soil/canopy moisture content and as such of major importance for landatmosphere flux exchanges. Other aspects in the flight line design were the need for multiple viewing angles and the need to cover a full daily cycle. The first objective resulted in flight lines that had a considerable overlap, see Fig. 5-3. The second objective resulted in planning for a daytime flight, followed by a night-time flight, immediately followed by another daytime flight the next afternoon.

Weather conditions were such that the window of 25th and 26th of July was chosen for acquiring the airborne data. The flight lines were then designed to match the selected calibration/validation sites as well as the flux observation sites. 

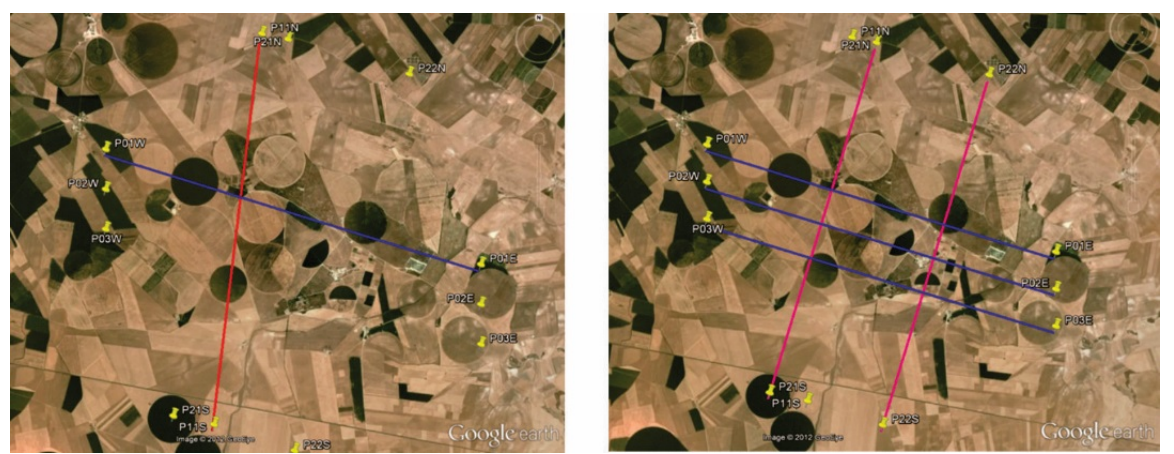

Figure 5-3 Left panel, the flight pattern for the low (1000 $\mathrm{m}$ above ground) flights, right panel the flight pattern for the high $(2000 \mathrm{~m}$ above ground) flights. Presented on Google Earth

The first flight was on Wednesday, July 25th 2012. Weather conditions were some high clouds, southern wind with a variable intensity. Data acquisition started at 08:41UTC (10:41 local time). Two lines are performed over the test site at 1000 meter above the ground level, resulting in a high spatial resolution, and five more lines are covered at an altitude of 2000 meter above ground, resulting in a reduced resolution, Table 5-1. Data acquisition is completed at 09:47UTC (11:47 local time). The second flight was a night flight and took place on the same day. Weather conditions were clear skies. Data acquisition started at 21:30UTC (23:30 local time) and was completed at 22:41UTC (00:41 local time).

Table 5-1 Overview of the space- and air-borne observations

\begin{tabular}{cccccc}
\hline Sensor & $\begin{array}{c}\text { \# of } \\
\text { channels }\end{array}$ & $\begin{array}{c}\text { Spectral } \\
\text { range }[\mu \mathrm{m}]\end{array}$ & $\begin{array}{c}\text { Resolution } \\
{[\mathrm{m}]}\end{array}$ & Acq. date & $\begin{array}{c}\text { Acq. } \\
\text { DOY }\end{array}$ \\
\hline MSG & 12 & $0.60-14.40$ & $1000 / 3000$ & $18-28$ July '12 & $200-210$ \\
CHRIS & 63 & $0.40-1.05$ & 36 & 22 July '12 & 204 \\
AHS & 80 & $0.43-12.70$ & $2.1 / 3.9$ & $25 / 26$ July '12 & $207-208$ \\
CASI & $144 / 288$ & $0.38-1.05$ & $0.48 / 0.98$ & $25 / 26$ July'12 & $207-208$ \\
\hline
\end{tabular}

The third flight took place on Thursday, July 26th 2012, when weather conditions were clear skies with a south-eastern wind. Data acquisition started at 08:42UTC (10:42 local time) and was completed at 09:38UTC (11:38 local time). The flight lines for the second and the third flights were similar to the first flight with the exception of lines P02 and P03, see Fig. 5-3, which were skipped since the multi-directional aspect was covered during the first flight. Additional details of the flight 
lines (timing, exact location) are provided in the flight report, which is present in the REFLEX12 database.

The Airborne Hyper-spectral Scanner (AHS) is a linescanner with a concept shared with classical airborne linescanners, similar to the well-known HyMap instrument. The INTA AHS sensor has 63 bands in the reflective part of the electromagnetic spectrum, 7 bands in the 3 to 5 microns range and 10 bands in the 8 to 13 microns region. The Instantaneous Field Of View (IFOV) equals $2.5 \mathrm{mrad}$, and the Field Of View (FOV) is $90^{\circ}$. This resulted in a resolution of 2.1 and $3.9 \mathrm{~m}$ at the low and high altitude flights respectively.

The CASI sensor is a pushbroom imager based on a bidimensional Charge Coupled Device (CCD); the instrument measures the incoming radiance along up to 1500 spatial pixels "across-track" in up to 288 separate spectral bands. The spectral bands can be placed anywhere within a $\sim 680 \mathrm{~nm}$ spectral range, which itself can be placed anywhere between 380 and $1050 \mathrm{~nm}$. The CASI is thus sensitive to wavelengths in the visible part of the electromagnetic spectrum, as well as in the Near Infrared. In the current campaign the settings were such that 144 spectral bands were used covering the full range from 0.38 to $1.05 \mu \mathrm{m}$ during the high altitude flights whereas for the low flights the full spectral resolution was used, resulting in 288 spectral bands. The FOV is $40^{\circ}$ and IFOV is 0.5 mrad, thus potentially providing a spatial resolution 5 times better than AHS at the same flight altitude. In the current setting this resulted in a spatial resolution of 0.48 and $0.98 \mathrm{~m}$ at the low and high altitude flights respectively.

\subsubsection{In situ measurements}

Atmospheric data acquisitions

Knowledge of the atmospheric conditions, especially the ozone and water vapour content, as well as their vertical profiles are required to perform accurate atmospheric corrections of the space and airborne observations. Two types of measurements are available during this campaign; routinely collected 
atmospheric soundings and in-situ ground-based atmospheric measurements.

Though remote (some $150 \mathrm{~km}$ from the area), atmospheric soundings from Murcia and Madrid are typical for atmospheric conditions on site, depending on wind directions. When eastern winds are prevailing typical on-site conditions usually resemble atmospheric characteristics as recorded over Murcia. Under western winds the Madrid conditions prevail in the study area. These soundings are carried out twice daily and for the days of airborne overpasses these soundings are available in the database. They contain profiles of pressure, air temperature, dew point, relative humidity, mixing ratio, wind direction, wind speed, potential air temperature and virtual potential air temperature, Fig. 5-4.
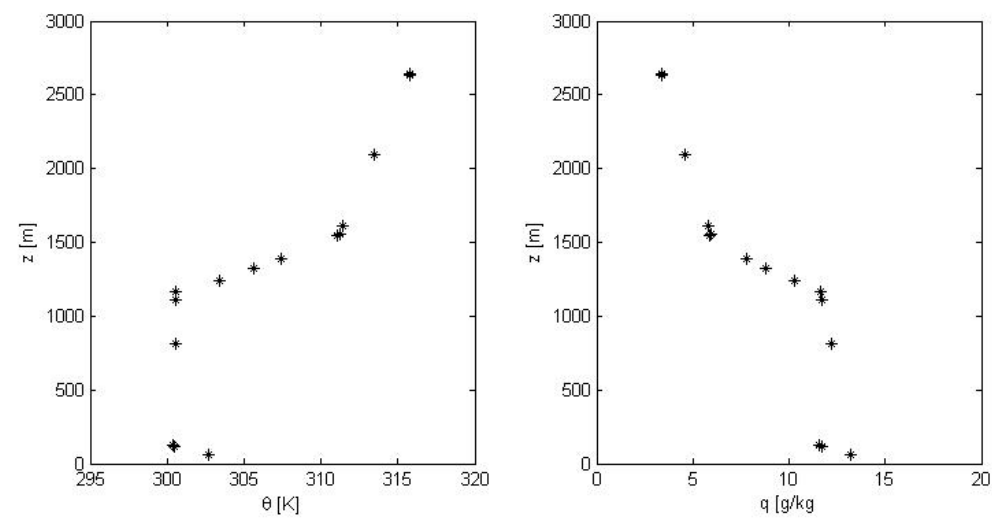

Figure 5-4 Madrid mid-day sounding for 26 July 2012, showing profiles of potential temperature, $\theta[\mathrm{K}]$, and specific humidity, $q$ $[\mathrm{g} / \mathrm{kg}]$

In addition, in-situ atmospheric measurements were carried out at several selected sites using Microtops sunphotometers. The instruments were configured to measure total water vapour column and aerosol optical thickness at $500 \mathrm{~nm}$. These measurements, carried out by several teams, on a continuous basis throughout the airborne overpasses, were made in conjunction with radiometric characterization observations at these selected sites. They are described in more detail in the next section. 


\section{Radiometric measurements}

Several ground radiometric measurements were carried out at different selected sites. They mainly comprised near-ground spectroscopy, so-called solar range radiometric measurements and thermal infrared radiometric measurements. The sites were selected based on homogeneity at a sufficiently large scale and representativeness of the main land-cover units. In addition they should show a sufficiently large spread in reflective and emissive behaviour and ideally also cover the flux observation sites. An overview of the different locations of these measurements is shown in Fig. 5-5, where also the flux tower sites and the reference meteorological stations are shown.

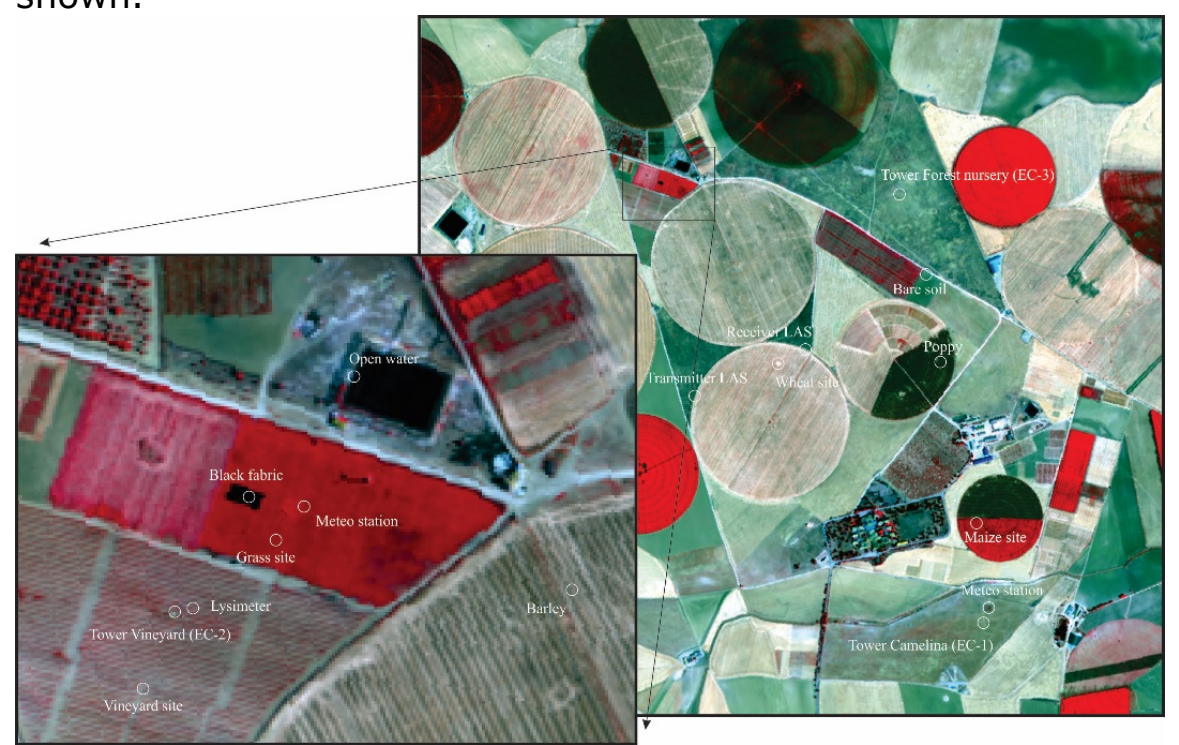

Figure 5-5 Overview of the main ground observation location, background image is a false colour composite of AHS channels 15-8-4 (RGB) of the $25^{\text {th }}$ of July morning overpass. The zoom is on the grassland super site central in the area, where a high concentration of ground observations took place

Near-ground spectroscopy was carried out for calibration and validation purposes at 5 selected sites comprising grass, wheat stubble, maize, camelina and vineyard. At these sites detailed Bidirectional Reflectance Distribution Functions (BRDFs), calibration reflectance and irradiance measurements were carried out as well as observations of atmospheric optical 
thickness and water vapour content and hemispherical sky photos. At a number of additional sites, comprising of bare soil, poppy, wheat stubble, black fabric, grass and open water calibration reflectance measurements were carried out as well.

Radiometric measurements in the thermal infrared region were also carried out with various instruments that included fixed Field Of View (FOV) and single band as well as multi-band radiometers. In addition, black bodies (calibration sources) for calibrating the instruments were used. These measurements, which aimed at calibrating and validating the thermal air-borne observations, consisted of transects which were carried out concurrently to the overpasses of AHS/CASI. They consisted of temperature measurements with different field radiometers (CIMEL, RAYTEK, OPTRIS and EVEREST), at regular steps of 3 meters over different land covers. These comprised grass, barley stubble, alfalfa, forest nursery, bare soil, wheat stubble, vineyard, poppy, maize and open water. The data was acquired in a period of time centred around the flight overpasses. The data was then processed following the so-called Temperature and Emissivity Separation (TES) algorithm (Gillespie et al., 1998), to obtain Land Surface Temperature (LST) and surface emissivity.

\section{Biophysical measurements}

Biophysical measurements consisted of the collection of Leaf Area Indices $(L A I)$, Leaf Angle Distribution, fraction of Absorbed Photosynthetically Active Radiation (fAPAR) and soil moisture, as well as leaf-level measurements of fluorescence, water and nitrogen content. For the fluorescence measurements use has been made of the Pulse-Amplitude Modulated (PAM) method as well as by a so-called leaf-clip, developed by the Laboratory for Earth Observation of the University of Valencia, whereas leaf water- and nitrogencontent analyses were carried out at the David J Bonfil Laboratory at the Gilat agricultural research center, Israel. The measurements, which were basically limited to the maize and, partly, sunflower fields, were carried out at several selected plots within the fields. The plots were selected in order to cover the slightly wide range of canopy heights, fAPAR and $L A I$ of the maize field, due to non-homogeneous irrigation, terrain 
morphology, and soil texture. Data acquisition took place at days 25, 26 and 27 of July 2012.

Top-of canopy fAPAR measurements were performed at the plots, by means of a SSI Sunscan Delta-T system. In addition to these top-of-canopy fAPAR observations, incident PAR measurements were carried out at $0.25 \mathrm{~m}$ intervals throughout the canopy to characterize the fAPAR profile in the canopy.

\section{Thermo-dynamic measurements}

The architecture of most vegetation canopies leads to a complex three-dimensional exchange of heat requiring temperature measurements of the different canopy and soil components at a very local scale. Therefore a MIDAC thermal range hyper-spectral Fourier Transform Infrared Spectrometer (FTIR) spectrometer was employed along with sensors such as a ThermoTracer thermal camera and thermal radiometers. The ThermoTracer was mounted on a tripoid to acquire daytime cycle very high spatial and temporal resolution observations, which were calibrated versus a gold plate with well-known emissivity and temperature. As such these sensors monitored the temperatures of different land surface components (shadowed versus sunlit, leafs versus soil) on a continuous basis. These component temperatures might then be implemented into a canopy model for the simulation of directional temperatures.

Surface energy budget and micrometeorological measurements Measurements of boundary layer heat and moisture fluxes, carbon fluxes, high resolution (in a spectral, spatial and temporal sense) thermal radiation and other relevant meteorological variables were continuously logged from 16 to 28 July 2012. The objective of the collection of this type of data was to facilitate the modelling of heat, water and carbon transfer inside and above the canopy as well as above bare soil. Several characteristic areas were carefully selected, which resulted in the installation of three Eddy Covariance (EC) fluxtowers; one over a camelina field, one over the vineyard and another over the main reforestation area, see Fig. 5-5 for their respective locations. In addition, a Large Aperture Scintillometer (LAS) was installed over a wheat-stubble field, whereas two reference meteorological stations were 
continuously storing relevant meteorological variables over the grassland super site and the camelina as well. An overview of the instrumentation used at the flux sites is shown in Table 52.

Table 5-2 Instrumentation overview of the flux sites

\begin{tabular}{lllll}
\hline System & EC-1 & EC-2 & EC-3 & LAS \\
\hline Landcover & Camelina & Vineyard & Forest nursery & Wheat \\
Canopy height & 0.50 & 2.00 & 1.00 & 0.15 \\
Scintillometer & & & & 2.18 \\
3-D Sonic & $1.30,2.38,5.20$ & 5.70 & 5.00 & \\
H2O & 2.38 & 5.70 & 5.00 & \\
CO2 & 2.38 & & 5.00 & \\
Rel. Hum. & $1.30,2.20,4.10$ & $2.50,3.50,5.00$ & $1.45,2.50,4.00$ & 2.18 \\
Air temperature & $1.30,2.20,4.10$ & $2.50,3.50,5.00$ & $1.45,2.50,4.00$ & 2.18 \\
Net radiometer & 1.00 & 4.00 & & \\
Surface temperature & & & 4.00 & \\
Soil heat flux & $-0.08,-0.13$ & -0.02 & -0.10 & -0.13 \\
Soil moisture & $-0.05,-0.10,-0.20$ & & -0.10 & \\
Soil temperature & $-0.01,-0.02,-0.04$, & -0.025 & & \\
& $-0.08,-0.16,-0.32$ & & & \\
Wind speed & & $2.50,3.50,5.00$ & $1.45,2.50,4.00$ & 1.85 \\
Air pressure & 1.80 & & & \\
\hline
\end{tabular}

At these so-called flux sites continuous monitoring took place of the main components that determine the surface energy budget:

$$
R_{N}=G+H+\lambda E
$$

where $R_{\mathrm{N}}$ represents net radiation, $G$ soil heat flux, $H$ sensible heat flux and $\lambda E$ latent heat flux, all in $\left[\mathrm{W} \cdot \mathrm{m}^{-2}\right]$. At the scintillometer site however, no net radiation and latent heat flux was measured, whereas at the forest nursery site, for net radiation, only the outgoing longwave component was monitored. An example is shown in the top panel of Fig. 5-6, where the four fluxes are plotted for a larger part of the campaign at the camelina site.

Profile measurements of meteorological variables (relative humidity, air temperature, wind speed, and at selected places wind direction) were carried out at all sites, for which the humidity and temperature sensors were inter-calibrated to ensure a sufficiently high accuracy. Wind speed at higher levels was clearly showing higher values than at lower levels, as may be expected. During daytime, when typically strongly unstable atmospheric conditions prevailed, the lower temperature 
sensors showed higher responses, whereas the opposite was noted for the humidity sensors. During the night, characterized by stable atmospheric conditions, the lower temperature sensors at most times recorded lower temperatures, but differences were significantly smaller than during daytime.

Soil moisture and soil temperature observations, needed for post-processing the soil heat fluxes (Van der Tol, 2012), were obtained at several depths as well. Typically largest daily fluctuations were noticed close to the surface, whereas a damping and delay effect is noticed further away from the surface.
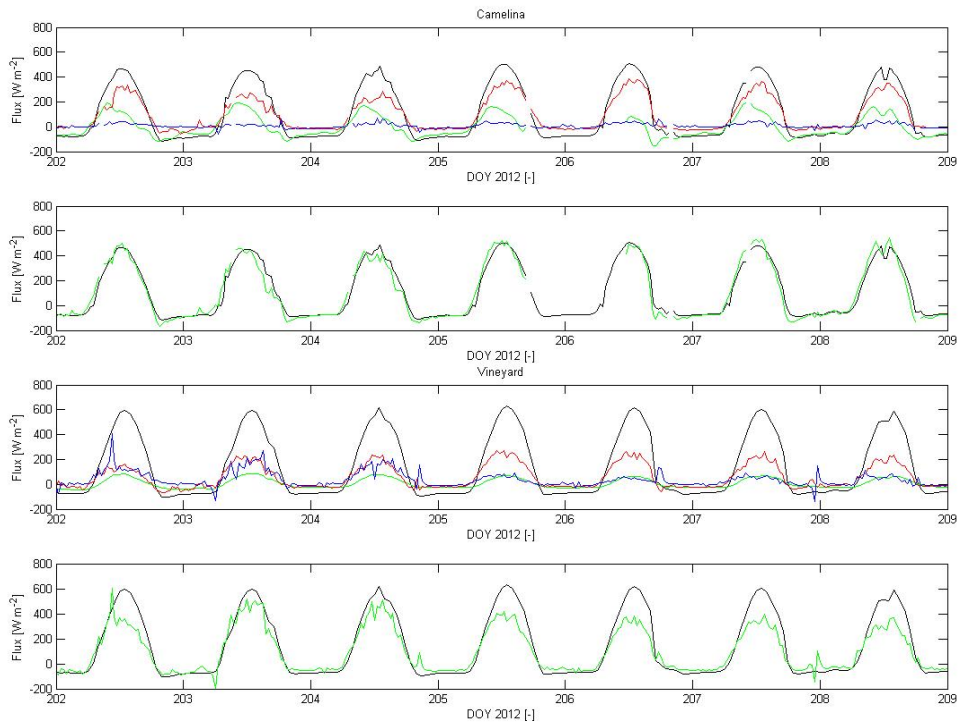

Figure 5-6 Surface energy budget components $\left(R_{\mathrm{N}}\right.$ in black, $G$ in green, $H$ in red and $\lambda E$ in blue) measured during the campaign period. In the second and fourth panel the sum of the components is represented in green

In the second panel of Fig. 5-6 the net radiation is plotted versus the sum of soil and turbulent fluxes, i.e. sensible and latent heat flux, to examine the well-known energy closure issue (Foken, 2008) over the camelina site. In this site, the closure is quite good throughout the campaign, which might be attributed to the very low values of one of the turbulent fluxes (the latent heat flux). However, at certain moments the sum of 
the soil and turbulent fluxes is slightly larger than the net radiation. This is attributed to the correction procedure necessary to convert soil heat flux from the measured depth to the surface value. Details on this procedure and a discussion of the obtained results are provided in Van der Tol et al. (2015). The closure over the vineyard site is considerably poorer. This is shown in the lower two panels of Fig. 5-6, where in the third panel from the top the four individual fluxes are shown and in the lowest panel the net radiation and the sum of the soil, sensible and latent heat flux.

It is noted that the measured net radiation, especially during daytime conditions, is consistently higher than the sum of the components. This is attributed to the fact that the field of view of the net radiometer was dominated by canopy, resulting in a relatively low albedo and thus high net radiation. Another striking feature is that starting on Day Of Year (DOY) 205 the latent heat fluxes drop from a daily maximum around 200 $\mathrm{W} \cdot \mathrm{m}^{-2}$ to a value as low as $50 \mathrm{~W} \cdot \mathrm{m}^{-2}$. Wind conditions play a major role here. The first period of the campaign was characterized by winds between 1.5 and $3.0 \mathrm{~m} \cdot \mathrm{s}^{-1}$ for $90 \%$ of the time, whereas the second period daytime wind speed was higher than $5 \mathrm{~m} \cdot \mathrm{s}^{-1}$ during $90 \%$ of the time. Moreover, prevailing wind direction in the first period was from the NorthWest, whereas in the second period this was from the SouthEast. To the North of the vineyard a well-irrigated grassland was located, whereas to the East a large wheat stubble field existed. The observed fluxes in the first period may be partly influenced by the (wet) grassland, whereas during the second period the fluxes may be partly influenced by the (dry) wheatstubble field. Detailed footprint analyses have to be carried out when a useful comparison between remote sensing-based and ground-based estimates of these fluxes has to be made (Timmermans et al., 2009).

\subsubsection{Data quality}

Remote sensing data

With respect to the space-borne data acquisitions both the CHRIS as well as the MSG data are available at level 1 , meaning they consist of radiometrically calibrated and geo- 
located at-aperture radiances. However, no additional ground validation has been carried out yet for the space-borne observations.

The airborne data acquisitions are available at level 2, meaning they consist of the radiometrically calibrated and geo-located hemispherical-directional reflectance factor and the kinematic temperature. As for the AHS system, the radiometric calibration of the Visible and Near InfraRed (VNIR) and Shortwave InfraRed (SWIR) detectors is achieved by illuminating the system with a uniform and known radiance source. The thermal infrared detectors, Middle InfraRed (MIR) and Thermal InfraRed (TIR), are calibrated by means of an extended black body source set at known temperature. Radiometric calibration of the detectors also provides SignalNoise-Ratio (SNR) values, used to check if the system performance keeps within specified values. Channels 44 and 46 had a very low Signal-To-Noise Ratio (SNR) due to detector malfunctioning, they should be used with reservations. Flight line AHS P11BD on July $26^{\text {th }}$ shows a recording anomaly, which resulted in a small data gap.

For the CASI system, the radiometric calibration is achieved by illuminating the system with an integrating sphere. As with the AHS sensor, the radiometric calibration also provides SNR values which are used to check if the system performance keeps within specified values. For the high altitude flights column number 1441 is not valid. All CASI images suffer from a slight spectral shift under flight conditions. A resampling of the input radiance from the estimated band centres to the reported band centres is performed before calibration. This procedure has a limited accuracy and might affect the radiometric accuracy in the absorption regions. The SNR for each band is reported in a statistics file, which should be checked before data analysis.

In-situ data

The majority of the REFLEX12 in-situ data has undergone standard post-processing up to level 2, meaning they are available in geo-physical units that are calibrated and geolocated. The atmospheric in-situ data and the radiometric and biophysical measurements are quality checked and the 
corresponding data are accompanied by metadata describing this.

With respect to the surface energy budget and micrometeorological measurements additional analysis was carried out on top of the standard post-processing and quality checking (Van der Tol et al., 2015). Air temperature and humidity sensors from the several sites were cross-calibrated versus each other which removed the bias and reduced relative errors induced by differences in sensor sensitivities by up to $90 \%$. Energy closure at the different sites was variable ranging from $94 \%$ at the homogeneous camelina site to $67 \%$ for the vineyard site. A detailed analysis of the turbulent fluxes and the energy balance is provided in Van der Tol et al. (2015).

\subsection{Preliminary results and recommendations}

A complete overview of the airborne and in-situ measurements of the REFLEX12 Campaign, designed to advance our understanding of land-atmosphere exchanges of water and heat in space and time, is presented in this chapter. Some preliminary analysis of the observational data is presented in some of the sections. The analysis included a near-surface atmospheric characterization and retrieval of a limited amount of biophysical variables. Envisaged advanced products include the following:

- Land Surface Temperature and emissivity from AHS data

- Emissivity from hyperspectral thermal in-situ observations

- Intercomparison/Cross-calibration of spectroscopy sensors

- Monitoring of turbulence observations over multiple sites

- Intercomparison of energy/water balance modeling schemes

- Thermal component derivation for multiple source energy flux estimates

- Estimation of evapotranspiration from airborne hyperspectral scanner data

- Photochemical reflectance index (PRI) as a water-stress index

- Soil moisture and surface emissivity over the heterogeneous Barrax site 
Full details of several of the products above, and additional analyses, are reported elsewhere. As such they represent the current state-of-the-art in the process understanding of landatmosphere interactions and at the same time provide a base for expanding our understanding of these interactions.

Therefore, all data and all described advanced products that are obtained during and after the campaign are available via the REFLEX12 Campaign ftp site (ftp.uv.es/reflex/reflex database). The database is freely available to the scientific community and access can be acquired through a username and password which can be obtained by sending an email to w.j.timmermans@utwente.nl, or by contacting the individual authors directly.

In the paper on which this chapter was based the authors acknowledge funding from the European Community's 7th Framework Programme (FP7/2008-2013) under EUFAR contract $n^{\circ}$ 227159, Cost Action ES0903-EUROSPEC and ESA Grant D/EOP/rp/2012/48. 


\title{
Chapter 6 Parameterization issues in modelling energy exchange across the air-land interface*
}

\begin{abstract}
Generally, remote sensing-based Land Surface Models (LSM) are driven by spatially heterogeneous surface inputs and spatially uniform inputs from the lower Atmospheric Boundary Layer (ABL). Since near-surface $A B L$ properties are far from uniform the inclusion of their spatial variability in remote sensing-based LSMs might be expected to improve the resulting turbulent flux estimates. In this contribution a large-eddy-simulation (LES) model is dynamically coupled to a remote sensing-based LSM, to study the magnitude of these atmospheric property variations and their corresponding feedback effects on turbulent flux estimates. Recently developed parameterizations, such as scale-dependent dynamic sub-grid-scale viscosity and diffusivity models, and adjusted spatial discretization, showed results that better followed theory using synthetic data sets. Evaluation of the coupled model output versus observational data from a large-scale field experiment over a very heterogeneous agricultural area showed improved estimates for sensible heat flux but a worsening for latent heat flux when compared to estimates from the stand-alone LSM. The dominant feedback effect, both over synthetic as well as over a natural heterogeneous surface, was found to be the horizontal wind speed. Attempts to account for this effect failed due to the complex interplay between buoyancy-driven and mechanically-driven variation in horizontal wind speed.
\end{abstract}

\footnotetext{
* Submitted to Water Resources Research
} 


\subsection{Introduction}

Since the late seventies and early eighties of the previous century the potential of thermal remote sensing for determining soil moisture status and crop water stress has been recognized (Idso et al., 1975; Jackson et al., 1983; Jackson et al., 1977; Price, 1982). The advent of satellite remote sensing offered the possibility of collecting data of the earth's surface at a temporal and spatial scale suitable for operational local and regional monitoring. Almost two decades later this has led to the development of numerous remote sensing-driven soil-vegetation-atmosphere-transfer (SVAT) schemes (Anderson et al., 1997; Bastiaanssen et al., 1998; Norman et al., 1995; Roerink et al., 2000; Su, 2002). Despite their varying complexity in one way or another they all utilize the provision of high resolution input data on surface state, i.e. Land Surface Temperature ( $L S T$ ) here, to monitor the turbulent latent and sensible heat fluxes, as adequately reviewed in Kalma et al. (2008).

Although several groups of approaches have since then evolved, these turbulent fluxes cannot be directly sensed because they depend on near-surface gradients in Atmospheric Boundary Layer (ABL) states (Bateni et al., 2013). Recently, atmospheric sounders, such as the Atmospheric Infrared Sounder (AIRS) on board NASA's Aqua platform provide ABL profile data, see for example Raju et al. (2015). However, both the temporal as well as the horizontal and vertical spatial resolutions are by far insufficient for operational local and regional monitoring of turbulent fluxes. Ideally, the $A B L$ states should be available at several meters above the surface at the same temporal and spatial resolution as the surface state.

Therefore, for a little more than a decade now, research has been carried out to investigate whether and how incorporation of lower $A B L$ variability in remote sensing data driven flux schemes could improve turbulent flux estimates (Albertson et al., 2001; Bertoldi et al., 2007; Bertoldi et al., 2008, 2013; Kustas \& Albertson, 2003; Timmermans et al., 2008). This is done by coupling a Large-Eddy Simulation (LES) model to a remote sensing-based Land Surface Model (LSM), where the coupling takes place in the lowest nodes of the LES model. Although recently turbulent flow models have been coupled to multi-layered LSMs (Dupont et al., 2011; Dupont \& Brunet, 
2008; Shao et al., 2013), naturally the coupling takes place in the nodes near the surface, or wall in Computational Fluid Dynamics (CFD) vocabulary. It is well-known that the region near the surface boundary condition is exactly where LES results need to be interpreted with care, even when applied over homogeneous surfaces (Abkar \& Porte-Agel, 2012; Bose \& Moin, 2014; Brasseur \& Wei, 2010; Podvin \& Fraigneau, 2014). When applying a coupled LES-LSM scheme for studying the lower ABL variability over heterogeneous terrain the nearsurface discretization and sub-grid scale parameterizations of momentum and scalar fluxes are of major importance (Bertoldi et al., 2008; Porte-Agel et al., 2000). The SGS parameterizations of viscosity (for momentum flux) and diffusivity (for scalar fluxes) generally employ some form of flux-concentration gradient relationship (Huang \& Margulis, 2009; Mason \& Callen, 1986; Porte-Agel, 2004; Schmidt \& Schumann, 1989). Therefore, not only the manner in which the viscosity and diffusivity are parameterized, but also the discretization of the near-surface vertical gradients of wind speed and scalar concentrations is rather critical. Although temporal averaging (typically remote sensing-based schemes require input of half-hourly averages of $A B L$ states) might reduce the relevance of this discretization and parameterizations, their effect on resulting atmospheric states and thus on flux estimates over heterogeneous natural surfaces is currently to a large extent unknown to the knowledge of the author. Moreover, it is unknown whether incorporation of lower $A B L$ states in a remote sensing-driven LSM in general would improve turbulent flux estimates over a natural surface, as also stated by Bertoldi et al. (2008) who noted only a marginal improvement when applied over the Southern Great Plains, USA.

In this contribution we first intend to illustrate the near-surface performance of recent discretizations and parameterizations in the coupled LES-LSM model and then to quantify the consequences of the relevant feedback effects. The main objective however, is to examine whether, and if yes, to what extent, incorporation of lower ABL from a coupled LES-LSM model improves local to regional turbulent flux estimates over a natural heterogeneous surface as made with a typical remote sensing-based LSM where coupling is not possible. 
Thereto, section 2 of this chapter describes the model characteristics and recent parameterization and discretization implementations, followed by an illustration of the effect these implementations over synthetic homogeneous surfaces in section 3. Section 4 deals with the effect of step changes in surface states and surface conditions typical for remote sensing-based SVAT models on the atmospheric states and the potential feedback effects. In section 5 these effects are analysed over a natural surface using data from a large-scale field campaign whereas concluding remarks are provided in section 6.

\subsection{Model characteristics}

\subsubsection{Governing equations}

Turbulent flow for an incompressible fluid with viscosity, $v$ and velocity $u$ is generally described by the continuity and the Navier-Stokes equations. Using Einstein's summation notation they are given by:

$$
\begin{aligned}
& \frac{\partial \mathrm{u}_{j}}{\partial \mathrm{x}_{j}}=0 \\
& \text { and } \\
& \frac{\partial \mathrm{u}_{i}}{\partial t}+\mathrm{u}_{j} \frac{\partial \mathrm{u}_{i}}{\partial \mathrm{x}_{j}}=-g \delta_{i 3}-\frac{1}{\rho_{a}} \frac{\partial \mathrm{p}}{\partial \mathrm{x}_{i}}+v \frac{\partial^{2} \mathrm{u}_{i}}{\partial \mathrm{x}_{j}^{2}}
\end{aligned}
$$

respectively. Here, time is represented by $t$, the acceleration due to gravity is given by $g, \delta_{13}$ represents the Kronecker delta and $\rho_{a}$ is the density of the fluid (here: air), whereas $p$ represents pressure. The transport of any scalar in such a fluid is represented by:

$$
\frac{\partial \mathrm{c}}{\partial t}+\mathrm{u}_{j} \frac{\partial \mathrm{c}}{\partial \mathrm{x}_{j}}=v_{c} \frac{\partial^{2} \mathrm{c}}{\partial \mathrm{x}_{j}^{2}}
$$

where $c$ represents the scalar concentration and $v_{c}$ is the molecular diffusivity of the scalar in the fluid (Stull, 1988). Solving these turbulent transport equations for the $A B L$ at all scales of motion is currently impossible. Large-eddy-simulation (LES) approaches deal with this limitation by solving the equations for all scales larger than a certain threshold, the model grid size, $\Delta[\mathrm{m}]$. The contribution of scales smaller than the model grid size is then parameterized. For atmospheric boundary layer $(A B L)$ modelling typically this model grid size is 
on the order of $10 \mathrm{~m}$. The separation of resolved and sub-grid scales (SGS) in LES is achieved by filtering equations (6.1-6.3), where the filter width generally is equal to $\Delta$. Under the Boussinesq assumption, using temperature variations rather than explicitly simulating density variations, and neglecting Coriolis effects, this results in:

$$
\begin{aligned}
& \frac{\partial \widetilde{u}_{i}}{\partial x_{i}}=0 \\
& \frac{\partial \widetilde{u}_{i}}{\partial t}+\frac{\partial \widetilde{u}_{i} \widetilde{u}_{j}}{\partial x_{j}}=-g \delta_{i 3} \frac{\widetilde{\theta}_{v}-\left\langle\widetilde{\theta}_{v}\right\rangle}{\left\langle\widetilde{\theta}_{v}\right\rangle}-\frac{1}{\rho_{a}} \cdot \frac{\partial \tilde{p}}{\partial x_{i}}-\frac{\partial \tau_{i j}}{\partial x_{j}} \\
& \frac{\partial \widetilde{\theta}}{\partial t}+\frac{\partial \widetilde{u}_{j} \tilde{\theta}}{\partial x_{j}}=-\frac{\partial \tau_{i \theta}}{\partial x_{i}}+\widetilde{T_{\theta}}
\end{aligned}
$$

where the tilde indicates a parameter is spatially filtered and the brackets indicate a spatial averaging in the horizontal plane; see for example Stoll and Porte-Agel (2006) and Huang et al. (2008). The scalar quantity in space and time, Eq. (6.6), is here represented by potential temperature, $\theta[\mathrm{K}]$, although this may be replaced by any non-reactive scalar, such as specific humidity, $q[\mathrm{~kg}]$, or carbon, $[\mu \mathrm{mol}]$. The last term on the right hand side of Eq. (6.6), $T_{\theta}$, represents a source/sink term of the scalar under consideration. Note that the density differences are represented by potential temperature fluctuations where positive temperature fluctuations tend to induce an upward (buoyant) acceleration. The effects of the unresolved scales appear in the sub-grid scale stress, $\tau_{i j}$, Eq. (6.5), and in the sub-grid scale temperature flux, $\tau_{i \theta}$, Eq. (6.6). They are defined (Huang et al., 2008; Stoll \& Porte-Agel, 2006) as:

$$
\begin{aligned}
& \tau_{i j}=\widetilde{u_{\imath} u_{J}}-\widetilde{u_{\imath}} \widetilde{u_{J}} \\
& \tau_{i \theta}=\widetilde{u_{l} \theta}-\widetilde{u_{l}} \tilde{\theta}
\end{aligned}
$$

Both need to be parameterized as a function of the resolved velocity and scalar fields, using an appropriate SGS model.

\subsubsection{Sub-Grid Scale models}

The sub-grid scale stress (Eq. 6.7) is parameterized with an eddy viscosity model (Albertson \& Parlange, 1999b; Bou-Zeid et al., 2004; Kumar et al., 2006) as:

$$
\tau_{i j}=-2 \cdot v_{T} \cdot S_{i j}
$$

where $S_{\mathrm{ij}}$ is the resolved, or large-scale, strain rate tensor:

$S_{i j}=0.5 \cdot\left(\frac{\partial \widetilde{u}_{i}}{\partial x_{j}}+\frac{\partial \widetilde{u}_{j}}{\partial x_{i}}\right)$ 
and $\imath_{\uparrow}$ the turbulent eddy viscosity. The sub-grid scale scalar, here temperature, flux (Eq. 6.8) is parameterized with an eddy diffusivity model following:

$\tau_{i \theta}=-D_{T} \cdot \frac{\partial \widetilde{\theta}}{\partial x_{i}}$

where $D_{\mathrm{T}}$ is the eddy diffusivity and given as $\nu_{\top} \cdot \operatorname{Pr}^{-1}$ SGS where $P r_{\text {SGS }}$ is the SGS Prandtl number (Albertson \& Parlange, 1999a; Kumar et al., 2006; Stoll \& Porte-Agel, 2006). In case the scalar under consideration is moisture the SGS Prandtl number is replaced by the SGS Schmidt number $S c_{S G S}$ (Vercauteren et al., 2008).

The classical approach to determine $\imath_{\uparrow}$ is given by Smagorinsky (1963), following:

$v_{T}=\left(c_{S} \cdot \Delta\right)^{2} \cdot \sqrt{2 \cdot S_{i j} \cdot S_{i j}}$

where $c_{S}$ is the so-called Smagorinsky constant. Under idealized and homogeneous conditions isotropic assumptions can be made to specify universal and constant values for both $C_{\mathrm{S}}$ and $\operatorname{Pr}_{\mathrm{SGS}}$ a priori. However, under inhomogeneous conditions, such as in wall-bounded flows like the $A B L$, other values for $c_{S}, P r_{S G S}$ and $S c_{S G S}$ need to be assigned. Numerous work has been carried out to ensure the proper asymptotic behaviour of the SGS shear stresses and the SGS scalar fluxes near the wall. This is done by either adjusting the coefficients (Deardorff, 1970; Mason \& Callen, 1986), basically $c_{S}$, and thus $\nu_{T}$, should decrease towards the wall and $P r_{\text {SGS }}$ and $S C_{S G S}$ should increase towards the wall with the rate of change depending on both flow characteristics and wall characteristics, or by applying a correction factor on the filter width as originally proposed by van Driest (1956).

However, when assuming scale-invariance using a second filter with size $2 \Delta$ in Eq. (6.12) should give a similar value for $\nu_{\uparrow}$. This is what was done by Germano et al. (1991), and refined by Lilly (1992), such that the eddy viscosity $\nu_{\uparrow}$ could be determined dynamically. In a similar fashion the eddy diffusivity, $D_{\mathrm{T}}$, and thus $\operatorname{Pr}_{\mathrm{SGS}}$ or $S c_{\mathrm{SGS}}$ can be determined dynamically as well. This concept is further developed by PorteAgel et al. (2000) and Porte-Agel (2004) who used a third filter with size $4 . \Delta$ to determine dynamic scale-dependent $C_{S}, \operatorname{Pr}_{\mathrm{SGS}}$ and $S c_{\text {SGS }}$ coefficients. 


\subsubsection{Bottom boundary conditions}

The grid is staggered, meaning here that the scalar quantities, pressure and horizontal velocity variables are stored at the cell centres and the vertical velocity variable at the cell faces. As such, the vertical velocity component, $w$, is stored at an off-set of half the vertical grid size $\Delta_{z}$. As a result the lowest level for $w$ starts at the wall, or surface, whereas the horizontal velocity components start at $0.5 \Delta \mathrm{z}$. Therefore the boundary condition for the vertical velocity is simply given by $w=0$ at $z=0$. Since the horizontal velocities start at $0.5 \Delta_{z}$ the no-slip boundary condition cannot be used, which is common in LES modelling as the motion is not completely resolved at the surface. Therefore the surface shear stress, $\tau_{\mathrm{ijo}}$, and surface heat, or moisture, flux $\tau_{\theta 00}$, are calculated from Monin-Obukhov Similarity Theory (MOST) originally developed by Monin and Obukhov (1954) and more recently summarized by Foken (2006). Despite that MOST is strictly only valid for homogeneous time averaged quantities, it is widely used in LES modelling of the ABL (Albertson \& Parlange, 1999a, b; Huang \& Margulis, 2009; Mason \& Callen, 1986; Moeng, 1984; Porte-Agel, 2004; Schmidt \& Schumann, 1989). The instantaneous surface shear stress and surface heat fluxes are thus given by:

$\tau_{i 3,0}=-u_{*}^{2} \cdot\left(\frac{\widetilde{u}_{i}}{\widetilde{u}_{r}}\right)$

and

$\tau_{3 \theta, 0}=\left(\frac{\theta_{0}-\widetilde{\theta}_{1}}{R_{a H}}\right)$

where $\tilde{u}_{r}=\left(\tilde{u}_{1}^{2}+\tilde{u}_{2}^{2}\right)^{0.5}$ is the local instantaneous horizontal filtered velocity magnitude at the first level, $\tilde{u}_{1}$ and $\tilde{u}_{2}$ are the streamwise $(i=1)$ and spanwise $(i=2)$ local instantaneous filtered velocity components, $\theta_{0}$ is the local instantaneous aerodynamic surface potential temperature, or within-canopy air temperature, and $\tilde{\theta}_{1}$ the local filtered instantaneous potential temperature at the first level, i.e. $0.5 \Delta_{\mathrm{z}} . R_{\mathrm{aH}}$ is the aerodynamic resistance to heat transport (e.g. Norman et al. (2000)) between the surface and level $0.5 \Delta_{z}$, given by:

$r_{a H}=\frac{\left[\ln \left(\frac{0.5 \Delta_{Z}-d_{0}}{z_{0 M}}\right)-\psi_{M}\right] \cdot\left[\ln \left(\frac{0.5 \Delta_{z}-d_{0}}{z_{0 H}}\right)-\psi_{H}\right]}{\kappa^{2} \cdot u}$

and $u_{*}$ is the so-called friction velocity, given by: 
$u_{*}=\frac{\widetilde{u}_{r} \cdot k}{\ln \left(\frac{0.5 \Delta_{Z}-d_{0}}{z_{0 M}}\right)-\psi_{M}}$

where $k$ is the Von Karman constant $[-], d_{0}$ the displacement height $[\mathrm{m}], z_{\mathrm{OM}}[\mathrm{m}]$ and $z_{\mathrm{OH}}[\mathrm{m}]$ the roughness length for momentum and heat respectively. Symbols $\psi_{\mathrm{M}}$ and $\psi_{\mathrm{H}}$ are the integrated (from the surface to $0.5 \Delta_{z}$ ) MOST functions (Brutsaert, 1982) which represent the dimensionless wind speed and temperature gradients defined as:

$\frac{\partial \widetilde{u}_{r}}{\partial x_{3}} \cdot \frac{\kappa \cdot x_{3}}{u_{*}}=\varphi_{M}\left(\frac{X_{3}}{L}\right)$

and

$\frac{\partial \widetilde{\theta}}{\partial x_{3}} \cdot \frac{\kappa \cdot x_{3}}{\theta_{*}}=\varphi_{H}\left(\frac{X_{3}}{L}\right)$

which are (supposedly) universal functions of $x_{3} / L$, or $z / L$, where $L[\mathrm{~m}]$ is the Monin-Obukhov length:

$L=\frac{-\widetilde{u}^{3} \cdot \widetilde{\theta}}{\kappa \cdot g \cdot \tau_{3 \theta}}$

where $g\left[\mathrm{~m} \cdot \mathrm{s}^{-2}\right]$ is the acceleration due to gravity and $\theta_{*}$ is a temperature scale equal to $-\tau_{3 \theta} / u_{*}$. For the integrated MOST functions we used for stable conditions $(L>0)$ the expressions given by Kader and Yaglom (1990) and for unstable conditions $(L<0)$ the expressions given by Cheng and Brutsaert (2005).

In Eq. (6.14-6.19) the surface sensible heat flux is used to illustrate the bottom boundary condition for the transport of the scalar (potential) temperature. The same holds true for the transport of the scalar moisture, where $\theta, \theta_{*}, r_{\mathrm{aH}}$, and $\varphi_{\mathrm{H}}$ and $\psi_{\mathrm{H}}$ should be replaced by $q, q_{*}, r_{\mathrm{a} V}$, and $\varphi_{\vee}$ and $\psi_{\vee}$, which is in principle valid for any passive scalar.

In the current coupled model version the bottom heat flux boundary conditions are provided by the series version of the Two-Source Energy Balance model (TSEB) as described by Norman et al. (1995). The temperature flux is given by:

$H_{T S E B}=H_{C}+H_{S}=\rho_{a} \cdot C_{P} \cdot\left[\frac{\left(\theta_{C}-\theta_{0}\right)}{r_{x}}+\frac{\left(\theta_{S}-\theta_{0}\right)}{r_{s}}\right]=\rho_{a} \cdot C_{P} \cdot\left[\frac{\left(\theta_{0}-\theta_{a}\right)}{r_{a H}}\right]=\rho_{a} \cdot C_{P} \cdot \tau_{3 \theta, 0}$

where $H\left[\mathrm{~W} \cdot \mathrm{m}^{-2}\right]$ is surface sensible heat flux, $\rho_{\mathrm{a}}$ is the density of air, $c_{p}$ the heat capacity of air, $r$ is resistance $\left[\mathrm{s} \cdot \mathrm{m}^{-1}\right]$ and subscripts " $\mathrm{C}$ " and " $\mathrm{S}$ " stand for the canopy and soil components whereas subscript " $x$ " represents the total canopy of leaves. For details on the determination of these parameters one is referred to Appendix A of Norman et al. (1995). The air 
potential temperature, $\theta_{\mathrm{a}}$, needed in Eq. (6.20) is taken equal to $\tilde{\theta}_{1}$, the local filtered instantaneous potential temperature at the first level, i.e. $0.5 \Delta_{z}$, of the LES modelling domain.

The moisture flux is, after some intermediate steps, provided by:

$\lambda E_{T S E B}=R_{N}-G_{S}-H_{T S E B}=\rho_{a} \cdot \lambda \cdot \tau_{3 q, 0}$

where $\lambda E\left[\mathrm{~W} \cdot \mathrm{m}^{-2}\right]$ is surface latent heat flux, $R_{\mathrm{N}}$ the net radiation at the earth's surface, $G$ the surface soil heat flux and $\lambda$ the latent heat of vaporization.

For the determination of $r_{\mathrm{aH}}$, Eq. (6.15), the local instantaneous horizontal filtered velocity magnitude, $\tilde{u}_{\mathrm{r}}$, at the first level of the LES domain is used in combination with Eqs. (6.16-6.19). As such the bottom boundary condition for shear stress, Eq. (6.13), is also provided by the TSEB model in combination with the streamwise and spanwise local instantaneous filtered velocity components.

\subsubsection{Bottom spatial discretization}

Due to the fact that the motion very near the wall (i.e. below $0.5 \Delta_{z}$ ) is not resolved in LES modelling, the finite differencing scheme, which is used in the vertical, cannot be applied in a straightforward way. Therefore the derivatives in the surface normal direction $(i=3)$ need to be treated in a special manner. Here a similar reasoning is followed as in the Appendix of Porte-Agel et al. (2000) who proposed to use a correction factor for the lowest node vertical derivative of the velocity components in the streamwise and spanwise directions based on the logarithmic wind profile, from here onwards called the "log3-approach".

Using the MOST functions (Eq. 6.17 and 6.18) the lowest node vertical $(i=3)$ derivatives can be taken directly from the TSEB model. This is not only done for the velocity components, as in Porte-Agel et al. (2000) for neutral conditions, but also for the scalars which results in:

$\frac{\partial \widetilde{u}_{i}}{\partial x_{3}}=\frac{\varphi_{M} \cdot u_{*}}{\kappa \cdot x_{3}} \cdot \frac{\widetilde{u}_{i}}{\widetilde{u}_{r}}$

and for the scalars in: 
$\frac{\partial \widetilde{\theta}}{\partial x_{3}}=\frac{\varphi_{H} \cdot \theta_{*}}{\kappa \cdot x_{3}}$

where $\theta$ and $\mathrm{H}$ should be replaced by $q$ and $\mathrm{V}$ respectively when dealing with moisture. This approach will from here onwards be referred to as the "MO-approach".

\subsection{Model performance over synthetic homogeneous surfaces}

The coupled model used in this contribution is based on the model originally described in Albertson et al. (2001). Since then the code has undergone several modifications which we will shortly summarize here.

First and foremost these are the implementations as mentioned in sections 6.2.2, 6.2.3 and 6.2.4, comprising the implementation of SGS models that dynamically determine scale-dependent $c_{S}, P r_{S G S}$ and $S c_{S G S}$ coefficients, the direct use of TSEB-derived bottom boundary conditions with respect to both momentum and scalar fluxes, and the discretization of the lowest node vertical derivatives for horizontal wind speed and scalar concentration respectively. These are implemented as turn-on/turn-off options in the current code.

Mathematically, all Fourier computations have been redesigned such that use now is made of the FFTW3 package, which resulted in a speed-up factor of about 3. In addition this removed the original criterion of the code making use of a square horizontal domain size equal to powers of 2 (e.g. $N x=$ $N y=32,64,128$ or 256 nodes); now any rectangular sized domain can be used. Furthermore, the determination of the root of the 5-th degree polynomial using the Newton-Raphson method, necessary in determining the scale-dependence in the dynamic SGS models (Porte-Agel, 2004; Porte-Agel et al., 2000), has been re-designed such that when the NewtonRaphson method fails, the method of Brent is used, making the code another factor 2 faster. Optionally two modern real rootfinders are implemented as well. Last but not least, the code has been parallelized using the OpenMPI software, which naturally resulted in a considerable speed-up factor, naturally showing a better scaling at larger sized domains.

Running the code over very heterogeneous surfaces at times created numeric instability. This resulted from spikes in 
momentum and scalar fluxes originating at consecutive changes in surface states which then penetrated into the inversion layer and reflected at the top of the domain. Therefore a damping layer for both momentum and scalars with variable depth was implemented at the top of the domain following Durran and Klemp (1983).

To investigate the effect of the conceptual changes, described in section 6.2, the code was run over homogeneous surfaces using synthetic input data, which are discussed in this paragraph. However, the purpose of this section is not to carry out a detailed inter-comparison in the line of Nieuwstadt et al. (1993) and Andren et al. (1994) or Beare et al. (2006) and Holtslag et al. (2013) who performed detailed analyses of LES models for the neutral to convective or stable boundary layers respectively. Since we are basically interested in near-surface gradients of the $A B L$ state, the idea here is merely to illustrate the consequences of near-surface performance of recent discretization and parameterization modifications in the coupled LES-LSM model.

\subsubsection{Simulation scenarios}

Basically four different scenarios are run, of which the settings are listed in Table 6-1.

Table 6-1 Key settings of the homogeneous synthetic scenarios

\begin{tabular}{lllll}
\hline Scenario & $\mathrm{U} 1$ & $\mathrm{U} 2$ & $\mathrm{~S} 1$ & $\mathrm{~S} 2$ \\
\hline & & & & \\
Runtime $[\mathrm{hr}]$ & 2.0 & 2.0 & 6.0 & 6.0 \\
Averaging time $[\mathrm{hr}]$ & 0.5 & 0.5 & 0.5 & 0.5 \\
$\Delta x[\mathrm{~m}]$ & 50 & 50 & 25 & 25 \\
$\Delta z[\mathrm{~m}]$ & 25 & 12.5 & 6.25 & 3.125 \\
$L_{\mathrm{z}}[\mathrm{m}]$ & 750 & 750 & 375 & 375 \\
$z_{\mathrm{d}}[\mathrm{m}]$ & 600 & 600 & 300 & 300 \\
$r_{\mathrm{t}}[\mathrm{s}]$ & 60 & 60 & 60 & 60 \\
$z_{\text {inv }}[\mathrm{m}]$ & 500 & 500 & 275 & 275 \\
$R_{\mathrm{S}}\left[\mathrm{W} \cdot \mathrm{m}^{-2}\right]$ & 700 & 700 & 100 & 100 \\
$z_{0 \mathrm{M}}[\mathrm{m}]$ & 0.10 & 0.10 & 0.10 & 0.10 \\
$L S T[\mathrm{~K}]$ & 312.0 & 312.0 & 290.5 & 290.5 \\
$\theta_{\text {mix }}[\mathrm{K}]$ & 297.5 & 297.5 & 297.5 & 297.5 \\
$q_{\text {mix }}\left[\mathrm{g} \cdot \mathrm{kg}^{-1}\right]$ & 4.0 & 4.0 & 4.0 & 4.0 \\
$u_{*}\left[\mathrm{~m} \cdot \mathrm{s}^{-1}\right]$ & 0.20 & 0.20 & 0.50 & 0.50 \\
\hline & & & & \\
$<H_{\mathrm{srf}}>\left[\mathrm{W} \cdot \mathrm{m}^{-2}\right]$ & 145.8 & 151.3 & -25.1 & -23.7 \\
$<\lambda E_{\mathrm{srf}}>\left[\mathrm{W} \cdot \mathrm{m}^{-2}\right]$ & 133.0 & 128.9 & 10.4 & 8.6 \\
$<u_{\text {srr }}>\left[\mathrm{m} \cdot \mathrm{s}^{-1}\right]$ & 2.6 & 2.4 & 4.0 & 2.8 \\
$z_{1} / L[-]$ & -0.8189 & -0.3720 & 0.0078 & 0.0004 \\
\hline
\end{tabular}


In Table 6-1 $\Delta x$ and $\Delta z$ represent the horizontal and vertical grid sizes $[\mathrm{m}], L_{z}$ is the vertical domain size $[\mathrm{m}], z_{\mathrm{d}}$ the depth of the damping layer $[\mathrm{m}], r_{\mathrm{t}}$ the relaxation time $[\mathrm{s}], z_{\text {inv }}$ the height of the inversion layer $[\mathrm{m}], R_{\mathrm{S}}$ the incoming shortwave radiation $\left[\mathrm{W} \cdot \mathrm{m}^{-2}\right]$ and $\theta_{\text {mix }}$ and $q_{\text {mix }}$ the initial settings of the potential temperature and specific humidity of the mixed layer. The simulations were performed for a homogeneous surface simulating unstable (scenarios U1 and U2) and (mildly) stable conditions (scenarios S1 and S2) at different vertical and horizontal resolutions. All four scenarios are run using constant $\left(c_{s}=0.20, \operatorname{Pr}=S c=0.80\right.$ ) and dynamic SGS models (both for momentum and scalars) and using the log3-approach as well as the MO-approach for the lowest node vertical derivatives. From here on they will be indicated as "-C-", "-D-" and "log3" and "MO" respectively. It should be mentioned that running scenarios S1 and S2 was not possible using the constant SGS models. Using the coefficient settings as mentioned above no turbulence was generated at all. Lowering the $c_{s}$ coefficient in order to generate turbulence resulted in numerical instability. As such, a total of 14 different simulations have been run.

\subsubsection{Simulation results}

The results of the simulations for the lower $A B L$ profiles of the mean vertical derivatives of main wind speed, temperature and specific humidity, as well as mean turbulent viscosity and mean turbulent Prandtl and Schmidt numbers are shown in Fig. 6-1 for unstable conditions and in Fig. 6-2 for stable conditions. For the purpose of clearness only results for scenarios U2 and S1 are shown, but results for the other scenarios showed rather similar behaviour. 

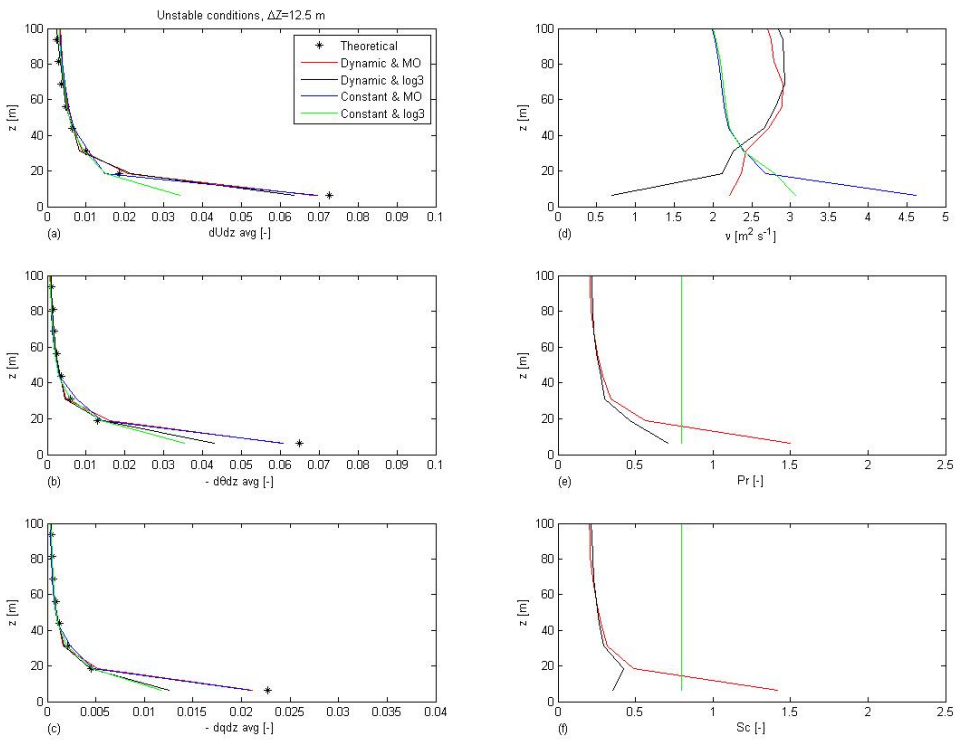

Figure 6-1 Half-hourly mean profiles of vertical derivatives of windspeed (a), potential temperature (b) and specific humidity (c), mean profiles of turbulent viscosity (d) and profiles of the turbulent Prandtl (e) and Schmidt (f) number for scenario U2

In the left panels of Fig. 6-1 the black diamonds represent the theoretical value for the several gradients following MOST. With respect to horizontal windspeed the "U2-C-log3" scenario shows the largest discrepancy with theory close to the surface, where the "MO" scenarios show closest resemblance with theory. From node 3 upwards no large discrepancies between the scenarios are noted. For the profiles of the vertical derivatives for both scalars a similar trend is seen. Though not exactly following theory, the "MO" scenarios show the closest resemblance with MOST, with the "U2-C-log3" scenario showing worst performance.

In Fig. 6-1 (d) the profiles of the mean simulated turbulent viscosity from the four U2 scenarios is shown. The most striking difference between the scenarios is that the "-C-" scenarios show a gradual increase of $\nu_{\uparrow}$ towards the surface, whereas the "-D-" scenarios show a gradual decrease towards the surface. Lowest node values for $\nu_{\uparrow}$ range from $0.7\left[\mathrm{~m}^{2} \cdot \mathrm{s}^{-1}\right]$ for the "U2-D-log3" scenario towards $4.7\left[\mathrm{~m}^{2} \cdot \mathrm{s}^{-1}\right]$ for the "U2- 
C-MO" scenario. From node 2 to 3 upwards hardly any discrepancy is seen anymore between the two "U2-C-" scenarios and between the two "U2-D-" scenarios that show values of around $2.0\left[\mathrm{~m}^{2} \cdot \mathrm{s}^{-1}\right]$ and $2.7\left[\mathrm{~m}^{2} \cdot \mathrm{s}^{-1}\right]$ respectively at some $100[\mathrm{~m}]$ above the surface.

Concerning the profiles of the mean turbulent $\mathrm{Pr}$ and $\mathrm{Sc}$ numbers, naturally the "-C-" scenarios show constant values of 0.80 plotted on top of each other. The "-D-" scenarios show a gradual increase towards the surface from a value of 0.25 [-] at some $100[\mathrm{~m}]$ above the surface towards a value of around 1.5 for both $\mathrm{Pr}$ and Sc for the "U2-D-MO" scenario and just above 0.5 for $P r$ and just below 0.5 for Sc for the "U2-D-log3" scenario. Remarkable is the decrease in Sc for the "U2-D-log3" scenario at the lowest node.
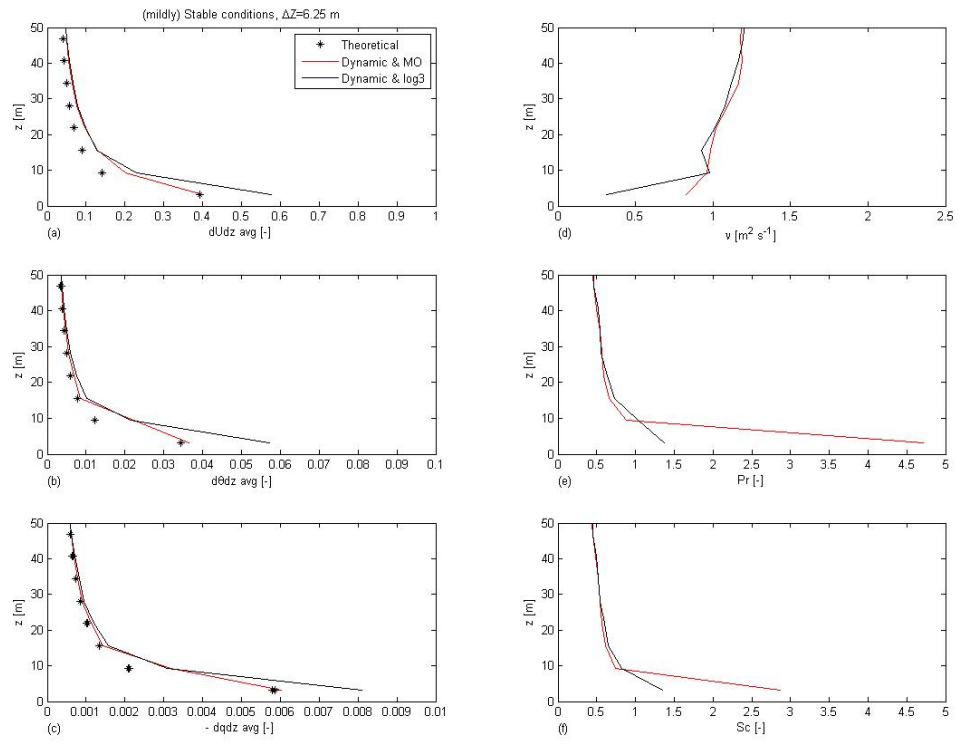

Figure 6-2 As Figure 6-1 but for scenario S1

For the stable simulations (no "-C-" scenarios) the "MO" scenario shows a closer resemblance with MOST for both the horizontal wind speed as well as for the scalar concentrations. Despite the rather large differences between the two at the lowest node, there are hardly any differences noted from node 2 upwards. 
With respect to the profile of mean turbulent viscosity both scenarios show a decrease towards the surface where, similar to the unstable simulations the "log3" scenario shows lower values at the lowest node than the "MO" scenario. In both cases they are a factor 2 to 3 lower than for the unstable simulations. Also here there are hardly any differences between the "MO" and "log3" scenarios from node 2 upwards.

The same holds true for the profiles of the mean $\mathrm{Pr}$ and $\mathrm{Sc}$ numbers: hardly any difference between the "MO" and "log3" scenarios from node 2 upwards. Both again gradually increase towards the surface. At the lowest node however, a sharp increase in both $\mathrm{Pr}$ and $\mathrm{Sc}$ is noted for the "S1-D-MO" scenario towards values around 4.7 and 2.8 respectively. For the "S1-Dlog3" scenario at node 1 hardly any difference is noted between $\mathrm{Pr}$ and $\mathrm{Sc}$ at values around 1.3. A bit further away from the surface slightly higher values for $\mathrm{Pr}$ are noted than for $S c$ in this scenario.

\subsubsection{Discussion of scenarios}

With respect to the profiles of mean vertical derivatives clearly the "MO" scenarios show a closer resemblance with MOST than the "log3" scenarios, where the "-D-" scenarios outperform the "-C-" scenarios. This holds true for the horizontal wind speed as well as for both scalars. The "MO" scenarios performing better here than the "log3" scenarios may be less obvious than it seems at first instance. Naturally under the "MO" scenarios the lowest node vertical derivative is forced to follow MOST at each individual time-step at each individual grid-point. Under highly non-linear circumstances this does not necessarily imply a perfect match with theory after temporal and spatial averaging, as is also illustrated for the unstable simulations in Fig. 6-1. In fact, such forcing might dampen velocities and as such cause a deviation from MOST. However, obviously, over homogeneous surfaces the "MO" scenarios clearly yield better performance with respect to the profiles of mean vertical derivatives for horizontal wind speed and for scalars.

Despite the fact that the "-C-" scenarios utilize a type of Van Driest damping (van Driest, 1956) near the surface they do not show a decrease in $\imath_{\uparrow}$ when approaching the surface. Without going into unnecessary deep theory on turbulent near-wall 
channel flow it is clear that, since $v_{T}$ determines the SGS stresses, Eq. (6.9), it should show a gradual decrease towards the surface, reaching a value of 0 at a solid boundary (Germano et al., 1991; Piomelli et al., 1988). Although the flow is not resolved at the (solid) boundary, the lower values for the "log3" approach at node 1 might indicate a slightly better performance near the surface with respect to mean $v_{\text {个. }}$.

With respect to the profiles of $\operatorname{Pr}$ and Sc the "MO" and "log3" scenarios do not really differ from node 3 upwards. Under unstable conditions they show a gradual increase from values around 0.25 to 0.3 away from the surface towards values around 0.5 when approaching the lowest node and under stable conditions a gradual increase from 0.5 to wards values around 0.8 are noted, which both resemble values reported in literature (Vercauteren et al., 2008). The only notable difference between the two scenarios is in the lowest node. The "MO" approach returns values around 1.5 for both $\mathrm{Pr}$ and Sc for unstable conditions and values around 3.0 for Sc and 4.5 for $\mathrm{Pr}$ for stable conditions. The "log3" approach returns values around 0.8 for $\mathrm{Pr}$ and 0.4 for Sc under unstable conditions and values of 1.4 for both $\mathrm{Pr}$ and Sc under stable conditions. Although it is difficult to judge in a rather limited number of simulations, the values of the "MO" approach at node 1 seem rather high. However, rather high Prandtl numbers are also reported by Stoll and Porte-Agel (2008) close to the surface, easily reaching values higher than 3.0. Another issue is the sudden decrease in $S c$ at node 1 for the unstable simulations, which is not logical and which we cannot explain at this point.

Overall the "-D-" scenarios well outperform the "-C-" scenarios under all conditions and the "MO" scenarios clearly outperform the "log3" scenarios for the profiles of the vertical derivatives for both the horizontal wind speed as well as for both scalars. The difference in performance between the "MO" and "log3" scenarios with respect to the profiles of $\iota_{\uparrow}, \operatorname{Pr}$ and $S c$ is less strong, with a slight preference for "log3" in the case of $v_{\uparrow}$ and a slight preference for "MO" in the case of $\operatorname{Pr}$ and Sc. Therefore in the remainder of this chapter we will mainly utilize the dynamic SGS model parameterizations and the "MO" approach for the lowest node vertical derivatives and show typical deviations with other parameterizations when appropriate. 


\subsection{Model performance over synthetic step- changes}

\subsubsection{Simulation scenarios}

Typical input in remote sensing-driven SVAT models comprises spatially distributed $L S T$, whether or not accompanied by spatially distributed roughness length (for momentum and heat) and fractional vegetation cover. In order to understand the effect of such typical step-changes on the lower $A B L$ state and subsequently its effect on the turbulent fluxes the coupled model described in section III was used. Several scenarios have been run over step changes in $L S T, z_{0 M}, F C V$ and $z_{0 H}$ at different resolution and patch sizes, see Fig. 6-3 for an explanatory sketch.

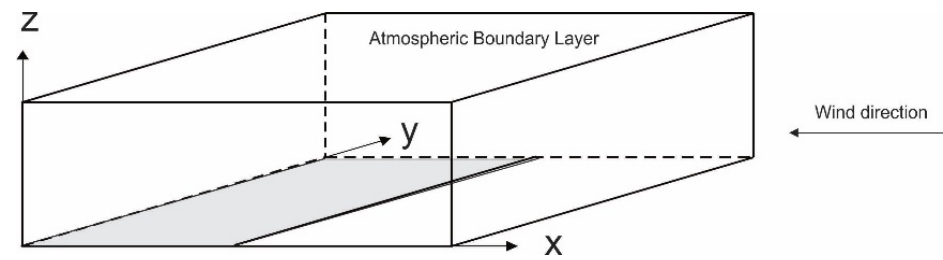

Figure 6-3 Example step-change setup

Main wind direction is from the right to the left. However, please note that due to the cyclic horizontal boundary conditions the patches show a continuous alternating pattern. A summary of the simulation settings and values of the step changes is provided in Table 6-2. In addition a row is included indicating what landuse types the simulated step changes typically would or could represent.

Table 6-2 Patch settings for step-change simulations, row "Uniform" contains inputs when no changes in a given parameter are enforced

\begin{tabular}{|c|c|c|c|c|c|c|c|c|}
\hline \multirow{3}{*}{$\begin{array}{l}\text { Uniform } \\
\text { Landuse }\end{array}$} & \multicolumn{2}{|c|}{ LST $[\mathrm{K}]$} & \multicolumn{2}{|c|}{$z_{0 M}[\mathrm{~m}]$} & \multicolumn{2}{|c|}{ FCV [-] } & \multicolumn{2}{|c|}{$\mathrm{kB}^{-1}$ at $z_{O M}=0.10[\mathrm{~m}]$} \\
\hline & \multicolumn{2}{|c|}{312.0} & \multicolumn{2}{|c|}{0.10} & \multicolumn{2}{|c|}{0.25} & \multicolumn{2}{|c|}{2.3} \\
\hline & $\begin{array}{l}\text { Bare } \\
312.0\end{array}$ & $\begin{array}{l}\text { Canopy } \\
297.5\end{array}$ & $\begin{array}{l}\text { Canopy } \\
0.25\end{array}$ & $\begin{array}{l}\text { Bare } \\
0.0025\end{array}$ & $\begin{array}{l}\text { Canopy } \\
0.70\end{array}$ & $\begin{array}{l}\text { Bare } \\
0.15\end{array}$ & $\begin{array}{l}\text { Bare } \\
1.0\end{array}$ & $\begin{array}{l}\text { Canopy } \\
10.0\end{array}$ \\
\hline
\end{tabular}

Two sets of different spatial resolution were run, both with $N x=N y=64$. One set used a $50[\mathrm{~m}]$ horizontal grid size and a 
10 [m] vertical grid size whereas the other used a 100 [m] horizontal grid size and 25 [m] in the vertical. The other relevant inputs were kept the same for all simulations, see Table 6-3.

Table 6-3 Simulation settings

\begin{tabular}{lcccccccc}
\hline Parameter & $L_{z}[\mathrm{~m}]$ & $z_{\mathrm{d}}[\mathrm{m}]$ & $r_{\mathrm{t}}[\mathrm{s}]$ & $z_{\text {inv }}[\mathrm{m}]$ & $\theta_{\text {mix }}[\mathrm{K}]$ & $q_{\text {mix }}\left[\mathrm{g} \cdot \mathrm{kg}^{-1}\right]$ & $u *\left[\mathrm{~m} \cdot \mathrm{s}^{-1}\right]$ & $u_{\text {dir }}\left[{ }^{\circ}\right]$ \\
Value & 750 & 600 & 60 & 500 & 297.5 & 4.0 & 0.20 & 90 \\
\hline
\end{tabular}

All simulations are typically representing daytime convective boundary layers and were run for 2 hours. The results of the last 30 minutes where then averaged for analysis purposes.

\subsubsection{Simulation results}

As mentioned above, the output from the 2 hour simulations were averaged every 30 minutes. The averages of the last 30 minutes were then used for analysis purposes. This is because after about 1 hour of simulation time a quasi-stationary turbulence state is developed and 30 minutes is a typical averaging time for meteorological input in remote sensingdriven SVAT models. Furthermore here we only examine output spatially averaged along the patches and only for the lowest node in the $A B L$ since this is typically the level where the meteorological input parameters are taken from. To further facilitate easy interpretation the step changes have been chosen such that they yield a higher mean $H_{\text {surface }}$ over the left patch as compared to the right patch.

Typical output is presented in Fig. 6-4. In the upper first left panel the step input is shown and in the other left panels the resulting lowest node $A B L$ states averaged along the crosssection. In the upper first right panel the resulting sensible heat flux at the lowest node is shown and in the lower right panels the three parameters that determine the variation in $\mathrm{H}$ in the TSEB Land Surface Model; $\theta_{0}, \theta_{\mathrm{a}}$ and $r_{\mathrm{aH}}$, see one but the last term on the RHS of Eq. (6.20). Parameter $\theta_{0}$, the potential aerodynamic surface temperature, in the current parameterization (see Appendix A of Norman et al. (1995) for a more detailed explanation) is also known as the within-canopy potential air temperature, $\theta_{\mathrm{ac}}$. 

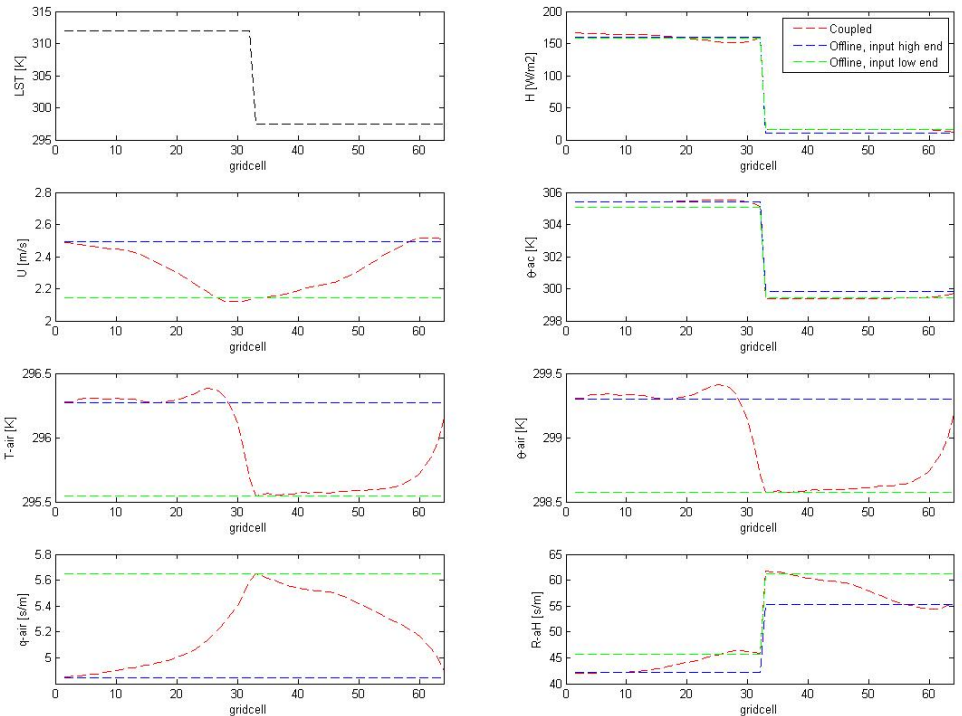

Figure 6-4 Simulation results over a $14.5[\mathrm{~K}]$ step change in LST

We focus here on $H$, since $\lambda E$ in the TSEB scheme does not directly depend on the lower ABL states, but is determined indirectly, Eq. (6.21). In all panels the red lines indicate results from a coupled run, whereas blue and green represent decoupled runs. With "decoupled" here is meant that the LSM is run stand-alone from the LES model, meaning that homogeneous and constant $A B L$ inputs are used. The blue lines represent a decoupled run where the input $A B L$ parameters are taken equal to the coupled output values downwind at the left panel, whereas for the green lines the input was taken equal to the values downwind at the right panel. We suppose equilibrium has been reached, although for the current analysis this is not of crucial importance.

An example is shown in Fig. 6-4 for a step-change in LST at a vertical resolution of $10[\mathrm{~m}]$ and a horizontal resolution of 50 [m].

What is noticed immediately is that the main wind speed shows a considerable variation over the patches. This phenomenon, also reported by Patton et al. (2005) for cases with zero mean horizontal wind, is due to an upward motion over the patches 
with higher $H$ and a downward motion over the patches with lower $H$. This causes a rise in horizontal wind speed near the surface at locations where the counter-rotating cells meet. When adding a mean horizontal wind, like in the current cases, a pattern of alternating minimum and maximum horizontal wind speed results.

Naturally $T_{a}$ shows a rise immediately after the step change, due to an increase in $H$. After reaching a maximum, occurring at $350[\mathrm{~m}]$ downwind the step change, a minor decrease is noted towards a new equilibrium value. The minor decrease however is comparable in size to the variation further downwind, which is less than $0.1[\mathrm{~K}]$, and can be considered negligible.

Also the effect on specific humidity is shown in the lower left panel. A decreasing trend is noted immediately after the step change, which is due to a decrease in $\lambda E$ (following an increase in $H$ ). However, this has hardly any effect on the magnitude of $H$, other than indirectly through the variation in magnitude of the density of air, which is marginal. Therefore it is not discussed further.

Naturally the potential air temperature, $\theta_{a}$, follows an almost identical pattern as the air temperature, $T_{a}$. Less obvious, because of the rather different scales needed for plotting $\theta_{\mathrm{ac}}$ and $\theta_{\mathrm{a}}$, is that also $\theta_{\mathrm{ac}}$ shows a rise in temperature just downwind the step change. In fact also here a similar trend is shown as for $\theta_{\mathrm{a}}$, though different in magnitude over the patches. However, at the step change in LST a sudden step change is also noted in $\theta_{\mathrm{ac}}$. $\theta_{\mathrm{ac}}$ is determined by a rather complicated procedure summarized in Eq. (A.4) of Appendix A of Norman et al. (1995) involving an interplay of several component resistances and component temperatures. Without going into details it is the latter that causes the sudden jump in $\theta_{\mathrm{ac}}$.

The aerodynamic resistance to heat transport, $r_{\mathrm{aH}}$, inversely follows the pattern of the variation of the horizontal wind speed over the patches. When the wind speed goes down the resistance goes up and vice versa, see also Eq. (6.15). Less obvious at this point is the sudden jump that is noted at the step change. When examining Eq. (6.15) $r_{\mathrm{aH}}$ seems to be driven only by atmospheric variables that do not change abruptly and by parameters that do not change over the step 
change in the current example. However, a closer look at Eq. (6.20) reveals that in the current model parameterization $r_{\mathrm{aH}}$ is not determined directly but is composed of $r_{\mathrm{x}}$ and $r_{\mathrm{s}}$. It is in the parameterization of $r_{\mathrm{s}}$, which is taken from Eq. (5) in Kustas and Norman (1999), where the soil and canopy component temperatures cause this sudden jump.

Though different in magnitude, the general response of the lower $A B L$ states to the different step changes are rather similar. In the next section it will be discussed how the different step changes and the response of the $A B L$ influence the sensible heat flux.

\subsubsection{Feedback effects}

Before starting to discuss the feedback effects it might be worthwhile to summarize the effects of the $A B L$ states on the determination of $H$. In the example used in the previous section, just downwind of the step change the coupled $H$ shows a lower value than in the case of a decoupled run. This is not only due to a rise in air temperature (as such lowering the temperature gradient between the lower $A B L$ and the surface) but also due to a reduction in wind speed which causes a rise in aerodynamic resistance. This in turn yields a further lowering of $H$. The effect of the rise in $\theta_{\mathrm{ac}}$ is counter-acting on the magnitude of $\mathrm{H}$ as compared to the effect of a rise in $\theta_{\mathrm{a}}$.

In the panels below the coupling effect of the individual parameters that determine $H$ are quantified for step changes in $L S T, z_{\mathrm{OM}}, F C V$ and $z_{\mathrm{OH}}$. For each step change in the left panels the effect over the left patch is shown, whereas in the right panels the effect over the right patch is shown. The solid lines represent the sensible heat flux from the coupled and decoupled runs. The dotted lines show the isolated effect of the coupling on the three parameters that determine $H$. For example the magenta dotted line indicates the effect of the coupling on $H$ if only the within-canopy potential air temperature, $\theta_{\mathrm{ac}}$, would be influenced by the coupling. The other parameters that determine $H$, the potential air temperature, $\theta_{\mathrm{a}}$, and aerodynamic resistance, $r_{\mathrm{aH}}$, in this scenario are taken from the decoupled run for that particular patch. 

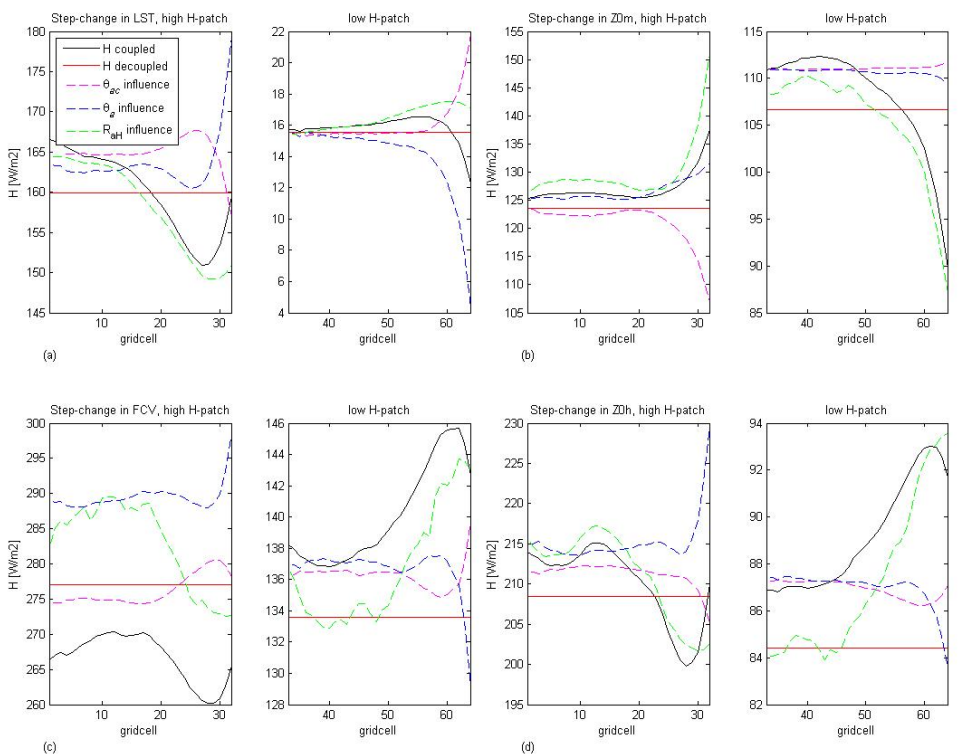

Figure 6-5 Feedback effect on $H\left[\mathrm{~W} \cdot \mathrm{m}^{-2}\right]$ of $\theta_{\mathrm{a}}, \theta_{\mathrm{ac}}$ and $r_{\mathrm{aH}}$ for step changes in $L S T, z_{0 \mathrm{M}}, F C V$ and $z_{\mathrm{OH}}$

It is clearly noticed that in all four cases the development of $\theta_{\mathrm{ac}}$ and $\theta_{a}$ show an opposite, though not always cancelling, effect on $H$. As a result the development of the aerodynamic resistance, $r_{\mathrm{aH}}$, is dominant in the development of $H$ in the coupled runs. This is demonstrated by the fact that in all cases the response of the fully coupled run shows a similar trend as the run using only coupling for the resistance. This means that the wind speed is the major feedback factor determining the differences between coupled and decoupled runs. Please note that the wind speed is not only determined by surface roughness but also by convective plumes creating counterrotating cells, as explained before.

For the runs using the constant SGS models the results (not shown) show exactly the same trends over the different step changes. The absolute differences though between coupled and decoupled $H$ are larger when using the constant SGS models for all 4 variables.

The magnitudes of the step changes, Table 6-2, were chosen such as to represent typical maximum changes in land cover or surface state. Their effects on $H$ in an absolute manner are 
therefore not directly comparable, but we have attempted to normalize the effects by calculating a feedback factor $f$ following:

$f=\frac{H_{\text {decoupled }}-H_{\text {coupled }}}{H_{\text {coupled }}} \times 100 \%$

where for $H_{\text {decoupled }}$ the individual effects of the separate parameters are explained above. The results are shown in Fig. 6-6.
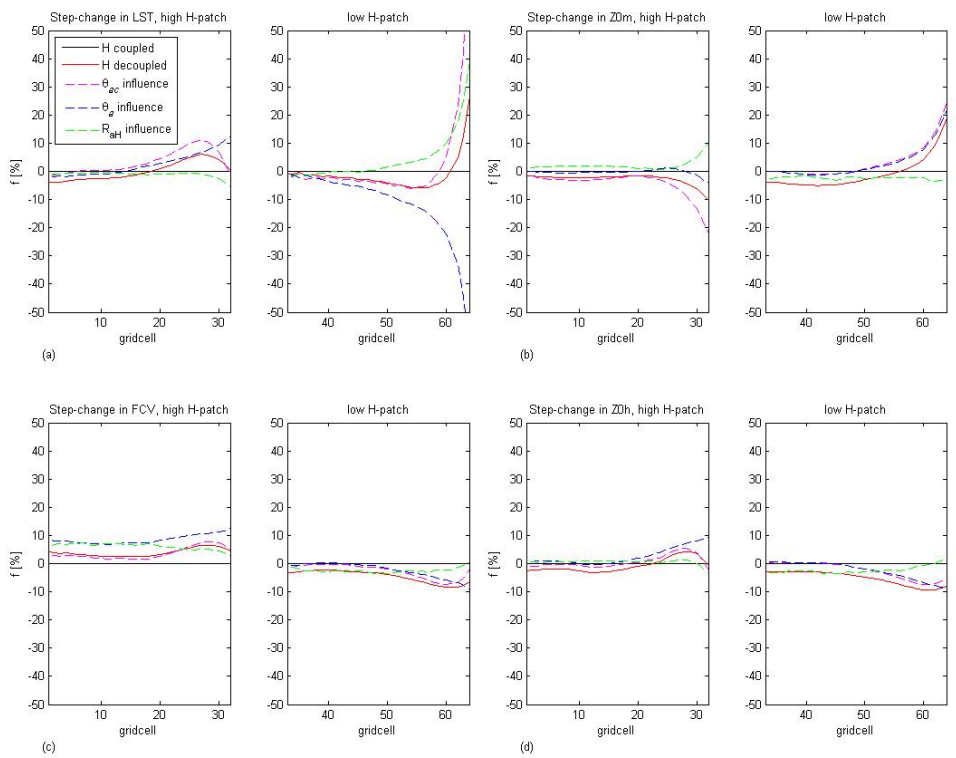

Figure 6-6 Feedback factor $f$ [\%] for $H$ [\%] determined by $\theta_{a}, \theta_{\mathrm{ac}}$ and $r_{\mathrm{aH}}$ for step changes in $L S T, z_{\mathrm{OM}}, F C V$ and $z_{\mathrm{OH}}$

Clearly the effect of the step changes in $L S T$ and $z_{0 M}$ are largest as compared to the other parameters. It should be noted at this point that this is not only due to the magnitude of the step change in LST but is a characteristic of the LSM model parameterization, which is reported to show the largest sensitivity to the LST input (Anderson et al., 1997; Timmermans et al., 2007; Timmermans et al., 2015b; Zhan et al., 1996). For the other step changes the deviations are remarkably similar in magnitude. Largest deviations are seen immediately after a step change from high to low LST ( $f=$ $25 \%$ ) and immediately after a step change from high to low $z_{0 M}$ 
$(f=20 \%)$. In all other cases maximum deviations are between 5 and $10 \%$.

Another important issue is the extent of the area that is influenced downwind the step change. Naturally the extension of this area depends on local aerodynamic properties. Under the given circumstances the location of the maximum deviations either occur at some 200 to 300 [m] downwind the step change, i.e. the left panels for $L S T, Z_{0 M}$ and $F C V$, or immediately after the step change, i.e. almost all right panels and the left panel for $z_{0 M}$. It should be noted that for certain land cover changes these deviations may be counter-acting. For example over a step change from vegetated to bare, see Table 6-2, the deviations resulting from accompanied typical changes in $L S T$ and FCV are opposite. Net results thereby will among others depend on the magnitude of either step change. How these typical step changes inter-act in a natural heterogeneous environment is discussed in the next section.

\subsection{Model performance over a natural surface}

\subsubsection{Data set and simulation description}

The data used in this section is taken from the REFLEX-2012 airborne field campaign organized during July 2012 over a very heterogeneous agricultural test site in the south-east of Spain (Timmermans et al., 2015a). Remote sensing data is taken from the Advanced Hyperspectral Scanner (AHS) flown on the $25^{\text {th }}$ of July 2012 at 11:28 local time, 09:28 UTC. The data is processed, post-processed and calibrated versus field observations as described in detail in de Miguel et al. (2015) and in Andreu et al. (2015) and therefore not discussed in detail in this contribution. However, for the current study the original spatial resolution has been downgraded to 50 [m].

Unfortunately no atmospheric sounding information was available for this location at the time of airplane overpass. However, the area is known to be influenced by basically two systems, depending on wind directions, being either an inland wind or a seaside wind. Therefore sounding information from Madrid and Murcia were averaged to provide the mixing layer 
initial settings. They are provided together with the other relevant simulation settings in Table 6-4.

Table 6-4 Simulation settings

\begin{tabular}{|c|c|c|c|c|c|c|c|c|c|}
\hline Parameter & $\begin{array}{l}L_{z} \\
{[\mathrm{~m}]}\end{array}$ & $\begin{array}{l}z_{\mathrm{d}} \\
{[\mathrm{m}]}\end{array}$ & $\begin{array}{l}r_{\mathrm{t}} \\
{[\mathrm{s}]}\end{array}$ & $\begin{array}{l}Z_{\text {inv }} \\
{[\mathrm{m}]}\end{array}$ & $\begin{array}{l}R_{\mathrm{S}} \\
{\left[\mathrm{W} \cdot \mathrm{m}^{-2}\right]}\end{array}$ & $\begin{array}{l}\theta_{\text {mix }} \\
{[\mathrm{K}]}\end{array}$ & $\begin{array}{l}q_{\text {mix }} \\
{\left[\mathrm{g} \cdot \mathrm{kg}^{-1}\right]}\end{array}$ & $\begin{array}{l}u_{*} \\
{\left[\mathrm{~m} \cdot \mathrm{s}^{-1}\right]}\end{array}$ & $\begin{array}{l}u_{\text {dir }} \\
{\left[{ }^{\circ}\right]}\end{array}$ \\
\hline Value & 1200 & 800 & 60 & 600 & 715.8 & 301.20 & 9.0 & 0.238 & 86.6 \\
\hline
\end{tabular}

Ground data is obtained from 3 flux stations and a standard meteorological station over "camelina" (senescent high grass type), a forest nursery, a vineyard and an irrigated grass site respectively. As with the remote sensing data the details of these data have been described elsewhere (Van der Tol et al., 2015) and are therefore not described in detail here again. However an overview of the utilized ground flux and meteo data ( $A B L$ state) is provided in Table 6-5.

Table 6-5 Overview of ground meteo and flux data

\begin{tabular}{lllll}
\hline Land cover: & Grass & Vineyard & Forest nursery & Camelina \\
\hline & & & & \\
Fluxes: & & & 194 & 232 \\
$H\left[\mathrm{~W} / \mathrm{m}^{2}\right]$ & 54 (rest-term) & 145 & 35 & 19 \\
$\lambda E\left[\mathrm{~W} / \mathrm{m}^{2}\right]$ & 360 & 53 & & \\
& & & & \\
\hline Meteo at $5 \mathrm{~m}:$ & & & 3.40 & 2.95 \\
$u[\mathrm{~m} / \mathrm{s}]$ & 2.91 & 3.11 & 303.3 & 303.8 \\
$\theta[\mathrm{K}]$ & 302.6 & 303.9 & 8.88 & 8.81 \\
$q[\mathrm{~g} / \mathrm{kg}]$ & 9.11 & 9.06 & 0.324 & 0.338 \\
$u_{*}[\mathrm{~m} / \mathrm{s}]$ & N.A. & 0.318 & & \\
\hline
\end{tabular}

A first glance at the meteorological observations reveals that despite a rather large spread in magnitude of turbulent fluxes the variation in lower $A B L$ state at $5[\mathrm{~m}]$ is rather limited. Further, the largest $H$ fluxes do not necessarily produce the highest air temperatures. For the forest nursery, that shows a relatively low air temperature compared to the vineyard and the camelina, this may be due to a somewhat larger wind speed. The highest air temperature is recorded over the vineyard, which may be explained by the fact that the canopy height, i.e. $1.3[\mathrm{~m}]$, is considerably higher than over the other sites. This also might explain the relatively high specific humidity at this site.

Aerodynamic roughness length for the flux sites were found to depend slightly on wind direction (Van der Tol et al., 2015) and average values for an Eastern wind direction were found to be 
equal to $0.05,0.04$ and $0.05[\mathrm{~m}]$ for the vineyard, forest nursery and camelina sites respectively. Aerodynamic properties for the remaining land cover units were derived from the classical $z_{0 \mathrm{M}}=h_{\mathrm{c}} / 8$ and $d_{0}=2 \cdot h_{\mathrm{c}} / 3$ rules (Brutsaert, 1982), especially since more sophisticated approaches utilizing canopy height, vertical leaf density and canopy structure, such as for example in Massman (1997), were found to yield unrealistic values due to the relatively high amount of senescent vegetation.

\subsubsection{Results versus observations}

Discussing differences in $H$ (or $\lambda E$ ) over different land cover between coupled and decoupled runs will depend on which reference site is taken for comparing the coupled and decoupled runs, see also Bertoldi et al. (2008). Here we have chosen to take the areal averages of lower ABL states $(u, \theta$ and $q$ ) to be the same between the coupled and decoupled runs. Taking for example the lower ABL states at a particular observation site to be comparable would yield different model output. However, in this contribution emphasis is on demonstrating the effect, and interplay, of the different feedback mechanisms on the turbulent fluxes and then to quantify and possibly correct for them in the case of a decoupled run.

Model performance (open circles for the decoupled run, closed circles for the coupled run) for the turbulent fluxes is presented in the panels in Fig. 6-7, using constant SGS models (upper panels) and dynamic SGS models (lower panels). Footprintweighted averages of the model output, following the procedure outlined in Timmermans et al. (2009), are shown here versus ground observations. A summary is provided in Table 6-6 where Root Mean Squared Differences (RMSD) between observations and modelled values are listed. In Fig. 67 the bright green indicates the irrigated grass site, dark green the vineyard, brown the forest nursery and red the "camelina" site. 

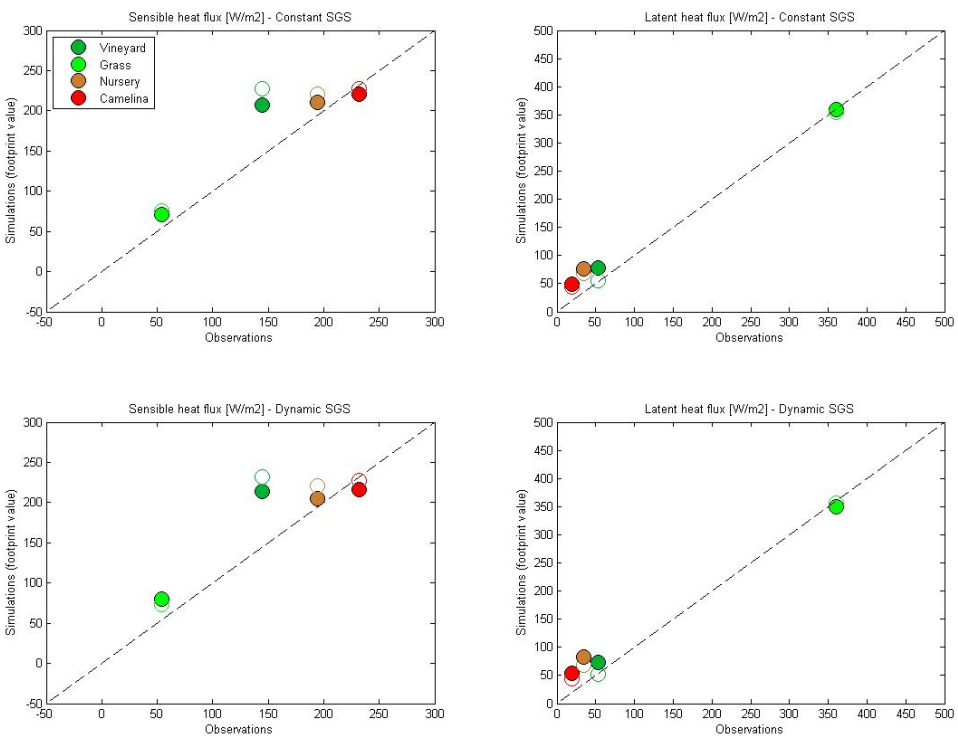

Figure 6-7 Simulated fluxes versus observed fluxes

A rather good fit is seen for both turbulent fluxes and for both the constant and dynamic model runs, as well as for the decoupled runs, with maybe the exception of the sensible heat flux over the vineyard. Not in all cases a coupled run yields a better fit with the observations than a decoupled run. Basically the estimates for $H$ improve whereas the estimates for $\lambda E$ deteriorate. This is logical given the nature of the current LSM model parameterization where $\lambda E$ is determined as a rest-term. However, the same trend is noted as also observed by Timmermans et al. (2008) and Bertoldi et al. (2007), namely that the feedback effects act to limit the variability of the fluxes.

Table 6-6 Root Mean Squared Differences (RMSD) between observations and modelled values

\begin{tabular}{lccccc}
\hline Simulation & $H$ & $\lambda E$ & $u$ & $\theta$ & $q$ \\
\hline Uncoupled & 46.7 & 20.9 & N.A. & N.A. & N.A. \\
Constant SGS & 33.6 & 28.9 & 0.256 & 0.459 & 0.180 \\
Dynamic SGS & 38.0 & 31.8 & 0.435 & 0.470 & 0.120 \\
\hline
\end{tabular}


In the panels in Fig. 6-8 the same is shown but then for the $A B L$ states, where the fits are relatively poor. Given the relatively minor spread in magnitude for part of the meteo observations this might be expected, but for air temperature, that does show some variation, the simulations show a rather flat response as compared to the observations. With respect to the windspeed, the forest nursery shows largest discrepancy with the observations, whereas for the other sites they resemble the observations rather well. With respect to the windspeed and temperature a larger variation is noted when using the dynamic models, whereas for the specific humidity the results are almost identical.
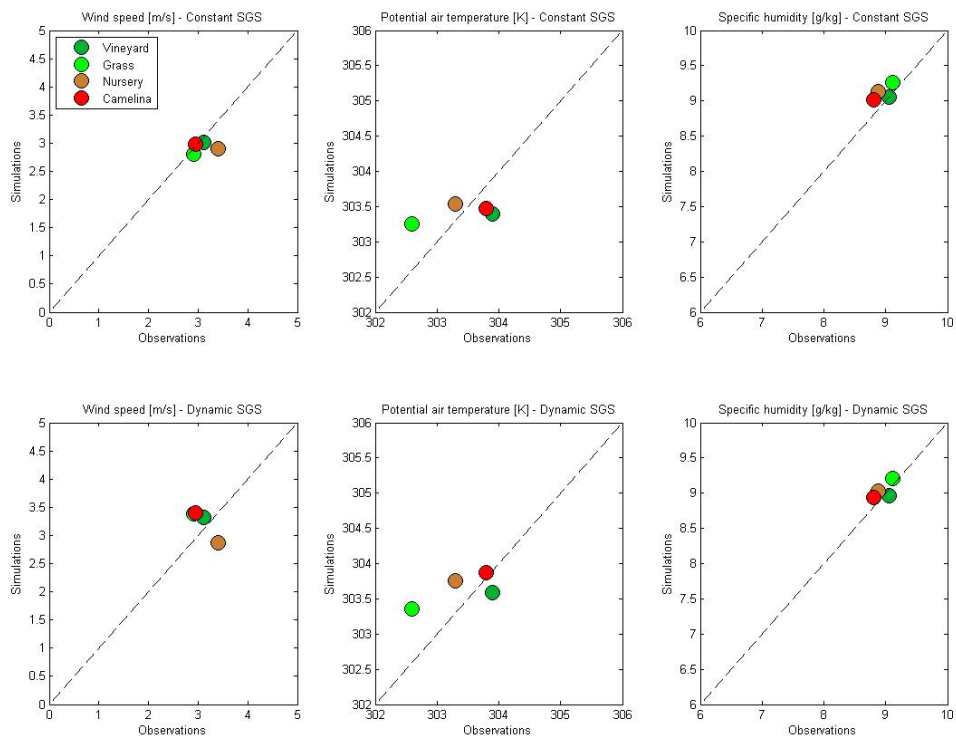

Figure 6-8 Simulated versus observed $A B L$ states

Summarizing, for the turbulent fluxes the coupled model runs showed generally a better performance for estimating $H$, but a worse performance for estimating $\lambda E$ as compared to a decoupled run. This holds true for the run using constant SGS models as well as for the run using dynamic SGS models. However, the run using dynamic SGS models showed a slightly worse performance versus observations as compared to using 
constant SGS models. The dynamic SGS models were among others incorporated to better reflect the observed range in $A B L$ states. Although the dynamic SGS models did show a larger range in $A B L$ states, they did not generally yield a better performance when compared versus observations. This mainly holds true for the horizontal wind speed, see Table 6-6. Consequently they also showed a worse performance for the turbulent fluxes. Possibly, the rather crude estimation of aerodynamic properties, for land cover units that were not covered by eddy-covariance observations, plays a role here. The dynamic SGS models were among others designed to better follow variation in aerodynamic roughness, consequently they are also more sensitive to errors in the estimation of the aerodynamic properties.

\subsubsection{Feedback effects and discussion}

In Fig. 6-9 below the coupled turbulent fluxes are plotted versus the decoupled ones, both for the constant SGS as well as for the dynamic SGS models. Although there is a significantly larger spread for the dynamic version, differences are rather limited in magnitude. Considering that currently accepted errors in turbulent flux estimates are $50\left[\mathrm{~W} \cdot \mathrm{m}^{-2}\right]$ or 20\% (Hanna \& Chang, 1991; Kalma et al., 2008; Kustas \& Norman, 2000; Twine et al., 2000), the percentage of the area where deviations are larger than this is very limited. Also note that these deviations are less than what is reported by Timmermans et al. (2008) over the same area but using a different (i.e. patch) version of the same LSM. 

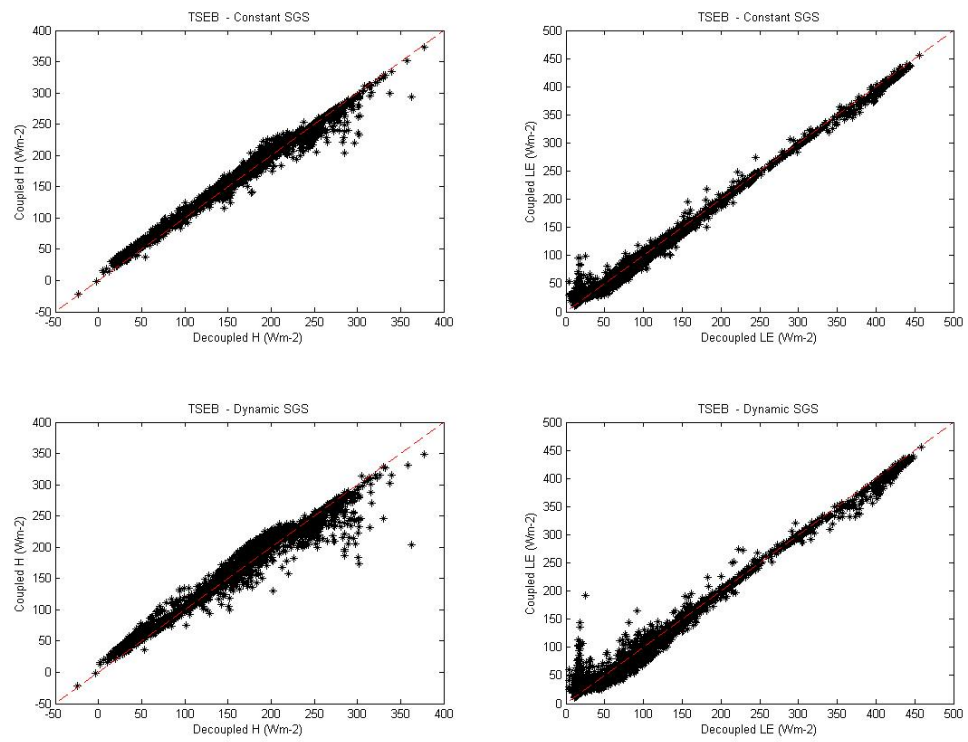

Figure 6-9 Coupled versus decoupled output for $H$ and $\lambda E$ using the constant (upper panels) and dynamic (lower panels) SGS models

Also the spatial averages and variability, Table 6-7, show a different response than what was reported previously by Timmermans et al. (2008). A-priori one might expect that coupled runs, at least for $H$, would yield lower average values. Obviously that is not the case, which can only be due to the combined feedback effects that partly counter-act, as described also in section 4.

Table 6-7 Spatial averages and variability of the turbulent fluxes

\begin{tabular}{lcccrc}
\hline TSEB & SGS & $H$-avg. & $H$-st.dev. & $\lambda E$-avg. & $\lambda E$-st.dev. \\
\hline Coupled & Constant & 191.4 & 11.21 & 96.5 & 31.58 \\
Decoupled & Constant & 189.4 & 11.88 & 98.5 & 31.76 \\
Coupled & Dynamic & 191.0 & 11.69 & 97.3 & 31.64 \\
Decoupled & Dynamic & 189.1 & 12.34 & 98.8 & 32.31 \\
\hline
\end{tabular}

The spatial differences between the coupled and decoupled fluxes are shown in Fig. 6-10. As before, naturally, the dynamic runs show a larger discrepancy. In both cases the discrepancies seem to be related to land cover type and they are larger over rougher surfaces. Naturally these differences in 
$H$ (or $\lambda E$ ) over different land cover between coupled and decoupled runs are subject to which reference is taken for comparing the coupled and decoupled runs, see also Bertoldi et al. (2008). Here we have chosen to take the areal averages of lower ABL states $(u, \theta$ and $q$ ) to be the same between the coupled and decoupled runs. Since the dynamic SGS models yield a considerably larger spread in wind speed, which is the main factor determining deviations in $H$ between coupled and decoupled runs, they also yield larger differences in $H$ (and thus $\lambda E$ ).
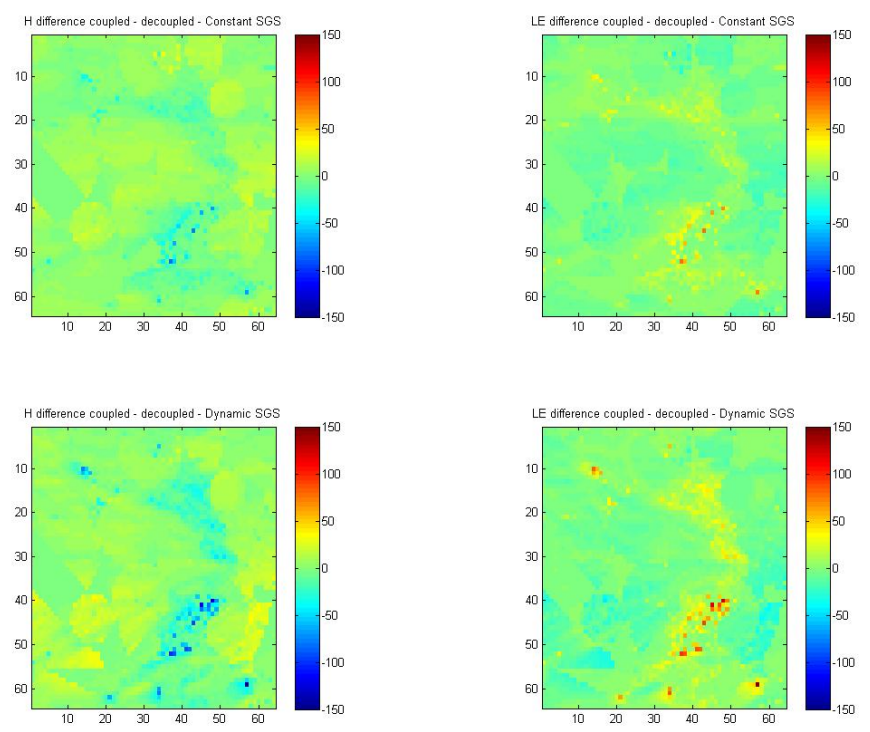

Figure 6-10 Coupled minus decoupled spatial output for $H$ and $\lambda E$ using the constant (upper panels) and dynamic (lower panels) SGS models

To unravel these differences and possibly correct them, an attempt was made to determine multi-scale relations between $\mathrm{ABL}$ state and land surface conditions, knowingly between $\theta_{a}$ and $H$, between $u$ and $\ln \left(z / z_{0 M}\right)$ and between $q$ and $\lambda E$. This approach is similar to those described in Timmermans et al. (2008) and Bertoldi et al. (2008), but results were rather different. Specifically, no lag shift was found between the 
surface states and $A B L$ states. Naturally this is related to the average wind speed, which was between 4.0 and $5.0\left[\mathrm{~m} \cdot \mathrm{s}^{-1}\right]$ in the previous studies, whereas here it is around $3.3\left[\mathrm{~m} \cdot \mathrm{s}^{-1}\right]$. More problematic was the fact that specifically the one but largest scales repeatedly showed correlations as low as 0.4 to 0.5 . This is also reflected in the overall linear spatial correlation coefficients between surface and ABL states, Table 6-8, which are considerably lower than reported by Bertoldi et al. (2008). One plausible reason for these lower correlations might be due to the co-existence of relatively large fields $(>500 \mathrm{~m}$ ) with extremely high and low values for $H$, which enhance the aforementioned counter-rotating cells. These in turn generate a near-surface variation in horizontal wind speed that will influence the local correlation between surface and $A B L$ state.

Table 6-8 Linear spatial correlation coefficients between surface property $\left(z_{0 M}\right)$ or flux $(H, \lambda E)$ and $\operatorname{ABL}$ state $(\theta, u, q)$, where $z_{1}$ means elevation of first node, i.e. $5[\mathrm{~m}]$

\begin{tabular}{cccc}
\hline SGS & $\rho(\theta, H)$ & $\rho\left(u, \log \left(z_{1} / z_{0 \mathrm{M}}\right)\right)$ & $\rho(q, \lambda E)$ \\
\hline Dynamic & 0.54 & 0.61 & 0.66 \\
Constant & 0.63 & 0.51 & 0.57 \\
\hline
\end{tabular}

In addition, the analyses showed remarkable differences between simulations using the constant SGS models and those using the dynamic SGS models. For example the constant SGS run seems to keep the same preferential scale for transferring surface temperature into the lower $A B L$ as in Timmermans et al. (2008). Using the dynamic SGS models however, shifts these to shorter length scales, more similar to what was found by Albertson et al. (2001). The combination of these two issues (low correlation and large differences between results from different SGS models) made it very difficult to continue along this path. Therefore, a similar approach is followed as in section 6.4. The differences between coupled and decoupled $H$ are differentiated per parameter that determines $H ; \theta_{a c}, \theta_{a}$ and $r_{\mathrm{aH}}$. In Fig. 6-11 the influences of the separate parameters on $H$ are shown in a similar fashion as in section 6.4. The influencing parameter is taken from the coupled run, whereas the others are taken from the decoupled run. A distinction is made between bare soil and vegetated areas, because from the plots above it was clear that over bare soil surfaces hardly any difference between $H$ from the coupled and decoupled runs 
existed. This is also shown in the upper left panel of Fig. 6-11 below, where the results over bare soil are displayed in black, whereas the other areas are plotted in red. Over bare soil areas the TSEB model uses a one-source approach, following:

$H_{T S E B}=H_{S}=\rho_{a} \cdot C_{P} \cdot\left[\frac{\left(\theta_{0}-\theta_{a}\right)}{r_{a H}}\right]$

where initially $\theta_{\mathrm{ac}}$, or $\theta_{0}$ over bare soil, in Eq. (6.25), is taken equal to the surface temperature. Clearly, when examining Fig. $6-11$, the interplay between changes in the three parameters almost perfectly neutralize each other over bare soil.
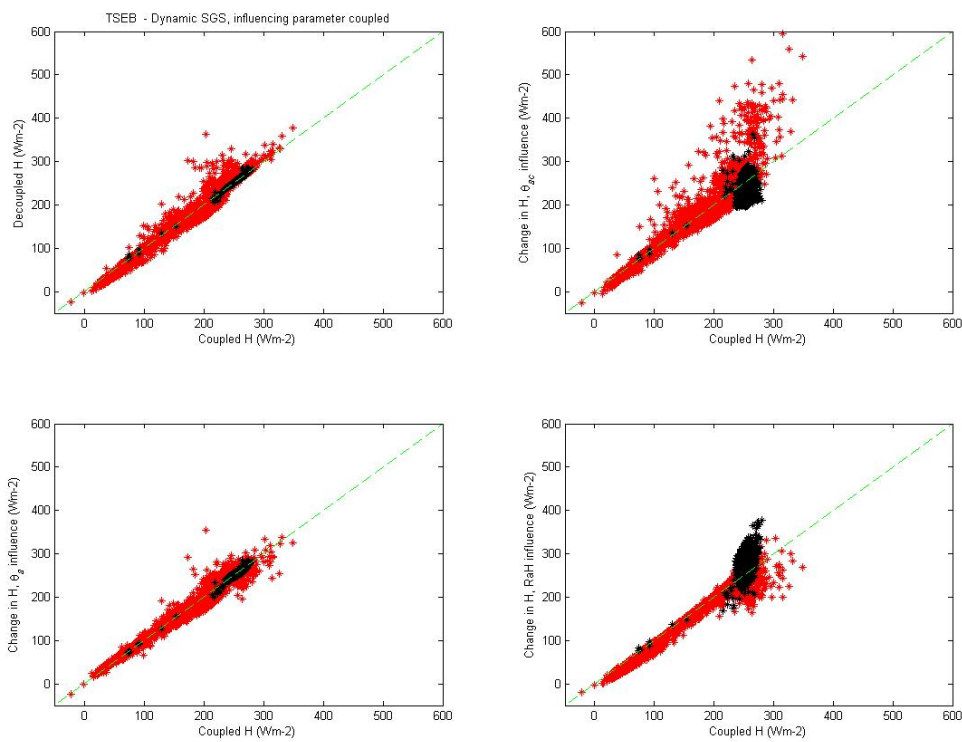

Figure 6-11 Feedback effect on $H\left[\mathrm{~W} \cdot \mathrm{m}^{-2}\right.$ ] separated per influence of $\theta_{\mathrm{a}}, \theta_{\mathrm{ac}}$ and $r_{\mathrm{aH}}$. Results over bare soil are plotted in black and the remaining areas are plotted in red

As in section 6.4 , the resulting changes in $H$ when only one influencing parameter is taken from the coupled run are often larger than when all parameters are taken from the coupled run (upper left panel). This means that also for the other areas the influencing parameters are counter-acting, though to a lesser extent. Since the wind speed difference, as shown in section 6.4 , is the main driver for the difference in $H$ between the coupled and decoupled run, a relation is sought between 
them in order to be able to correct for them. This relation is shown in Fig. 6-12, where at a first glance, no clear-cut relation seems to exist.

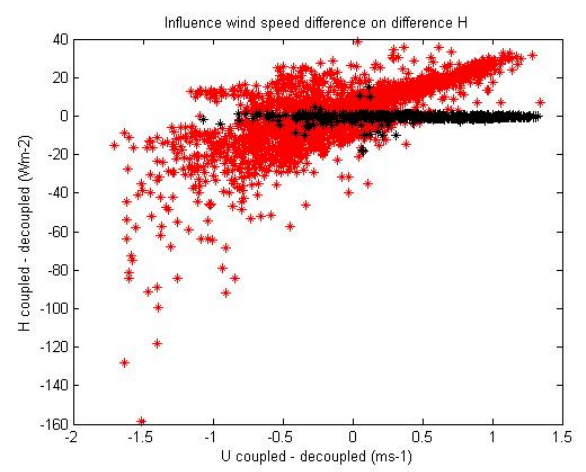

Figure 6-12 Relation between $u$ difference and $H$ difference

Nevertheless, Fig. 6-10 illustrated that differences between coupled and decoupled runs were related to land cover. Therefore, plots between wind speed difference and difference in $H$ were made for each land cover class (see Table 6-9 for their description) independently, which are shown in Fig. 6-13.

Table 6-9 Land cover tye and description

\begin{tabular}{lll}
\hline Land cover/ use & Code & Description \\
\hline Alfalfa & al & Alfalfa field, partly harvested \\
Bare Pasture & bp & Pasture, bare, more smooth than fallow land \\
Bare Soil & bs & Fields with no stubble, or harvested crop \\
Barley Stubble & ba & Barley field, harvested and remaining stubble \\
Building & bd & Farmhouse, office \\
Built Area & bu & Streets, parking lot or buildings \\
Camelina & ca & Camelina field, mostly dry \\
Corn & co & Actively growing corn field \\
Crops & cr & Small-sized crop fields, sometimes bare \\
Fallow Land & fl & Fields with bare soil, mostly ploughed \\
ForestNursery & fn & Forest plantation fields \\
Grass & gr & Grass field, actively grown, cut short \\
Harvested Cropland & hc & Harvested fields, remains still on top \\
Open Water & ow & Artificial ponds \\
Orchard & or & Walnut, Pistachio, or other sparse trees \\
Poppy & po & Poppy fields \\
Rape & ra & Rape fields \\
Stubble & st & Harvested fields with remaining stubble \\
Sunflower & sf & Sunflower fields, still small in height \\
Vineyard & vi & Vineyard \\
Wheat Stubble & ws & Wheat field, harvested and remaining stubble \\
\hline
\end{tabular}



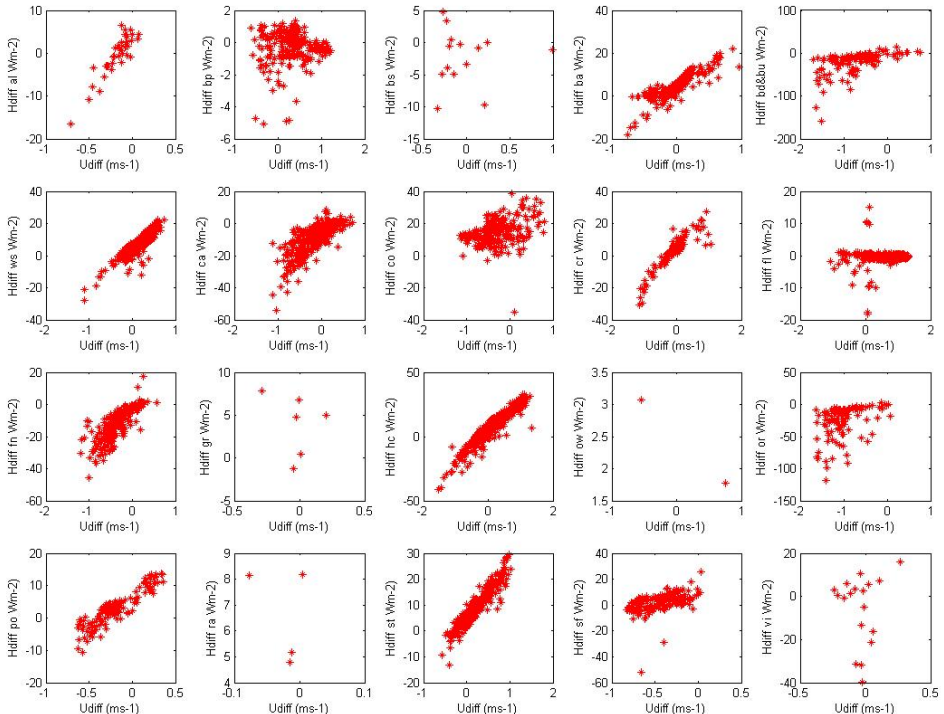

Figure 6-13 As Fig. 6-12 but separated per land cover type

When examining Fig. 6-13 most land cover types show a clear and mostly linear relation between difference in $u$ and difference in $H$ between coupled and decoupled runs. This means that for those land cover units, under this LSM parameterization, the differences in $H$ can be almost entirely traced back to the wind speed feedback. Consequently, if for a given land cover type one would be able to determine the difference in wind speed between a coupled and decoupled run, which is basically given by the wind speed from the coupled run, one would be able to correct for the difference in $H$. However, attempts to perform a multi-scale regression between $u$ and $\log \left(z_{1} / z_{0 M}\right)$ failed due to very low $(0.30$ to 0.40$)$ correlation coefficients, especially at the smaller scales. Again, the variation in horizontal wind speed driven by persistent convective cells plays a role here. Factors that play a role in the spatial variation of $u$ here are not only $z_{0 M}$, but also (1) magnitude of the step-change in other input parameters (LST, $F C V$ and $\left.z_{\mathrm{OH}}\right),(2)$ distance of the pixel under consideration to the specific step change, (3) distance to convective up/downdraft and (4) strength of the convective up/down-draft. 
Mapping the spatial variation in horizontal wind speed solely based on surface state or surface property is therefore not possible. It appears that the interplay between convection or buoyancy-driven horizontal wind speed variation and mechanically-driven horizontal wind speed variation in a natural landscape as in this study is too complex for such a solution.

\subsection{Summary and conclusion}

A tool is presented, by means of a coupled LES-LSM, which enables to quantify uncertainties in typical remote sensingdriven LSM flux output arising from utilizing uniform $A B L$ state inputs. Results are shown over synthetic as well as over natural and heterogeneous areas. The tool enables to examine each parameter of importance in terms of coupling, in addition to the turbulent fluxes. As such, it enables a much more detailed planning of field experiments and might potentially even be extended to other surfaces, like urban areas, where geometrical influences need special attention.

Incorporation of recently developed dynamic scale-dependent SGS model parameterizations in the LES part of the model and a new approach for discretizing vertical derivatives yielded near-wall results that better follow Monin-Obukhov Similarity Theory (MOST) for both momentum and for scalars over homogeneous synthetic surfaces. Moreover, resulting profiles of turbulent SGS viscosity, Schmidt and Prandtl number better represented values reported in literature, such as for example Piomelli et al. (1988), Germano et al. (1991), Vercauteren et al. (2008) and Stoll and Porte-Agel (2008). Notwithstanding that remote sensing-driven LSMs typically are designed to work over heterogeneous surfaces, where typically MOST is not valid, this still provided confidence in model performance.

Model runs over synthetic step-changes in typical remotely sensed input parameters, LST, $z_{\mathrm{OM}}, F V C$ and $z_{\mathrm{OH}}$, were used to examine the feedback effects on the individual parameters that directly determine sensible heat flux estimates in the current LSM parameterization, namely $\theta_{\mathrm{ac}}, \theta_{\mathrm{a}}$ and $r_{\mathrm{aH}}$. For all four input parameters the feedback effects of both temperatures showed an opposite, and at times even cancelling, effect. As a consequence the $r_{\mathrm{aH}}$, and thus wind speed, feedback effect was 
dominant for the magnitude of $H$. Largest deviations between $H$ in a coupled and de-coupled run were seen after step-changes in $L S T$ and to a somewhat lesser extent in $z_{0 M}$. The location of the maximum deviation under the simulated circumstances were either found immediately downwind or at some 200 to 300 meter downwind the step-change. This relatively large downwind influence, plus the fact that for certain land cover changes deviations in $H$ resulting from accompanied typical changes in input parameters show an opposite behaviour, potentially reduces the over-all feedback effect on $H$ over very heterogeneous areas.

Indeed, inclusion of the feedback effects for the current LSM parameterization over the heterogeneous REFLEX2012 site yielded deviations in flux estimates that are largely within turbulent flux observation accuracy. Though marginal, the feedback mechanisms did tend to limit the spatial variability of the turbulent fluxes, both for the constant as well as for the dynamic model runs. As in the case of the synthetic runs, the main feedback mechanism was the wind speed. Inclusion of the feedback effects over the REFLEX2012 site yielded an improved flux estimate for $\mathrm{H}$ and a worse estimate for $\lambda E$ with respect to the observations. However, this is logical given the nature of the current LSM parameterization where $\lambda E$ is largely determined as a rest-term. The slightly poorer performance of the dynamic over the constant SGS models with respect to turbulent fluxes was attributed to a rather crude estimate of the aerodynamic properties of land cover units that were not covered by eddy-covariance observations.

When examining the possibility to "correct" de-coupled flux estimates over the REFLEX2012 site no consistent and at times a significantly lower correlation than in previous studies was found between $A B L$ state and land surface conditions and also between $A B L$ state and turbulent fluxes. This was found for overall spatial as well as for a multi-scale correlation. Therefore, for the current heterogeneous area and LSM parameterization, no overall general approach could be established to correct decoupled fluxes. For individual land cover units though, clear and mostly linear relations were observed between differences in wind speed and differences in $H$ between decoupled and coupled runs, as such potentially providing a means to correct de-coupled $H$ flux estimates. 
However, the complex interplay between buoyancy-driven and mechanically-driven variation in horizontal wind speed hampered finding a manner to map the spatial variation in horizontal wind speed based solely on surface state or surface property.

Concluding, incorporation of lower ABL state using a coupled LES-LSM improved sensible heat flux estimates over the current natural and heterogeneous surface. Hereby the horizontal wind speed was found to be the dominant feedback factor. Implementation of recent dynamic and scale-dependent SGS model parameterizations increased spatial variability in wind speed and scalar concentration, but did not necessarily improve the flux estimates. This was found to be due to insufficient knowledge on aerodynamic properties. Attempts to improve de-coupled flux estimates ran ashore on the complex interplay between buoyancy-driven and mechanically-driven horizontal wind speed. Attention in future work should therefore be given to an accurate and just manner of parameterizing the aerodynamic properties over a very heterogeneous area.

In the paper on which this chapter was based the authors thank Dr. Willem Vermin, formerly SURFsara (https://www.surfsara.nl), who kindly carried out the cleaning and speeding up of the serial version of the code, performed the actual parallelization, and possibly most important, assisted even after his retirement. Without him the current contribution would not have been possible. 


\section{Chapter 7 Summary and perspectives}

In the first part of this chapter the main findings of this dissertation are presented. No details are provided since these have already been discussed extensively in Chapters 2 to 6 . The second part of this chapter comprises suggestions for future research building on the findings of the current work.

\subsection{Summary}

The subject of this dissertation is how to make effective use of remote-sensing based techniques in determining fluxes of water vapour and heat under conditions of surface and atmospheric heterogeneity. This concerned setting up of a model that (tries to) ignore, or minimize the influence of atmospheric heterogeneity on flux estimates, incorporating surface heterogeneity in ground-based observations that are used for flux validation and developing a method to incorporate and quantify the influence of atmospheric heterogeneity on flux estimates.

Minimization of atmospheric influence

A remote sensing-based framework was developed for the automated estimation of surface energy balance components from remotely sensed radiometric surface temperature only. The method can be used to derive a spatially distributed map of actual evapotranspiration over large heterogeneous areas, provided that hydrologic extremes or both wet and dry conditions are present.

This simple and fully automated scheme, which is of the physically-based index type, was shown to provide estimates of the available energy (net radiation less soil heat flux) and turbulent sensible and latent heat fluxes comparable to established and more complex remote sensing-based schemes. Only under dry and sparsely vegetated conditions discrepancies with observations were significant, a phenomenon not uncommon for these type of approaches. Given the simplicity of the algorithm and its ease of use, the proposed model has utility in identifying areas of high and low water use and therefore can serve as an operational tool for rapid monitoring 
of relative water use or plant stress conditions in regions having little ground information.

\section{Incorporation of surface influence}

A methodology was proposed to produce scintillometer-derived area-averages of sensible heat fluxes suitable for validating spatially distributed models that estimate surface fluxes by remote sensing observations. The soundness of the method is demonstrated by reproducing reference fluxes from land cover component fluxes. When applied over a very heterogeneous surface, some complications are noticed when both stable and unstable conditions occurred within the footprint of the scintillometer. However, when the contrast between land cover components is not too large, deviations between scintillometerbased estimates and reference values were within $20 \mathrm{Wm}^{-2}$.

Incorporation of atmospheric influence

A Large-Eddy Simulation (LES) model was linked with remotely sensed land surface states using a patch version of a dual source energy balance model to assess land-atmosphere coupling over the very heterogeneous agricultural landscape near Barrax, Spain. The coupled model was applied in a decoupled way, with static uniform atmospheric states and with spatially variable atmospheric states in a dynamically coupled way. A significant difference in the spatial averages and a decrease in spatial variance of the fluxes was found when comparing results from the coupled with the decoupled simulations. From a multi-scale analysis on the relation between surface and air temperature it was found that the spatial variability of the air temperature was induced preferentially from variations in surface temperature occurring at scales of 500 to 1000 meter. Though the spatial variation in air temperature was found to be fairly small as compared to those of the surface temperature, these results were in line with previous work over a natural semi-arid rangeland area.

These findings led to the development of a new tool that enables to examine each parameter of importance in terms of coupling, in addition to the turbulent fluxes. The tool contains recently developed Sub-Grid-Scale (SGS) model parameterizations and new discretizations in the LES part, and is dynamically coupled to the series version of the TSEB model. 
Model performance over homogeneous synthetic surfaces now showed near-surface results that better followed MoninObukhov Similarity Theory (MOST) and better represented typical profiles of parameters such as turbulent viscosity, Schmidt and Prandtl number.

Model results over heterogeneous, synthetic as well as natural, surfaces showed that the wind speed is the dominant factor for deviations between coupled and decoupled flux estimates. This holds true for heterogeneity in LST, $z_{\mathrm{OM}}, F V C$ as well as for $z_{\mathrm{OH}}$, which are typical spatially variable input parameters in remote sensing-based LSMs. For individual land cover units, clear and mostly linear relations were found between differences in wind speed and differences in $H$ between coupled and decoupled runs, potentially providing a means to incorporate atmospheric variability in decoupled models. However, no general approach could be established to map spatial variation in wind speed due to the complex interplay between buoyancy-driven and mechanically-driven variation in wind speed.

Evaluation of the new tool versus observations from the REFLEX2012 campaign, specifically designed for studying landatmosphere interactions over the heterogeneous Barrax area, showed an increased spatial variability in wind speed and scalar concentration, slightly better $H$ estimates and slightly poorer $\lambda E$ estimates. However, inclusion of the feedback effects for the current LSM parameterization over the current area yielded deviations in flux estimates that are largely within turbulent flux observation accuracy.

\subsection{Perspectives}

As an introduction to potential future research that may build upon the results obtained in the current work, it is worthwhile to state that currently accepted errors in ground-based observation of turbulent fluxes, originating for example from closure problems (Foken, 2008; Oncley et al., 2002; Wilson et al., 2002) or footprint uncertainties (Foken \& Leclerc, 2004; Hoedjes et al., 2007; Vesala et al., 2008), are on the order of $50\left[\mathrm{~W} \cdot \mathrm{m}^{-2}\right]$ during typical midday convective conditions. Since remote sensing-based algorithms for estimating the turbulent fluxes generally utilize satellite data obtained around this time 
of the day this number is something to keep in mind when discussing potential future model improvements.

Minimization of atmospheric influence

Concerning the use and development of (simplified) remote sensing-based algorithms that utilize different parameterizations and have different input requirements it cannot be mentioned often enough that no single model will outperform all others under all conditions, as demonstrated in chapter 2. Moreover, even the most sophisticated physicallybased models currently available will contain a certain level of parameterization. Careful selection of suitable algorithms and parameterizations under given conditions will benefit largely from inter-comparison studies (Choi et al., 2009; Corbari et al., 2015; Gao \& Long, 2008; Xia et al., 2015). At the same time such studies will bring a greater sense of the level of uncertainty in mapping and monitoring of the turbulent fluxes based on remote sensing observations, also in relation to the aforementioned uncertainty in ground observations.

\section{Incorporation of surface influence}

Regarding ground observations, in chapter 4 it was shown that when dealing with large contrasts in surface heterogeneity within the footprint of the scintillometer, potentially unreliable areal aggregate estimates of sensible heat flux are obtained. Especially the simultaneous occurrence of stable and unstable conditions within the footprint can currently not be dealt with. Possibly the combination of thermal remote sensing imaging with scintillometer observations in the line of Hoedjes et al. (2007) or the combined use of microwave and optical scintillometers (van Kesteren et al., 2013) needs to be further explored to solve this problem.

Incorporation of atmospheric influence

The general idea behind this dissertation is that when one employs a resistance scheme parameterization for estimating turbulent fluxes, as is typically the case in current remote sensing-based models, incorporation of $A B L$ variability should, theoretically, improve the flux estimates. However, when doing so through the use of the coupled model over a very heterogeneous area, using current LSM and LES-SGS 
parameterizations, the flux estimates did not necessarily improve. Sensible heat flux estimates improved, whereas latent heat flux estimates deteriorated when compared to observations. This was partly due to the nature of the LSM which calculates latent heat as a rest-term. It would be worthwhile to explore whether using another well-established LSM in the coupled model that employs a resistance scheme for both $H$ and $\lambda E$ independently will yield better estimates for both $H$ and $\lambda E$.

Incorporation of recently developed dynamic scale-dependent SGS model parameterizations yielded near-wall results that better follow Monin-Obukhov Similarity Theory (MOST) over homogeneous (synthetic) surfaces. Incorporation of these SGS models over real heterogeneous surfaces indeed yielded larger deviations from decoupled flux estimates than when using traditional SGS models. However, as stated also above, results versus observations did not necessarily improve. This concerned fluxes as well as wind speed and scalar concentrations. Apart from the fact that for the land cover units not covered by eddy-covariance observations the aerodynamic and thermo-dynamic properties were estimated from simple empirical relations, this may lead one to reconsider whether the SGS models should follow MOST over heterogeneous surfaces. Recent work on this matter (Abkar \& Porte-Agel, 2012; Lu \& Porte-Agel, 2010) for a single step-change in surface roughness indicates that local application of MOST is not the most suitable approach, but that a weighted interpolation between two logarithmic profiles yields better results for local velocity. This work should be expanded towards multiple changes in surface roughness length for momentum, as well as for heat, as they occur in a natural landscape. Related to this, but not analysed in the current work in detail, is the question whether the use of average characteristics (as also is the case with the above-mentioned average between two logarithmic profiles) in the SGS models is the proper approach, given the instantaneous and turbulent nature of the atmospheric flow.

Finally, one may reconsider whether MOST is the correct approach to follow when employing remote sensing-based flux models over heterogeneous surfaces, as is currently typically the case. Naturally this is a scale problem which ultimately 
depends on the scale of the heterogeneity. With some adaptations the developed coupled model can be used over synthetic heterogeneous surfaces to test alternative approaches. Such could probably be done best in line with the work of Christen et al. (2012) and Lagouarde et al. (2015) by coupling fast-fluctuating surface temperature observations over artificial surfaces to an LES, where the coupling in this case should be done by means of an LSM-approach with an instantaneous nature instead of using MOST. 


\section{References}

Abkar M. \& Porte-Agel F. (2012) A new boundary condition for largeeddy simulation of boundary-layer flows over surface roughness transitions. Journal of Turbulence 13, 1-18. doi: 10.1080/14685248.2012.695077

Addison P. S. (2002) The illustrated wavelet transform handbook Introductory theory and applications in Science, Engineering, Medicine and Finance. Institute of Physics Publishing, Bristol (UK) ISBN 075030692 0, 353 pp.

Albertson J. D. (1996) Large eddy simulation of land-atmosphere interaction. Ph.D. Thesis, Univ. of Calif., Davis, 185 pp.

Albertson J. D., Kustas W. P. \& Scanlon T. M. (2001) Large-eddy simulation over heterogeneous terrain with remotely sensed land surface conditions. Water Resources Research 37, 19391953.

Albertson J. D. \& Parlange M. B. (1999a) Natural integration of scalar fluxes from complex terrain. Advances in Water Resources 23, 239-252.

Albertson J. D. \& Parlange M. B. (1999b) Surface length scales and shear stress: Implications for land-atmosphere interaction over complex terrain. Water Resources Research 35, 21212132.

Anderson M. C., Kustas W. P. \& Norman J. M. (2003) Upscaling and downscaling - A regional view of the Soil-Plant-Atmsophere continuum. Agronomy Journal 95, 1408-1423.

Anderson M. C., Kustas W. P. \& Norman J. M. (2007) Upscaling flux observations from local to continental scales using thermal remote sensing. Agronomy Journal 99, 240-254. doi: 10.2134/agronj2005.0096S

Anderson M. C., Norman J. M., Diak G. R., Kustas W. P. \& Mecikalski J. R. (1997) A two-source time-integrated model for estimating surface fluxes using thermal infrared remote sensing. Remote Sensing Environment 60, 195-216.

Anderson M. C., Norman J. M., Kustas W. P., Li F., Prueger J. H. \& Mecikalski J. R. (2005) Effects of vegetation clumping on twosource model estimates of surface energy fluxes from an agricultural landscape during SMACEX. Journal of Hydrometeorology 6, 892-909.

Andren A., Brown A. R., Graf J., Mason P. J., Moeng C. H., Nieuwstadt F. T. M. \& Schumann U. (1994) Large-Eddy Simulation of a neutrally stratified boundary layer: A comparison of four computer codes. Q.J.R. Meteorol. Soc. 120, 1457-1484. 
Andreu A., Timmermans W., Skokovic D. \& Gonzalez-Dugo P. (2015) Influence of component temperature derivation from dual angle thermal infrared observations on TSEB flux estimates over an irrigated vineyard. Acta Geophysica 63, 1540-1570.

Avissar R. \& Pielke R. A. (1989) A parameterization of heterogeneous land surfaces for atmospheric numerical models and its impact on regional meteorology. Monthly Weather Review 117, 21132136.

Avissar R. \& Schmidt T. (1998) An evaluation of the scale at which ground-surface heat flux patchiness affects the convective boundary layer using large-eddy simulations. Journal of the Atmospheric Sciences 55, 2666-2689.

Bastiaanssen W. G. M. (1995) Regionalization of surface flux densities and moisture indicators in composite terrain - A remote sensing approach under clear skies in Mediterranean climates. PhD thesis - Wageningen Agricultural University, The Netherlands ISBN 90-5485-465-0, pp 273.

Bastiaanssen W. G. M., Menenti M., Feddes R. A. \& Holtslag A. A. M. (1998) A remote sensing surface energy balance algorithm for land (SEBAL): 1. Formulation. Journal of Hydrology 212-213, 198-212.

Bateni S. M., Entekhabi D. \& Castelli F. (2013) Mapping evaporation and estimation of surface control of evaporation using remotely sensed land surface temperature fromm a constellation of satellites. Water Resources Research 49, 950968. 10.1002/wrcr.20071

Bateni S. M., Entekhabi D., Margulis S., Castelli F. \& Kergoat L. (2014) Coupled estimation of surface heat fluxes and vegetation dynamics from remotely sensed land surface temperature and fraction of photosynthetically active radiation. Water Resources Research 50, 8420-8440. doi: 10.1002/2013WR014573

Beare R. J., Macvean M. K., Holtslag A. A. M., Cuxart J., Esau I., Golaz J.-C., Jimenez M. A., Khairoutdinov M., Kosovic B., Lewellen D., Lund T. S., Lundquist J. K., Mccabe A., Moene A. F., Noh Y., Raasch S. \& Sullivan P. (2006) An intercomparison of large-eddy simulations of the stable boundary layer. Boundary-Layer Meteorology 118, 247-272. doi: 10.1007/s10546-004-2820-6

Bertoldi G., Albertson J. D., Kustas W. P., Li F. \& Anderson M. C. (2007) On the opposing roles of air temperature and wind speed variability in flux estimation from remotely sensed land surface states. Water Resources Research 43. doi:10.1029/2007WR005911 
Bertoldi G., Kustas W. P. \& Albertson J. D. (2008) Estimating spatial variability in atmospheric properties over remotely sensed land surface conditions. Journal of Applied Meteorology and Climatology 47, 2147-2165. doi: 10.1175/2007JAMC1828.1

Bertoldi G., Kustas W. P. \& Albertson J. D. (2013) Evaluating source area contributions from aircraft flux measurements over heterogeneous land cover by large eddy simulation. BoundaryLayer Meteorology 147, 261-279. doi: 10.1007/s10546-0129781-y

Bose S. T. \& Moin P. (2014) A dynamic slip boundary condition for wall-modelled large-eddy simulation. Physics of Fluids 26, 118.

Bou-Zeid E., Meneveau C. \& Parlange M. B. (2004) Large-eddy simulation of neutral atmospheric boundary layer flow over heterogeneous surfaces: Blending height and effective surface roughness. Water Resources Research 40, W02505. doi:10.1029/2003WR002475

Boussinesq J. (1877) Essai sur la theorie des eaux courantes. Memoires presentes par divers savants a l'Academie des Sciences de l'Institut de France 23, 1-660.

Brasseur J. G. \& Wei T. (2010) Designing large-eddy simulation of the turbulent boundary layer to capture law-of-the-wall scaling. Physics of Fluids 22, 1-21.

Brunsell N. A., Ham J. M. \& Arnold K. A. (2011) Validating remotely sensed land surface fluxes in heterogeneous terrain with large aperture scintillometry. International Journal of Remote Sensing iFirst, 1-20. doi: 10.1080/01431161.2010.508058

Brutsaert W. (1982) Evaporation into the atmosphere. Reidel, Dordrecht, The Netherlands, 299.

Brutsaert W. \& Chen D. (1996) Diurnal variation of surface fluxes during thorough drying (or severe drought) of natural prairie. Water Resources Research 32, 2013-2019.

Bsaïbes A., Prévot L., Voltz M., Lagouarde J.-P. \& Irvine M. (2006) Modelling evapotranspiration at the watershed scale using a multi-local approach. European Meteorological Society, 6th EMS / 6th ECAC, Ljubljana, Slovenia, 4- 8 September 2006.

Burridge D. M. \& Gadd A. J. (1974) The Meteorological Office Operational 10 Level Numerical Weather Prediction Model (December 1974). British Met. Office Tech. Notes 12 and 48. London Rd. Bracknell, Berkshire, RG12 2SZ, England, 57 pp.

Cammalleri C., Anderson M. C. \& Kustas W. P. (2014) Upscaling of evapotranspiration fluxes from instantaneous to daytime scales for thermal remote sensing applications. Hydrology and Earth System Sciences 18, 1885-1894. doi:10.5194/hess-181885-2014 
Campbell G. S. \& Norman J. M. (1998) An introduction to Environmental Biophysics. Springer, New York ISBN 0-38794937-2, $286 \mathrm{pp}$.

Carlson T. N. \& Ripley D. A. (1997) On the relation between NDVI, Fractional Vegetation cover, and Leaf Area Index. Remote Sensing of Environment 62, 241-252.

Chehbouni A., Hoedjes J. C. B., Rodriguez J.-C., Watts C. J., Garatuza J., Jacob F. \& Kerr Y. H. (2008) Using remotely sensed data to estimate area-averaged daily surface fluxes over a semi-arid mixed agricultural land. Agricultural and Forest Meteorology $148,330-342$.

Chehbouni A., Watts C., Lagouarde J.-P., Kerr Y. H., Rodriguez J.-C., Bonnefond J.-M., Santiago F., Dedieu G., Goodrich D. C. \& Unkrich C. (2000) Estimation of heat and momentum fluxes over complex terrain using a large aperture scintillometer. Agricultural and Forest Meteorology 105, 215-226.

Cheng Y. \& Brutsaert W. (2005) Flux-profile relationships for wind speed and temperature in the stable atmspheric boundary layer. Boundary-Layer Meteorology 114, 519-538.

Choi M., Kustas W. P., Anderson M. C., Allen R. G., Li F. \& Kjaersgaard J. H. (2009) An intercomparison of three remote sensing-based surface energy balance algorithms over a corn and soybean production region (Iowa, U.S.) during SMACEX. Agricultural and Forest Meteorology 149, 2082-2097. doi: 10.1016/j.agrformet.2009.07.002

Choudhury B. J. (1987) Relationships between vegetation indices, radiation absorption, and net photosynthesis evaluated by a sensitivity analysis. Remote Sensing Environment 22, 209233.

Choudhury B. J., Ahmed N. U., Idso S. B., Reginato R. J. \& Daughtry C. S. T. (1994) Relations between evaporation coefficients and vegetation indices studied by model simulations. Remote Sensing Environment 50, 1-17.

Christen A., Meier F. \& Scherer D. (2012) High-frequency fluctuations of surface temperatures in an urban environment. Theoretical and Applied Climatolgy 108, 301-324. doi: 10.1007/s00704011-0521-x

Corbari C., Timmermans W. \& Andreu A. (2015) Intercomparison of surface energy fluxes estimates from the FEST-EWB and TSEB models over the heterogeneous REFLEX 2012 site (Barrax, Spain). Acta Geophysica 63, 1609-1638.

Crago R. D. (1996) Conservation and variability of the evaporative fraction during the daytime. Journal of Hydrology 180, 173194. 
de Bruin H. A. R. (1987) From Penman to Makkink. Proceedings and information: TNO Committee on Hydrological Research 39, 531.

de Bruin H. A. R. (1994) Analytical solutions of the equations governing the temperature fluctuation method. BoundaryLayer Meteorology 68, 427-432.

de Bruin H. A. R., Hurk B. J. J. M. v. d. \& Kohsiek W. (1995) The scintillation method tested over a dry vineyard area. Boundary-Layer Meteorology 76, 25-40.

de Bruin H. A. R., Kohsiek W. \& Hurk B. J. J. M. v. d. (1993) A verification of some methods to determine the fluxes of momentum, sensible heat, and water vapour using standard deviation and structure parameter of scalar meteorological quantities. Boundary-Layer Meteorology 63, 231-257.

de Miguel E., Jimenez M., Perez I., Gutierrez de la Camara Ó., Munoz F. \& Gomez-Sanchez J. A. (2015) AHS and CASI processing for the REFLEX remote sensing campaign: Methods and results. Acta Geophysica 63. doi: 10.1015/acgeo-2015-0031

Deardorff J. W. (1970) A numerical study of 3 dimensional turbulent channel flow at large Reynolds numbers. Journal of fluid mechanics 41, 453-480.

Delogu E., Boulet G., Olioso A., Coudert B., Chirouze J., Ceschia E., Dantec V. L., Marloie O., Chehbouni G. \& Lagouarde J.-P. (2012) Reconstruction of temporal variations of evapotranspiration using instantaneous estimates at the time of satellite overpass. HESS 16, 2995-3010. doi:10.5194/hess16-2995-2012

Droogers P. \& Bastiaanssen W. (2002) Irrigation Performance using Hydrological and Remote Sensing Modeling. Journal of Irrigation and Drainage Engineering 128, 11-18.

Duffie J. A. \& Beckman W. A. (1991) Solar engineering of thermal processes 2nd Ed.

Dupont S., Bonnefond J.-M., Irvine M. R., Lamaud E. \& Brunet Y. (2011) Long-distance edge effects in a pine forest with a deep and sparse trunk space: In situ and numerical experiments. Agricultural and Forest Meteorology 151, 328-344. doi: $10.1016 /$ j.agrformet.2010.11.007

Dupont S. \& Brunet Y. (2008) Influence of foliar density profile on canopy flow: A large-eddy simulation study. Agricultural and Forest Meteorology 148, 976-990. 10.1016/j.agrformet.2008.01.014

Durran D. R. \& Klemp J. B. (1983) A compressible model for the simulation of moist mountain waves. Monthly Weather Review $111,2341-2361$. 
Ezzahar J. \& Chehbouni A. (2009) The use of scintillometry for validating aggregation schemes over heterogeneous grids. Agricultural and Forest Meteorology 149, 2098-2109. doi: 10.1016/j.agrformet.2009.09.004

Ezzahar J., Chehbouni A., Hoedjes J. C. B. \& Chehbouni A. (2007) On the application of scintillometry over heterogeneous grids. Journal of Hydrology 334, 493-501.

Fick A. (1855) Ueber Diffusion. Ann. Phys. u. Chemie 94, 59-86.

Foken T. (2006) 50 Years of the Monin-Obukhov similarity theory. Boundary-Layer Meteorology 119, 431-447. doi: 10.1007/s10546-006-9048-6

Foken T. (2008) The energy balance closure problem: an overview. Ecological Applications 18, 1351-1367.

Foken T. \& Leclerc M. Y. (2004) Methods and limitations in validation of footprint models. Agricultural and Forest Meteorology 127, 223-234.

Fourier J. (1822) Theorie Analytique de la Chaleur. English translation by Freeman (1878); republication by Dover, New York (1955).

French A. N., Jacob F., Anderson M. C., Kustas W. P., Timmermans W. J., Gieske A., Su Z., Su H., McCabe M. F., Li F., Prueger J. \& Brunsell N. (2005a) Corrigendum to "Surface energy fluxes with the Advanced Spaceborne Thermal Emission and Reflection radiometer (ASTER) at the Iowa 2000 SMACEX site (USA)". Remote Sensing of Environment 99, 471.

French A. N., Jacob F., Anderson M. C., Kustas W. P., Timmermans W. J., Gieske A., Su Z., Su H., McCabe M. F., Li F., Prueger J. \& Brunsell N. (2005b) Surface energy fluxes with the Advanced Spaceborne Thermal Emission and Reflection radiometer (ASTER) at the Iowa 2000 SMACEX site (USA). Remote Sensing of Environment 99, 55-65.

French A. N., Schmugge T. J., Kustas W. P., Brubaker K. L. \& Prueger J. (2003) Surface energy fluxes over El Reno, Oklahoma, using high-resolution remotely sensed data. Water Resources Research 39, 1164. doi: 10.1029/2002WR1734

Gamon J. A., Coburn C., Flanagan L. B., Huemmrich K. F., Kiddle C., Sanchez-Azofeifa G. A., Thayer D. R., Vescovo L., Gianelle D., Sims D. A., Rahman A. F. \& Pastorello G. Z. (2010) SpecNet revisited: bridging flux and remote sensing communities. Canadian Journal Remote Sensing 36, 376 - 390.

Gao Y. \& Long D. (2008) Intercomparison of remote sensing-based models for estimation of evapotranspiration and accuracy assessment based on SWAT. Hydrological Processes 22, 48504869. doi: 10.1002/hyp.7104

Garratt J. R. (1992) The atmospheric boundary layer. Cambridge University Press. Cambridge, UK. 
Gentine P., Entekhabi D., Chehbouni A., Boulet G. \& Duchemin B. (2007) Analysis of evaporative fraction diurnal behaviour. Agricultural and Forest Meteorology 143, 13-29.

Germano M., Piomelli U., Moin P. \& Cabot W. H. (1991) A dynamic subgrid-scale eddy viscosity model. Phys. Fluids A 3, 17601765.

Gieske A. \& Meijninger W. (2005) High density NOAA time series of ET in the Gediz Basin, Turkey. Irrigation and Drainage Systems 19, 285-299.

Gillespie A., Rokugawa S., Matsunaga T., Cothern J. S., Hook S. \& Kahle A. B. (1998) A temperature and emissivity separation algorithm for Advanced Spaceborne Thermal Emission and Reflection Radiometer (ASTER) images. IEEE Transactions on geoscience and remote sensing 36, 1113-1126.

Goetz S. J., Prince S. D., Goward S. N., Thawley M. M. \& Small J. (1999) Satellite remote sensing of primary production: an improved production efficiency modeling approach. Ecological Modelling 122, 239-255.

Green A. E., Astill M. S., McAneney K. J. \& Nieveen J. P. (2001) Pathaveraged surface fluxes determined from infrared and microwave scintillometers. Agricultural and Forest Meteorology 109, 233-247.

Hanna S. R. \& Chang J. C. (1991) Boundary-layer parameterizations for applied dispersion modeling over urban areas. BoundaryLayer Meteorology 58, 229-259.

Hartogensis O. K., Watts C. J., Rodriguez J.-C. \& de Bruin H. A. R. (2003) Derivation of an effective height for scintillometers: La Poza Experiment in Nortwest Mexico. Journal of Hydrometeorology 4, 915-928.

Hoedjes J. C. B., Chehbouni A., Ezzahar J., Escadafal R. \& de Bruin H. A. R. (2007) Comparison of large aperture scintillometer and eddy covariance measurements: Can thermal infrared data be used to capture footprint-induced differences? Journal of Hydrometeorology 8, 144-159.

Holtslag A. A. M., Svensson G., Baas P., Basu S., Beare B., Beljaars A. C. M., Bosveld F. C., Cuxart J., Lindvall J., Steeneveld G. J., Tjernstrom M. \& B.J.H. v. d. W. (2013) Stable Atmpospheric Boundary Layers and diurnal cycles - Challenges for Weather and Climate Models Bull. Amer. Met. Soc. 49, 1691-1706. 10.1175/BAMS-D-11-00187.1

Horst T. W. \& Weil J. C. (1992) Footprint estimation for scalar flux measurements in the atmospheric surface layer. BoundaryLayer Meteorology 59, 279-296.

Hsieh C.-I., Katul G. \& Chi T.-w. (2000) An approximate analytical model for footprint estimation of scalar fluxes in thermaaly 
stratified atmospheric flows. Advances in Water Resources 23, 765-772.

Huang H.-Y. \& Margulis S. A. (2009) On the impact of surface heterogeneity on a realistic convective boundary layer. Water Resources Research 45. doi: 10.1029/2008WR007175

Huang H.-Y., Stevens B. \& Margulis S. A. (2008) Application of dynamic subgrid-scale models for large-eddy simulation of the daytime convective boundary layer over heterogeneous surfaces. Boundary-Layer Meteorology 126, 327-348. doi: 10.1007/s10546-007-9239-9

Humes K. S., Kustas W. P. \& Goodrich D. C. (1997) Spatially distributed sensible heat flux over a semiarid watershed. Part 1: Use of radiometric surface temperaturea and a spatially uniform resistance. Journal of Applied Meteorology 36, 281292.

Humes K. S., Kustas W. P. \& Moran M. S. (1994) Use of remote sensing and reference site measurements to estimate instantaneous surface energy balance components over a semiarid rangeland watershed. Water Resources Research 30, 1363-1373.

Idso S. B., Schmugge T. J., Jackson R. D. \& Reginato R. J. (1975) The utility of surface temperature measurements for the remote sensing of the soil water status. Journal of Geophysical Research 80, 3044-3049.

Jackson R. D., Hatfield J. L., Reginato R. J., Idso S. B. \& Pinter (Jr) P. J. (1983) Estimation of daily evapotranspiration from one time-of-day measurements. Agricultural and Water Management 7, 351-362.

Jackson R. D., Idso S. B., Reginato R. J. \& Pinter (Jr) P. J. (1981) Canopy temperature as a crop water stress indicator. Water Resources Research 17, 1133-1138.

Jackson R. D., Reginato R. J. \& Idso S. B. (1977) Wheat canopy temperature: A practical tool for evaluating water requirements. Water Resources Research 13, 651-656.

Jackson T. J., Vine D. M. L., Hsu A. Y., Oldak A., Starks P. J., Swift C. T., Isham J. D. \& Haken M. (1999) Soil moisture mapping at regional scales using microwave radiometry: the Southern Great Plains hydrology experiment. IEEE Transactions on geoscience and remote sensing 37, 2136-2151.

Jacob F., Olioso A., Gu X. F., Su Z. \& Seguin B. (2002) Mapping surface fluxes using airborne visible, near infrared, thermal infrared remote sensing data and a spatialized surface energy balance model. Agronomie 22, 669-680. 
Jiang L. \& Islam S. (2001) Estimation of surface evaporation map over southern Great Plains using remote sensing data. Water Resources Research 37, 329-340.

Kader B. A. \& Yaglom A. M. (1990) Mean fields and fluctuation moments in unstably stratified turbulent boundary layers. Journal of fluid mechanics 212, 637-662.

Kalma J. D., McVicar T. R. \& McCabe M. F. (2008) Estimating Land Surface Evaporation: A Review of Methods Using Remotely Sensed Surface Temperature Data. Surveys in Geophysics 29, 421-469. doi.org/10.1007/s10712-008-9037-z.

Katul G. G. \& Albertson J. D. (1998) An investigation of higher order closure models for a forested canopy. Boundary-Layer Meteorology 89, 47-74.

Katul G. G. \& Albertson J. D. (1999) Modeling CO2 sources, sinks, and fluxes within a forest canopy. Journal of Geophysical Research 104, 6081-6091.

Kite G. W. \& Droogers P. (2000) Comparing evapotranspiration estimates from satellites, hydrological models and field data. Journal of Hydrology 229, 3-18.

Kornelsen K. C. \& Coulibalya P. (2013) Advances in soil moisture retrieval from synthetic aperture radar and hydrological applications. Journal of Hydrology 476, 460-489. doi: 10.1016/j.hydrol.2012.10.044

Kumar V., Kleissl J., Meneveau C. \& Parlange M. B. (2006) Largeeddy simulation of a diurnal cycle of the atmospheric boundary layer: Atmospheric stability and scaling issues. Water Resources Research 42, W06D09. doi: 1029/2005WR004651

Kustas W. P. \& Albertson J. D. (2003) Effects of surface temperature contrast on land-atmosphere ex-change: A case study from Monsoon 90. Water Resources Research 39, 1159-1173.

Kustas W. p., Hatfield J. L. \& Prueger J. H. (2005) The Soil-MoistureAtmosphere Couopling Experiment (SMACEX): Background, Hydrometeorological Conditions, and Preliminary Findings. Journal of Hydrometeorology 6, 791-804.

Kustas W. P., Moran M. S., Humes K. S., Stannard D. I., P.J. Pinter j., Hipps L. E., Swiatek E. \& Goodrich D. C. (1994a) Surface energy balance estimates at local and regional scales using optical remote sensing from an aircraft platform and atmospheric data collected over semiarid rangelands. Water Resources Research 30, 1241-1259.

Kustas W. P. \& Norman J. M. (1997) A two-source approach for estimating turbulent fluxes using multiple angle thermal infrared observations. Water Resources Research 33, 14951508. 
Kustas W. P. \& Norman J. M. (1999) Evaluation of soil and vegetation heat flux predictions using a simple two-source model with radiometric temperatures for partial canopy cover. Agricultural and Forest Meteorology 94, 13-29.

Kustas W. P. \& Norman J. M. (2000) Evaluating the effects of subpixel heterogeneity on pixel average fluxes. Remote Sensing Environment 74, 327-342.

Kustas W. P., Perry E. M., Doraiswamy P. \& Moran S. (1994b) Using satellite remote sensing (to extrapolate evapotranspiration estimates in time and space over a semiarid rangeland basin). Remote Sensing of Environment 49, 275-286.

Kustas W. P., Zhan X. \& Schmugge T. J. (1998) Combining optical and microwave remote sensing for mapping energy fluxes in a semiarid watershed. Remote Sensing Environment 64, 116131.

Lagouarde J.-P., Bonnefond J.-M., Kerr Y. H., McAneney K. J. \& Irvine M. (2002a) Integrated sensible heat flux measurements of a two-surface composite landscape using scintillometry. Boundary-Layer Meteorology 105, 5-35.

Lagouarde J.-P., Irvine M. \& Dupont S. (2015) Atmospheric turbulence induced errors on measurements of surface temperature from space. Remote Sensing of Environment 168, 40-53. doi: $10.1016 /$ j.rse.2015.06.018

Lagouarde J.-P., Jacob F., Gu X. F., Olioso A., Bonnefond J.-M., Kerr Y., Mcaneney K. J. \& Irvine M. (2002b) Spazialization of sensible heat flux over a heterogeneous landscape. Agronomie 22, 627-633.

Liang S. (2000) Narrowband to broadband conversions of land surface albedo: I. Algorithms. Remote Sensing Environment 76, 213-238.

Lilly D. K. (1992) A proposed modification of the Germano subgridscale closure method. Phys. Fluids A 4, 633-635.

Lu H. \& Porte-Agel F. (2010) A modulated gradient model for largeeddy simulation: Application to a neutral atmospheric boundary layer. Physics of Fluids 22, 015109.

Mahrt L., McPherson J. I. \& Desjardins R. (1994) Observations of fluxes over heterogeneous surfaces. Boundary-Layer Meteorology 67, 345-367.

Mason P. J. \& Callen N. S. (1986) On the magnitude of the subgridscale eddy coefficient in large-eddy simulations of turbulent channel flow. Journal of fluid mechanics 162, 439-462.

Massman W. J. (1997) An analytical one-dimensional model of momentum transfer by vegetation of arbitrary strucutre. Boundary-Layer Meteorology 83, 407-421. 
McAneney K. J., Green A. E. \& Astill M. S. (1995) Large-Aperture Scintillometry: the homogeneous case. Agricultural and Forest Meteorology 76, 149-162.

McCabe M. F. \& Wood E. F. (2006) Scale influences on the remote estimation of evapotranspiration using multiple satellite sensors. Remote Sensing of Environment 105, 271-285.

Mecikalski J. r., Diak G. R., Anderson M. C. \& Norman J. M. (1999) Estimating fluxes on continental scales using remotely sensed data in an atmospheric-land exchange model. Journal of Applied Meteorology 38, 1352-1369.

Meijninger W. M. L. (2003) Surface fluxes over natural landscapes using scintillometry. Ph.D. Dissertation, Wageningen University, Wageningen, The Netherlands.

Meijninger W. M. L. \& de Bruin H. A. R. (2000) The sensible heat fluxes over irrigated areas in western Turkey determined with a large aperture scintillometer. Journal of Hydrology 229, 4249.

Meijninger W. M. L., Hartogensis O., Kohsiek W., Hoedjes J. C. B., Zuurbier R. M. \& de Bruin H. A. R. (2002) Determination of area-averaged sensible heat fluxes with a large aperture scintillometer over a heterogeneous surface - Flevoland field experiment. Boundary-Layer Meteorology 105, 37-62.

Menenti M., Bastiaanssen W. G. M. \& Eick D. v. (1989) Determination of surface hemispherical reflectance with Thematic Mapper data. Remote Sensing of Environment 28, 327-337.

Menenti M. \& Choudhury B. J. (1993) Parameterization of land surface evaporation by means of location dependant potential evaporation and surface temperature range. Exchange Processes at the Land surface for a range of space and time scales Proceedings of the Yokohama Symposium.

Mishra A. K. \& Singh V. P. (2011) Drought monitoring - A review. Journal of Hydrology 403, 157-175. doi: 10.1016/j.hydrol.2011.03.049

Moeng C.-H. (1984) A large-eddy-simulation model for the study of planetary boundary-layer turbulence. Journal of the Atmospheric Sciences 41, 2052-2062.

Monin A. S. \& Obukhov A. M. (1954) Osnovnye zakonomernosti turbulentnogo peremeshivanija $v$ prizemnom sloe atmosfery (Basic Laws of Turbulent Mixing in the Atmosphere Near the Ground). Trudy geofiz. inst. AN SSSR 24, 163-187.

Monteith J. L. \& Unsworth M. H. (1990) Principles of Environmental Physics. Edward Arnold Publishers, London, $291 \mathrm{pp}$.

Newton I. (1686) The Principia, Mathematical Principles of Natural Philosophy. translation by I. Bernard Cohen and Anne Whitman, University of California Press, 1999. 
Nichols W. E. \& Cuenca R. H. (1993) Evaluation of the evaporative fraction for parameterization of the surface energy balance. Water Resources Research 29, 3681-3690.

Nieuwstadt F. T. M., Mason P. J., Moeng C.-H. \& Schumann U. (1993) Large-Eddy Simulation of the Convective Boundary Layer: A Comparison of Four Computer Codes. Turbulent Shear Flows 8, 343-367.

Norman J. M., Anderson M. C. \& Kustas W. P. (2006) Are SingleSource, Remote-Sensing Surface-Flux Models Too Simple? Proceedings of the International Conference on Earth Observation for Vegetation Monitoring and Water Management. (Editors: G.D'Urso, M.A. Osann Jochum, J.Moreno) American Institute of Physics 852.

Norman J. M., Kustas W. P. \& Humes K. S. (1995) Source approach for estimating soil and vegetation energy fluxes in observations of directional radiometric surface temperature. Agricultural and Forest Meteorology 77, 263-293.

Norman J. M., Kustas W. P., Prueger J. H. \& Diak G. R. (2000) Surface flux estimation using radiometric temperature: A dualtemperature-difference method to minimize measurement errors. Water Resources Research 36, 2263-2274.

Novick K., Brantley S., Miniat C. F., Walker J. \& Vosee J. M. (2014) Inferring the contribution of advection to total ecosystem scalar fluxes over a tall forest in complex terrain. Agricultural and Forest Meteorology 185, 1-13. doi: 10.1016/j.agrformet.2013.10.010

Oncley S., Foken T., Vogt R., Bernhofer C., Kohsiek W., Liu H., Pitacco A., Grantz D., Ribeiro L. \& Weidinger T. (2002) The energy balance experiment EBEX-2000. Proc. of the 15th Symposium on Boundary Layers and Turbulence, American Meteorological society (AMS), 15-19 July 2002, Wageningen University, Wageningen, The Netherlands.

Panofsky H. A. \& Dutton J. A. (1984) Atmospheric Turbulence: Models and Methods for Engineering Applications. John Wiley \& Sons, New York, 397 pp.

Parlange M. B., Eichinger W. E. \& Albertson J. D. (1995) Regional scale evaporation and the atmospheric boundary layer. Reviews of Geophysics 33, 99-124.

Patton E. G., Sullivan P. P. \& Moeng C. H. (2005) The influence of idealized heterogeneity on wet and dry planetary boundary layers coupled to the land surface. Journal of the Atmospheric Sciences 62, 2078-2097.

Pauwels V. R. N., Timmermans W. J. \& Loew A. (2008) Comparison of the estimated water and energy budgets of a large winter wheat field during AgriSAR 2006 by multiple sensors and 
models. Journal of Hydrology 349, 425-440. doi:10.1016/j.jhydrol.2007.11.016

Pelgrum H. \& Bastiaanssen W. G. M. (1996) An intercomparison of techniques to determine the area-averaged latent heat flux from individual in situ observations: Aremote sensing approach using the European Field Experiment in a Desertification-Threatened Area data. Water Resources Research 32, 2775-2786.

Piomelli U., Moin P. \& Ferziger J. H. (1988) Model consistency in large eddy simulation of turbulent channel flows. Physics of Fluids 31, 1884-1891.

Podvin B. \& Fraigneau Y. (2014) POD-based wall boundary conditions for the numerical simulation of turbulent channel flows. Journal of Turbulence 15, 145-171. doi: $10.1080 / 14685248.2014 .884279$

Porte-Agel F. (2004) A scale-dependent dynamic model for scalar transport in large-eddy simulations of the atmospheric boundary layer. Boundary-Layer Meteorology 112, 81-105.

Porte-Agel F., Meneveau C. \& Parlange M. B. (2000) A scaledependent dynamic model for large-eddy simulation: application to a neutral atmospheric boundary layer. Journal of fluid mechanics 415, 261-284.

Price J. C. (1982) Estimation of regional scale evapotranspiration through analysis of satellite thermal-infrared data. IEEE Transactions Geoscience and Remote Sensing GE-20, 286292.

Priestly C. H. B. \& Taylor R. J. (1972) On the assessment of surface heat flux and evaporation using large-scale parameters. Monthly Weather Review 100, 81-92.

Prihodko L. \& Goward S. N. (1997) Estimation of air temperature from remotely sensed surface observations. Remote Sensing Environment 60, 335-346.

Prince S. D., Goetz S. J., Dubayah R. O., Czajkowski K. P. \& Thawley M. (1998) Inference of surface and air temperature, atmospheric precipitable water and vapor pressure deficit using Advanced Very High-Resolution Radiometer satellite observations: comparison with field observations. Journal of Hydrology 212, 230-249.

Prueger J. H., Alfieri J. G., Hipps L. E., Kustas W. P., Chavez J. L., Evett S. R., Anderson M. C., French A. N., Neale C. M. U., McKee L. G., Hatfield J. L., Howell T. A. \& Agam N. (2012) Patch scale turbulence over dryland and irrigated surfaces in a semi-arid landscape under advective conditions during BEAREX08. Advances in Water Resources 50, 106-119. doi: 10.1016/j.advwatres.2012.07.014 
Prueger J. H., Hatfield J. L., Kustas W. P., Hipps L. E., MacPherson J. I. \& Parkin T. B. (2005) Tower and aircraft eddy covariance measurements of water, energy and carbon fluxes during SMACEX. Journal of Hydrometeorology 6, 954-960.

Raju A., Parekh A., Kumar P. \& Gnanaseelan C. (2015) Evaluation of the impact of AIRS profiles on prediction of Indian summer monsoon using WRF variational data assimilation system. Journal of Geophysical Research: Atmospheres 120, 81128131. doi: 10.1002/2014JD023024

Rast M., Johannessen J. \& Mauser W. (2014) Review of Understanding of Earth's Hydrological Cycle: Observations, Theory and Modelling. Surveys in Geophysics 35, 491-513. doi: $10.1007 / \mathrm{s} 10712-014-9279-x$

Reynolds O. (1874) On the extent and action of the heating surface for steam boilers. Proc. Manchester Liter. Phil. Soc. 14, 7-12.

Rodell M., Houser P. R., Jambor U., Gottschalk J., Mitchell K., Meng C.-J., Arsenault K., Cosgrove B., Radakovich J., Bosilovich M., Entin K., Walker J. P., Lohmann D. \& Toll D. (2004) The global land and data assimilation system. Bulletin American Meteorological Society 85, 381-394. doi: 10.1175/BAMS-85-3381

Roerink G. J., Su Z. \& Menenti M. (2000) S-SEBI: A simple remote sensing algorithm to estimate the surface energy balance. Physics and Chemistry of the Earth (B) 25, 147-157.

Salama M. S., van der Velde R., van der Woerd H. J., Kromkamp J. C., Philippart C. J. M., Joseph A. T., O'Neill P. E., Lang R. H., Gish T., Werdell P. J. \& Su Z. (2012) Technical Note: Calibration and validation of geophysical observation models. Biogeosciences 9, 2195-2201. doi: 10.5194/bg-9-2195-2012

Santanello J. A. \& Freidl M. A. (2003) Diurnal covariation in soil heat flux and net radiation. Journal of Applied Meteorology 42, 851862.

Schmid H. P. (1994) Source areas for scalars and scalar fluxes. Boundary-Layer Meteorology 67, 293-318.

Schmid H. P. (2002) Footprint modeling for vegetation atmosphere exchange studies: a review and perspective. Agricultural and Forest Meteorology 113, 159-183.

Schmidt H. \& Schumann U. (1989) Coherent structure of the convective boundary layer derived from large-eddy simulations. Journal of fluid mechanics 200, 511-562. doi: $10.1017 /$ S0022112089000753

Schomburg A., Venema V., Lindau R., Ament F. \& Simmer C. (2010) A downscaling scheme for atmospheric variables to drive soilvegetation-atmosphere transfer models. Tellus series $B$ - 
Chemical and physical meteorology 62B, 242-258. doi: 10.1111/j.1600-0889.2010.00466.x

Schuepp P. H., Leclerc M. Y., Macpherson J. I. \& Desjardins R. L. (1990) Footprint prediction of scalar fluxes from analytical solutions of the diffusion equation. Boundary-Layer Meteorology 50, 355-373.

Senay G. B., Bohms S., Singh R. K., Gowda P. H., Velpuri N. M., Alemu H. \& VErdin K. P. (2013) Operational evapotranspiration mapping using remote sensing and weather datasets: A new parameterization for the SSEB approach. Journal of the American Water Resources Association 49, 577-591.

Seneviratne S. I., Corti T., Davin E. L., Hirschi M., Jaeger E. B., Lehner I., Orlowsky B. \& Teuling A. J. (2010) Investigating soil moisture-climate interactions in a changing climate: A review. Earth-Science Reviews 99, 125-161. doi: 10.1016/j.earscirev.2010.02.004

Shao Y., Liu S., Schween J. H. \& Crewell S. (2013) Large-eddy atmosphere-land-surface modelling over heterogeneous surfaces: Model development and comparison with measurements. Boundary-Layer Meteorology 148, 333-356. doi: $10.1007 / \mathrm{s} 10546-013-9823-0$

Shaw R. H. \& Pereira A. R. (1982) Aerodynamic roughness of a plant canopy: A numerical experiment. Agricultural Meteorology 26, 51-65.

Shuttleworth W. J., Gurney R. J., Hsu A. Y. \& Ormsby J. P. (1989) FIFE: The variation in energy partition at surface flux sites. IAHS Publication 186, 67-74.

Smagorinsky J. (1963) General circulation experiments with the primitive equations. I: The basic experiment. Monthly Weather Review 91, 99-165.

Sobrino J. A., Jimenez-Munoz J. C., Zarco-Tejada P. J., SepulcreCanto G., Miguel E. d., Soria G., Romaguera M., Julien Y., Cuenca J., Hidalgo V., Franch B., Mattar C., Morales L., Gillespie A., Sabol D., Balick L., Su Z., Jia L., Gieske A., Timmermans W. J., Olioso A., Nerry F., Guanter L., Moreno J. \& Shen Q. (2009) Thermal remote sensing from Airborne Hyperspectral Scanner data in the framework of the SPARC and SEN2FLEX projects: an overview. HESS 13, 2031-2037.

Soegaard H., Jensen N. O., Boegh E., Hasager C. B., Schelde K. \& Thomsen A. (2003) Carbon dioxide exchange over agricultural landscape using eddy correlation and footprint modelling. Agricultural and Forest Meteorology 114, 153-173.

Stoll R. \& Porte-Agel F. (2006) Dynamic subgrid-scale models for momentum and scalar fluxes in large eddy simulations of neutrally stratified atmospheric boundary layers over 
heterogeneous terrain. Water Resources Research 42. doi: $10.1029 / 2005$ WR003989

Stoll R. \& Porte-Agel F. (2008) Large-eddy simulation of the stable atmospheric boundary layer using dynamic models with different averaging schemes. Boundary-Layer Meteorology $126,1-28$.

Stull R. B. (1988) An Introduction to Boundary Layer Meteorology. Kluwer Academic Publishers.

Su Z. (2002) The Surface Energy Balance System (SEBS) for estimation of turbulent heat fluxes. Hydrology and Earth System Sciences 6, 85-99.

Su Z., Jia L., Jin X., Elbers J., Gieske A., Timmermans W. J., Kwast H. v. d., Olioso A., Sobrino J. A., Moreno J., Nerry F. \& Sabol D. (2005) In-situ measurements of land-atmosphere exchanges of water, energy and carbon dioxide in space and time over the heterogeneous BARRAX site during SPARC2004. ESA Proceedings WPP-250, SPARC Final Workshop, ITC Enschede, 4-5 July 2005, The Netherlands.

Su Z., Roebeling R. A., Schulz J., Holleman I., Levizzani V., Timmermans W. J., Rott H., Mognard-Campbell N., de Jeu R., Wagner W., Rodell M., Salama M. S., Parodi G. N. \& Wang L. (2011) Observation of Hydrological Processes Using Remote Sensing. In: Peter Wilderer (ed.) Treatise on Water Science, vol. 1, pp. 351-399 Oxford: Academic Press.

Su Z., Timmermans W. J., Gieske A. S. M., Jia L., Elbers J. A., Olioso A., Timmermans J., Van der Velde R., Jin X., Van der Kwast H., Sabol D., Sobrino J. A., Moreno J. \& Bianchi R. (2008) Quantification of land-atmosphere exchanges of water, energy and carbon dioxide in space and time over the heterogeneous Barrax site. International Journal of Remote Sensing 29, 52155235. doi: 10.1080/01431160802326099

Tasumi M., Allen R. G. \& Bastiaanssen W. G. M. (2000) The theoretical basis of SEBAL. In: Morse et.al. (2000).

Timmermans J., Su Z., van der Tol C., Verhoef A. \& Verhoef W. (2013) Quantifying the uncertainty of surface-atmosphere fluxes through joint evaluation of the SEBS and SCOPE models. Hydrol. Earth Syst. Sci. 17, 1561-1573. doi: 10.5194/hess-17-1561-2013

Timmermans W., Tol C. v. d., Timmermans J., Ucer M., Chen X., Alonso L., Moreno J., Carrara A., Lopez R., Tercero F. d. I. C., Corcoles H. L., Miguel E. d., Sanchez J. A. G., Pérez I., Franch B., Munoz J.-C. J., Skokovic D., Sobrino J., Soria G., MacArthur A., Vescovo L., Reusen I., Andreu A., Burkart A., Cilia C., Contreras S., Corbari C., Calleja J. F., Guzinski R., Hellmann C., Herrmann I., Kerr G., Lazar A.-L., Leutner B., 
Mendiguren G., Nasilowska S., Nieto H., Pachego-Labrador J., Pulanekar S., Raj R., Schikling A., Siegmann B., Bueren S. v. \& Su Z. (2015a) An overview of the Regional Experiments For Land-atmosphere Exchanges (REFLEX) 2012 Campaign. Acta Geophysica 63, 1465-1484. doi: 10.2478/s11600-014-0254-1

Timmermans W. J., Bertoldi G., Albertson J. D., Olioso A., Su Z. \& Gieske A. S. M. (2008) Accounting for atmospheric boundary layer variability on flux estimation from RS observations. International Journal of Remote Sensing 29, 5275-5290. doi:10.1080/01431160802036383

Timmermans W. J., Kustas W. P., Anderson M. C. \& French A. N. (2007) An Intercomparison of the Surface Energy Balance Algorithm for Land (SEBAL) and the Two-Source Energy Balance (TSEB) Modeling Schemes. Remote Sensing of Environment 108, 369-384.

Timmermans W. J., Kustas W. P. \& Andreu A. (2015b) Utility of an automated thermal-based approach for monitoring evapotranspiration. Acta Geophysica 63, 1571-1608. doi: 10.1515/acgeo-2015-0016

Timmermans W. J., Su Z. \& Olioso A. (2009) Footprint issues in scintillometry over heterogeneous landscapes. Hydrol. Earth Syst. Sci. 13, 2179-2190.

Twine T. E., Kustas W. P., Norman J. M., Cook D. R., Houser P. R., Meyers T. P., Prueger J. H., Starks P. J. \& Wesely M. L. (2000) Correcting eddy-covariance flux underestimates over a grassland. Agricultural and Forest Meteorology 103, 279-300.

Van der Kwast J., Timmermans W. J., Gieske A. S. M., Su Z., Olioso A., Jia L., Elbers J., Karssenberg D. \& de Jong S. (2009) Evaluation of the Surface Energy Balance System (SEBS) applied to ASTER imagery with flux-measurements at the SPARC 2004 site (Barrax, Spain). Hydrol. Earth Syst. Sci. 13, 1337-1347.

Van der Tol C. (2012) Validation of remote sensing of bare soil ground heat flux. Remote Sensing of Environment 121, 275286.

Van der Tol C., Timmermans W., Corbari C., Carrara A., Timmermans J. \& Su Z. (2015) An analysis of turbulent heat fluxes and the energy balance during the REFLEX campaign. Acta Geophysica 63, 1516-1539. doi: 10.1515/acgeo-2015-0061

Van Dijk A. I. J. M. \& Renzullo L. J. (2011) Water resource monitoring systems and the role of satellite observations. Hydrol. Earth Syst. Sci. 15, 39-55. doi:10.5194/hess-15-39-2011

van Driest E. R. (1956) On turbulent flow near a wall. Journal of the Aeronautical Sciences 23, 1007-1011. 
van Kesteren B., Hartogensis O. K., van Dinther D., Moene A. F. \& de Bruin H. A. R. (2013) Measuring $\mathrm{H} 2 \mathrm{O}$ and $\mathrm{CO} 2$ fluxes at field scales with scintillometry: Part 1 - Introduction and validation of four methods. Agricultural and Forest Meteorology 178-179, 75-87. doi: 10.1016/j.agrformet.2012.09.013

Vercauteren N., Bou-Zeid E., Parlange M. B., Lemmin U., Huwald H., Selker H. \& Meneveau C. (2008) Sub-grid scale dynamics of water vapour, heat and momentum over a lake. BoundaryLayer Meteorology 128, 205-228. doi: 10.1007/s10546-0089287-9

Vesala T., Kljun N., Rannik U., Rinne J., Sogachev A., Markkanen T., Sabelfeld K., Foken T. \& Leclerc M. Y. (2008) Flux and concentration footprint modelling: State of the art. Environmental Pollution 152, 653-666. doi: 10.1016/j.envpol.2007.06.070

Von Randow C., Kruijt B. \& Holtslag A. A. M. (2008) Exploring eddycovariance and large-aperture scintillometer measurements in an Amazonian rain forest. Agricultural and Forest Meteorology $148,680-690$.

Wang K. \& Dickinson R. E. (2012) A review of global terrestrial evapotranspiration: Observation, modeling, climatology, and climatic variability. Reviews of Geophysics 50, RG2005. doi:10.1029/2011RG000373

Watts C. J., Chehbouni A., Rodriguez J.-C., Kerr Y. H., Hartogensis O. \& de Bruin H. A. R. (2000) Comparison of sensible heat flux estimates using AVHRR with scintillometer measurements over semi-arid grassland in northwest Mexico. Agricultural and Forest Meteorology 105, 81-89.

Wieringa J. (1986) Roughness-dependent geographical interpolation of surface wind speed averages. Q.J.R. Meteorol. Soc. 112, 867-889.

Willmot C. J. (1984) On the evaluation of model performance in physical geography. In Spatial Statistics and Models. G.L. Gaile and C.J. Willmott, Eds. D. Reidel, 443-459.

Wilson K., Goldstein A., Falge E., Aubinet M., Baldocchi D., Berbigier P., Bernhofer C., Ceulemans R., Dolman H., Field C., Grelle A., Ibrom A., Law B. E., Kowalski A., Meyers T., Moncrieff J., Monson R., Oechel W., Tenhunen J., Valentini R. \& Verma S. (2002) Energy balance closure at FLUXNET sites. Agricultural and Forest Meteorology 113, 223-243.

Wu H. \& Li Z.-L. (2009) Scale Issues in Remote Sensing: A Review on Analysis, Processing and Modeling. Sensors 9, 1768-1793. doi: $10.3390 / s 90301768$ 
Wyngaard J. C., Izumi Y. \& Collins S. A. (1971) Behavior of the refractive-index-structure parameter near the ground. Journal of the Optical Society of America 61, 1646-1650.

Xia T., Kustas W. P., Anderson M. C., Alfieri J. G., Gao F., McKee L., Prueger J. H., Geli H. M. E., Neale C. M. U., Sanchez L., Alsina M. M. \& Wang Z. (2015) Mapping evapotranspiration with high resolution aircraft imagery over vineyards using one and two source modeling schemes. HESSD 12, 11905-11957.

Yebra M., van Dijk A., Leuning R., Huete A. \& Guerschman J. P. (2013) Evaluation of optical remote sensing to estimate actual evapotranspiration and canopy conductance. Remote Sensing Environment 129, 250-261. doi: 10.1016/j.rse.2012.11.004

Zhan X., Kustas W. P. \& Humes K. S. (1996) An intercomparison study on models of sensible heat flux over partial canopy surfaces with remotely sensed surface temperature. Remote Sensing Environment 58, 242-256. 


\title{
List of abbreviations
}

\author{
$A B L$ - Atmospheric Boundary Layer \\ AHS - Airborne Hyperspectral Scanner \\ AIRS - Atmospheric InfraRed Sounder \\ ALEXI - Atmosphere Land EXchange Inverse \\ ALTERRA - Alterra Wageningen University \& Research Centre \\ AOT - Aerosol Optical Thickness \\ ARS - Agricultural Research Service \\ ASD - Analytical Spectral Devices \\ ASTER - Advanced Space-borne Thermal Emission and reflection \\ Radiometer \\ AVHRR - Advanced Very High Resolution Radiometer \\ BRDF - Bidirectional Reflectance Distribution Function \\ CASI - Compact Airborne Spectrographic Imager \\ CCD - Charge Coupled Device \\ CFD - Computational Fluid Dynamics \\ CHRIS - Compact High Resolution Imaging Spectrometer \\ DATTUTDUT - Deriving Atmosphere Turbulent Transport Useful To \\ Dummies Using Temperature \\ disALEXI - Disaggregated Atmosphere Land EXchange Inverse \\ DOY - Day Of Year \\ DWT - Discrete Wavelet Transform \\ EC - Eddy Covariance \\ EOS - Earth Observing System \\ ESA - European Space Agency \\ ET - EvapoTranspiration \\ EUFAR - EUropean Facility for Airborne Research \\ EUROSPEC - SPECtral sampling tools for vegetation biophysical \\ parameters and flux measurements in EURope \\ fAPAR - fraction of Absorbed Photosynthetically Active Radiation \\ FOV - Field Of View \\ FP7 - 7th Framework Programme \\ FTIR - Fourier Transform Infrared Spectrometer \\ FVC - Fractional Vegetation Cover \\ GCM - General Circulation Model \\ GDRS - General Directorate of Rural Services \\ HRV - High Resolution Visible \\ IFOV - Instantaneous Field Of View \\ INRA - Institut National de la Recherche Agronomique \\ INTA - Instituto Nacional Técnica Aeroespacial \\ ITAP - Instituto Técnico Agronómico Provincial \\ IWMI - International Water Management Institute \\ LAI - Leaf Area Index
}




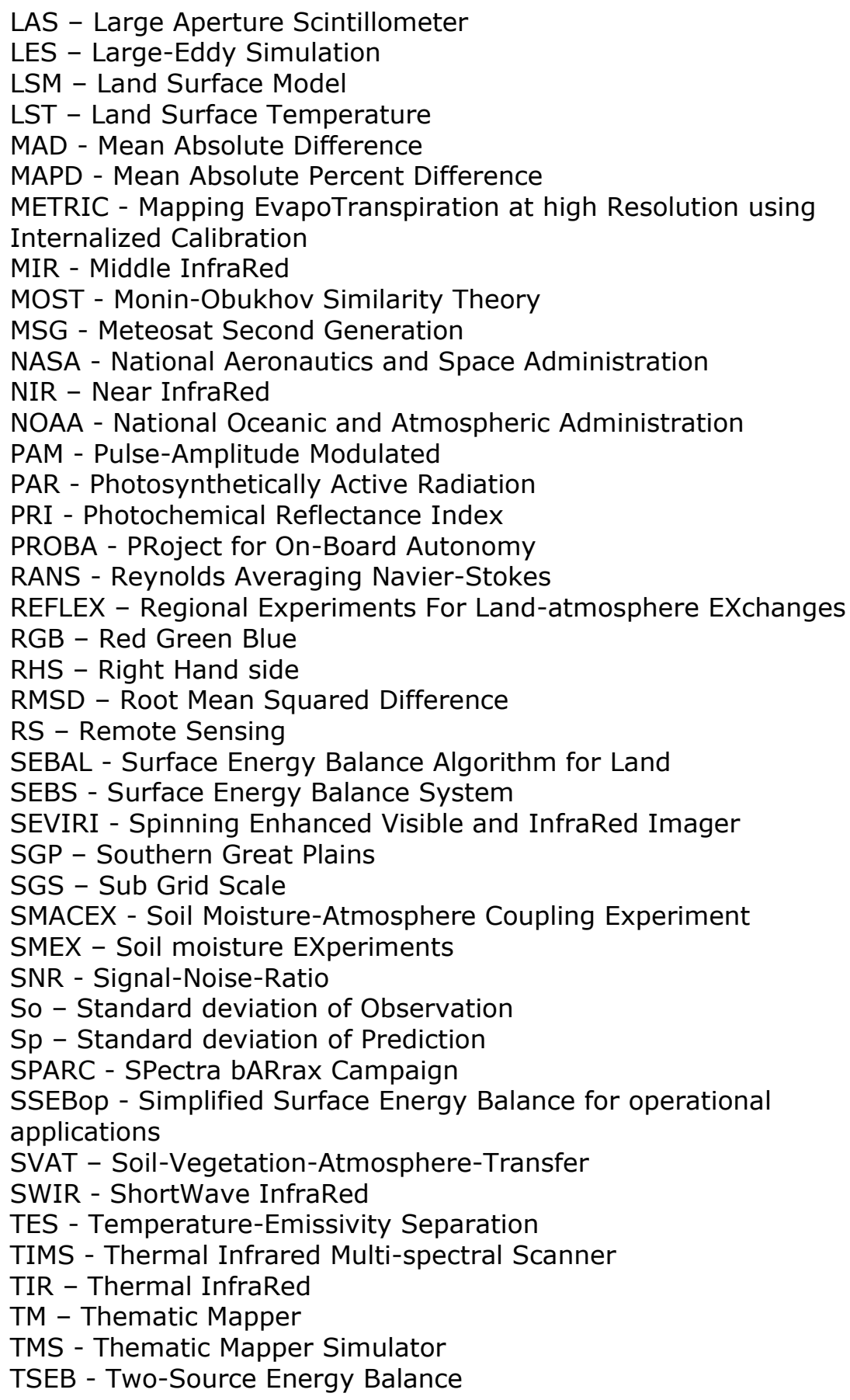


UMARF - Unified Meteorological Archive and Retrieval Facility USDA - United States Department of Agriculture

UTC - Coordinated Universal Time

VIS - Visible

VNIR - Visible and Near InfraRed 


\title{
List of symbols
}

\author{
General symbols \\ $B^{-1} \quad$ sublayer Stanton number [-] \\ C scalar concentration \\ $c_{1} \quad$ constant to convert instantaneous to daily albedo [-] \\ $c_{\mathrm{p}} \quad$ specific heat of air at constant pressure $\left[\mathrm{J} \cdot \mathrm{kg}^{-1} \cdot \mathrm{K}^{-1}\right]$ \\ $C_{S} \quad$ Smagorinsky constant [-] \\ $c_{\mathrm{T} 1,2,3}$ empirical constants in stability function for heat transfer[-] \\ $C_{\mathrm{N}}{ }^{2}$ structure parameter of the refractive index of air $\left[\mathrm{m}^{-2 / 3}\right]$ \\ $C_{\mathrm{T}}{ }^{2} \quad$ structure parameter for temperature $\left[\mathrm{K} \cdot \mathrm{m}^{-2 / 3}\right]$ \\ $d_{0} \quad$ zero-plane displacement height [m] \\ $D_{\mathrm{T}} \quad$ eddy diffusivity $\left[\mathrm{m}^{2} \cdot \mathrm{s}^{-1}\right]$ \\ E evaporation rate of water per unit area $\left[\mathrm{kg} \cdot \mathrm{s}^{-1} \cdot \mathrm{m}^{-2}\right]$ \\ $f_{\mathrm{c}} \quad$ fractional canopy cover [-] \\ $F \quad$ footprint contribution, or source strength [-] \\ $g \quad$ acceleration of gravity $\left[\mathrm{m} \cdot \mathrm{s}^{-2}\right]$ \\ $G \quad$ soil heat flux $\left[\mathrm{W} \cdot \mathrm{m}^{-2}\right]$ \\ $h_{\mathrm{c}} \quad$ canopy height $[\mathrm{m}]$ \\ $H \quad$ sensible heat flux $\left[\mathrm{W} \cdot \mathrm{m}^{-2}\right]$ \\ $H_{\mathrm{C}} \quad$ canopy sensible heat flux $\left[\mathrm{W} \cdot \mathrm{m}^{-2}\right]$ \\ $H_{\text {LAS }} \quad$ LAS derived sensible heat flux $\left[\mathrm{W} \cdot \mathrm{m}^{-2}\right]$ \\ $H_{\text {ref }} \quad$ reference sensible heat flux $\left[\mathrm{W} \cdot \mathrm{m}^{-2}\right]$ \\ $H_{\mathrm{S}} \quad$ soil sensible heat flux $\left[\mathrm{W} \cdot \mathrm{m}^{-2}\right]$ \\ $H_{\text {sim }} \quad$ LAS simulated sensible heat flux $\left[\mathrm{W} \cdot \mathrm{m}^{-2}\right]$ \\ $I \quad$ irradiance $\left[\mathrm{W} \cdot \mathrm{m}^{-2}\right]$ \\ $J_{1} \quad$ Bessel function of the first kind of order one [-] \\ $k$ von Karman constant [-] \\ $k_{\mathrm{i}} \quad$ optical wave number $\left[\mathrm{m}^{-1}\right]$ \\ $K \quad$ three-dimensional spatial wave number $\left[\mathrm{m}^{-1}\right]$ \\ $L \quad$ Monin-Obhukov length [m] \\ $L_{z} \quad$ height of domain [m] \\ $p \quad$ pressure $\left[\mathrm{kg} \cdot \mathrm{m}^{-1} \cdot \mathrm{s}^{-2}\right]$, or $[\mathrm{Pa}]$ \\ $P \quad$ LAS path length $[\mathrm{m}]$ \\ $P_{\mathrm{r}} \quad$ Prandtl number $[-]$ \\ $q \quad$ specific humidity $\left[\mathrm{g} \cdot \mathrm{kg}^{-1}\right]$ \\ $q_{0} \quad$ air specific humidity at the surface $\left[\mathrm{g} \cdot \mathrm{kg}^{-1}\right]$ \\ $q_{\mathrm{a}} \quad$ air specific humidity $\left[\mathrm{g} \cdot \mathrm{kg}^{-1}\right]$ \\ $q_{\text {mix }} \quad$ mixed layer specific humidity $\left[\mathrm{g} \cdot \mathrm{kg}^{-1}\right]$
}

* In multi-disciplinary science the dual use of symbols is nearly unavoidable. Here an attempt is made to avoid confusion where possible while maintaining common standards. 
$q_{*} \quad$ humidity scaling parameter $\left[\mathrm{g} \cdot \mathrm{kg}^{-1}\right]$

$r_{\mathrm{aH}}$ aerodynamic resistance to heat transport $\left[\mathrm{s} \cdot \mathrm{m}^{-1}\right]$

$r_{\mathrm{av}} \quad$ aerodynamic resistance to vapour transport $\left[\mathrm{s} \cdot \mathrm{m}^{-1}\right]$

$r f p_{\mathrm{i}} \quad$ relative footprint contribution [-]

$r_{\mathrm{i}} \quad$ proportional area within LAS footprint [-]

$r_{\mathrm{s}} \quad$ soil resistance to heat transport $\left[\mathrm{s} \cdot \mathrm{m}^{-1}\right]$

$r_{\mathrm{t}} \quad$ relaxation time [s]

$r_{\mathrm{x}} \quad$ canopy resistance to heat transport $\left[\mathrm{s} \cdot \mathrm{m}^{-1}\right]$

$R_{\mathrm{L}} \quad$ longwave radiation $\left[\mathrm{W} \cdot \mathrm{m}^{-2}\right.$ ]

$R_{\mathrm{N}} \quad$ net radiation $\left[\mathrm{W} \cdot \mathrm{m}^{-2}\right]$

$R_{\mathrm{S}} \quad$ shortwave radiation $\left[\mathrm{W} \cdot \mathrm{m}^{-2}\right]$

$s \quad$ saturation vapour pressure slope $\left[\mathrm{kg} \cdot \mathrm{m}^{-1} \cdot \mathrm{s}^{-2} \cdot \mathrm{K}^{-1}\right]$, or $\left[\mathrm{Pa} \cdot \mathrm{K}^{-1}\right]$

$S_{\text {exo }} \quad$ exo-atmospheric radiation $\left[\mathrm{MJ} \cdot \mathrm{m}^{-2}\right]$

$S_{i j} \quad$ strain rate $\left[\mathrm{s}^{-1}\right]$

$S_{c} \quad$ Schmidt number [-]

$t \quad$ time $[\mathrm{s}]$

$T \quad$ temperature $[\mathrm{K}]$

$T_{*} \quad$ temperature scaling parameter $[\mathrm{K}]$

$T_{0} \quad$ aerodynamic surface temperature $[\mathrm{K}]$

$T_{\mathrm{a}} \quad$ air temperature $[\mathrm{K}]$

$T_{\mathrm{c}} \quad$ canopy temperature [K]

$T_{\mathrm{r}} \quad$ radiometric temperature $[\mathrm{K}]$

$T_{\mathrm{s}} \quad$ soil temperature $[\mathrm{K}]$

$T_{\theta} \quad$ temperature source/sink rate $\left[\mathrm{K} \cdot \mathrm{s}^{-1}\right]$

$u \quad$ wind speed $\left[\mathrm{m} \cdot \mathrm{s}^{-1}\right]$

$u \quad$ LAS normalized path distance [-]

$u_{*} \quad$ friction velocity $\left[\mathrm{m} \cdot \mathrm{s}^{-1}\right]$

$w \quad$ leaf width [m]

$w \quad$ vertical wind speed $\left[\mathrm{m} \cdot \mathrm{s}^{-1}\right]$

$W(u) \quad$ LAS weighting function [-]

$y_{i} \quad$ proportionality factor $\left[\mathrm{m}^{5 / 3} \cdot \mathrm{s}^{-1} \cdot \mathrm{K}^{-1}\right]$

$z_{0 M} \quad$ surface roughness length for momentum [m]

$Z_{\mathrm{OH}} \quad$ surface roughness length for heat [m]

$z_{\mathrm{d}} \quad$ damping layer depth [m]

$z_{\text {inv }} \quad$ inversion layer height $[\mathrm{m}]$

Greek symbols

$\alpha \quad$ solar elevation angle [rad]

$\alpha_{\mathrm{PT}} \quad$ Priestley and Taylor coefficient [-]

$\beta \quad$ Bowen ratio [-]

$\Psi_{\mathrm{M}} \quad$ integrated stability function for momentum transfer [-]

$\Psi_{\mathrm{H}} \quad$ integrated stability function for heat transfer [-]

$\Psi_{V} \quad$ integrated stability function for vapour transfer [-] 
$\delta_{13} \quad$ Kronecker delta [-]

$\Delta \quad$ grid size [m]

$\varepsilon \quad$ emissivity [-]

$\phi_{M} \quad$ stability function for momentum transfer [-]

$\phi_{\mathrm{H}} \quad$ stability function for heat transfer [-]

$\phi \quad$ stability function for vapour transfer [-]

$\Phi_{\mathrm{N}} \quad$ three-dimensional Kolmogorov spectrum $\left[\mathrm{m}^{3}\right]$

$\gamma \quad$ psychrometric constant $\left[\mathrm{kg} \cdot \mathrm{m}^{-1} \cdot \mathrm{s}^{-2} \cdot \mathrm{K}^{-1}\right]$, or $\left[\mathrm{Pa} \cdot \mathrm{K}^{-1}\right]$

$\gamma_{a} \quad$ refractive index for air $\left[\mathrm{K} \cdot \mathrm{Pa}^{-1}\right]$

$\Gamma \quad$ ratio between soil heat flux and net radiation [-]

$\lambda \quad$ latent heat of vaporization $\left[\mathrm{J} \cdot \mathrm{kg}^{-1}\right]$

$\lambda E \quad$ latent heat flux $\left[\mathrm{W} \cdot \mathrm{m}^{-2}\right]$

$\lambda E_{\mathrm{C}} \quad$ canopy latent heat flux $\left[\mathrm{W} \cdot \mathrm{m}^{-2}\right]$

$\lambda E_{\mathrm{S}} \quad$ soil latent heat flux $\left[\mathrm{W} \cdot \mathrm{m}^{-2}\right]$

$\lambda_{i} \quad$ wave length $[\mathrm{m}]$

$\Lambda \quad$ evaporative fraction [-]

$\nu_{\uparrow} \quad$ turbulent eddy viscosity $\left[\mathrm{m}^{2} \cdot \mathrm{s}^{-1}\right]$

$\rho_{\mathrm{a}} \quad$ density of air $\left[\mathrm{kg} \cdot \mathrm{m}^{-3}\right]$

$\rho \quad$ correlation coefficient [-]

$\rho \quad$ albedo [-]

$\rho^{2} \quad$ coefficient of determination [-]

$\sigma \quad$ Stefan-Boltzmann constant $\left[\mathrm{W} \cdot \mathrm{m}^{-2} \cdot \mathrm{K}^{-4}\right]$

$\sigma^{2} \quad$ variance [-]

$\tau_{\mathrm{SW}} \quad$ shortwave atmospheric transmissivity [-]

$\tau_{i j} \quad$ shear stress $\left[\mathrm{m}^{2} \cdot \mathrm{s}^{-2}\right]$

$\tau_{i \theta} \quad$ temperature flux $\left[\mathrm{K} \cdot \mathrm{m} \cdot \mathrm{s}^{-1}\right]$

$\theta \quad$ potential temperature [K]

$\theta_{*} \quad$ potential temperature scaling parameter $[\mathrm{K}]$

$\theta_{0} \quad$ potential aerodynamic surface temperature [K]

$\theta_{\mathrm{a}} \quad$ potential air temperature [K]

$\theta_{\mathrm{ac}} \quad$ within-canopy potential air temperature [K]

$\theta_{\text {mix }} \quad$ mixed layer potential temperature [K]

$\theta_{v} \quad$ potential virtual temperature $[\mathrm{K}]$

$v \quad$ kinematic viscosity $\left[\mathrm{m}^{2} \cdot \mathrm{s}^{-1}\right]$

$v_{C} \quad$ diffusivity of scalar $\mathrm{c}\left[\mathrm{m}^{2} \cdot \mathrm{s}^{-1}\right]$ 


\section{Samenvatting}

Het onderwerp van deze dissertatie behelst het effectief gebruik maken van remote sensing technieken voor het bepalen van fluxen van waterdamp en warmte onder heterogene omstandigheden voor wat betreft het aardoppervlak als mede de atmosfeer. Dit betreft het opzetten van een model dat de invloed van heterogeniteit in de atmosfeer op flux schattingen minimaliseert, of probeert te negeren, het meenemen van heterogeniteit van het aardoppervlak in grondgebaseerde waarnemingen welke gebruikt worden voor het valideren van flux schattingen en het ontwikkelen van een methode voor het meenemen en kwantificeren van de invloed van atmosferische heterogeniteit op flux schattingen.

Minimalisatie van atmosferische invloeden

$\mathrm{Er}$ is een remote sensing-gebaseerd raamwerk ontwikkeld voor de automatische bepaling van oppervlakte energiebalans componenten uit slechts een beeld van de radiometrische oppervlaktetemperatuur. De methode kan gebruikt worden om een actuele verdampingskaart te maken over grote heterogene gebieden, onder de aanname dat er hydrologische extremen of natte en droge omstandigheden aanwezig zijn.

Deze eenvoudige en volledig geautomatiseerde methode, welke van het fysisch gebaseerde type is, bewees schattingen van beschikbare energie (netto straling minus bodem warmte flux) en turbulente voelbare en latente warmtefluxen te kunnen leveren welke vergelijkbaar zijn met die van algemeen erkende en meer ingewikkelde op remote sensing gebaseerde modellen. Slechts onder omstandigheden van droogte en spaarzame vegetatie werden significante afwijkingen met observaties waargenomen, een niet onbekend fenomeen voor dit type benaderingen. Gezien de eenvoud van het algoritme, gepaard aan het gebruikersgemak, heeft het voorgestelde model toepassing in het identificeren van gebieden met een hoog en laag watergebruik en kan daardoor dienst doen als een operationeel middel voor de snelle monitoring van relatief watergebruik of plant stress condities in regio's waar weinig grondwaarnemingen voorhanden zijn.

\section{Inachtneming van (aard)oppervlakte invloeden}

Een methode is voorgesteld om scintillometer-gebaseerde gebiedsgemiddelden van voelbare warmte flux te produceren welke geschikt zijn ter validatie van ruimtelijk verdeelde modellen welke oppervlakte fluxen schatten uit remote sensing waarnemingen. De geschiktheid van de methode is gedemonstreerd door het 
reproduceren van referentie fluxen uit landgebruiks-component fluxen. Indien toegepast boven een zeer heterogeen landschap ontstaan er enige complicaties wanneer er binnen het gezichtsveld van de scintillometer tegelijkertijd stabiele en onstabiele condities voorkomen. Echter, wanneer het contrast tussen de verschillende landgebruiks-componenten niet al te groot zijn bedragen de verschillen tussen de referentie fluxen en de scintillometergebaseerde schattingen niet meer dan $20 \mathrm{~W} \cdot \mathrm{m}^{-2}$.

\section{Inachtneming van atmosferische invloeden}

Een Large-Eddy Simulation (LES) model, grote dwarrelwind simulatie in correct Nederlands, is gekoppeld met een remote sensing landoppervlaktemodel door gebruikmaking van een lap-versie van een twee-brons energiebalans model om land-atmosfeer koppeling te bepalen boven het zeer heterogene agrarische landschap nabij Barrax in Spanje. Het gekoppelde model is toegepast op een ontkoppelde manier, met statische en uniforme atmosfeertoestanden en met ruimtelijk variabele atmosfeertoestanden op een dynamisch gekoppelde manier. Er werd een significant verschil in de ruimtelijke gemiddelden en een afname in ruimtelijke variantie van de fluxen gevonden wanneer de resultaten van de gekoppelde simulaties vergeleken werden met die van de ontkoppelde simulaties. Uit een analyse op meerdere schalen naar de relatie tussen landoppervlakstemperatuur en luchttemperatuur bleek dat de ruimtelijke variabiliteit van de luchttemperatuur voornamelijk veroorzaakt werd door variaties in de oppervlaktetemperatuur op een schaal tussen de 500 en 1000 meter. Hoewel de gevonden ruimtelijke variatie in luchttemperatuur redelijk klein was vergeleken met die van de oppervlaktetemperatuur, kwamen deze resultaten overeen met eerder werk over een natuurlijk semi-aride rangeland gebied.

Deze bevindingen leidden tot de ontwikkeling van een nieuw gereedschap dat het onderzoeken van elke parameter van belang toelaat, in termen van koppeling, alsmede ter bepaling van de turbulente fluxen. Het gereedschap, of model, bevat recentelijk ontwikkelde zogenaamde Sub-Grid-Schaal (SGS) model parameterizaties en nieuwe discretisaties in het LES gedeelte en is dynamisch gekoppeld aan de seriële versie van het twee-brons energiebalans model. Modelberekeningen over homogene synthetische oppervlakten laten nu resultaten zien die beter de zogenaamde Monin-Obukhov Gelijksoortigheids Theorie (MOST) volgen en betere gelijkenis vertonen met typische profielen van parameters als turbulente viscositeit, het Schmidt- en het Prandtl getal.

Modelresultaten boven heterogene, synthetische als mede natuurlijke, oppervlakten laten zien dat de windsnelheid de 
dominante factor is voor de verschillen tussen gekoppelde en ontkoppelde fluxmodelschattingen. Dit geldt zowel voor de heterogeniteit in landoppervlakte temperatuur, in ruwheidslengte voor momentum, en fractie gewasbedekking als voor de heterogeniteit in ruwheidslengte voor warmte, welke typische ruimtelijk variabele invoerparameters zijn in op remote sensinggebaseerde landoppervlaktemodellen. Voor individuele landgebruiks eenheden zijn er duidelijke en meestal lineaire relaties gevonden tussen verschillen in windsnelheid en verschillen in voelbare warmte fluxen voor wat betreft gekoppelde en ontkoppelde simulaties, wat potentieel een manier oplevert om variaties in de atmosfeer mee te nemen in ontkoppelde modellen. Echter, er is geen algemeen toepasbare manier gevonden om de ruimtelijke variatie in windsnelheid in kaart te brengen; dit vanwege de complexe interactie tussen windsnelheidsvariatie opgewekt door thermale opstijging dan wel door drukverschillen.

Evaluatie van het nieuwe gereedschap versus waarnemingen gedaan in de REFLEX2012 meetcampagne, specifiek ontworpen voor het bestuderen van de land-atmosfeer interactie boven het heterogene Barrax gebied, liet een toename zien in windsnelheidsvariatie en in variatie van luchttemperatuur en luchtvochtigheid, iets betere schattingen van voelbare warmtefluxen en iets slechtere schattingen van latente warmtefluxen. Echter, het meenemen van de terugkoppelingseffecten in het hier beschouwde landoppervlakmodel en voor het hier beschouwde gebied leverde afwijkingen op in de flux schattingen welke grotendeels binnen de nauwkeurigheid van turbulente fluxwaarnemingen vallen. 


\section{ITC Dissertation List}

http://www.itc.nl/research/phd/phd graduates.aspx 
ISBN: 978-90-365-4234-0

DOI: $10.3990 / 1.9789036542340$

ITC

UNIVERSITY OF TWENTE.

Dissertation number: 290 